Portland State University

PDXScholar

$1-1-1985$

\title{
Physical illness and depression: changes over time in middle aged and elderly persons
}

Ann K. Williams

Portland State University

Follow this and additional works at: https://pdxscholar.library.pdx.edu/open_access_etds Let us know how access to this document benefits you.

\section{Recommended Citation}

Williams, Ann K., "Physical illness and depression: changes over time in middle aged and elderly persons" (1985). Dissertations and Theses. Paper 540.

https://doi.org/10.15760/etd.540

This Dissertation is brought to you for free and open access. It has been accepted for inclusion in Dissertations and Theses by an authorized administrator of PDXScholar. Please contact us if we can make this document more accessible: pdxscholar@pdx.edu. 
PHYSICAL ILLNESS AND DEPRESSION: CHANGES OVER TIME IN MIDDLE AGED AND ELDERLY PERSONS

by

ANN K. WILLIAMS

A dissertation submitted in partial fulfillment of the requirements for the degree of

\author{
DOCTOR OF PHILOSOPHY \\ in \\ URBAN STUDIES
}

PORTLAND STATE UNIVERSITY
(C) $1985 \mathrm{Ann}$ K. Williams 
TO THE OFFICE OF GRADUATE STUDIES AND RESEARCH:

The members of the Committee approve the dissertation of Ann K. Williams presented August 15, 1985.
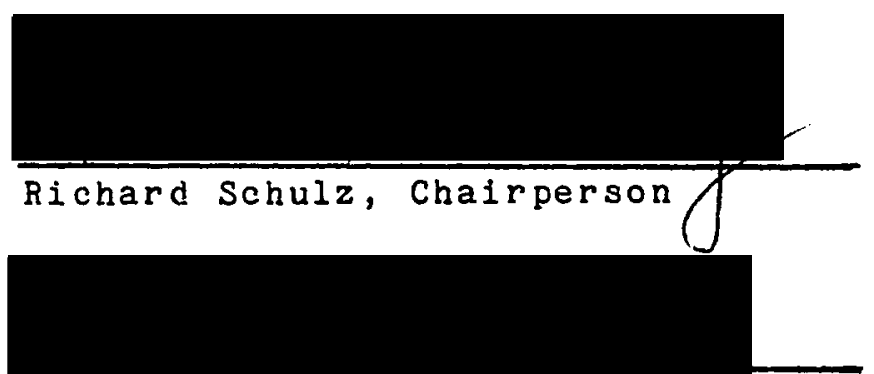

Seymouf Adler

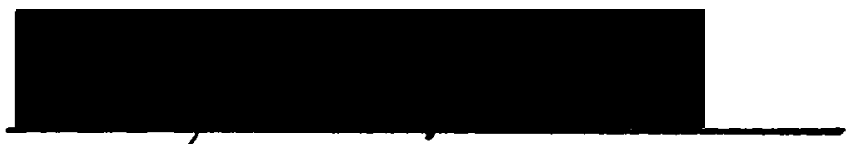

Nancy Chapman
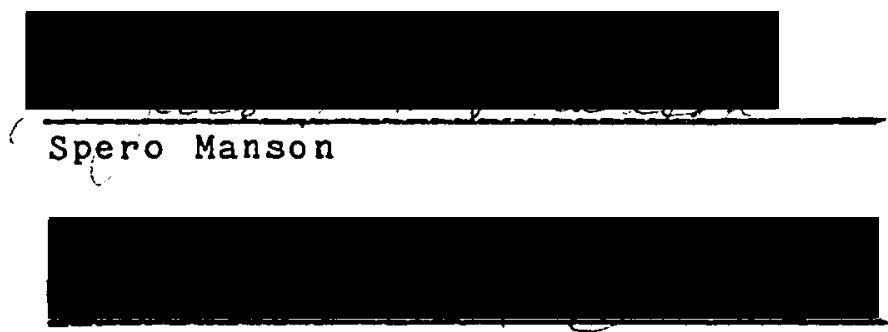

Cathleen Smith

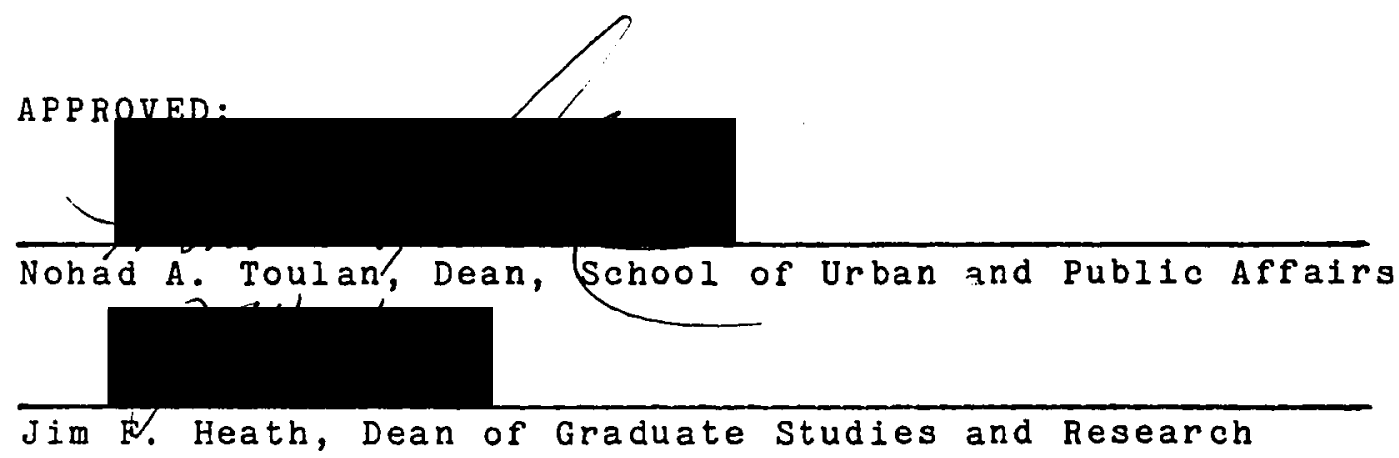



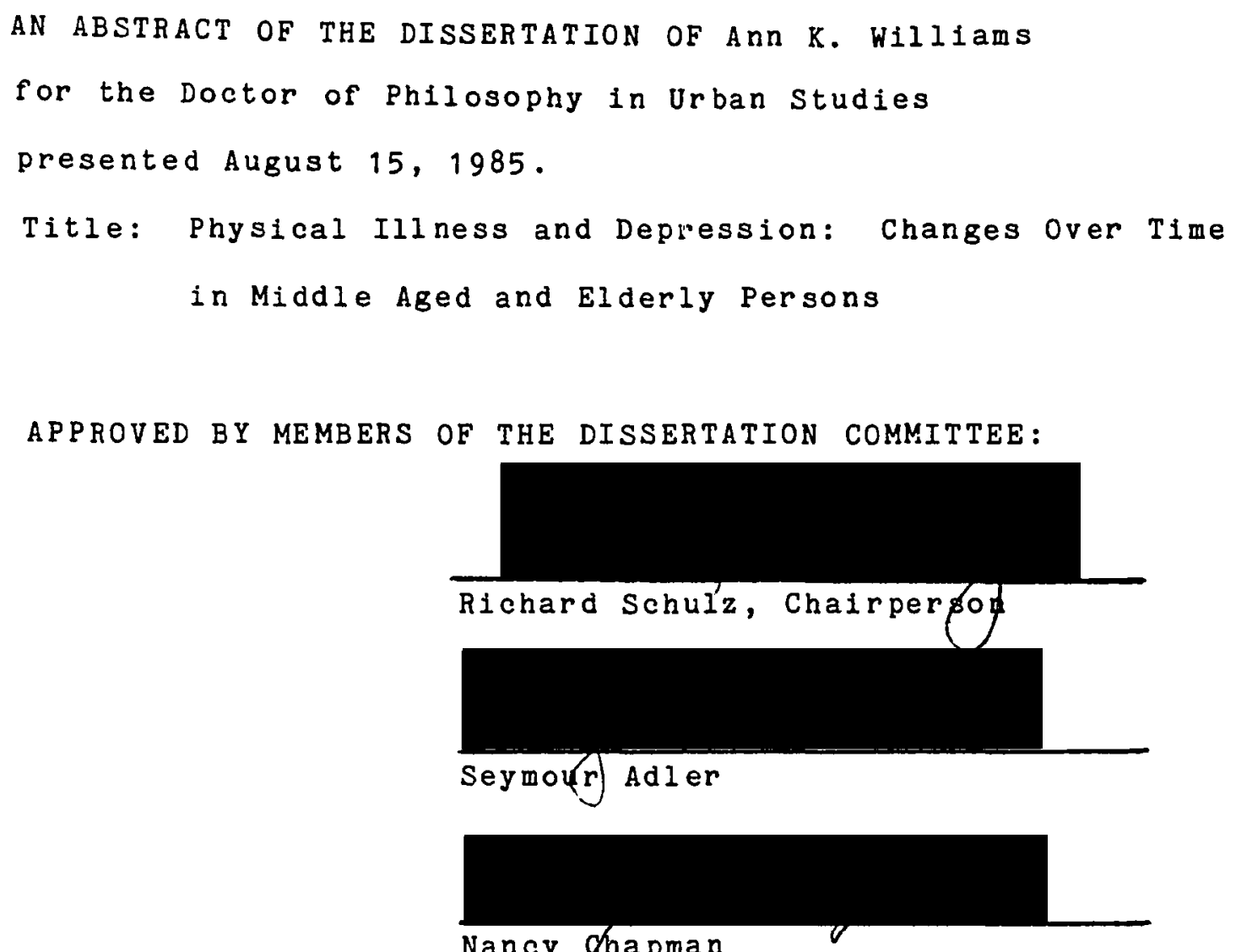

Nancy Chapman
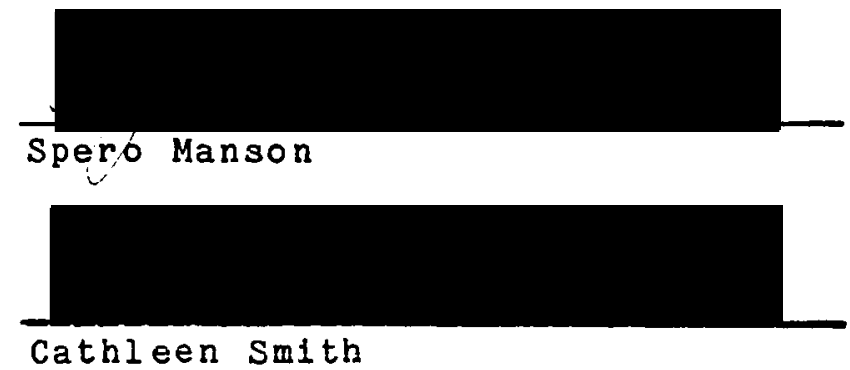

Recent research in gerontology and geriatrics has identified that one factor repeatedly associated with depression in the elderly is the presence of physical 
illness. However, conflicting research results make it unclear if age is a factor in the relationship of physical illness and depression. While the response of the elderly individual to the stress of physical illness is variable, the increasing numbers of elderly persons in the population and their high rate of chronic physical illness make it important to identify critical disease and individual characteristics that play a role in the association of depression and physical illness. In addition, increased concern with community care for the disabled elderly has intensified the need for information about the medical resource needs and social support patterns of elderly persons with physical illness residing in the community. In order to investigate and clarify these relationships and concerns, a panel survey of $133 \mathrm{middle}$ aged and elderly persons with recent exacerbations of various physical illnesses was completed. Subjects were referred by medical offices and agencies in the Portland metropolitan area. Two in-depth interviews were completed approximately three months apart.

The data were analyzed using descriptive statistics, correlational analyses, analyses of variance, multiple regression, and dynamic (change focused) correlational analyses. Results indicated a slight but consistent decrease in level of depression with increasing age. 
Increased levels of income, social support, religiosity, subjective health, internal locus of control for health, and life expectancy were associated with decreased levels of depression. Conversely, increased levels of pain, physical dependency, progressiveness of the disease, death anxiety, external locus of control for health, and worry about medical resources were associated with increased levels of depression. While the residential setting of urban, suburban, or rural had a significant effect on income and a slight effect on size of support system, it had no significant impact on level of depression. The four best predictors of level of depression at Time 1 were subjective health, pain, death anxiety, and income. Analysis of change over time revealed moderate stability in levels of depression. The best predictor of level of depression at Time 2 was level at Time 1 . Only change in pain added significantly to the prediction of depression at Time 2. Locus of control for health and progressiveness of the disease were able to discriminate between change groups for depression.

The results of this study will help to identify physically ill middle aged and elderly persons at risk for the development of depression. Analysis of change over time suggests causal relationships for further investigation. These data will be valuable in the 
development of strategies designed to prevent the occurrence of depression in physically ill elderly individuals. 


\section{ACKNOWLEDGEMENTS}

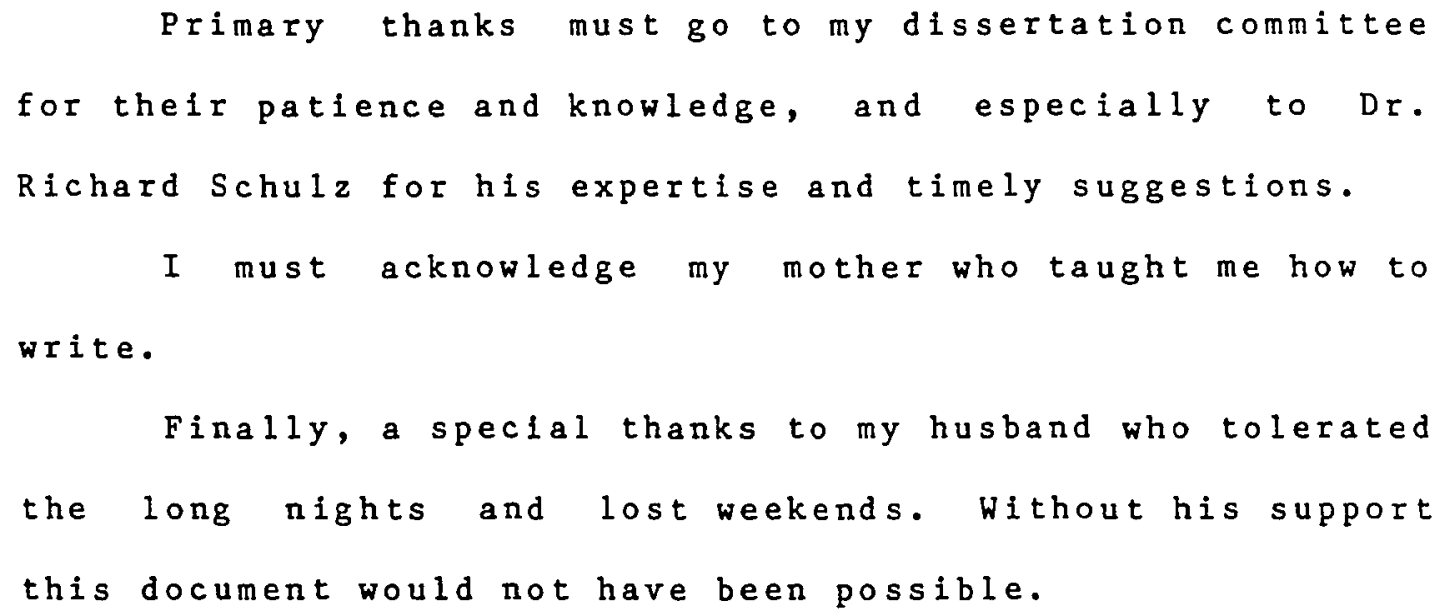


TABLE OF CONTENTS

PAGE

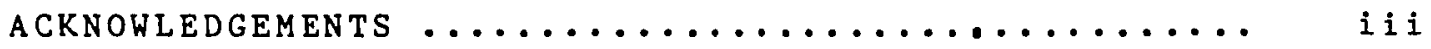

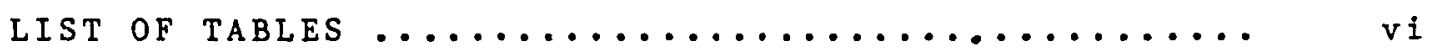

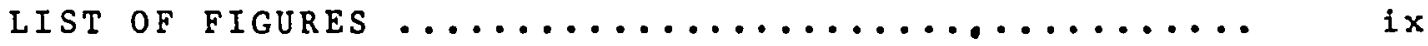

CHAPTER

I INTRODUCTION AND LITERATURE REVIEW .......

Introduction ...................... 1

Physical Illness and Depression

A Review of the Literature ............ 2

II THEORETICAL FRAMEWORK ................ 32

III METHODOLOGY ......................... 40

The sample ...................... 40

Data Collection ................... 44

Human Subjects Protection ........... 46

Variables - Operational Definitions .... 47

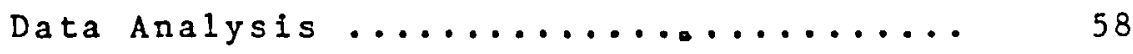

IV DESCRIPTIVE ANALYSIS .................. 62

Demographic Characteristics

of the Sample ..................... 62

Characteristics of the

Soc1al support system ................. 68

Medical Resources -

Utilization and Needs ............... 77 
V FACTORS AFFECTING DEPRESSION

AND LIFE SATISFACTION

TIME 1 AND TIME $2 \ldots \ldots \ldots \ldots \ldots \ldots \ldots . \ldots \ldots$

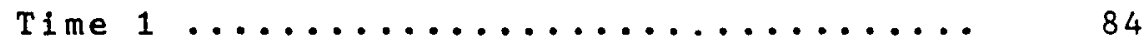

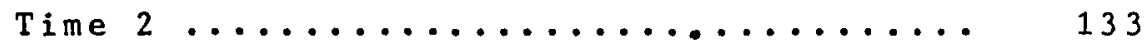

VI CHANGES IN DEPRESSION AND

LIFE SATISFACTION OVER TIME ........... 155

Descriptive and Correlational Analysis. 155

Regression Analysis ................ 160

Dynamic (Change Focused)

Correlational Analysis ............ 165

$\begin{array}{lllllll}\text { VII DISCUSSION } & \text { AND } & \text { IMPLICATIONS OF } & \text { THE } & \text { STUDY } & \ldots & 179\end{array}$

Discussion ...................... 179

Implications for Policy and

Future Research ................. 190

Summary and Conclusions ........... 193

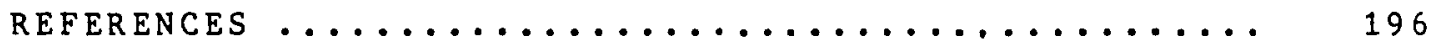

APPENDIX

A Informed Consent ..................... 210

B Initial Interview ................ 212

C Second Interview ..................... 242

D Codebook for Interview $1 \ldots \ldots \ldots 262$

E Codebook for Interview $2 \ldots \ldots \ldots \ldots . \ldots$ 


\section{LIST OF TABLES}

TABLE

PAGE

I Previous Studies Depresston and

Physical Illness $\ldots \ldots \ldots \ldots \ldots \ldots \ldots \ldots$

I Classification of Variables and

Hypothesized Relationship to Depression. 35

II Diagnoses of subjects ............... 42

IV General Demographic Data ............. 63

V Characteristics of the

Social Support System ............. 69

VI Characteristics of Support System

by Marital status ................ 74

VII Mean Values for Selected Variables ....... 81

VIII Correlations with CES-D Time $1 \ldots \ldots \ldots \ldots . . .82$

IX Correlations with LSIA Time $1 \ldots \ldots \ldots \ldots$

$X$ Percentages Reporting the Presence

and Persistence of Items on CES-D..... 87

XI Comparison of Depression by

CES-D $\geq 16$, RDC, and DSM III $\ldots \ldots \ldots \ldots .89$

XII Percent of Sample Giving High

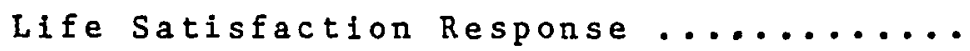


XIII Correlations of Social Support

Measures to CES-D ................ 101

XIV Values of Selected Variables by Diagnosis. 106

XV Correlations between Selected

Variables Time $1 \ldots \ldots \ldots \ldots \ldots \ldots . \ldots \ldots$

XVI Effect of Other Significant Life Events ... 117

XVII Stepwise Regression for CES-D Time $1 \ldots \ldots .120$

XVII Hierarchical Regression for CES-D Time 1 .. 121

XIX Stepwise Regression for CESD 20

Life Expectancy and Death Anxiety

Not Included .................... 125

XX Stepwise Regression for LSIA-A Time $1 \ldots \ldots 128$

XXI Hierarchical Regression LSIA-A Time $1 \ldots . . .129$

XXII Correlation with CES-D Time $2 \ldots \ldots \ldots \ldots . . .135$

XXII Correlations with LSIA-A Time $2 \ldots \ldots \ldots \ldots . . .136$

XXIV Type of Social Support as Related

to Marital Status and Relationship

to subject ..................... 139

XXV Correlations between Selected

Variables Time $2 \ldots \ldots \ldots \ldots \ldots \ldots \ldots \ldots$

XXVI Stepwise Regression for CES-D Time $2 \ldots \ldots$.... 147

XXVII Hierarchical Regression for CES-D Time 2 .. 149

XXVIII Stepwise Regression for LSIA-A Time $2 \ldots \ldots .151$ 
viii

TABLE

PAGE

XXIX Hierarchical Regression for LSIA-A Time 2 .

153

XXX Hierarchical Regression for CES-D

Time 1 and Time $2 \ldots \ldots \ldots \ldots \ldots \ldots \ldots$

XXXI Hierarchical Regression for LSIA-A

Time 1 and Time $2 \ldots \ldots \ldots \ldots \ldots \ldots$ 


\section{LIST OF FIGURES}

FIGURE

PAGE

1. General Model .................... 37

2. Mean CES-D for age groups ( 9 groups) ....... 95

3. Mean CES-D for age groups ( 4 groups) ...... 96

4. Mean LSIA-A for age groups ( 9 groups) ...... 98

5. Mean LSIA-A for age groups ( 4 groups) ..... 99

6. Cross-Lagged Panel Analysis

Pain and CES-D .................. 171

7. Cross-Lagged Panel Analysis

CES-D and LSIA-A ................ 175

8. Model for the study ................... 188 


\section{CHAPTER I}

\section{INTRODUCTION AND LITERATURE REVIEW}

\section{INTRODUCTION}

In an industrialized and urbanized society such as the United States, increasing numbers of physically ill older persons result in large demands on health care systems. The needs of these persons include not only immediate medical care, but also instrumental assistance in the community and support for mental health problems. Previous studies have identified that one factor repeatedly associated with physical illness in all age groups has been the mood disturbance of depression. While some individuals may cope well with the stress of physical illness, many studies have demonstrated high rates of depression among the physically ill. The increasing numbers of older persons and their high rate of physical illness make necessary the study of factors that identify physically ill individuals in this age group at risk for the development of depression.

In order to systematically study the interrelationship of physical illness and depression in older persons, a Iiterature review was undertaken to 
identify key factors that may affect the emotional response to physical illness. The following literature review is divided into three sections. First, the rates of depression in the elderly will be examined. Next the rates of depression in the physically ill will be reviewed; and finally, specific factors mediating the relationship between physical illness and depression will be discussed. Based on this review, a theoretical framework is derived in Chapter II and then tested in the study described in later chapters.

\section{PHYSICAL ILLNESS AND DERRESSION - \\ A REVIEW OF THE LITERATURE}

Research has consistently found an association between physical illness and depression. other epidemiological studies have investigated the psychosocial correlates of depression, and a few recent studies have begun to investigate factors that modify the relationship between physical illness and depression.

The Rate of Depression in the Elderly and Its Relationship to Physical Illness

The prevalence of depression in the elderly is estimated to be between $9 \%$ and $20 \%$ (Boyd \& Weissman, 1981). Many previous studies had underestimated this prevalence 
because they were based on data regarding only patients who had sought psychiatric treatment (Helgason, 1977). Commity studies have also demonstrated a wide variation in prevalence rates possibly due to differences in. diagnostic and classification criteria (Boyd \& Weissman, 1981). For example, the inclusion of somatic symptoms as diagnostic criteria is especially problematic in the elderly as many of these symptoms commonly occur in old age (Blumenthal, 1975; Gallagher, 1980; Salzman \& Shader, 1978; Steuer, Bank, Olsen, \& Jarvik, 1980). Thus while mood alteration is the primary criterion for the diagnosis of depression, some authors insist that somatic or behavioral signs must also occur (American Psychiatric Association, 1980; Gurland \& Toner, 1982; Stenbach, 1980). Recently some authors have applied the terms demoralization, dysphoria, or mild depression selectively to mood a terations and reserve the term depression for cases where behavioral and somatic signs of depression are present (Blazer \& Williams, 1980; Gurland \& Toner, 1980).

Three recent community-based epidemiological studies deserve special mention in determining the prevalence of depression in the elderly. Weissman and Myers (1978) interviewed 515 persons in New Haven, Connecticut and found an overall prevalence rate for both major and minor depression in the elderly of $8.1 \%$. Blazer and Williams 
(1980) studied 997 elderly persons in Durham County, North Carolina and found the prevalence of substantial depressive symptomatology to be $14.7 \%$. In a cross-national study Gurland, Copeland, Kuriansky, Kelleger, Sharpe, and Dean (1983) established a prevalence of pervasive depression (needing clinical attention) in New York and London of $13 \%$ and $12.4 \%$, respectively.

Three commuty studies of depression were found which used the Center for Epidemiological Studies Depression Scale (CES-D), the scale that was used in this study. All of these community studies utilized a score of 16 or greater on the CES-D as indicative of depression. While the CES-D has been criticized as overestimating the rate of depression (Weissman, Sholomskas, Pottenger, Prusoff, \& Locke, 1977), the figures found in these community studies were not much higher than those cited above. In a study of two communities of 3,845 persons, Comstock and Helsing (1976) found a prevalence of depression in the over 65 aged population of $14.8 \%$. Goldberg, Van Natta and Comstock (1985) reported a rate of depression of $9.5 \%$ in a study of 1,144 married women aged 65-75. The inclusion of only married and young-old (aged 65 to 75) women in this report could explain the lower percentage of depression. Finally, Davis (1984) demonstrated a $16.7 \%$ depression rate in a sample of elderly subjects from a high rise tower project. Thus all these 
community studies suggest a prevalence of depression in the elderly of around $12 \%$.

Depression is related to loss of well-being, and the gerontological research in this area indicates a relationship between loss of health and decrease in subjective well-being (Okun, Stock, Haring, \& Witter, 1984; Zautra \& Hempel, 1984). A meta-analysis of numerous studies presented by okun et al. (1984) demonstrated $95 \%$ confidence estimates of the zero-order effect size of .29 to .35 for the relationship between health and subjective well-being. Another review of the literature on the well-being of older Americans by Larson (1978) pointed to the importance of health and activity in determining subjective well-being. Sauer (1977) studied black urban aged and found self-perceived health the best single predictor of morale. In a longitudinal study, Palmore and Kivett (1977) demonstrated that after controling for previous level of life satisfaction, only self-rated health significantly added to the prediction of life satisfaction. In a later report, Palmore (1981) showed that self-ratings of health predicted $8 \%$ of the life satisfaction of men and $4 \%$ of the life satisfaction of women.

These studies on well-being suggested an association between depression and loss of health, and this relationship has been generally supported by the literature on depression. Numerous authorities have cited the close 
relationship of physical fllness to depression in the elderly (Pfeiffer \& Busse, 1973; Stenbach, 1980; Thomae, 1980). Gurland et al. (1983) noted that "Demoralization syndromes certainly, and probably clinical depression as well, occur at considerably increased rates in the presence of physical illness and disability" ( $p .230$ ).

Systematic research studies have also supported this association of physical illness and depression in the elderly. Anderson and Davidson (1975) found that the percentage of individuals who had abnormal responses to life stress doubled when physical illness was also considered. In a study of persons 55 years or older, they found that $13 \%$ of physically healthy men and $17.8 \%$ of physically healthy women had an abnormal emotional disturbance. The figures for physically ill men and women were $31.2 \%$ and $38.2 \%$ respectively. Roth and Kay (1956) found a significantly higher rate of physical disability and illness in persons who had their first incident of an affective disorder after the age of 60 . In their community study of the elderly, Blazer and Williams (1980) found $6.5 \%$ of the total sample to have a medically related depression. These 65 subjects made up $44 \%$ of the depressed group. Conlin and Fennell (1983) identified a $68 \%$ depression rate among elderly outpatients in a general medical cinic. 
Cheah and Beard (1980) tested 262 patients in an acute illness geriatric unit and found $31 \%$ to be dysphoric or depressed. Twenty-two percent were rated as having a moderate to severe depression. Gurland et al. (1983) found a correlation of depression to physical illness of .47 in New York and .37 in London. They found that the most consistent parallel with the rates of depression was degree of physical illness and stated "Physical illness, disability and dependence [are! probably the major determinants of depressior in the elderly" (p. 245).

The Rate of Depression in Physically Ill Adults of All Ages and Its Relationship to the Elderly

While a few studies indicated that chronic physically ill adults do not differ from the general population in rates of depression, most research demonstrated that adults of all ages with various physical diseases show a high rate of depression. Table I outlines many of these studies and categorizes them by medical diagnosis. The first two categories in Table I include studies that investigated samples with a variety of diagnoses. As is clearfrom the third category, the effect of cardiac disease, usually myocardial infarction, on the mental health of adults has been extensively studied. Almost all studies found that depression and emotional distress are frequently 
Trisit: I

PREVIOUS STUDIES DEPRESSION AND PHYSICAL ILLNESS

\begin{tabular}{|c|c|c|c|c|c|c|}
\hline Diagnosis & Source & N of subjects & nge & General Finclings & Nge Differences & Instrument \\
\hline \multirow[t]{4}{*}{$\begin{array}{l}\text { Misc. } \\
\text { Chronic } \\
\text { Diseases }\end{array}$} & $\begin{array}{c}\text { Westbrook } \\
\text { \& } \\
\text { Viney } \\
(1982)\end{array}$ & $\begin{array}{c}126 \\
\text { (55 females) } \\
(71 \text { males) }\end{array}$ & $\bar{x}=54.2$ & $\begin{array}{l}\text { Subjects more } \\
\text { depressed than } \\
\text { controls }\end{array}$ & $\begin{array}{l}\text { Older subjects } \\
\text { less depressed }\end{array}$ & $\begin{array}{l}\text { Content Analysis } \\
\text { Ogen-ended } \\
\text { question }\end{array}$ \\
\hline & $\begin{array}{c}\text { Blazer } \\
\& \\
\text { Williams } \\
(1980)\end{array}$ & 997 & $\geq 65$ & Not given & $\begin{array}{l}\text { Older subjects } \\
\text { more depressed }\end{array}$ & $\begin{array}{l}\text { OARS Depression } \\
\text { Scale }\end{array}$ \\
\hline & $\begin{array}{l}\text { Cavanaugh } \\
\text { (1983) }\end{array}$ & 335 & $\bar{x}=57$ & $\begin{array}{l}14 \% \text { clinically } \\
\text { depressed } \\
368 \text { at least mildly } \\
\text { depressed }\end{array}$ & Not given & $\begin{array}{l}\text { Beck Depression } \\
\text { Inventory }\end{array}$ \\
\hline & $\begin{array}{l}\text { Cassileth } \\
\text { et al. } \\
(1980)\end{array}$ & $\begin{array}{c}658 \\
\text { (493 females) } \\
\text { (165 males) }\end{array}$ & $R=18-99$ & $\begin{array}{l}\text { No significant diff } \\
\text { ill and general } \\
\text { population }\end{array}$ & Older less depressed & $\begin{array}{l}\text { Mental Health } \\
\text { Index }\end{array}$ \\
\hline \multirow[t]{2}{*}{$\begin{array}{l}\text { Chronic } \\
\text { Pain }\end{array}$} & $\begin{array}{l}\text { Watson } \\
\text { (1982) }\end{array}$ & $\begin{array}{l}\quad 144 \\
(75 \text { females) } \\
(69 \text { males) }\end{array}$ & Not given & $\begin{array}{l}\text { D-Scale elevated } \\
\bar{x}=69.9\end{array}$ & Not given & MMP I \\
\hline & $\begin{array}{l}\text { Kramlinger } \\
\text { et al. } \\
\text { (1983) }\end{array}$ & $\begin{array}{c}100 \\
(62 \text { fenales }) \\
(38 \text { males })\end{array}$ & $\begin{array}{l}\bar{X}=43.6 \\
R=23-67\end{array}$ & $\begin{array}{l}253 \text { definitely } \\
393 \text { probably } \\
\text { depressed }\end{array}$ & Not significant & $\begin{array}{l}\text { MMPI } \\
\text { RDC } \\
\text { Hamilton Rating }\end{array}$ \\
\hline
\end{tabular}

\section{Cardiac \\ Discase}

Hosp MI

Rosen

$\varepsilon$

Biloring

(1966)
50

(50 males)

$R=35-67 \quad 428$ overtiy

depressed
Older less depressed Nurse Observ. 
TABLE I (CONTINUED)

PREVIOUS S'TUDIES DEPRESSION AND PHYSICAL ILLNESS

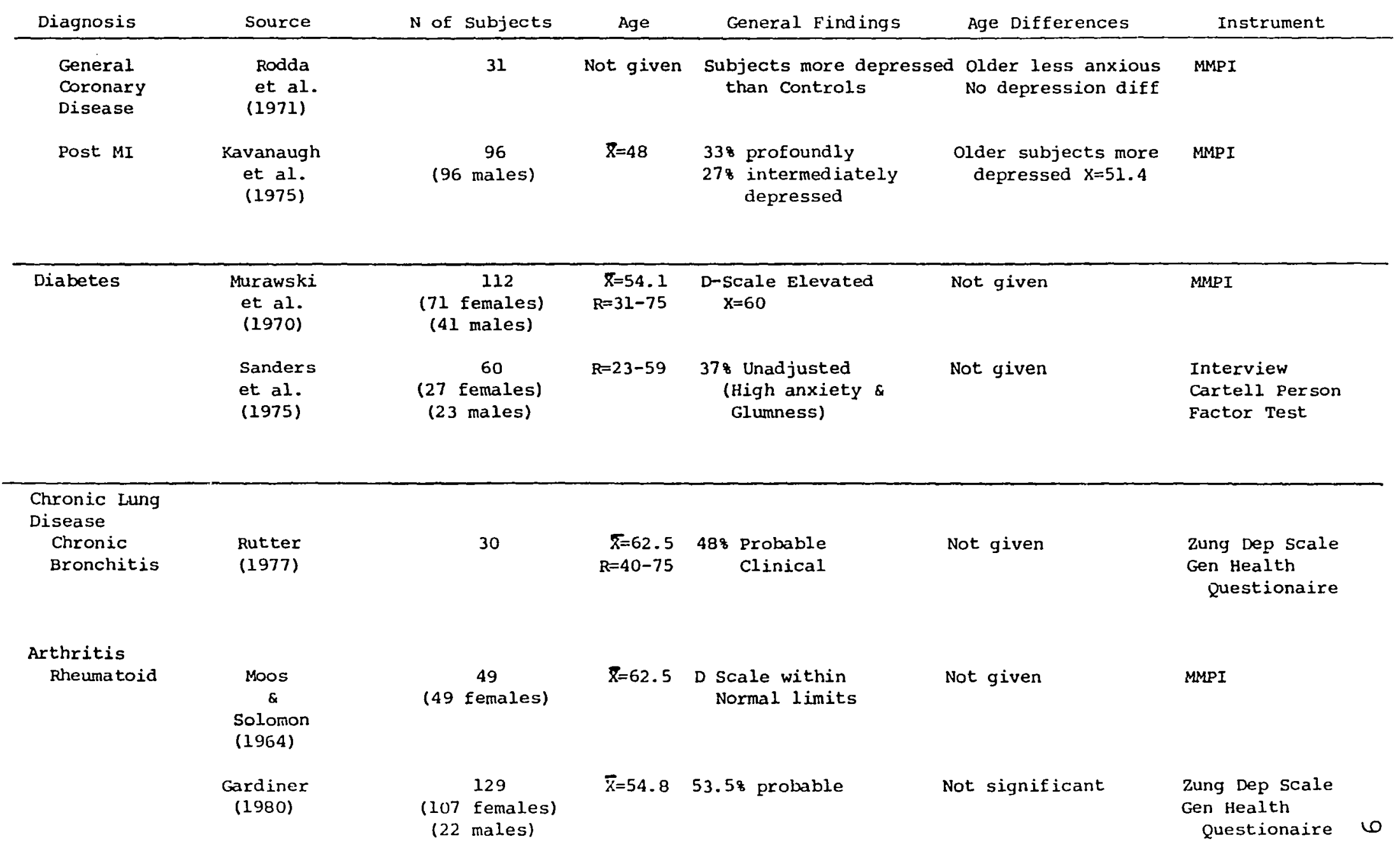


TABLE I (CONTINUED)

PREVIOUS STUDIES DEPRESSION AND PHYSICAL ILLNESS

\begin{tabular}{|c|c|c|c|c|c|c|}
\hline Diagnosis & Source & $\mathrm{N}$ of subjects & Age & General Findings & Age Differences & Instrument \\
\hline \multirow[t]{3}{*}{ Cancer } & $\begin{array}{l}\text { Plumb } \\
\quad \& \\
\text { Holland } \\
\text { (1981) }\end{array}$ & $\begin{array}{c}80 \\
(40 \text { females }) \\
(40 \text { males })\end{array}$ & $\begin{array}{c}\mathrm{R}=15-70 \\
\text { Median }=35\end{array}$ & $\begin{array}{l}458 \text { moderately to } \\
\text { severely depressed }\end{array}$ & $\begin{array}{l}\text { older subjects } \\
\text { slt more } \\
\text { depressed }\end{array}$ & $\begin{array}{l}\text { Current \& Past } \\
\text { Psychopathology } \\
\text { Scale }\end{array}$ \\
\hline & $\begin{array}{l}\text { Plumb } \\
\quad \& \\
\text { Holland } \\
(1977)\end{array}$ & $\begin{array}{c}97 \\
(50 \text { females) } \\
(47 \text { males })\end{array}$ & $\begin{array}{c}\bar{X}=41 \\
R=17-72\end{array}$ & $\begin{array}{l}238 \text { moderately to } \\
\text { severely depressed }\end{array}$ & $\begin{array}{l}\text { Younger more guilt } \\
\& \text { self-dislike }\end{array}$ & Beck Dep Scale \\
\hline & $\begin{array}{l}\text { Craig } \\
\quad \& \\
\text { Abeloff } \\
(1974)\end{array}$ & 30 & $\bar{x}=47$ & $\begin{array}{l}53.88 \text { moderately to } \\
\text { severely depresse }\end{array}$ & $\begin{array}{l}\text { Younger more } \\
\text { ed depressed }\end{array}$ & $\begin{array}{l}90 \text { Symptom } \\
\text { Checklist }\end{array}$ \\
\hline $\begin{array}{l}\text { Multiple } \\
\text { Sclerosis }\end{array}$ & $\begin{array}{l}\text { McIvor } \\
\text { et al. } \\
(1984)\end{array}$ & $\begin{array}{c}120 \\
(88 \text { females) } \\
(32 \text { males })\end{array}$ & $\begin{array}{c}\bar{X}=45 \\
R=25-71\end{array}$ & $x=22.03$ & $\begin{array}{l}\text { Older more } \\
\text { depressed }\end{array}$ & $\begin{array}{l}\text { Beck Depression } \\
\text { Inventory }\end{array}$ \\
\hline
\end{tabular}


encountered in patients with heart disease. Studies of diabetic adults and individuals with chronic lung disease and arthritis also consistently demonstrated a high level of depression. As is clear frcm Table I, the rates of depression in various studies of physically ill adults are quite variable. In a review of the general medical literature, Fauman (1983) found estimates of the percentage of patients with psychological problems (as defined by the physician) to vary between $4 \%$ and $88 \%$; however, the data in Table I are not quite so variable. Taking an average of all of the studies cited in Table I results in an estimate of the rate of depression in physically ill adults of $37.7 \%$.

As Table I indicates, several of the studies specifically investigated the effect of age on the association of depression to physical illness; however, the results are quite variable. Of the 11 studies that considered age as a factor, 3 showed no age differences, 4 showed the rate of depression to increase with age, and 4 showed the rate of depression to decrease with age. There could be several explanations for these variable results. The assessment procedures varied widely from open-ended questions to professional judgments to a myriad of scales. Diagnosis of the subject did not appear to affect the impact of age on depression. It should be noted that age ranges were frequently not given, and few of the subjects 
were elderly. These conflicting results make it difficult to reach firm conclusions regarding the effect of age on the association of depression and physical illness.

Comparing data on rates of physical illness, rates of depression, and rates of depression related to iliness suggests that the elderly do not have a higher rate of depression in response to physical illness than younger adults. In order to compare depression and physical illness for different age groups, estimations of the overall rate of physical illness are necessary. An estimation of the total rate of physical illness in the elderly is difficult due to overlapping categories, such as heart disease and diabetes. Data from the 1979 National Health Survey (Department of Health \& Human Services, 1982 , 1983) of 110,000 adults indicated the rate of limitation due to chronic physical conditions. This large study estimated that $39.2 \%$ of persons age 65 and older have chronic physical conditions of enough severity to cause limitations in a major activity such as walking, going outside, bathing, dressing, using the toilet, getting in or out of a bed or chair, or eating. Using the average of $38 \%$ depression rate for physically ill adults as mentioned previously, a depression rate of at least $14.4 \%$ would then be expected in the elderly. Blazer and Williams' survey (1980) was the only study found that estimated the percent 
of elderly depressives who had a medically related depression. This rate was found to be $44 \%$. If the overall rate of depression in the elderly is about $12 \%$ (see preceding section), then the rate of medically related depression would be about $5.3 \%$. Thus there is considerable discrepancy between the predicted rates using disability statistics and those using depression statistics (14.4\% vs. 5.3\%). Even allowing for considerable error in these statistics, one could suggest that the elderly cope at least as well as other adults to the onset of physical illness, possibly better.

Several explanations are possible for this apparent coping ability in the elderly. While it has been suggested that the elderly have less recuperative capacities (Verwoerdt, 1973) and tend to return to primitive defense mechanisms (Pfeiffer, 1977), McCrae (1982) demonstrated in a cross-sectional study that the elderly use about the same coping mechanisms as younger adults. In fact, the elderly showed significant decreases in the use of self-blame and withdrawal. Another possibility is that perhaps a large number of the elderly have achieved the ego-integrity of Erikson (1968) and can accept a decline in their health. Also, the elderly may alter their comparison groups as they get older, and as the health of their peers declines, their own loss becomes expected. The older individual may expect 
more health problems and accept them as a normal part of aging (Brody \& Kleban, 1983). As suggested by Schulz and Rau (1985), temporally normative events may cause less stress. Thus the apparent ability of the elderly to adapt to physical illness may be due to a life time of practice in successful coping, achievement of ego-integrity, or a change in expectations.

Other Factors Affecting Depression and Physical Illness

Despite the apparent ability of many elderly to adapt to chronic physical illness, the very high rate of physical illness in this age group continues to result in a high rate of medically related depression. Thus, those factors that identify individuals at risk to develop a medically related depression must be identified. Critical characteristics of the disease might include associated physical dependency, pain, and time since onset. Perception of the disease as life threatening, perceived predictability and controllability of the course of the disease, and perceived areas of life affected by the disease may also be crucial. Other critical characteristics of the individual might include age, gender, socioeconomic status, available social support, death anxiety, and centrality of roles.

Characteristics of the Disease. While physical illness and 
physical dependency are often interrelated, their respective contributions to depression are unclear. Palmore (1981) found that the physical function scale did not correlate as well with life satisfaction as did perceived health status. Other studies, however, point to a close association between dependency and physical illness as they relate to depression. Moos and Solomon (1964) demonstrated that rheumatoid arthritics with greater functional incapacity showed more depression and apathy. When the level of physical disability was controlled, Linn, Hunter, \& Harris (1980) found that physical illness no longer predicted degree of depression. Gurland et al. (1983) identified only a slightly higher correlation of depression to physical illness than to immobility. McIvor, Riklan, and Reznikoff (1984) found that in multiple sclerosis patients higher levels of disability were associated with higher levels of depression. In the Casileth et al. (1984) study, bedridden diabetics did not differ from functional diabetics on mental health status; however, cancer patients capable of normal activity had significantly better mental health. Certainly, further study is needed to clarify the differential effects of dependency on depression in the physically ill elderly.

A comparison of the dependency rates from a survey by the National Center for Health Statistics (Department of 
Health \& Human Services, 1983) with the depression rates from Blazer and Williams' study (1980) indicates a possible confounding effect of age on the relationship between dependency and depression. In the 65 to 74 age group the rates of medically-related depression and dependency were nearly the same $(5.4 \%$ and $7.0 \%$, respectively) while there was a wide disparity in the 75 and older age group ( $8.8 \%$ and $21 . \%$, respectively). Cape and Henschke (1980) confirmed this rapidly increasing rate of dependency with age above 65. Yet the rates of depression increased much more slowly with age. Perhaps the very elderly have different expectations regarding dependency and are therefore better able to adapt to it. It must be noted that these speculations are tenuous as the data described above were gathered from entirely separate samples. As indicated in Table I, chronic pain patients of all adult ages show increased rates of depression (Kraminger, Swanson, \& Maruta, 1983; Romano \& Turner, 1985; Roy, 1984; Watson, 1982). In a recent review of the literature on chronic pain and depression, Romano and Turner (1985) reported a wide variation of depression rates in chronic pain patients from $31 \%$ to $100 \%$. They found very few studies that compared persons with pain to persons without pain in nonpsychiatric settings; however, these few studies indicated higher depression rates with pain. Pain is a 
complex phenomenon which combines factors from the sensory, cognitive, and affective domains. In an elderly group, Brody and Kleban (1983) found that $63 \%$ of a community sample reported pain of some type, and $66 \%$ of those with pain were bothered "alot" or a "medium amount" by their pain. Results from experimental research is variable; age has been shown to correlate to decreased, similar, or increased sensitivity to pain (Harkins \& Warner, 1980). While pain threshold may increase with age, pain tolerance may decrease (Harkins \& Warner, 1980). It should be noted that these experimental studies dealt with acute, sharp pain; chronic, clinical pain has not been studied in an experimental setting (Harkins \& Warner, 1980). Thus pain is likely to be assoclated with depression; however, this relationship and the factors affecting it deserve further study.

Time may also be a critical element in the relationship between depression and physical illness. Time since onset of disease is of particular interest. Studies of various diseases show conflicting results. Patients with diabetes of long standing have higher levels of depression (Sanders, Mills, \& Horne, 1975) while patients with cardiac disease generally show a decrease of depression with time (Doehrman, 1977; Dpvenmuehle \& Verwoerdt, 1963; Niven, 1976). Cassileth et al. (1984) 
found recently diagnosed (less than 3 months) patients to have poorer mental health and greater depression than those with longer standing illness. McIror et al. (1984) found a tendency of persons with multiple sclerosis to show increases in levels of depression the longer they had the disease while Decker (1982) found that elderly spinal cord injured persons, most of whom were injured years previously, were relatively well adjusted to their disability. The variable effects of time may be due to other characteristics of the illness such as progressiveness of the disease. For example, spinal cord injured persons usually have a static level of disability while persons with multiple sclerosis or diabetes may show an increase in disability over time.

Perceptions of the Disease by the Individual. As the life-threatening aspect of a disease increases, its associated depression might be expected to increase also. Hauser \& Pollets (1979) suggested that the depression in diabetic adults might be partially due to the constant threat of disaster. Cassileth et al. (1984) found patients receiving palliative treatment (all cancer patients) to have poorer mental health than those receiving active treatment. When studying heart patients, Cay, vetter, Philip, and Dugard (1972) and Doehrman (1977) found the patients with the most severe disease to be the most 
depressed; however, Dovermuehle and Verwoerdt (1963) found no relationship between depression and severity of the disease. In a longitudinal study, Kavenaugh, Shepherd, \& Tuck, 1975) found depression related to the severity of heart ischemia but not to the recurrence of heart attacks. He also found that the depressed patients were more likely to have angina, an interesting finding in light of the importance of pain described previously.

Theoretical considerations and research findings in the areas of depression, relocation, and adjustment to institutionalization suggest that the individual's perception of control and predictability are critical issues in well-being (Conlin \& Fennell, 1985; Garber \& Seligman, 1980; Molinari \& Niedereke, 1984; Schulz, 1976; Schulz \& Brenner, 1977). Several studies demonstrate the importance of these factors in patients with physical iliness. In the Cassileth, et al. (1984) study, depression and perceived loss of control increased together. Conlin and Fennell (1985) demonstrated a strong external locus of control for health in elderly outpatients. These outpatients also exhibited a high prevalance of depression, but the numbers of subjects were too small to draw conclusions.

In a review of intervention studies about control of health, Krantz, Baum, and Wideman (1980) divided the 
studies into those providing information and those enhancing actual or perceived control. Langer, Janis, and Wolfer (1975) found that providing surgical patients with a coping strategy and/or information reduced their post-operative use of pain medications. The coping strategy (directing attention to the favorable aspects of the situation) was much more effective than information. other studies demonstrated that allowing the patient to be a more active participant in treatment and increasing choice, self-monitoring, and self-care had beneficial effects for the patient (Krantz et al,, 1980). Cohen and Lazarus (1979) cautioned that information alone had variable effects on the well-being of patients, especially surgical patients. Wallston, Wallston, Kaplan, \& Maides (1976) and Krantz et al. (1980) demonstrated that individual differences existed in an internal versus external locus of control regarding health issues and preferences for information and in taking an active role in health care. The Health Locus of Control (HLC) (Wallston et a 1., 1976) and the Health Opinion Survey (HOS) (Krantz, 1980) are instruments designed to assess these individual differences. Matching individual preferences to the appropriate intervention and treatment techniques may enhance outcomes. Molinari \& Niedereke (1984) stated that an internal locus of control has been repeatedly associated 
with good psychological adjustment and that elderly persons with an internal locus of control score consistently lower on depression scales. They suggested that an external locus of control is not a dispositional factor leading to depression but rather a result of the actual loss of control of health that comes with aging.

Another crucial aspect in the relationship between physical illness and depression may be the number or type of aspects of life that the individual perceives to be affected by the disease. Both Nerenz and Leventhal (1983) and Wright (1960) emphasized the importance of encapsulating the disease so that it does not affect all aspects of life. Hauser \& Pollets (1979) reasoned that the persistent depression in diabetic adults is caused by the dramatic life style changes required. There may be differential effects on depression depending upon the aspect of life affected. Westbrook and Viney (1982) found that the patients who perceived their iliness as interfering with their ability to carry on interpersonal relationships and care for themselves experienced the most depression. The degree to which the disease interfered with their mobility was not a significant factor. Characteristics of the Individual. Whenever the relationship between physical and mental health problems is studied, the possibility of pre-existing personality 
characteristics underlying both problems must be considered. Watson (1982) and Woodforde \& Merskey (1972) discounted this possibility in the case of chronically ill patients and asserted that their depression was a response to chronic pain. Other authorities agreed that there is no reliable evidence of a pre-diabetic personality (Dunn \& Tuttle, 1981; Wilkinson, 1981) and attributed the depression and pessimism of diabetic adults to the effects of chronic disease. Both Gardiner (1980) and Moos \& Solomon (1964) stated that the increased depression in arthritics was not a pre-existing condition but rather caused by the disease. Thus the possibility of a personality pre-disposing to depression has been disputed for persons with chronic pain, diabetes, and arthritis. Also, the study by Cassileth et al. (1984) documented the similarity in psychological response between patients with arthritis, cancer, diabetes, renal disease, and dermatological disorders. This similarity in response could point to common factors of illnesses causing adjustment problems rather than pre-existing personality characteristics.

The possibility of pre-disposing individual characteristics cannot be discounted for cardiac patients, however. Documentation of a coronary-prone profile is extensive, and numerous retrospective and prospective 
studies have indicated that individuals with the type A behavior pattern are more likely to develop coronary heart disease (Sparacino, 1982). The hard driving, aggressive type A individual would appear to be the antithesis of the depressed person; however, Haynes, Feinleib, \& Kannel (1980) demonstrated from the Framingham study that in the 65-74 age group the type B pattern is more associated with myocardial infarction among blue collar workers. While the type B characteristics are not necessarily those of depression, they are not contradictory either. Thus the effect of pre-existing patterns on heart disease may be affected by work status and may be age dependent. The possibility of a pre-existing behavioral pattern in depressed elderly cardiac patients cannot be dismissed. One characteristic of the individual of particular concern in this study is age. For all types of physical illness, studies have demonstrated an inconsistent relationship between age and depression levels. However, studies on overall depression rates have generally shown a decrease of depression in the elderly (Comstock \& Helsing, 1976; George, Landerman, \& Melville, 1984; Hirschfeld \& Cross, 1982; Nol1 \& Dubinsky, 1985). In these studies, rates of depression peaked in the middle aged and declined in older age groups.

Two other characteristics of the individual that have 
demonstrated an effect on depression include gender and socioeconomic status. General mental health studies have shown a fairly consistently higher rate of depressive psychosis and neurosis in women (Dohrenwend, 1975; Hirschfeld \& Cross, 1982; Radloff \& Rae, 1981). Studies specifically on depression demonstrated conflicting results. Studies in Europe generally have shown a higher incidence of depression in women (Bollerup, 1975; Essen-Moller \& Hagnel1, 1961; Gurland et al., 1983). However, in the United States, Weissman and Myers (1978) found gender unrelated to the prevalence of depression. In the New York sample, Gurland et al. (1983) found variable gender effects with the highest rate of depression in very elderly males. Warheit, Holzer, and Schwab (1973) and Comstock and Helsing (1976) demonstrated that females had a significantly higher rate of depression. Noll and Dubinsky (1985) found that once socioeconomic status was included in the analysis, gender had no effect on depression. Studies using physically ill subjects did not find gender to be a contributing factor (Westbrook \& Viney, 1982; Blazer \& Williams, 1980; Cassileth et al., 1984). Blazer \& Williams studied elderly subjects with a medically related depression. They found an almost identical percentage of females in the overall sample (61.9\%) compared to those with a medically related depression (64.6\%). Thus gender 
may not be a significant factor when relating depression to physical illness.

With regard to social class, the results are again conflicting. General studies of depression have consistently demonstrated a higher rate of depression with lower income and socioeconomic status (Comstock \& Helsing, 1976 ; Goldberg et al., 1985; Hirschfeld \& Cross, 1982; Noll \& Dubinsky, 1985; Warheit et al., 1973). Comstock and Helsing (1976) found that controlling for socioeconomic status greatly reduced the effects of race and gender on depression. Pearlin and Schooler (1978) demonstrated that the most effective coping mechanisms were used by men, the educated, and the wealthy. On the other hand, Dohrenwend (1975) concluded that the usual connection of lower social class to increased mental illness is not very consistent for neurosis and depressive psychosis. Studies of depression and physical illness have shown more variation. In a study of hospitalized patients, Westbrook \& Viney (1982) found the more educated and higher occupational status individuals to show more depression. Conversely, Blazer \& Williams (1980) found the economic resources of the group with a medically related depression to be significantly less than the overall sample. Blazer \& Williams' subjects were much older than those of Westbrook \& Viney. Thus while lower social class may increase the 
risk of depression, this relationship may be confounded by the factors of age and physical iliness.

Numerous studies have demonstrated both a direct and buffering effect of social support on psychological pathology in the work setting (House and Wells, 1979; LaRocco, House, \& French, 1980; Winnubst, Marcilissen, \& Kleber, 1982), in the community (Aneshensel \& Frericks, 1982 ; Dean \& Ensel, 1982; Lin, Ensel, Simone, and Kuo, 1979; Gore 1973, 1978; Schaefer, Coyne, \& Lazarus, 1981; Williams, Ware, \& Donald, 1981), and in the elderly (Blazer, 1982, 1983; Chapman, Pancoast, \& Parker, 1983; Cohen, Teresi, \& Holmes, 1985; Flaherty, Gaviria, Black, Altman, \& Mitchell, 1983; Goldberg et al., 1985). The general theory in these studies has been that social support reduced the impact of negative significant life events and therefore reduced anxiety and depression. Thus social support has consistently demonstrated a buffering effect in the psychological response to stress (Kessler \& Mcleod, 1985; Leavy, 1983). It should be mentioned that most of these studies dealt only with emotional support. Recently, several authorities have suggested that social support be broken down into three categories: emotional, informational, and instrumental or tangible (Thoits, 1982; Schaefer et al., 1981; Wallston et al., 1983). This differentiation of social support may be especially 
important for the dependent elderly who require instrumental support to remain in the community (Johnson, 1983). Other important aspects of social support might include appraisal and motivational support (Wills, 1985).

Regarding the effect of social support on persons with physical illness, DiMatteo and Hays (1981) have done an extensive review of the literature and concluded that "taken as a whole, the research suggests that social support may, in fact, be associated with recovery, and coping with serious physical illness and injury" (p. 121). This beneficial effect of social support is not universal, however; some studies have demonstrated higher anxiety and dependence in patients with more social support (DiMatteo \& Hays, 1981). Wortman and Conway (1985) cautioned that persons who are very ill or in pain may have difficulty mobilizing their support systems. Furthermore, Kessler \& Mcleod (1985) suggested that the causal directions between social support and mental health are unclear. Both factors may be connected in a complex web of mutual influence. Thus while the literature indicates a negative relationship between emotional support and depression; the nature of this relationship for the physically ill elderly and especially the effect of instrumental support requires further investigation.

Several studies have shown a relationship between 
increased death anxiety and depression (Rhudick \& Dibner, 1961; Templer, 1970) and between increased death anxiety and loss of health (Rhudick \& Dibner, 1961; Templer, 1971). The possible intervening variable of religiosity has demonstrated inconsistent effects on death anxiety (Aday, 1984). Death anxiety as measured by the Templer Death Anxiety Scale (DAS) (Templer, 1970) is accepted as a trait of the individual (Littlefield \& Fleming, 1984). Generally, in the literature the topic of death is assumed to universally provoke anxiety, and repression is assumed to occur in the absence of self-reported death anxiety (Littlefield \& Fleming, 1984). Thus the physically ill person may no longer be able to repress the fear of death, and measurement of this trait will increase with loss of hea 1 th. Wass and Myers (1982) cautioned, however, that the elderly may more readily discuss death, so that the relationship of death anxiety to loss of health may be confounded by age.

One final characteristic of the individual that may affect the interaction of physical illness and depression in the elderly is the number and centrality of roles. This factor is suggested in the literature but has not been further investigated. Goldstein (1979) and Schaefer et al. (1981) hinted that the diversity and importance of various 
roles may have implications for individual motivation and behavior and therefore affect mental health.

\section{Conclusions of the Literature Review}

In summary, this review of the literature on physical illness and depression in the elderly revealed several consistent findings as well as some inconsistencies and methodological problems. Many of the postulated factors affecting the interrelationship between physical iliness and depression were presented in experiential and anecdotal documents with little systematic data to support them. Also, much of the systematic data were cross-sectional and correlational. Therefore, identified causal patterns were tenuous. However, the diversity of studies provided support for the hypotheses that rates of depression are substantial in the elderly and that one factor consistently associated with this depression is physical illness. However, given the high rate of chronic physical illness in the elderly, the identified rates of depression and medically related depression in this age group suggested that the elderly cope at least as well as younger adults with the stress of physical iliness, possibly better. This may be due to a lifetime of coping experience, the achievement of ego-integrity, or lowered expectations regarding health. 
The apparent ability of many elderly to cope with chronic illness notwithstanding, the high rate of chronic physical iliness in this age group requires the identification of attributes of the disease and the individual that identify those at-risk for the development of depression. The separate and combined contributions of these various characteristics to the association of physical illness and depression are unclear. The degree of physical dependency, associated pain, and perceived threat to life are probably critical factors. Several studies suggested that time reduces the negative effects of a physical illness, but the studies on persons with diabetes and multiple sclerosis did not support the healing power of time. The progressiveness of the disease might be important in this effect of time. While social support probably decreases the association between depression and physical illness, the contributions of gender, socioeconomic status, controllability, perceived areas of life affected by the disease, and role centrality are uncertain. In order for timely prevention and intervention strategies in mental health to be effective, the importance of these factors in the psychological response to physical illness in the elderly must be identified.

The similarity of psychological responses to physical illness across numerous diagnostic categories suggests that 
systematic studies of chronic illness combining many diseases would be appropriate. This has seldom been done, however. Studies combining diagnostic groups would be especially relevant for the elderly who frequently have several physical diseases simultaneously. Two recent studies by Westbrook and Viney (1982) and Cassileth et al. (1984) did combine disease groups and study chronic illness in general. Westbrook and Viney (1982) studied hospitalized patients and found them significantly more depressed and anxious than the control group. In an analysis of clinic patients, Cassileth et al. (1984) found that diagnostic groups did not differ from each other or the general population in mental health status. Thus general studies also present conflicting results.

The research study discussed in the following chapters presents additional data to help clarify these interrelationships between various disease and psychosocial variables that may affect the mental health of middle aged and elderly individuals with physical illness. 
CHAPTER II

THEORETICAL FRAMEWORK

The preceding literature review indicates a strong relationship between physical illness and depression. Past research has also begun to identify factors in this relationship; however, much of this research is experiential or disease specific. Systematic studies regarding depression and physical illness that have combined many factors, several diseases, or specifically dealt with older persons are rare. This research project will provide additional data to help clarify the interrelationships of disease and individual characteristics as they affect the psychological response to illness in older persons. In this chapter a theoretical framework is developed to guide later discussion.

Coping with physical illness is certainly a major stress for most people. The illness may causemajor life-style changes, loss of independence, large financial outlays, pain and discomfort, loss of accustomed roles, and/or shortening of life. Because physical illness is much more common in older persons, other factors may operate to 
alter the relationship between depression and physical illness in this age group. Based on Festinger's social comparison theory (West \& Wicklund, 1980), the elderly may compare their health to their peer group and therefore find their physical illness "normal". This view of illness as an expected problem is related to Neugarten's (1979) suggestion that "on-time" problems cause less stress and to Schulz and Rau's (1985) discussion of temporally normative events. An alternative explanation is Vaillant's "growth hypothesis" (McCrae, 1982) that the elderly may have a lifetime of coping experience that helps them to successfully adapt. This would suggest that the relationship of physical illness and depression may require special considerations for the elderly.

Previous research provides strong support for the inclusion of certain variables in any study of the relationship between physical illness and depression. Pain, physical dependency, income, social support, and perceived controllability have consistently shown effects in general studies of depression. Higher levels of pain and physical dependency have been associated with higher levels of depression while lower levels of income, social support, and perceived controllability have been related to higher levels of depression.

other factors have been frequently studied, but 
research results are so varied as to make predictions of effects difficult. Included in this group are age, gender, and length of liliness.

The literature suggests aditional variables that have been seldom studied. High levels of religiosity, life expectancy, subjective health, and number and centrality of roles would be expected to be associated with lower levels of depression. Conversely, high levels of death anxiety, worry about medical resources, and perceived areas of life affected would probably be related to high levels of depression.

An overview of adaption to stress by Schlossberg (1981) provided a system for the categorization of the many variables described above. Schlossberg outlined three categories of important factors: characteristics of the environment, characteristics of the individual, and perceptions of the transition. Modifying this system to the situation of the physically ill elderly, the variables mentioned above could be divided into characteristics of the disease, characteristics of the individual, and perceptions of the disease. Table II classifies the variables into these three categories. Characteristics of the disease include pain, physical dependency, and length of illness. Age, gender, income, social support, religiosity, death anxiety, worry about medical resources, 
TABLE II

CLASSIFICATION OF VARIABLES AND HYPOTHESIZED RELATIONSHIP TO DEPRESSION

Hypothesized

Relationship

Characteristics of the Individual

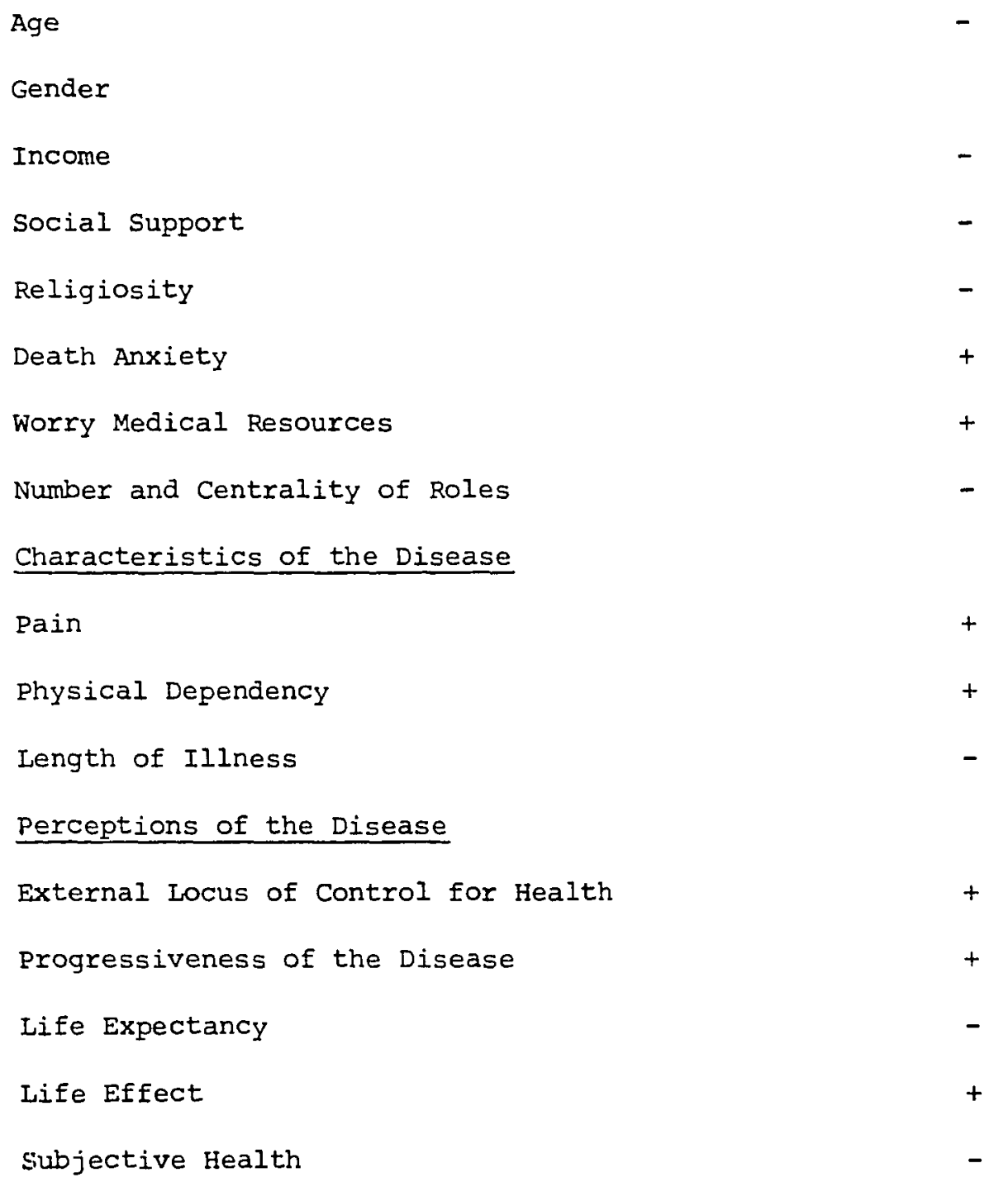


and number and centrality of roles are classified under characteristics of the individual. Perceptions of the disease include perceived controllability, life expectancy, areas of life affected, subjective health, and perceived progressiveness of the disease.

Table II outines the hypothesized impact of these variables on levels of depression in the physically ill elderly. Higher levels of pain, physical dependency, death anxiety, worry about medical resources, perceived progressiveness of the disease, and external locus of control for health are hypothesized to be associated with higher levels of depression. Income, social support, length of illness, life expectancy, subjective lealth, and age are expected to be negatively related to levels of depression. That is, lower values of these variables would be associated with higher levels of depression.

Based upon the above hypothesized relationships, a general model for the study was derived as diagrammed in Figure 1. In this model, level of depression can be affected directly by all three categories of variables. For example, characteristics of the disease such as pain or physical dependency could have a direct impact on depression. So also could perceptions of the disease such as subjective health, progressiveness of the disease, or life expectancy. Characteristics of the individual such as 


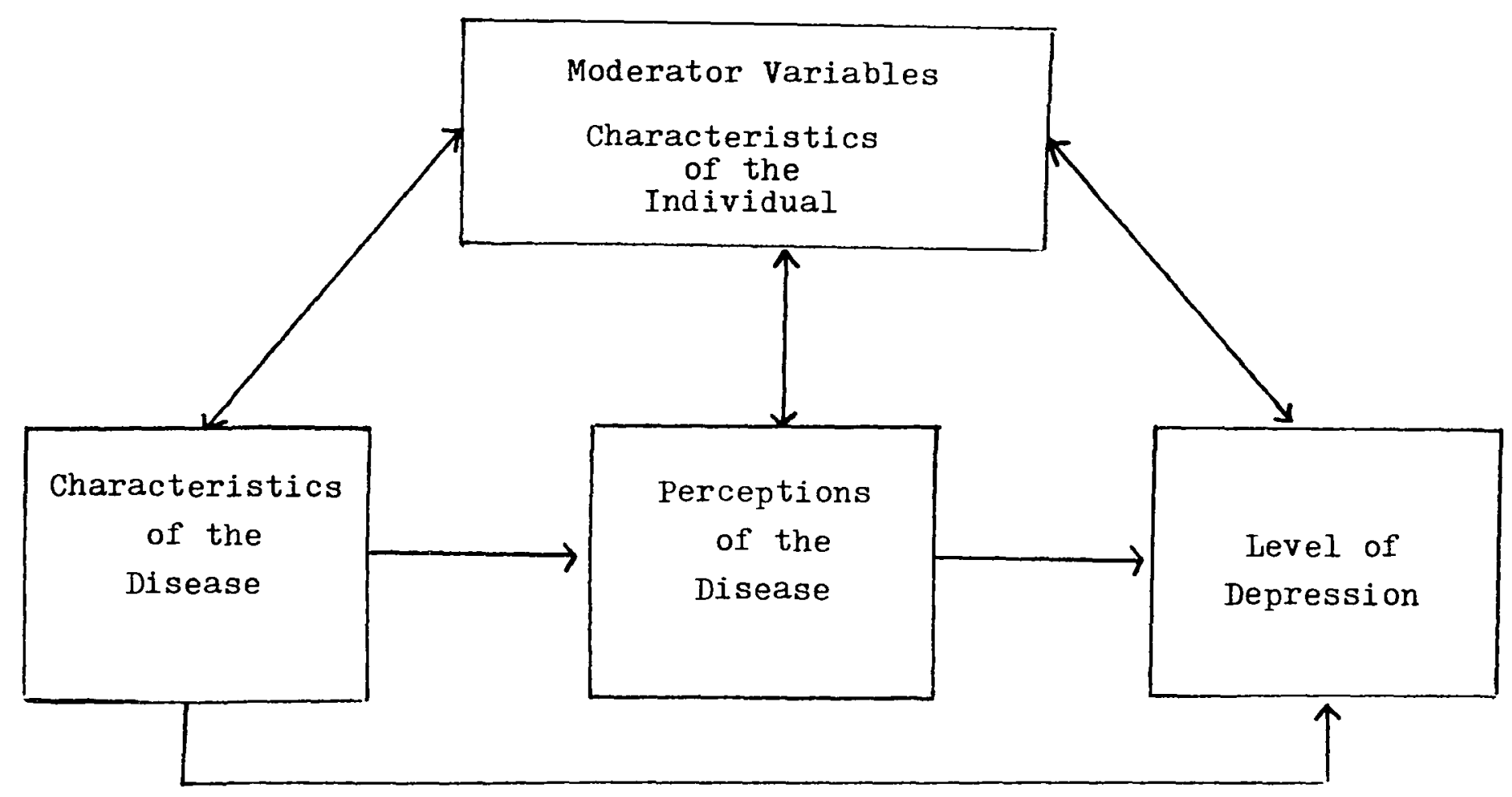

Figure 1. General Model 
age, social support, or income could also directly affect levels of depression. In addition to these direct effects, many of these variables could also have indirect effects on depression through their influence on related variables. For example, income as a characteristic of the individual might be expected to affect the disease characteristic of physical dependency or the perception of controllability as well as directly influence depression. Physical dependency as a characteristic of the disease would be expected to be related to income and social support. Life expectancy, progressiveness of the disease, death anxiety, and religiosity would also be projected to impact upon each other. Therefore, in the model connections are placed between the categories of variables as well as directly to depression.

The literature provides little systematic data about change in depression levels over time and even less about factors associated with that change. Nevertheless, change in the key variables associated with depression at one point in time would be expected to be related to change in depression over time. The design of this project will allow for the study of the impact of these variables on depression at two points in time and analysis of change in the variables over a three month period of time. Chapter II will describe in detail the design of the study and the 
operational definitions of the numerous variables outlined above. 
CHAPTER III

\section{METHODOLOGY}

A panel survey research design was chosen to investigate the relationship between characteristics of the illness and the individual and the psychological response of middle aged and elderly persons to physical illness. Additional information regarding the nature of the social support and available medical resources of physically ill middle aged and elderly persons residing in the community was gathered. Two structured in-person interviews, given three months apart, were the primary data gathering tool. Limited information was also obtained from medical records. The following sections describe the sampling procedure, operational definitions of the variables measured, the data analysis, and research questions investigated.

\section{THE SAMPLE}

The first interview was completed by 133 persons who were referred by medical clinics and agencies in the Portland metropolitan area. Twenty-two subjects were referred by 5 hospital clinics, 26 were referred by 8 private physicians, 4 were referred by 2 hospital social 
service departments, 76 were referred by 4 home health agencies, and 5 were referred by other subjects. The large number of referrals from home health agencies was probably due to the frequent contact with patients made by these agencies. A large number and variety of referral sources was purposefully chosen in order to provide a range of diagnoses and socioeconomic levels and to counter any selection bias that might occur from any one source.

The criteria for inclusion in the study were that the subjects must be 50 years of age or older, have been recently diagnosed or suffered an exacerbation of a physical illness, have the physical and mental ability to verbally complete the interview, and not be residing in a nursing home or intermediate care facility.

The age range of the subjects was from 50 to 92 , with a mean age of 68.8 years. The number and percentage of subjects with various diagnoses is listed in Table III. The diagnoses of the subjects was fairly evenly split between the seven categories. The percentages total more than $100 \%$ because many subjects had multiple diagnoses. A detailed description of the demographic characteristics of the sample is included in Chapter IV.

In order to investigate possible biases in the sampling procedure, an attempt was made to document the reasons given by potential subjects when they refused to 
TABLE II I

DIAGNOSES OF SUBJECTS

$N=133$

\begin{tabular}{lcc}
\hline Disease & $\begin{array}{c}\text { Percent of Sample } \\
\text { Having Disease* }\end{array}$ & Mean CES-D Score \\
\hline Chronic Heart Disease & 27.8 & 16.9 \\
Chronic Lung Disease & 18.0 & 19.6 \\
Cancer & 19.5 & 14.1 \\
Diabetes & 25.6 & 16.4 \\
Arthritis & 30.1 & 18.4 \\
Fracture & 9.0 & 12.8 \\
Other & 25.6 & 18.0 \\
\hline
\end{tabular}

* Total is greater than $100 \%$ as many subjects have more than one disease. 
participate. As most subjects were first contacted by the referral agency, this documentation was not always possible. Reasons for refusal were itemized for 53 potential subjects. Nine potential subjects felt too sick to participate in the study, and 19 simply stated that they were not interested. Other reasons for nonparticipation were being involved in other studies, being too busy, inappropriate referrals, or death before the interview could be arranged. In the investigator's opinion, individuals who were acutely ill, angry, unwilling to share their time and personal thoughts, and sometimes those who were busily functioning at a normal level tended not to participate. This may have resulted in lower levels of depression and higher levels of overall satisfaction than in the total physically ill population.

One hundred and fourteen of the original 133 subjects completed the second interview approximately 3 months later. Eight subjects died between the first and second interview, five were too sick or confused to complete the second interview, three were unlocatable, and three simply refused. Thus $86 \%$ of the original sample completed both interviews.

The interval of three months between interviews was chosen because the full impact of the exacerbation of the illness could be expected to occur during this time while 
the effect of other intervening factors could be minimized. A three month interval was supported by a year long study of physical illness and depression by Anhensel, Frerichs, and Huba (1984). They found the greatest effect of physical illness to be within 4 months and less effect over 8 and 12 month periods.

\section{DATA COLLECTION}

Data from the two structured interviews was collected from September 1984 through June 1985. Subjects referred by the various medical agencies were contacted by phone or letter to explain the study. If they agreed to participate, the first interview of approximately one hour was scheduled at a time and place of their convenience. In-person interviews were deemed necessary because of the personal nature of the questions and the physical limitations of the subjects. Most subjects were interviewed in their homes, but 2 were interviewed in the hospital and 3 at their workplace. Eighty-six of the subjects were able to complete the self-report questionnaires themselves while 47 required that these be given verbally.

The shorter second interview of about 45 minutes was completed approximately 3 months later. Again most of the interviews were completed in the subject's home. However, 
as some subjects had moved to distant locations or in-person interviews could not be scheduled, five second interviews were completed by telephone.

The total of 247 interviews were given by 3 interviewers. The initial interview was pre-tested on six individuals and revised. The author gave 36 first interviews and 44 second interviews for a total of 80 or 32 percent. The other two interviewers were experienced interviewers who were trained and tested by the author. The first research assistant completed 97 first interviews and 48 second interviews for a total of 145 or 59 percent. The second research assistant completed 22 second interviews or 9 percent. Frequent contact was maintained between all the interviewers to assure consistency and to clarify ambiguous responses.

Medical records were obtained for 128 of the subjects. These consisted of a summary of the medical history or recent hospitalization. These records ranged from very detailed to very brief and generally contained little information on the psychological response of the subject. The medical records were used to validate diagnoses and when possible to document a history of psychological problems or alcoholism. 
HUMAN SUBJECTS PROTECTION

At the time of the first interview, all subjects signed informed consent forms and medical release forms. The interviewer explained to each subject that they could refuse to answer any question and could withdraw from the study at any time.

The potential risks to the subjects were considered to be psychological. Certain questions might cause distress or anxiety or might be perceived to be an invasion of privacy. Also, the length of the interview might be fatiguing to subjects with more severe disease. Interviewers were trained to watch for signs of anxiety or distress. If the subject became fatigued, the interview was completed at a later time. Generally, the risks were considered to be low, and most subjects appeared to enjoy the interview.

Careful precautions were taken to assure the confidentiality of the information. Questionnaires included only code identification numbers, and all identifying information was immediately removed from the medical records. The project received the approval of the Human Subject Review Board of Portland State University and the various referral agencies. 
VARIABLES - OPERATIONAL DEFINITIONS

The data for the variables to be measured came from three general sources. Both interviews included two parts: standardized instruments that had been frequently used and tested, and interview questions specifically designed for this project. Some data was also taken from the medical record, though the inconsistent quality of these records made this source unreliable.

The variables to be measured were divided into five general categories: characteristics of the disease, individual perceptions of the disease, characteristics of the individual, confounding variables, and outcome variables.

Characteristics of the Disease

Pain and Discomfort. This variable was measured by the answers to specific interview items. A pain index consisting of the four aspects of general pain level, pain level in the last week, pain score in the last week, and general discomfort level was computed. This findex had a maximum score of 19. The Cronbach's alpha for this index was .71 indicating a moderately high level of internal consistency.

Physical Dependency. The degree of physical dependency was measured by an activities of living scale 
that included both in-home and outside-of-the-home functions. Subjects were rated on whether or not they performed the various activities independently, with or without an assistive device, with slight assistance, much assistance, or were no longer able to perform the activity. The maximum score of 44 indicated a high level of physical dependency.

Length of Illness. Subjects reported the length of time in months and years since they were diagnosed as having the disease associated with their most recent problem.

Perceptions of the Disease by the Individual

Life Expectancy. The degree to which subjects perceived their life to be shortened by their diseases was assessed by their life expectancy. Subjects were asked how many more years they expected to live, and this figure was added to their age.

Perceived Progressiveness of the Disease. The perceived progressiveness of the disease was measured by the subject's response to three questions about the expected future of the disease in six months, the expected future of their health in six months, and their belief in future recovery. The resultant progressiveness of the disease index had a maximum score of 12 and a Cronbach's 
alpha of .74 . In the second interview an additional question was included regarding the progression of the illness in the intervening time.

Perceived Areas of Life Affected. Subjects were asked to assess the degree to which the disease had affected their ability to care for themselves, ability to carefor others, eating and sleeping habits, hobbies, ability to work, and ability to maintain friendships. These areas of life affected were combined to form an index with maximum score of 45 and a Cronbach's alpha of 0.89 . As subjects tended to interpret the areas of life affected in terms of their physical abilities, this index correlated highly with the physical dependency score showing a Pearson's correlation coefficient of $\underline{r}=.793, p<.001$.

Perceived Controllability. The Health Locus of Control Scale as developed by Wallston et al. (1976) was completed by the subjects. With a possible score of 11 to 66, this scale is scored higher for an external locus of control. The Health Locus of Control Scale is composed of 11 items chosen from a longer list based on a high item-to-scale correlation and a low correlation to a social desirability scale. The alpha reliability of the scale in the original sample was 0.72 . In the present study, the Cronbach's alpha for the scale was 0.59 . As the questions on this scale are somewhat general, three specific 
questions regarding predictability and controllability of the subject's present problem were also included. The Cronbach's alpha for these questions was .49. Because of the low internal consistency of these scales, individual questions were investigated for their inclusion in the statistical analyses. The wording of some of the questions appeared to confuse the subjects; for example, "accidental happenings" was frequently interpreted to mean accidents. Finally, question 1 which read "If I take care of myself, I can avoid illness" was chosen to represent a general health locus of control for the statistical analyses. The question "I can generally control the symptoms of my disease" was chosen to represent locus of control for the specific illness. These two questions did not correlate highly with each other, $\underline{r}=.275$, p<.002, and general and specific locus of control scores were retained as separate variables.

Subjective Health. The measure of overall health and comparative health status were combined to form a subjective health rating. Subjects were asked to rate their overall health on a scale of (1) poor to (4) excellent. Information on more objective measures of health status, such as number of recent hospitalizations, number of visits to the doctor, and numbers of medications was also gathered. However, because of the wide variety of 
medical treatments for the varied diagnoses of the subjects, these objective measures had little relationship to the subjective measure of health or to the outcome variables.

subjects were also asked to assess their health status in relation to others their age on a scale of (1) much worse to (5) much better. Subjects were also asked to compare themselves and their level of pain to other persons with the same disease; however, many of the subjects were unable to identify anyone with whom to compare these characteristics. The correlation of comparative health status to overall health rating was moderately strong, $\underline{r}=.54, p<.003$; therefore, these two questions were combined to form a subjective health rating with a maximum score of nine.

\section{Characteristics of the Individual}

Age. Subjects gave their age at the time of the first interview.

Gender. Gender of the subject was determined by interviewer observation.

Income. Income was the primary measure of socioeconomic status. Information on the subject's education and occupation was also gathered; however, of ten the education and occupational status of the spouse was 
more important in determining available resources. Therefore, income was felt to be the best indicator of available resources.

Religiosity. Religiosity was determined by the answer to two questions: the importance of religion and the level of church attendance before the latest health problem. This religiosity index had a maximum score of 12 and a Cronbach's alpha of .58.

Social Support. Social support measures the numbers of individuals from both formal and informal networks available to provide emotional, informational, or instrumental assistance. Subjects were asked to identify the individuals who would and/or did provide these types of assistance and their satisfaction with these relationships. For each individual on the social support list, the gender and relationship to the subject were also recorded.

Various indices of social support were computed. Persons who would or did provide personal care, household assistance, and transportation were combined to form an index of instrumental support. Emotional support was computed as a combination of persons who would or did provide personal advice or emotional support. Informational support was the combination of persons who would or did provide general advice or information. Attempts to combine these indices of social support resulted in an index with 
Low internal consistency, probably because the indices measure different aspects of social support. Therefore, total exchanges in the social support system was chosen as the best overall measure of social support for later statistical analyses. Whenever a subject named someone who would or did provide a particular type of assistance, this was counted as an exchange. These exchanges were not necessarily reciprocal, and one support person might have numerous exchanges with the subject. Subjects were asked to name support persons in reference to their most recent health problem. Therefore, the measure of social support applied to approximately the previous month before the interview.

Medical Resources. Subjects were asked to identify the sources of their funding for medical expenses. They were also asked to assess the adequacy of their resources for health care expenses and their degree of worry about paying these expenses in the future.

Death Anxiety. In this study, death anxiety refers to the subject's acknowledged concern with her/his own death and the dying process. The Templer Death Anxiety scale was used to measure this variable as it has been validated (Templer, 1970) and has norms for various age groups (Templer \& Ruff, 1971). Templer (1970) demonstrated a test-retest reliability for this scale of .83. Cronbach's 
alpha for the Templer Death Anxiety scale in this study was .70 .

Number and Centrality of Roles. The subjects were asked various questions about possible roles in which others depend upon them. These roles included employment, caregiver, support-giver, and activity in various associations. A role centrality index composed of employment status, total number of group memberships, and total number of persons to which the subject gave household help, advice, or help in an illness was computed yielding a Cronbach's alpha of .72 .

\section{Possible Confounding Variables}

Social Desirability. As the desire to give the socially acceptable response might influence the results, each subject was asked to complete the Marlowe-Crowne Social Desirability scale. This scale is designed to measure the denial of socially acceptable behavior and has been shown to have a test-retest reliability of .89 and a internal consistency coefficient of .88 (Crowne \& Marlowe, 1960). However, it is the investigator's opinion that this scale did not demonstrate social desirability for this sample. Because the interview dealt with recent experiences, the subjects tended to focus on the recent past. If they could not think of a specific incident to 
the contrary, they would answer the question in the socially acceptable manner. They often did not notice categorical words such as "never" or "always". As a result, scores on this scale were falsely elevated. Medications Causing Depression. Subjects were asked to identify all the medications they were regularly taking in order to identify those that have been recognized as possibly causing depression.

Past or Present Treatment for Depression. Subjects were asked if they had or were now receiving professional help for depression.

other Significant Life Events. Subjects were asked to identify any important events, good or bad, other than their illness that they had experienced in the last year. These major life events might also precipitate a depressive episode.

\section{Outcome Variables}

Two standardized instruments were chosen as outcome measures: the Center for Epidemiological Studies Depression Scale (CES-D) and the Life Satisfaction Index (LSIA-A). While the measurement of factors associated with depression was the primary focus of this study, life satisfaction was also chosen as a closely related aspect of subjective well-being. George (1981) outlined these two parallel but 
distinct substantive traditions within the study of subjective well-being: studies from the mental health literature and studies on life satisfaction. She suggested that measures of psychiatric symptoms and life satisfaction are indicators of various elements of the construct of subjective well-being. Depression as measured by the CES-D is a measure of present psychiatric symptomatology; life satisfaction is related but implies assessment of the past and future as well as the present.

Dysphoria/depression. Dysphoria refers to the presence of a down, gloomy mood while depression refers to the presence of this mood plus the other cognitive, behavioral, and somatic characteristics of depression as defined by the Diagnostic and Statistical Manual of Mental Disorders III (DSM-III, American Psychiatric Association, 1980). The Center for Epidemiological Studies Depression Scale (CES-D) was chosen to assess this outcome variable. This scale was constructed from other validated depression scales and was specifically designed for use with community samples. It has been used in numerous studies and has norms for many age groups. Several authors have also attempted to convert CES-D scores to DSM-III classification criteria (Noh, Wood \& Turner, 1984). The reduced emphasis in the CES-D on the somatic components of depression makes it a good instrument for use with elderly and physicaliy 
ill subjects. The CES-D also provides a good gradation of the persistence of the symptoms of dysphoria or depression. In a recent study, Davis (1984) compared the Geriatric Depression Scale, the Depression Adjective Checklist, the Hamilton Rating Scalefor Depression, and the CES-D. The CES-D demonstrated good internal consistency, was well understood by older subjects, correlated well with other measures of depression and differentiated between depressed and non-depressed subjects. The CES-D had a high specificity rate but had a lower sensitivity rate for older subjects than the Geriatric Depression Scale.

Radloff (1977) found a coefficient of internal consistency of .85 for the CES-D, the Cronbach's alpha for this sample was .86 . The CES-D has been shown to produce a high number of false positive cases of depression, but it is recognized as a valid screening device for community samples (Craig \& Van Natta, 1976; Myers \& Weissman, 1980; Noh, et al., 1984, Roberts \& Vernon, 1983). A professional assessment of the subject's depression was precluded by financial limitations.

Life Satisfaction. Life satisfaction is the subject's stated contentment and happiness with his/her past, present, and future. Life satisfaction is often used as synonomous with subjective well-being, though life 
satisfaction also deals with past aspects of life. The Life Satisfaction Index (LSIA-A) as developed by Neugatten, Havighurst, and Tobin (1961) and modified by Adams (1969) was used to measure this variable. This index has been factor analyzed many times in order to identify specific components. The voluminous literature on the index appears to agree on three factors (Adams, 1969; George, 1981; Hoyt \& Creech, 1983; Liang, 1984, Neugarten et al, 1961). These are mood tone, primarily happiness; zest, an optimistic and positive outlook on life in the present and the future; and congruence, an assessment of the extent to which a person's life is generally satisfying and the degree to which one has attained one's goals. The LSIA-A has much normative data in the literature, is well balanced with positive and negative items, and is easy for elderly persons to complete. No reliability estimates for the LSIA-A were available; however, in this study the Cronbach's alpha was .84 indicating a high level of internal consistency.

DATA ANALYSIS

The majority of the statistical analyses described below were done using SPSS, The Statistical Package for the Soclal Sciences (Nie, Hull, Jenkins, Steinbrenner, \& Bent, 1975). 
Descriptive Analysis

General descriptive statistics including measures of central tendency, standard deviation, and frequency were computed. These descriptive statistics were used to answer the following research questions:

1. What are the demographic characteristics of the sample?

2. What are the medical resources and needs of the sample?

3. What is the nature of the social support system of the sample?

Analysis of Relationships at One Point in Time

For both the first and second interviews, the relationship of the numerous variables described above to the scores on the CES-D and LSIA-A was determined. The statistical procedures included Pearson product-moment correlation, Spearman's coefficient of rank order correlation, chi-square test, t-test, and analysis of variance. The intercorrelations among independent variables were also examined before carrying out multivariate analyses. Using multiple linear regression procedures, the relative importance of variables in relation to the outcome variables was investigated. This analysis attempted to answer the following research 
questions and hypotheses:

1. What is the relationship of age to the level of depression? It was hypothesized that age would be inversely related to the level of depression. That is, the middle aged and young-old would cope with physical illness less well than the old-old.

2. What is the relationship of the various independent variables to the levels of depression and life satisfaction? The hypothesized relationships are listed in Table II in Chapter II.

3. What is the relationship between the various independent variables investigated in this study?

4. What is the relative importance of the various independent variables to the levels of depression and life satisfaction?

Analysis of Change Over Time

A comparison of the data from Time 1 and Time 2 interviews allowed the investigation of the longer term impact of an exacerbation of an illness and the emotional response to it. Also, many of the variables measured in this project cannot be experimentally manipulated, and some possible causal relationships were investigated using multiple linear regression and dynamic (change focused) correlational analysis. The following research questions 
were investigated:

1. What is the change over time of the various independent and outcome variables?

2. What relationship does change in key variables over time have to change in the outcome variables?

3. What is the effect of the various variables on change groups for the CES-D and LSIA-A?

Presentation of Findings

The following chapters present in detail the results of the data analyses. Chapter IV describes the demographic characteristics of the sample as well as reporting on the nature of the social support system, medical resources, and medical needs of the subjects. Chapter V discusses the interrelationships of the various factors as measured at one point in time. Finally, changes in these interrelationships over time are presented in Chapter VI. 


\title{
CHAPTER IV
}

\section{DESCRIPTIVE ANALYSIS}

\begin{abstract}
Before examining the emotional impact of a physical illness, the general characteristics of the individual, their social support system, and available medical resources require investigation. This chapter will describe the demographic characteristics of the study subjects, the size and quality of their social support system, and the attributes of their available medical resources.
\end{abstract}

\section{DEMOGRAPHIC CHARACTERISTICS OF THE SAMPLE}

The demographic characteristics of the subjects are summarized in Table IV. Although the sample had approximately the same racial composition as the portland SMSA, the study subjects were older, less educated, less likely to be married, and had a lower median income than the total over aged 50 population in the Portland standard Metropolitan Statistical Area (SMSA) (National Decision Systems, 1982). These demographic characteristics will be discussed in detail in the following sections. 
TABLE IV

GENERAL DEMCGRAPHIC DATA

$\underline{A G E}$

$\begin{array}{ll}118 & 50-54 \text { YRS, } \\ 308 & 55-64 \\ 308 & 65-74 \\ 228 & 75-84 \\ 78 & 85-92\end{array}$

MEAN $=68.8$ YRS.

RANGE $=50-92$

GENDER

$70 \%$ FEMALE

308 MALE

ETHINIC STATUS

97\% WHITE

3\% BLACK

MARITAL STATUS

7\% SINGLE, NEVER MARRIED

$48 \%$ MARRIED

$37 \%$ WIDOWED

68 DIVORCED

$2 \%$ SEPARATED

EDUCATION

35\% LESS THAN HIGH SCHOOL GRAD

19\% HIGH SCHOOI GRAD

7\% TECHNICAL SCHOOL

38\% SOME COLLEGE

$6 \%$ COLLEGE GRAD

68 GRADUATE OR PROFESSICNAL SCHOOL

INCOME

$\begin{array}{lr}238 & \text { LESS THAN } \$ 5000 / Y R \\ 28 \% & 5,000-9,999 / Y R \\ 25 \% & 10,000-20,000 / Y R \\ 148 & 20,000-30,000 / Y R \\ 108 & 30,000 \text { AND ABOVE }\end{array}$

MEAN $=14,085$

MEDIAN $=9,850$

RESIDENTIAL SETTING

498 URBAN

$35 \%$ SUBURBAN

168 RURAL 
Age

The 133 subjects in the sample ranged in age from 50 to 92 years, with a mean age of 68.8 years, S.D.=10.0. If divided into age categories, the group of the middle aged, aged 50 to 64 , contained 54 individuals. The young old, aged 65 through 74 , included 41 subjects; and the old, aged 75 to 84 , had 29 individuals. The old old, aged 85 to 92 , contained only 9 individuals. Very old persons were harder to include in the study as they were referred less often, were less willing to share their feelings, and appeared to have fewer physical reserves remaining after the stress of illness. The age distribution in this study had a higher mean age than the total population of persons 50 years or older in the Portland SMSA (US Bureau of the Census, 1983b). The mean age was also higher than the over 50 population of the entire United States (US Bureau of the census, 1983a). This would be expected in a sample of persons with physical iliness as the prevalence of most of the diagnoses included in the study increases with age.

\section{$\underline{\text { Gender }}$}

Ninety-three of the subjects or $70 \%$ were female. While this percentage is greater than the percentage of females in the over 50 aged group in the Portland SMSA and in the United States (US Bureau of the Census, 1983a), the 
predominance of females was probably due to the increased age of the sample.

\section{Marital Status}

Overall the sample was predominately married (47\%) or widowed $(37 \%)$. Both the middle aged and elderly subjects were less likely to be married than the over 50 population in the Portland SMSA (US Bureau of the Census, 1983b). The higher percentage of older and female subjects would partially account for this; however, it is possible that unmarried persons were more likely to be referred because they may utilize home health services morefrequently. Also, it is possible that physically ill persons are less likely to marry or remarry. The subjects generally lived alone $(38 \%)$ or with a spouse $(44 \%)$. Only a small percentage ( $8 \%$ ) of the sample lived with their children or grandchildren.

\section{Education}

The subjects in the sample were only slightly less educated than the population of the portland smsA (US Bureau of the Census, 1983b). While $35 \%$ of the sample did not complete high school, $38 \%$ had at least some college education. The figures for the over 25 population in the Portland SMSA are $21 \%$ and $42 \%$, respectively (National Decision systems, 1982). The national figures for the over 
25 white population show that $29 \%$ did not complete high school and $33 \%$ had at least some college education (US Bureau of the Census, 1983a). Thus this sample was slightly less educated than the Portland SMSA but more educated than the national average.

\section{Income}

The sample had a mean income of $\$ 14,085$, S.D. $=10,000$, and a median income of $\$ 9,850$. This median income was $58 \%$ of the national median income for all households (US Bureau of the Census, 1982a). A better comparison to the Portland SMSA was possible if the subjects were divided into middle aged and elderly groups. The middle aged subjects had a median income of $\$ 15,315$ which was $60 \%$ of the median income for the same age group for the Portland SMSA. For the elderly subjects, their median income of $\$ 9,240$ was $66 \%$ of the median income for their corresponding age group in the Portland SMSA. The lower income of the middle aged group was probably because of their inability to be fully employed due to their health problems. The low income of the elderly group could be ascribed to the high number of widows in this group. Apparently, especially for the middle aged, physical illness had a strong impact on income. 
Residential Setting

Forty-nine percent of the subjects lived in an urban setting, $35 \%$ in a suburban setting, and $16 \%$ in a rural area. Fifty-six percent lived in single family homes and $26 \%$ in apartments. Over half or $57 \%$ owned thelr dwelling.

\section{Modes of Transportantion}

The automobile was the most frequent mode of transportation used by the subjects. Thirty-eight percent drove their own cars and most of the rest depended upon spouses, relatives, or friends to drive them. The bus was regularly used by $17 \%$ of the sample, and $9 \%$ used a senior van system. Only $6 \%$ regularly used a taxi for transportation.

\section{Organizational Membership}

Generally, the subjects belonged to few groups or organizations with nearly 50\% belonging to none. The mean number of memberships was $1.1, S . D .=1.48$. Of those who did belong, they most frequently were members of fraternal, professional, or church groups. Membership in charitable, political, or sport organizations was rare.

\section{Health Status}

The various diagnoses of the subjects was described in Chapter III. The subjects had an average of 1.54 
diagnoses per person, S.D.=.75; $37 \%$ had two or more diagnoses. With a maximum score on the physical dependency scale of 44, the mean score was 15.71, S.D.=12.2. About half of the subjects could maneuver fairly well in their homes but could not function outside the home without considerable help. Fifty percent of the subjects had been hospitalized just prior to their participation in the project. The subjects were hospitalized an average of 2.62 times, S.D. $=2.63$, in the last year; had visited the doctor an average of 8.34 times, S.D. $=7.89$, in the last $s i x$ months; and took an average of 4.57 prescription medications, S.D.=2.92. Forty-four percent of the subjects rated their health as good or excellent while $66 \%$ rated their health as fair or poor.

\section{CHARACTERISTICS OF THE SOCIAL SUPPORT SYSTEM}

Subjects were asked to identify those persons who would and/or did help them with instrumental, emotional, or informational support. Table $V$ includes the mean number of persons or mean percent of the support system in various categories. The following sections discuss the size, quality, and reciprocity of the social support system as well as the relationships between the demographic characteristics of this sample and the support system characteristics. 
CHARACTERISTICS OF THE SOCIAL SUPPORT SYSTEM

\begin{tabular}{|c|c|c|}
\hline & $\begin{array}{c}\text { MEAN \# } \\
\text { OP PERSONS } \\
\end{array}$ & $\begin{array}{l}\text { MEAN PERCENT } \\
\text { OF SYSTEM } \\
\end{array}$ \\
\hline \multicolumn{3}{|l|}{ SIZE } \\
\hline OVERALL & 7.12 & \\
\hline INSTRUMENTAL SUPPORT & 7.22 & \\
\hline EMOTIONAL SUPPORT & 5.16 & \\
\hline INFORMATIONAL SUPPORT & 2.90 & \\
\hline \multicolumn{3}{|l|}{ GENDER } \\
\hline MALE & 2.86 & $42 \%$ \\
\hline FEMALE & 4.04 & $58 \%$ \\
\hline \multicolumn{3}{|l|}{ RELATIONSHIP TO SUBJECT } \\
\hline RELATIVES & 4.23 & 598 \\
\hline FRIENDS & 1.70 & 238 \\
\hline NEIGHBORS & .67 & $10 \%$ \\
\hline COWORKER & & $0 \%$ \\
\hline CHURCH OR CLUB MEMBER & & $1 \%$ \\
\hline PROFESSIONAL HEALTH WORKER & & 38 \\
\hline OTHER & & 48 \\
\hline \multicolumn{3}{|l|}{ SUBJECT SATISFACTION } \\
\hline DISSATISFIED & & 18 \\
\hline NEUTRAL & & 38 \\
\hline SOMEWHAT SATISFIED & & 88 \\
\hline VERY SATISFIED & & 888 \\
\hline
\end{tabular}


$\underline{\text { Size }}$

The physically ill middle aged and elderly subjects in this study named an average number of 7.12 persons, S.D. $=2.8$, in their potential or actual social support system. The range was from 2 to 16 persons. The total number of exchanges in the system ranged from 4 to 82 with a mean of 25 exchanges, S.D.=12.7. Instrumental support, including personal care, household assistance, and transportation was or would be provided by an average of 7.22 persons, S.D. $=4.12$, per subject. Emotional support was available from an average of 5.16 persons, S.D.=2.99; and informational support from an average of 2.90 persons, S.D. $=2.27$. The social support system of the subjects was $42 \%$ male and $58 \%$ female. The system was predominantly composed of relatives $(59 \%)$, friends $(23 \%)$, and neighbors $(10 \%)$. Very few of the persons in the social support system were coworkers, church or club members, or professional health workers. It should be noted, however, that individuals were coded by their closest relationship to the subject; thus neighbors or coworkers who were also friends were coded as friends.

Quality

Subjects were asked to categorize their satisfaction with their relationships with the persons in their social 
support system as dissatisfied, neutral, somewhat satisfied, or very satisfied. The subjects were overwhelmingly very satisfied with the persons in their systems; $88 \%$ of the support persons fell into this category. This high level of satisfaction could be due to two factors. Many subjects appeared to have large enough support systems that they were able to choose to associate with those with whom they were satisfied. However, it is possible that individuals who are dependent upon others for support are less likely to find fault with these persons. Another indicator of the quality of the social support system was that the subjects believed that $43 \%$ of the persons in their systems would give more help if needed.

\section{Reciprocity}

The social support system of the subjects in this study exhibited very little reciprocity. only $13 \%$ of the persons named in the systems both gave and received household assistance or gave and received personal advice. Reciprocal exchanges of household assistance were most Erequent for friends and neighbors; while reciprocal exchanges of personal advice were most frequent for spouses and children. Many subjects expressed the concern that others did not come to them for advice or assistance because the subjects were perceived as already having many 
problems. Also, many of the subjects were simply too physically dependent to provide others with instrumental assistance.

Effect of Demographic Characteristics

Gender. While gender of the subject was not related to the total number of names listed in the social support network, men did have a stgnificantly larger number of total exchanges, $t=3.03, p<.004$, and more persons who would give more assistance if needed, $t=3.54, p<.002$. Women subjects were more likely to have a significantly larger percentage of neighbors in their systems, $t=2.30, p<.024$, while men were more likely to have a larger percentage of friends, $\quad t=2.20, \quad$ p $\quad .031$. Within the social support systems, women were somewhat more likely to give instrumental support, $t=1.68, p<.097$. Men and women were equally likely to give emotional or informational support.

Age. While the older subjects showed a tendency to fewer total names, $\underline{F}(3,129)=2.58, p<.057$, and exchanges, $\underline{F}(3,129)=2.54, p<.060$, in their social support systems, this relationship did not reach statistical significance at the .05 level. This was also true of the tendency of older subjects to have more relatives in their support systems, $\underline{F}(3,129)=2.62, \mathrm{p}<.055$. The age of the subject was not related to the amount of instrumental, $F(3,129)=.172$, 
$\mathrm{p}<.916$, emotional, $E(3,129)=2.16, \mathrm{p}<.101$, or informational, $\underline{F}(3,129)=1.87, p<.139$, support received by the subjects.

Marital status. Table VI shows the values for key support system variables classified by marital status. Total names and total exchanges are included as general measures of social support. The percentage of relatives, friends, neighbors, males, and females in the support system are outlined. The average number of persons providing the instrumental help of personal care, household assistance, or transportation is also included. Emotional help consisted of the mean number of persons who gave personal advice or emotional support. Persons who gave either advice for important decisions or information were classified as providing informational assistance. Analysis of variance using the four groups of married, widowed, separated or divorced, and single never-married was carried out for the various measures of social support.

Married and widowed subjects had significantly more total names, $\underline{F}(3,129)=4.49, \quad p<.006$, total exchanges, $\underline{F}(3,129)=4.24$, p. 002 , and emotional support, $\underline{F}(3,129)=5.66$, p<.006, in their social support systems. The presence of living children appeared to increase the size of several social support varlables; however, the number of married or widowed subjects without children was small and conclusions are tentative. In terms of size of support system, 
TABLE VI

CHARACTERISTICS OF SUPPORT SYSTEM BY MARITAL STATUS

(MAX IN PARENTHESIS)

\begin{tabular}{|c|c|c|c|c|c|c|c|c|c|c|}
\hline $\begin{array}{l}\text { MARITAL } \\
\text { STATUS } \\
\end{array}$ & $\begin{array}{l}\text { TOTAL \# } \\
\text { OF NAMES }\end{array}$ & $\begin{array}{c}\text { TOTAL \# } \\
\text { OF EXCHANISES }\end{array}$ & $\begin{array}{c}8 \\
\text { RELATIVES } \\
\end{array}$ & $\begin{array}{c}8 \\
\text { FRIENDS }\end{array}$ & NEIGHBORS & $\stackrel{8}{\text { MALE }}$ & $\begin{array}{c}8 \\
\text { FEMALE } \\
\end{array}$ & $\begin{array}{l}\text { INST } \\
\text { HELP } \\
\text { (23) }\end{array}$ & $\begin{array}{l}\text { N PARENTHES } \\
\text { EMOTTIONAL } \\
\text { MFIP } \\
\text { (14) }\end{array}$ & $\begin{array}{l}\text { INFORM } \\
\text { HELP } \\
(9)\end{array}$ \\
\hline \multicolumn{11}{|l|}{ MARRIED } \\
\hline \multicolumn{11}{|l|}{ WIDONED } \\
\hline $\begin{array}{l}\text { No Living Children } \\
\qquad(\mathbb{N}=5)\end{array}$ & $5.4^{\star}$ & $18 * *$ & $58 *$ & 8 & 19 & $27 \star$ & $73^{*}$ & $4.4 *$ & $3.2 \star$ & 2.2 \\
\hline $\begin{array}{l}\text { Living Children } \\
\qquad(\mathrm{N}=44)\end{array}$ & $7.0^{\star}$ & $24 * \star$ & 53* & 29 & 8 & $35 *$ & $65^{*}$ & $7.5^{\star}$ & $5.0^{\star}$ & 2.7 \\
\hline \multicolumn{11}{|l|}{ DIVORCED OR SEPARATED } \\
\hline $\begin{array}{l}\text { Living Children } \\
\qquad(\mathrm{N}=9)\end{array}$ & $5.9^{\star}$ & $19 * *$ & $48 *$ & 20 & 19 & $33 \star$ & $67^{\star}$ & $6.1^{\star}$ & $4.1^{\star}$ & 2.2 \\
\hline \multicolumn{11}{|l|}{ SINGLE， NEVER MARRIED } \\
\hline $\begin{array}{l}\text { (Probability of } p= \\
\text { Statistical } \\
\text { Significance) }\end{array}$ & .021 & .001 & .012 & .100 & .250 & .014 & .013 & .033 & .026 & .301 \\
\hline
\end{tabular}

* Significant at .05 Level

* Significant at .01 Level 
never-married subjects were at the greatest disadvantage having the smallest support system. Not surprisingly, married and widowed subjects had a significantly higher percentage of relatives in their support systems, $\underline{F}(3,129)=5.38, p<.003$, than subjects who were single or divorced; however, marital status had no impact on percentage of friends in the support system.

Income. A slight tendency for size to increase with income was noted, but generally income had little impact on the social support system.

Residential Setting. The subjects residing in suburban areas had significantly more persons in their support systems and urban residents had fewer persons, $\underline{F}(2,130)=5.86, p<.005$. Nevertheless, on all other measures of the support system there were no significant differences between urban, suburban, and rural residents. Therefore, it would appear that residential setting had little impact on the social support system.

Relationship to the subject. The effect of type of relationship to the subject on type of support given was complex. However, it was clear that spouses, children, and friends provided the majority of the instrumental and emotional support of the subjects. Overall, relatives (1.e. spouses and children) provided the majority of personal care $(66 \%)$ but friends did provide $17 \%$ of this 
type of care. Neighbors who were not also friends provided Ifttle assistance. For some of the subjects, grandchildren were key providers of instrumental support.

As would be expected, the pattern of relationships was dependent upon the marital status of the subject. The support systems of subjects who were married and had iiving children were strongly dominated by relatives. Relatives provided $80 \%$ of their personal care, $89 \%$ of their household assistance, and $77 \%$ of their emotional support. Spouses were key elements in these systems providing more personal care and household assistance than children. Relatives also provided the majority of the support for widowed subjects with living children; however, friends became a more important part of the support system for these subjects. Mariied subjects without children depended primarily upon spouses and friends for personal care, household assistance, and emotional support. On the other hand, neighbors were more important in the systems of widowed subjects with no living children and divorced or separated subjects with children. In the single never married group, each person had distinct patterns. Some had support systems dominated by friends, some were dominated by relatives. It should be remembered that these last four groups had few persons in them, so conclusions are tentative. 
MEDICAL RESOURCES - UTILIZATION AND NEEDS

\begin{abstract}
Through specific interview questions this study reviewed the medical resources used, satisfaction with them, and potential additional needs. Because of the referral system, only persons who utilized the medical care system were included; persons who either could not or would not use this system were excluded. Nevertheless, documentation of the medical resource utilization and needs of persons within the medical care system is important as these persons are most likely to place future demands on the system.
\end{abstract}

Financial Resources for Medical Care

As expected by the age of the subjects, $63 \%$ of the sample used Medicare to finance part of their medical care needs. Only $18 \%$ used Medicaid, while $68 \%$ had private medical insurance coverage. Subjects also frequently used their savings, work income, or social security pension to pay for medical expenses. Only four percent had used family support to meet medical expenses, and only $2 \%$ had utilized loans. Despite the large percentage of subjects with private insurance, forty-six percent of the subjects believed their medical resources for the future were inadequate, and $59 \%$ worried some or a great deal about meeting health care expenses in the future. Many subjects 
expressed their concern over the decreasing federal funds available for medical expenses.

\section{Community Service Utilization}

The subjects in this study utilized an average of .91 community agencies. Fourteen percent received meals delivered to their homes, and most of these had meals delivered everyday except weekends. Special transportation services were utilized by six percent of the subjects, and only two percent used a senior center. Clearly, very few of the physically ill elderly utilize communty services designed for the general elderly community such as transportion or senior centers. Since home health agencies were used as referral sources, it is not surprising that $43 \%$ of the sample indicated using home health services, generally several times a week.

\section{Satisfaction with Medical Care and Additional Needs}

Generally, the subjects were satisfied with the medical care they had received. Eighty-six percent believed the amount of care they were receiving was about right, and $91 \%$ were generally or very satisfied with their medical care. When asked if they would purchase any additional services if they could afford them, nearly $50 \%$ said they had no additional needs. However, $27 \%$ would purchase more household help if resources were available, 
and $14 \%$ could use more transportation services. Many subjects noted their special transportation needs and the unpredictability and unresponsiveness of the present system.

The next chapter will analyze the data for the relationships of the various factors to depression and Iife satisfaction at one point in time. 
CHAPTER V

FACTORS AFFECTING DEPRESSION AND LIFE SATISFACTION

TIME 1 AND TIME 2

\begin{abstract}
The model for this study as outlined in Chapter II presented characteristics of the individual, characteristics of the disease, and perceptions of the disease by the individual that were postulated to affect the relationship of physical illness and depression. This chapter will begin to test this model by examining these relationships as measured at a single point in time. For both Time 1 and Time 2, the interrelationship of the variables described in Chapter II will be discussed. The outcome variables of depression and life satisfaction will be described first, then the relationship of the other variables to these outcome variables will be discussed. Table VII presents the means and standard deviations for the major variables for Time 1 and Time 2. Tables VIII and IX outline the correlations between these variables and CES-D and LSIA-A scores, respectively. Finally, multiple regression will be used to investigate the relative importance of the variables as they affect levels of
\end{abstract}


TABIE VII

MEAN VALUES FOR SELECTED VARIABLES (MAXIMUM IN PARENTHESES)

\begin{tabular}{|c|c|c|c|c|}
\hline & TIME 1 & $(N=133)$ & TIME 2 & 14) \\
\hline & MEAN & S.D. & MEAN & S.D. \\
\hline CES-D $20 \quad(60)$ & 16.0 & 11.0 & 16.3 & 11.4 \\
\hline CES-D 28 (84) & 22.5 & 14.8 & 22.5 & 16.0 \\
\hline LSIA-A (36) & 21.7 & 8.1 & 22.4 & 8.4 \\
\hline $\begin{array}{l}\text { AGE } \\
\text { INCOME }\end{array}$ & 14.085 .8 & $11,700^{9.96}$ & - & $\overline{-}$ \\
\hline SOCIAL SUPFORT & & & & \\
\hline TOTAL NAMES & 7.12 & 2.79 & 6.90 & 3.0 \\
\hline TOTAL EXCHANGES & 25.18 & 12.8 & 21.47 & 11.4 \\
\hline EMOTIONAL SUPPORT (14) & 5.16 & 2.99 & 4.28 & 2.81 \\
\hline INSTRUMENTAL SUPPORT (23) & 7.22 & 4.12 & 5.54 & 3.26 \\
\hline INFORMATIONAL SUPPORT (9) & 2.90 & 2.27 & 2.76 & 2.33 \\
\hline ROLE CENTRALITY & 9.11 & 6.75 & & \\
\hline RELIGIOSITY (12) & 6.37 & 2.74 & 6.36 & 3.14 \\
\hline PAIN (19) & 9.04 & 5.79 & 8.5 & 5.6 \\
\hline PHYSICAL DEPENDENCY (44) & 15.71 & 12.2 & 13.54 & 11.9 \\
\hline LENGTH OF ILLNESS & 12.3 & 16.5 & - & - \\
\hline LIFE EFFECT (45) & 22.2 & 9.1 & 20.2 & 9.8 \\
\hline WORRY ABOUT MEDICAL & & & & \\
\hline RESOURCES (3) & 1.86 & 0.81 & 1.77 & 0.79 \\
\hline DEATH ANXIETY (15) & 5.04 & 2.94 & 4.94 & 2.93 \\
\hline LIFE EXPECTANCY & 77.9 & 10.6 & 77.3 & 10.7 \\
\hline PROGRESSIVENESS (12) & 6.43 & 2,5 & 8.34 & 2.88 \\
\hline CONTROLLABILITY & & & & \\
\hline $\begin{array}{l}\text { HEALTH LOCUS OF CONTROL } \\
\text { (HLC) (66) }\end{array}$ & 40.9 & 9.3 & 39.4 & 8.17 \\
\hline $\mathrm{HLC}-1$ (6) & 3.36 & 1.97 & 3.03 & 1.86 \\
\hline HLC-13 (6) & 3.96 & 1.99 & 3.82 & 1.97 \\
\hline SUBJECTIVE HEALTH (9) & 4.5 & 2.1 & 4.58 & 1.8 \\
\hline
\end{tabular}


TABIE VIII

CORRELATIONS WITH CES-D TIME 1

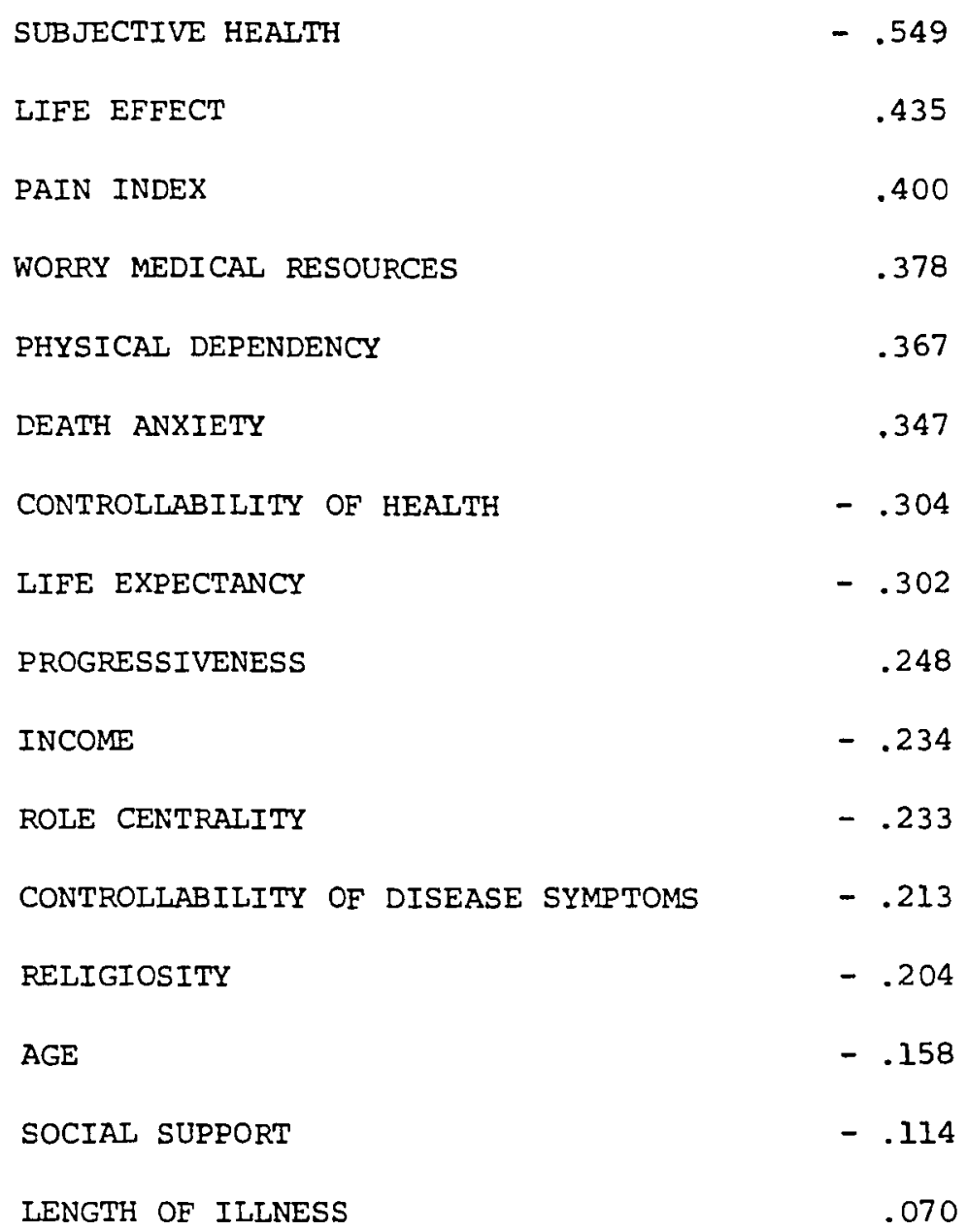


TABLE IX

CORREIATIONS WITH LSIA-A TIME 1

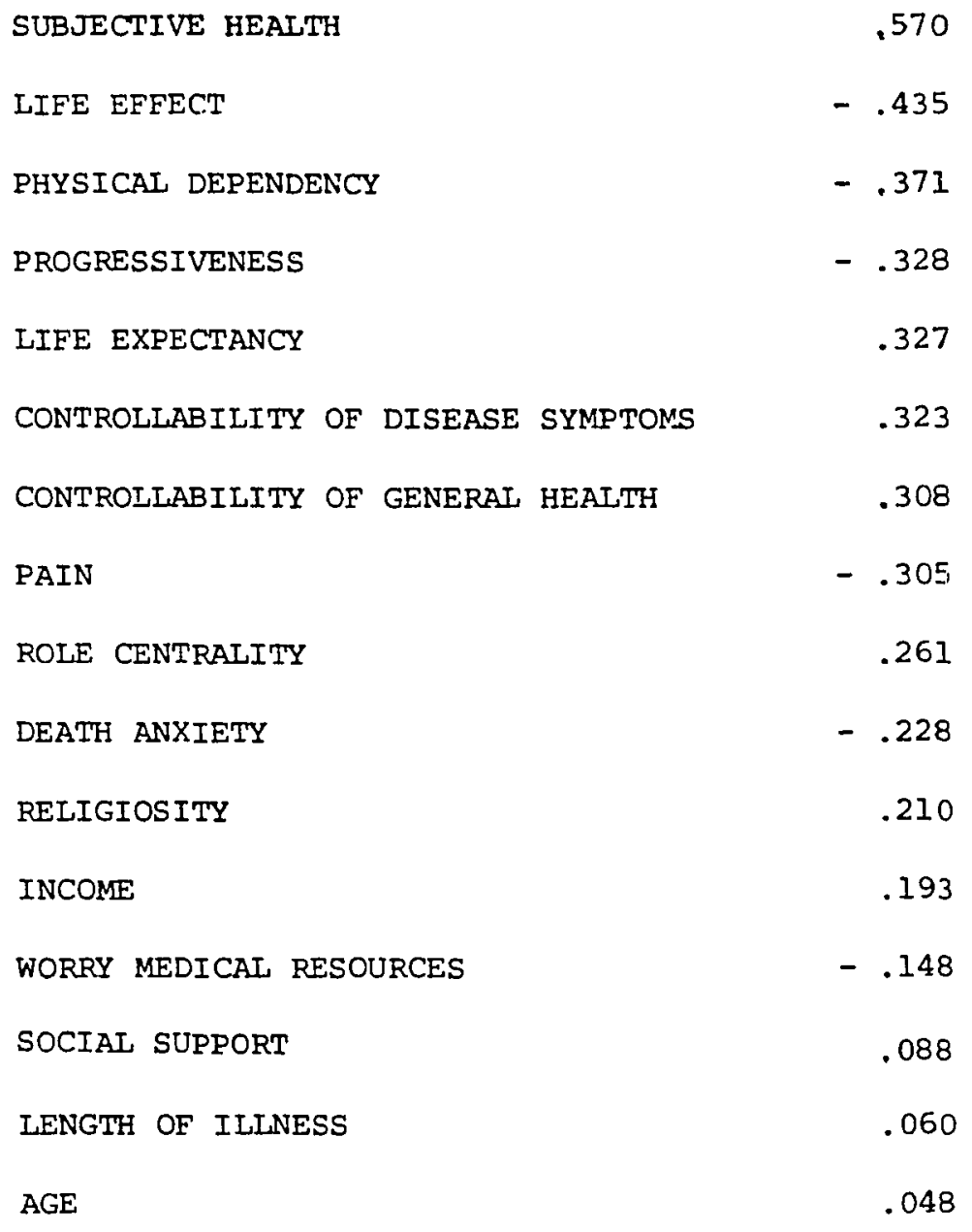


depression and life satisfaction.

TIME 1

Outcome Variables

Depression, CES-D. The results of the CES-D were analyzed in both the 20 and 28 item formats. As most of the literature uses the 20 item scale, these data will be the most frequently cited for comparative purposes. With a maximum score of 60 , the 20 -item CES-D had a mean value of 16.0 and a standard deviation of 11.0 for the 133 subjects in this study. Scores ranged from 0 to 47 , and the median score was 14.3 . The corresponding values for the 28 item CES-D were mean of 22.5 , standard deviation of 14.8 , range of 0 to 65 , and median of 19.5. The scores on the 20-item CES-D were considerably higher than the mean scores from general community studies in the same age group. In the HANES, Health and Nutrition Examination Study (DHEW, 1979 ; Comstock \& Helsing, 1976) of 4,945 community residents, the mean score for the middle aged subjects was 8.8 and the mean for the over 65 age group was 8.4 . In other community studies, Radloff (1977) reported average CES-D scores of 9. 25 and Davis (1984) 10.51. Studies of psychiatric depressed patients demonstrated mean CES-D scores of 24.4 (Radloff, 1977) and 38.1 (Weissman et al., 1977). Thus, as was true of the study of Noh, Wood, and Turner (1984) of 
the physically disabled, the physically ill subjects in this study scored higher on the CES-D than general community residents but lower than psychiatric patients.

Depression has psychological, interpersonal, and somatic elements, and Radloff (1977) identified these three components of depression as well as positive affect in a factor analysis of the CES-D. Radloff (1977) named the four factors of the CES-D depressed affect, positive affect, somatic and retarded activity, and interpersonal activity. A factor analysis of the CES-D scores in this study identified four factors with eigenvalues greater than one. The first factor was clearly depressed affect and the second was somatic activity. However, the third factor also dealt with somatic symptoms and the fourth factor dealt with depressed affect. The positive affect and interpersonal activity factors did not have eigenvalues greater than one in this study. The positive affect factor almost reached an eigenvalue of 1. Interestingly, the subjects in this study seldom experienced the interpersonal problems of depression such as unfriendly people or people disliking them. Radloff (1977) stressed that the factor structure of the CES-D should not be unduly emphasized as the CES-D score as a whole measures depressive symptomatology. The alpha coefficient of .86 of the CES-D in this study supports this conclusion. 
Table $x$ displays the percentage of the subjects in this study reporting the presence and persistence of various items on the CES-D. Figures from the Craig and Van Natta (1976) study with community residents and depressed patients are included for comparison. The persistence of symptoms has been suggested to be more important than the number of symptoms (Dohrenwend \& Crandall, 1970; Roberts \& Vernon, 1983). For the psychological symptoms of depression, the physically ill subjects in this study scored between the commity sample and the depressed patients in both presence and persistence of symptoms. For the somatic symptoms, the physically ill subjects still had lower percentages than the depressed patients. This was not true of the interpersonal items however, as the physically ill subjects scored even lower than the community residents on these items.

Nevertheless, the somatic aspects of depression remain a diagnostic problem for both elderly and physically ill populations as these activity patterns may be normal accompaniments of old age or physical illness (Blumenthal, 1975; Noh et al., 1984; Gallagher, Thompson, \& Levy, 1980; Salzman \& Shader, 1978; Steuer et al., 1980). The physically ill subjects in this study were more likely to describe somatic symptoms of depression rather than the psychological symptoms. On the average, the subjects 
TABLE $X$
PERCENTAGES REPORT'ING THE PRESENCE AND PERSISTENCE OF ITENS ON CES-D

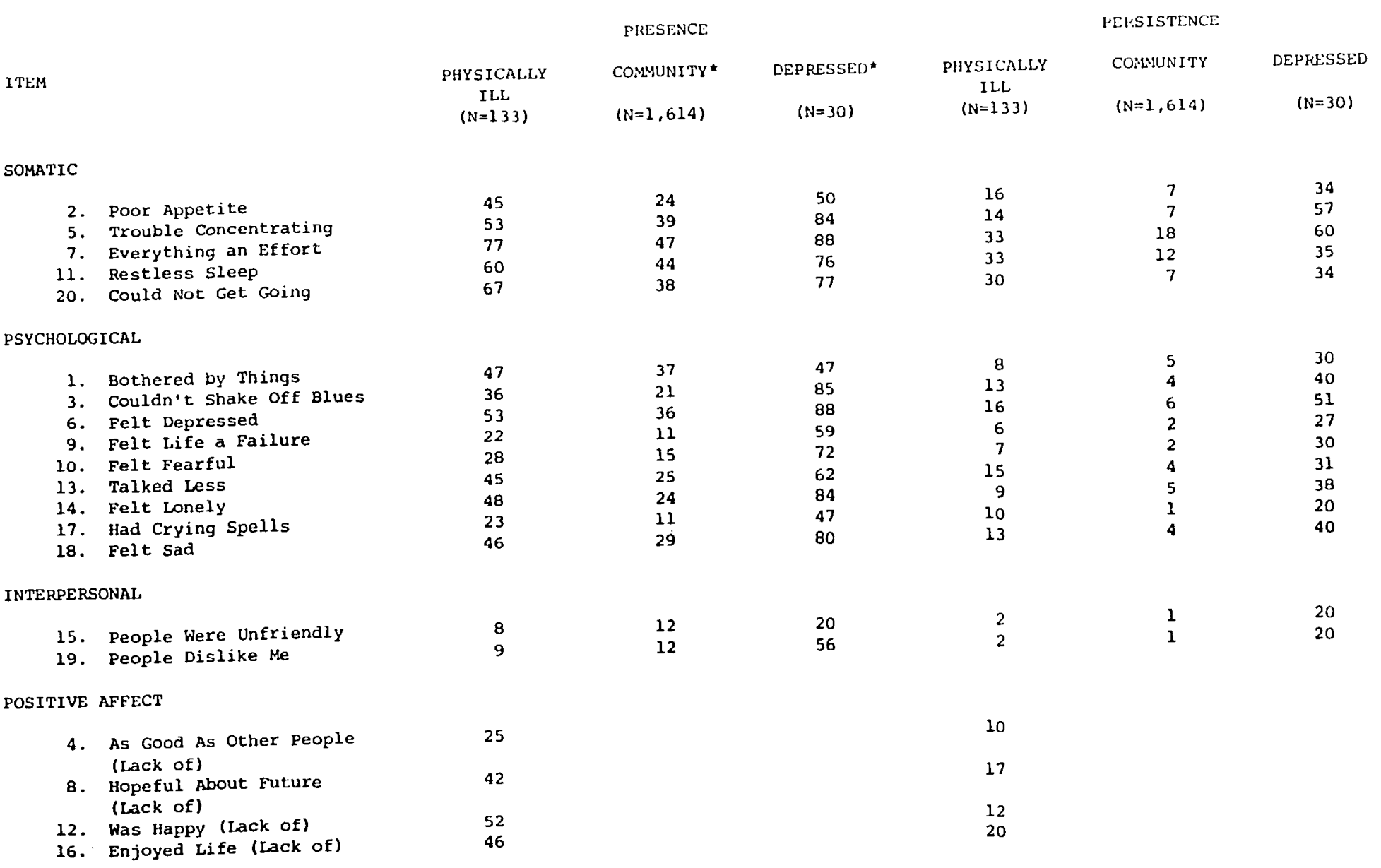


scored $42 \%$ of the total possible on the somatic items while they scored on 1 y $32 \%$ of the total possible on the other items. Therefore, while the physically ill subjects in this study were more likely to report almost all of the symptoms of depression, they were somewhat more likely to report somatic symptoms.

Many authors accept a cutoff point of 16 or higher on the CES-D as indicative of a high risk of depressive problems (Comstock \& Helsing, 1976; Eaton \& Kessler, 1981; Goldberg et al., 1985; Myers \& Weissman, 1980; Roberts \& Vernon, 1983). In this study, $47 \%$ or 63 of the subjects scored 16 or higher on the CES-D. This is considerably higher than the $17 \%$ reported for the general community by Comstock and Helsing (1976). It is also higher than the $35 \%$ of physically disabled scoring 16 or higher as reported by Noh et al. (1984). In order to help determine if this cutoff point resulted in an overestimation of depression, the subjects were reclassified using an algorithm as devised by Schoenbach (cited in Noh et al., 1984). The results of this reclassification by DSM-III or Research Diagnostic Criteria (RDC) is outlined in Table XI. This reclassification reduced the number of cases of depression to 28 or $21 \%$ by DSM-III criteria and to 17 or $13 \%$ by the RDC criteria. These rates for DSM-III criteria are higher than the 12 to $15 \%$ reported for general community samples 
TABLE XI

COMPARISON OF DEPRESSION BY CES-D $\geq 16$, RDC, AND DSM III

$$
\text { CES-D - } 16
$$

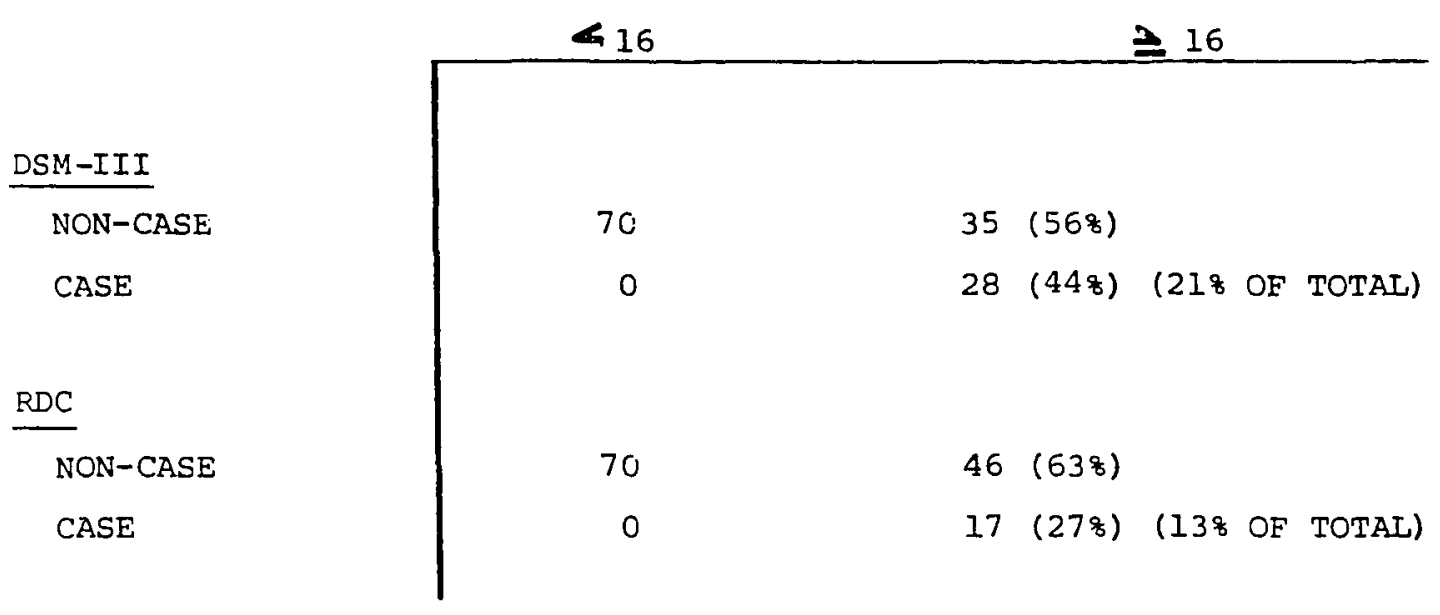

$\star$ RATES ON RDC \& DSM III DETERMINED BY ALGORITHM OF SCHOENBACH (CITED IN NOH, ET AL. (1984)).

$R D C$

\begin{tabular}{|c|c|c|}
\hline & CASE & NON-CASE \\
\hline \multicolumn{3}{|l|}{ DSM-III } \\
\hline NON-CASE & 1 & 104 (798) \\
\hline CASE & 16 & $12(218)$ \\
\hline & $(138)$ & $(87 \%)$ \\
\hline
\end{tabular}


(Blazer \& Williams, 1980; Gurland et al., 1983; Weissman \& Myers, 1978). Also, no cases that qualified as depressed by the DSM-III or RDC criteria were not identified by the cutoff of 16 on the CES-D. Thus, the CES-D may tend to overestimate the number of cases of depression, but it would appear to be an excellent screening device.

The reclassification of CES-D scores by DSM-III or RDC criteria also allows for an estimation of the number of cases suffering dysphoria with or without other depressive symptoms. This reclassification resulted in 49 cases of dysphoria or $37 \%$ by DSM-III criteria and 34 cases or $26 \%$ by RDC criteria. The rate of dysphoria was considerably higher than that for depression.

In conclusion, the physically ill middle aged and elderly persons in this study were more likely to report both the presence and persistence of most depressive symptoms as measured by the CES-D. Even when reclassified by DSM-III criteria, the rate of depression appeared to be elevated for this group.

Life Satisfaction, LSIA-A. Using the two point scoring system for the Life Satisfaction Index-A (LSIA-A) resulting in a maximum score of 36 for high life satisfaction, the subjects in this study had a mean score of 21.7 with a standard deviation of 8.1 . Scores ranged 
from 0 to 36 with a median score of 22.6. These scores were somewhat lower than those reported by Harris and Associates (1975). This large national study of 4,254 persons reported a median score of 26.0 for Americans over the age of 65 .

A factor analysis of the LSIA-A scores from this study revealed a somewhat different pattern than that reported by George (1981) and Liang (1984). The congruence factor was clearly present, but the happiness and zest factors did not present clear patterns in this study.

subjects in this study scored differently on most of the items on the LSIA-A when compared to Haris and Associates' large national sample (1975). Table XII includes the percentage of subjects scoring the high life satisfaction response in this study and the Harris sample. Physically ill elderly persons were much less likely to score positively on items dealing with present happiness. For example, $70 \%$ believed that their life could be happier than it is now as compared to on $1 y$ 45\% in the national sample. Only $64 \%$ agreed that "compared to other people my age I make a good appearance", while $83 \%$ agreed with this statement in the national sample. Surprisingly, the physically ill subjects in this study were more likely to have positive responses about the future than the subjects in the national sample. In assesing their past and 
TABLE XII

PERCENT OF SAMPLE GIVING HIGH LIFE SATISFACTION RESPONSE.

[Harris \& Assoc. Study (1975) Results in Parentheses]

\begin{tabular}{|c|c|c|c|}
\hline & Agree & Disagree & Uncertain \\
\hline 1. I am just as happy as when I was younger. & $\begin{array}{r}438 \\
(56) \\
\end{array}$ & & \\
\hline 2. These are the best years of my 1 ife. & $\begin{array}{r}268 \\
(32)\end{array}$ & & \\
\hline 3. My life could be happier than it is now. & & $\begin{array}{l}188 \\
(46)\end{array}$ & \\
\hline 4. This is the drearlest time of my life. & & $\begin{array}{r}588 \\
(72) \\
\end{array}$ & \\
\hline 5. Most of the things I do are boring or monotonous. & & $\begin{array}{r}678 \\
(82) \\
\end{array}$ & \\
\hline $\begin{array}{l}\text { 5. Compares to other people, I get down in the } \\
\text { dumps too often. }\end{array}$ & & $\begin{array}{r}758 \\
(81) \\
\end{array}$ & \\
\hline $\begin{array}{l}\text { 7. The things I do are as interesting to me as } \\
\text { they ever were. }\end{array}$ & $\begin{array}{r}648 \\
(72) \\
\end{array}$ & & \\
\hline $\begin{array}{l}\text { 8. I have made plans for things l'll be doing } \\
\text { a month or year from now. }\end{array}$ & $\begin{array}{r}548 \\
(53) \\
\end{array}$ & & \\
\hline $\begin{array}{l}\text { 9. Compared to other people my age, I make a } \\
\text { good a ppearance. }\end{array}$ & $\begin{array}{r}648 \\
(83) \\
\end{array}$ & & \\
\hline $\begin{array}{l}\text { 10. As I grow oider, things seem better than I } \\
\text { thought they would be. }\end{array}$ & $\begin{array}{r}438 \\
(64) \\
\end{array}$ & & \\
\hline $\begin{array}{l}\text { 11. I expect some interesting and pleasant things } \\
\text { to happen to me in the future. }\end{array}$ & $\begin{array}{r}688 \\
(57) \\
\end{array}$ & & \\
\hline 12. I feel old and somewhat tired. & & $\begin{array}{r}498 \\
(50) \\
\end{array}$ & \\
\hline 13. As I look back on my life, I am fairly well satisfled. & $\begin{array}{r}808 \\
(87) \\
\end{array}$ & & \\
\hline 14. I would not change my past even if I could. & $\begin{array}{r}478 \\
(62) \\
\end{array}$ & & \\
\hline 15. I've gotten pretty much what I expected out of Iife. & $\begin{array}{r}638 \\
(82) \\
\end{array}$ & & \\
\hline $\begin{array}{l}\text { 16. When I think back on my } 11 \text { fe, I didn't get most of } \\
\text { the important things I wanted. }\end{array}$ & & $\begin{array}{r}638 \\
(61) \\
\end{array}$ & \\
\hline $\begin{array}{l}\text { 17. In spite of what people say, the lot of the average } \\
\text { man is getting worse, not better. }\end{array}$ & & $\begin{array}{r}438 \\
(45)\end{array}$ & \\
\hline $\begin{array}{l}\text { 18. I have gotten more of the breaks in life than most } \\
\text { of the people I know. }\end{array}$ & $\begin{array}{r}438 \\
(63)\end{array}$ & & \\
\hline
\end{tabular}


congruence with their life goals, the physically ill subjects sometimes scored nearly the same as the national sample and sometimes lower. In sum, the physically ill middle aged and elderly appeared to be less happy with the present but more optimistic about the future.

Scores on the LSIA-A were strongly negatively correlated to the CES-D, with a Pearson's correlation coefficient of $\underline{r}=-.630, \mathrm{p}<.001$. This is probably due to the heavy emphasis in the LSIA-A on present happiness. Eleven of the 18 items deal with the present situation of the individual while only 5 are past oriented and 2 deal purely with the future. Also, the two scales measure some of the same moods and emotions. For example, the item in the LSIA-A concerning getting down in the dumps too often is also measuring depressed mood.

Characteristics of the Individual

When a person experiences the stress of an exacerbation of a physical illness and begins their psychological adjustment to it, they possess certain individual characteristics that may affect that adjustment. These include their age, gender, income, social support system, role centrality, death anxiety, worry about medical resources, and religiosity.

Age. Whether or not age affects the individual's 
ability to adjust to the stress of physical illness was a major issue in this study. Therefore, numerous analyses were carried out to investigate this relationship. The Pearson correlation coefficient between age and CES-D scores was $\underline{r}=-.158, p<.036$, indicating a slight tendency for CES-D scores to be lower for the older subjects. Subjects were also divided into groups by age, and an analysis of variance was done to determine if differences in CES-D scores were significant. Figure 2 shows a line graph of the scores on the 20 item CES-D scale by age groups of 5 years. An analysis of variance of these groups indicated no significarit differences due to age, $\underline{E}(8,123)=0.669, p<.719 . \quad$ Figure 3 shows the CES-D scores if age groups are collapsed into the middle aged (50-64), young-old (65-74), old (75-84), and old-old (85-92). Again the tendency of CES-D scores to decrease with age was present, but the analysis of variance indicated nonsignificant differences, $\quad \underline{F}(3,128)=0.826, \quad p<.483$. However, if the subjects were divided into depressed and non-depressed groups based upon a score on the CES-D of 16 or higher, the depressed group had a mean age of 66.7 and the non-depressed group had a mean age of 70.4 . A t-test indicated that the depressed group had a significantly lower age, $t=-2.20, p<.031$. Thus repeated statistical analysis indicated a weak relationship between age and 


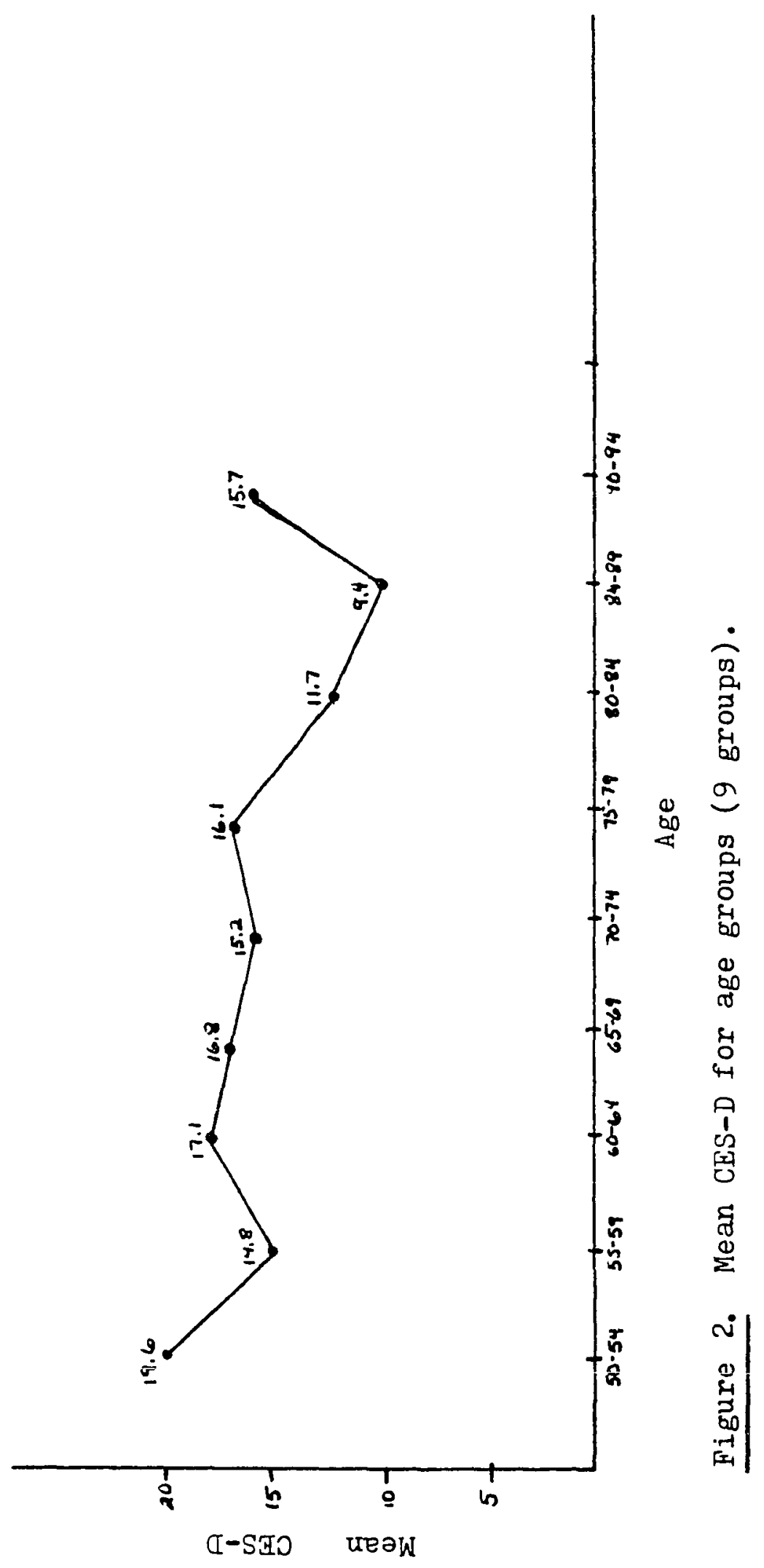




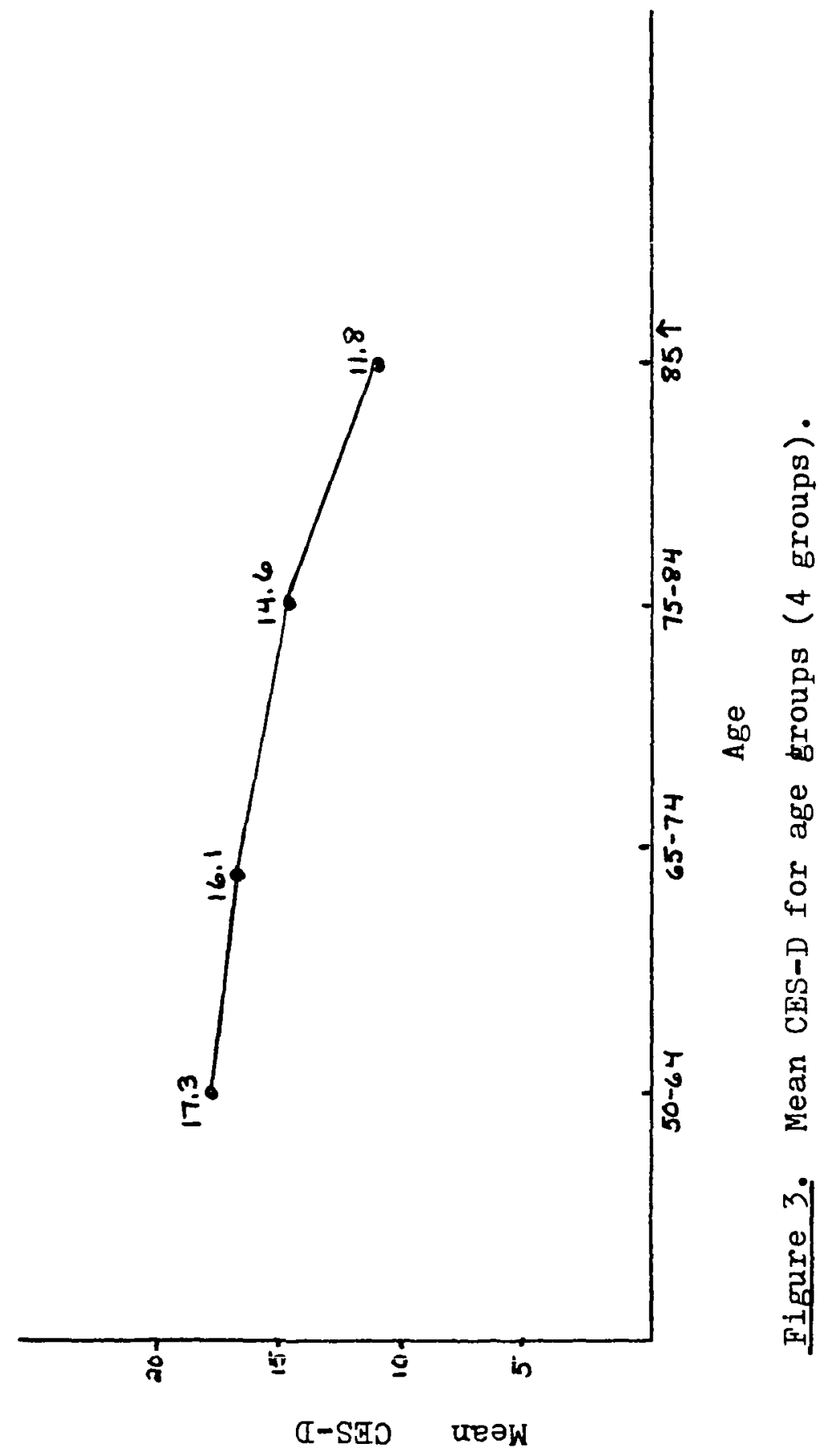


level of depression. However, this relationship was consistent, indicating lower levels of depression with increasing age.

The correlation between LSIA-A scores and age was $\underline{I}=.048, \mathrm{p}<.294$. Figures 4 and 5 graphically represent LSIA-A scores by the same age groups that were used for the CES-D. Analysis of variance revealed no significant differences between age groups and no pattern was evident, $\underline{F}(8,120)=0.854, p<.559, \underline{F}(3,125)=0.156, p<.927$. Unlike the Harris study (1975) that showed a consistent decrease in LSIA-A scores with age, there did not appear to be a relationship between life satisfaction and age for the physically ill middle aged and elderly subjects in this study.

Gender. Numerous t-tests were performed to identify gender differences. While the female subjects' mean score of 16.5 on the CES-D was higher than the male subjects' mean score of 15.0 , the difference was not significant, $t=0.72, p<.471$. The female subjects also had a slightly lower but not significantly lower score $(M=21.7)$ on the LSIA-A, $\underline{t}=-0.21, \mathrm{p}<.831$, than the male subjects $(\underline{M}=22.0)$. Females did, however, have a significantly higher score on the death anxiety scale, $\underline{t}=2.41, \mathrm{p}<.018$ (M Female=5.46, $\underline{M}$ Male=4.11) and significantly fewer total exchanges in their social support systems, $t=-3.03, p<.004$ (M Female=23.0, $\underline{M}$ 


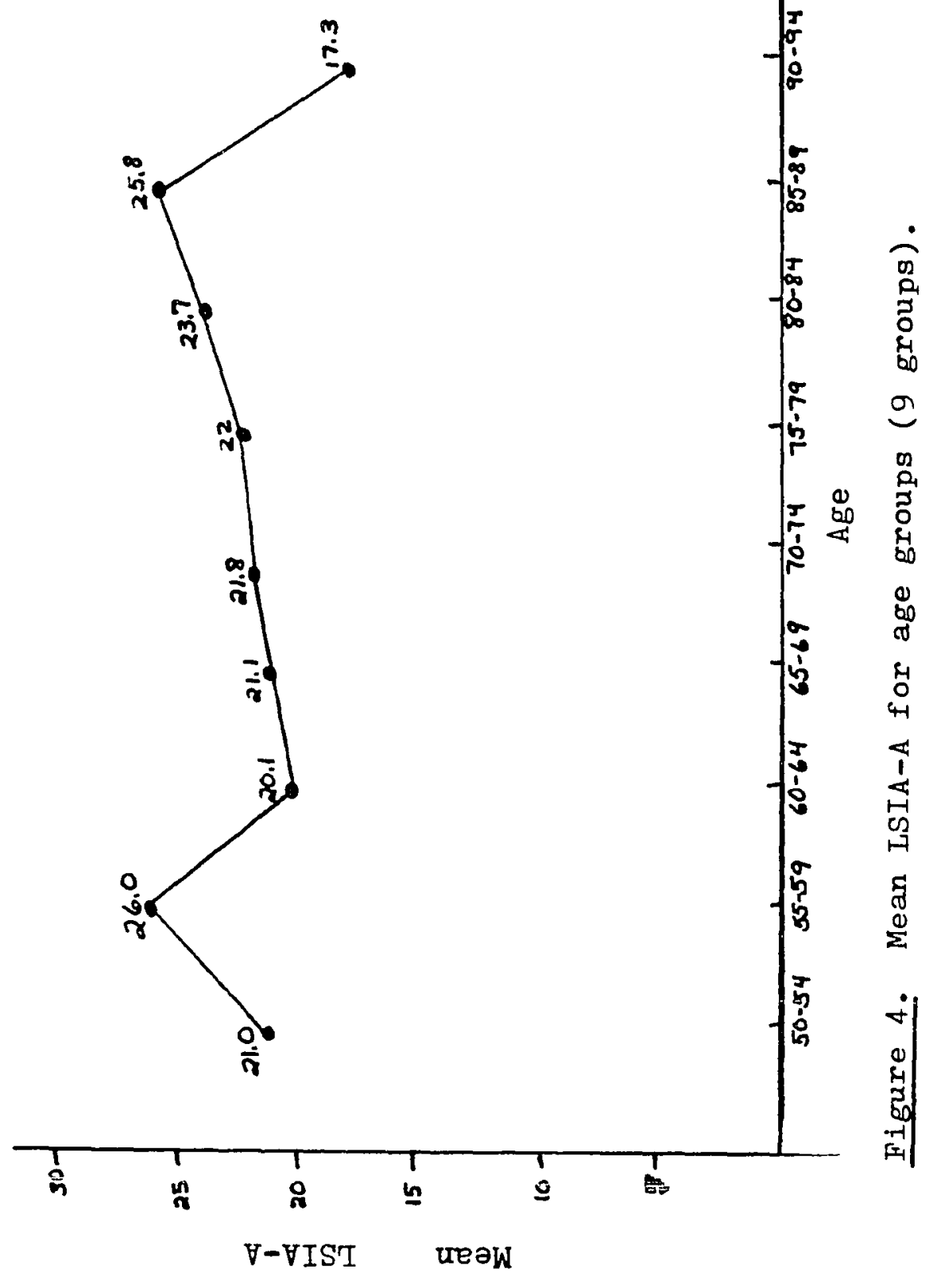




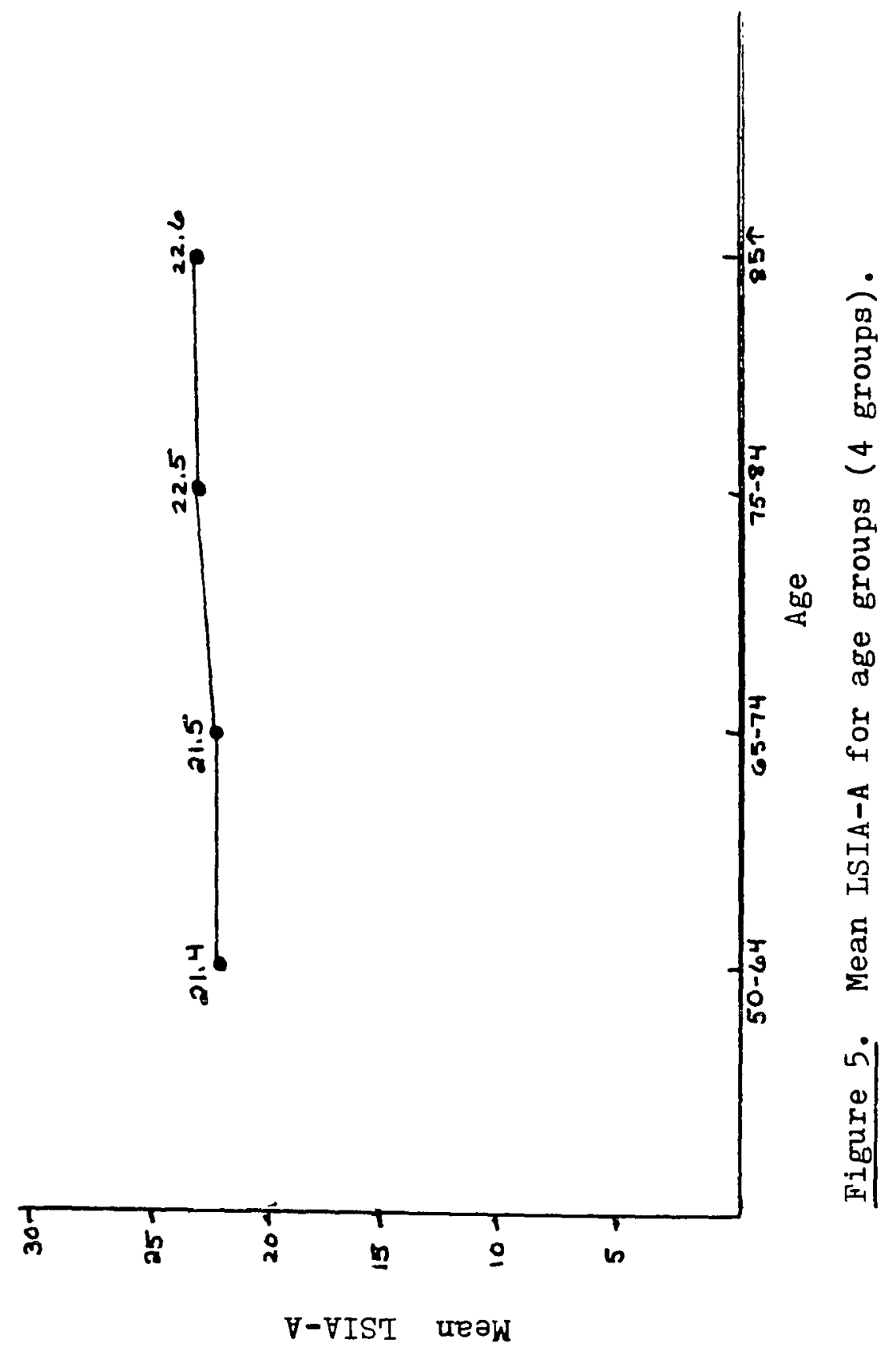


Male=30.1). Apparently these differences were not great enough, however, to affect their levels of depression or life satisfaction. Despite much of the literature citing a higher incidence of depression in females, this relationship did not occur for the physically ill subjects in this study. It is possible that women respond better to the stress of physical illness compared to other stresses, or that men respond less well to the stress of physical illness.

Income. The correlation between CES-D scores and income was $I=-.234, p<.006$. The correlation to LSIA-A scores was lower at $r=.193, \mathrm{p}<.020$. As expected, individuals with fewer material resources had lower life satisfaction and higher depression levels; however, this relationship was not strong.

Social support. Numerous measures of social support were correlated with CES-D scores, and generally these relationships were slight. Table XIII gives these correlations. For example, the index of instrumental help had a correlation with the CES-D of $\underline{x}=-.039, \mathrm{p}<.330$; and the correlation coefficient for emotional support was $\underline{r}=.008, p<.463$. The total number of names in the social support system had a correlation with the CESD of $\underline{r}=-.095$, p<.140. The corresponding value for the total number of exchanges was $r=-.114, p<.097$. The relationships were 
TABLE XIII

CORRELATIONS OF SOCIAL SUPPORT MEASURES TO CES-D

TIME 1

\begin{tabular}{lcc} 
CES-D 20 & CES-D 28 & LSIA-A \\
\hline-.095 & -.060 & .189 \\
-.114 & -.054 & .088 \\
-.034 & & \\
& & \\
& & \\
.008 & .001 & -.019 \\
-.131 & & \\
& &
\end{tabular}


generally in the expected direction, that is, greater social support resulted in lower depression; but the magnitude of the effect was small. Total number of exchanges was chosen as the most valid overall measure of the social support system for the regression analysis.

The relationship between social support and life satisfaction was similar. Corresponding correlations for the LSIA-A were $r=-.019, \mathrm{p}<.416$, for instrumental support, $\underline{r}=-.036, p<.344$, for emotional support, $\underline{r}=.188, p<.017$ for total names, and $\underline{r}=.088, p<.161$ for total exchanges. Therefore, size of the social support system had little effect on life satisfaction for the physically ill subjects in this study.

Role Centrality. Subjects who had more roles in which others depend upon them had lower levels of depression and higher life satisfaction. The correlation of the role centrality index with CES-D scores was $\underline{r}=-.223$, $\mathrm{p}<.006$, and $\underline{I}=.261, \mathrm{p}<.002$ with the LSIA-A. While this relationship was in the expected direction, it was complex and will be discussed again in the section on interrelationships between variables.

Death Anxiety. The Templer Death Anxiety Scale (DAS) completed by the subjects has a maximum score of 15 , and scores ranged from 0 to 14 in this study. The mean of 5.04 is close to the mean of 6.77 reported for a general 
population (Templer, 1970) and the mean of 4.33 reported for a retired population (Templer \& Ruff, 1971). Death anxiety correlated strongly with depression, $\underline{r}=.347$, $\mathrm{p}<.001$. The correlation to life satisfaction was $\underline{r}=-.228$, $p<.007$. Overall, death anxiety scores were not elevated for this population of physically ill middle aged and elderly persons; however, the variation in death anxiety was related to depression levels. This relationship could have been partly due to similar items. Both the CES-D and the Templer Death Anxiety Scale measure levels of fear and worry. Also, responses to the death anxiety scale appeared to be strongly affected by recent health experiences. For example, some of the subjects had suffered recent painful operations or heart problems and fear of operations or heart attacks was very real to them. Also, several faced the prospect of a painful death in the not distant future. Though scores on the Templer Death Anxiety Scale are frequently viewed as stable aspects of the personality, they may vary over time based upon recent severe health problems. Also, it should be noted that the death anxiety scale was not completed by 10 of the subjects. It was at the end of the interview and some very ill subjects were too fatigued to complete it. If relatives were present, they frequently objected to the topic, and some subjects found it upsetting. Also, some subjects objected to the 
repetitious nature of the scale.

Worry About Medical Resources. Physical illness may result in reduced income and large medical expenses. Therefore, increased concern with medical resources would be expected for the subjects in this study. Sixty percent of the subjects worried "some" or "a great deal" about medical expenses; however, only one mentioned expense as the worst thing about an illness. Worry about medical expenses correlated strongly with depression with a coefficient of $r=.378, p<.002$. Worry about medical resources had little effect on life satisfaction with a correlation of $\underline{r}=-.148, p<.048$. This might be due to financial concerns affecting immediate emotional responses but having little effect on global assessments regarding one's life.

Religiosity. The religiosity index measured both the subjective Importance of religion to the subject and their level of participation in religious activities. Religiosity did provide some buffer to the stress of physical illness as its correlation to the CES-D was $r=-.204, \mathrm{p}<.011$. Some of the subjects were deeply religious. When asked what was their greatest strength in adjusting to their illness, $19 \%$ of the subjects responded with religion. Their religiosity was evident in their responses to other questions about death anxiety and the future. The relationship of 
religiosity to life satisfaction was similar but in the opposite direction with a correlation coefficient with the LSIA-A of $\underline{r}=.210, p<.036$.

Residential setting. While the residence of the subjects in urban, suburban, or rural areas was not postulated to affect the depression or life satisfaction levels of the subjects, aralyses of variance were performed to check for an effect of this variable. While residential setting did have a significant effect on income, $\underline{F}(2,101)=8.20, \quad p<.001$, this effect did not extend to depression or life satisfaction levels. Thus, residence in urban, suburban, or rural areas had no significant effect on depression or life satisfaction.

Characteristics of the Disease

Various characteristics of the illness might affect the stress associated with it.

Diagnosis. Because much of the literature focused on particular diagnoses and ascribed certain problems exclusively to that diagnosis, it is important to investigate the responses of the subjects based upon their diagnoses. Table XIV gives mean values for several factors for each diagnosis. As many of the subjects had several diagnoses, these groups have much overlap. Analysis of variance was not possible because of this overlap; however, 
TABIE XIV

\section{VALUES OF SELECTED VARIABLES BY DIAGNOSIS \\ (MAXIMUM IN PARENTHESES)}

\begin{tabular}{|c|c|c|c|c|c|c|c|c|c|c|c|}
\hline & $2^{8}$ & $o_{0}^{c_{1}^{2}}$ & के & के & $\underset{Q^{\circ}}{\stackrel{9}{y}}$ & 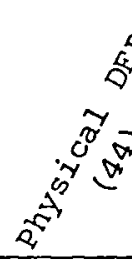 & $\Omega^{\sigma^{\sigma}}$ & 今" & 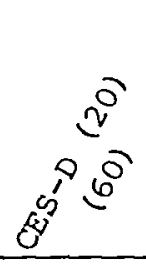 & 8 & $\underbrace{5}$ \\
\hline $\begin{array}{l}\text { Chronic Heart } \\
\text { Disease }\end{array}$ & 37 & 288 & 74.5 & 4.21 & 8.70 & 15.8 & 5.3 & 11,500 & 16.9 & 23.1 & 20.5 \\
\hline $\begin{array}{l}\text { Chronic Lung } \\
\text { Disease }\end{array}$ & 24 & 188 & 69.5 & 3.11 & 9.38 & 20.5 & 6.5 & 9,500 & 19.6 & 29.2 & 19.1 \\
\hline Cancer & 26 & $20 z$ & 64.2 & 4.08 & 7.76 & 11.4 & 5.3 & 18,500 & 14.1 & 20.4 & 25.1 \\
\hline Diabetes & 33 & 258 & 68.6 & 4.93 & 8.06 & 12.4 & 4.9 & 8,000 & 16.0 & 22.3 & 22.8 \\
\hline Arthritis & 42 & 328 & 70.7 & 4.22 & 12.3 & 18.0 & 5.1 & 8,000 & 19.2 & 26.3 & 19.8 \\
\hline Fracture & 12 & 98 & 68.0 & 6.42 & 11.2 & 18.3 & 4.2 & 12,500 & 12.8 & 16.5 & 24.6 \\
\hline
\end{tabular}


some differences were evident. The subjects with chronic lung disease and arthritis had somewhat higher depression levels and lower life satisfaction. The subjects with chronic lung disease also had higher death anxiety, greater physical dependency levels, lower income, lower age, and lower subjective health ratings. All these factors could explain their poorer adjustment to physical illness. The higher depression scores for the arthritic subjects could be explained by their high pain levels and low incomes. Therefore, differences between diagnostic groups could be attributed to various characteristics of the disease or the individual's perception of it rather than to the disease itself.

Pain. The index of pain used in this analysis measured the general level of pain and discomfort experienced by the subject and the level of pain within the last week. It had a maximum score of 19 . Scores on the index ranged from 0 to 19 with a mean of 9.04 and standard deviation of 5.79. As expected, the level of pain had a strong effect on the depression scores with a correlation coefficient of $r=.400, p<.001$. Level of pain had slightly less impact on life satisfaction with a correlation coefficient of $\underline{I}=-.305, \mathrm{p}<.001$. Nineteen subjects or $14 \%$ of the sample mentioned pain as the worst aspect of their illness. Clearly, pain was one of the critical factors in 
adjustment to an illness.

Physical Dependency. Physical dependency was measured by an activities of living scale that included activities both inside and outside the home and had a maximum score of 44. Scores on this scale ranged from 0 to 42 with a mean of 15.71 and standard deviation of 12.2 . The level of physical dependency had a large effect on depression scores with a correlation of $\underline{r}=.367, p<.001$. The corresponding relationship to life satisfaction was $I=-.371, \mathrm{p}<.001$. Restriction of their activities was mentioned as the worst thing about their illness by 84 or $63 \%$ of the subjects. In fact, given the predominance of this response, a larger correlation between physical dependency and depression might be expected.

Length of Illness. Subjects reported having had their diseases from 0 months to 74 years. The mean length of 11 lness was 12.3 years with a standard deviation of 16.5 years. The median length of illness was 5 years. Length of illness had little relationship to levels of depression or life satisfaction. The correlation of length of illness to depression was $\underline{r}=.070, p<.215$, and the correlation to life satisfaction was $\underline{x}=-.060, \quad p<.253$. Although individuals might be expected to adjust better to an illness if they had it longer, other factors appear to be more important in adjustment. 
Perceptions of the Disease by the Individual

The individual interprets their experience with an illness and develops various perceptions about it which may in turn affect their adjustment to the illness. These perceptions include the areas of life affected by the illness, life expectancy, progressiveness of the disease, and locus of control for health. Finally the individual provided a subjective health rating including their rating of their overall health and how their health compared to other people their age.

Life Effect. Subjects were asked to assess the effect their illnesses had on various aspects of their lives from caring for themselves to eating habits, working, and maintaining friendships. The computed index had a maximum score of 45 . The scores on this index ranged from 6 to 39 with a mean of 22.2 and standard deviation of 9.1 . This life effect index correlated very strongly with the CES-D with a coefficient of $r=.435, \quad p<.001$. The correlation with the LSIA-A was $\underline{r}=-.435, \mathrm{p}<.001$. The high correlation to the CES-D may have been partially due to the somatic items on the CES-D measuring similar factors such as problems with eating and sleeping.

Life Expectancy. As a measure of the life threatening aspect of their illness, subjects were asked how many more years they expected to live and this was 
added to their age. The resultant life expectancy had a wide range from 53 to 100 years of age. The mean was 77.9 years with a standard deviation of 10.6. The expectation of a normal life span correlated well to depression levels with a coefficient of $\underline{r}=-.302, p<.003$. Its relationship to life satisfaction was also strong with a correlation of $\underline{r}=.327, p<.002$.

As the measure of life expectancy would be highly correlated to age, analyses were also done using only the number of additional years the subject expected to live. While this variable correlated to life satisfaction with almost the same value as life expectancy, its correlation to depression was less with $\underline{r}=-.204, p<.029$. This change could be interpreted to indicate that while decreasing time to death is associated with increased depression, a shorter than normal life expectancy has a stronger impact on depression.

Progressiveness of the Disease. With a score of 14 the maximum possible on the index of progressiveness of the disease, the scores ranged from 3 to 12 . The mean was 6.43 with a standard deviation of 2.5. The expected progression of an illness correlated to depression levels with a coefficient of $\underline{r}=.248, p<.005$. The correlation to life satisfaction was somewhat higher at $\underline{r}=-.328, \mathrm{p}<.001$.

Controllability. Subjects completed the Health Locus 
of Control Scale with an average score of 40.9 , standard deviation 9.3. These scores are quite similar to the 40.1 reported for a group of hypertensives (Wallston et al., 1976) and the 39.4 reported for a group of geriatric outpatients (Conlin \& Fennell, 1985). The mean for a group of community residents reported by wallston et al. (1976) was 35.9. A score of 35 or more is considered indicative of an external locus of control as related to health. The external locus of control found in the subjects in this study could be due to their age, cohort, or their experience of physical illness. Another indicator of the external locus of control of the subjects was the fact that only $18 \%$ blamed themselves for their illness. It should be noted that the subjects' external locus of control was not necessarily inappropriate. Subjects were also asked to assess the controllability of the symptoms of their illness. Their answers tended toward a lack of perceived control with a mean score of 3.96. Thirty-nine of the subjects strongly disagreed with the statement that they could generally control the symptoms of their disease.

As discussed in Chapter III, because of the lack of internal consistency in the scores of the Health Locus of Control scale, the answer to the question "If I take care of myself I can avoid illness" was used as indicative of the subject's attitude about general control of health. The 
response to "I can generally control the symptoms of my disease" was used to indicate the perception of controllability of the specific illness. Scores were adjusted so that larger numbers indicated more external locus of control. For example, if the subject strongly agreed with the statement "I can generally control the symptoms of my disease", the score of 6 was changed to a score of 1. General and specific controllability of health were only moderately correlated to each other with a coefficient of $\underline{r}=.275, \mathrm{p}<.002$. Higher external locus of control of general health was strongly correlated with depression levels, $\underline{r}=.304, \quad \mathrm{p}<.002$. Beliefs about controllability of specific illness were in the same direction but less strong. Thus, greater external locus of control for the subject's illness was associated with higher depression, $I=.219, p<.007$. For life satisfaction, both general and specific health locus of control were strongly negatively correlated. The spearman correlation coefficients were $r=-.308, p<.002$ for general health locus of control and $I=-.323$, p<.002 for specific health locus of control. Subjects who believed they had more control over their general health and their specific illness were more satisfied with their life and less likely to be depressed.

Subjective Health. The subjective health rating combined the subjects' rating of their overall health with 
their rating of their health as compared to others their age. Generally, the subjects ranked their health low. Twenty-rine percent rated their health as poor, and $56 \%$ rated it as fair or poor. The subjects compared themselves slightly more favorably to their own age group as $62 \%$ rated their health as the same or better than others their age. Subjects often made comments about someone they knew whose health was worse than theirs. The scores on subjective health ranged from 2 to 9 with a mean of 4.5 and a standard deviation of 2.1 .

Subjective health had the strongest correlation to depression of all the variables with a coefficient of $\underline{r}=-.549, p<.001$. The correlation with life satisfaction was $\underline{r}=.570, p<.001$. The strong relationship between subjective health and life satisfaction reported in the literature appears to be also true of physically ill subjects.

\section{Interrelationships Between Variables}

Table XV presents a correlation matrix of the major factors discussed above. Some of these factors correlated strongly with each other and this affected later regression analysis. The high correlations between age and life expectancy $(\underline{r}=.741, p<.001)$ and between total exchanges and role centrality $(\underline{r}=.695, p<.001)$ are probably due to the same responses being used to compute parts of the 
TABIL: $x !$

CORIELATIONS BETTEEEI SELFCTRIJ VARIABLES TIME 1

Subjective Health

Life Effect

pain

Worry Medical Expenses

Physical Dependency

\section{Death Anxiety}

Life Expectancy

\section{Progressiveness}

Role Centrality

Income

Religiosity

Age

General Health Locus of Control

Specific Health Locus of control

Social Support

Total Exchanges

Length of Illness

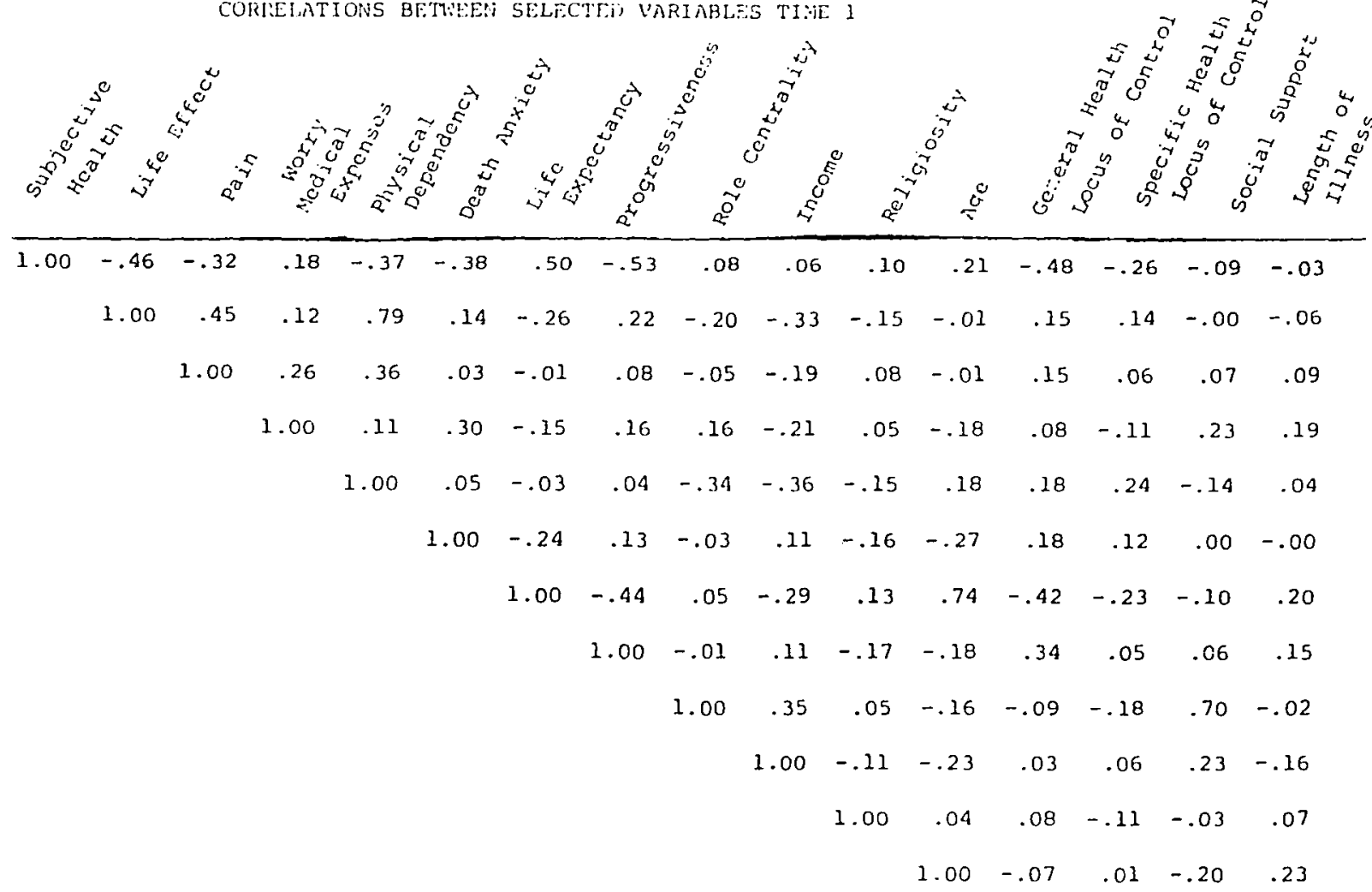

$\begin{array}{llll}1.00 & .27 & .03 & -.02\end{array}$

$1.00-.05-.04$

$1.00 \quad .05$

1.00 
variables. Physical dependency and life effect are strongly correlated with a coefficient of $x=.792, p<.001$ because the subjects tended to interpret the effect of their illness in terms of their physical limitations. Income was negatively correlated to both of these variables in part because physically dependent subjects were unable to work or supplement their incomes. The relationship between income and poor health is often debated. Does poverty cause sickness or sickness cause poverty? For these subjects both directions of causality appeared to have some basis, but illness causing poverty appeared more prevalent for the younger subjects. The middle aged subjects often described how their inability to work had reduced their incomes. The correlation of $\underline{r}=.338, p<.001$, between pain and physical dependency was probably due to the restriction of activity caused by long term pain. Presumably because of the inability of the physically dependent to work or assist others, physical dependency was negatively correlated to role centrality with a coefficent of $r=-.344, p<.001$. Finally, subjective health rating correlated fairly strongly with many of the variables especially life effect, pain, physical dependency, death anxiety, life expectancy, progressiveness, and health locus of control. It would appear that the subjects considered all these factors when forming an assessment of their 
health.

Effect of Confounding Variables

Medications Causing Depression. Although the subjects in this study took an average of 4.6 prescription medications, the taking of medications that could cause depression was very rare. The mean number of medications that could cause depression taken by the subjects was . 11. Only 14 subjects took 1 medication that could cause depression. For these 14 subjects the most frequently taken drugs that might have caused depression were Inderal, Corgard, or Catapres. A t-test indicated no significant difference between subjects taking these medications compared to the others for both depression scores, $\underline{t}=1.18$, $p<.240$, and life satisfaction scores, $t=-0.69, p<.491$. Therefore, this variable was not used in later analyses.

other Stressful Life Events. Subjects who had the additional stress of negative life events within the last year might have responded with higher depression levels and lower levels of life satisfaction. The data on the subjects who had experienced the death of someone close to them, a marital separation, job loss, or institutionalization of a spouse were analyzed for possible differences. As outlined in Table XVI, only two subjects had loss of job, one had a marital separation, and four had 
TABLE XVI

EFFECT OF OTHER SIGNIFICANT LIFE EVENTS

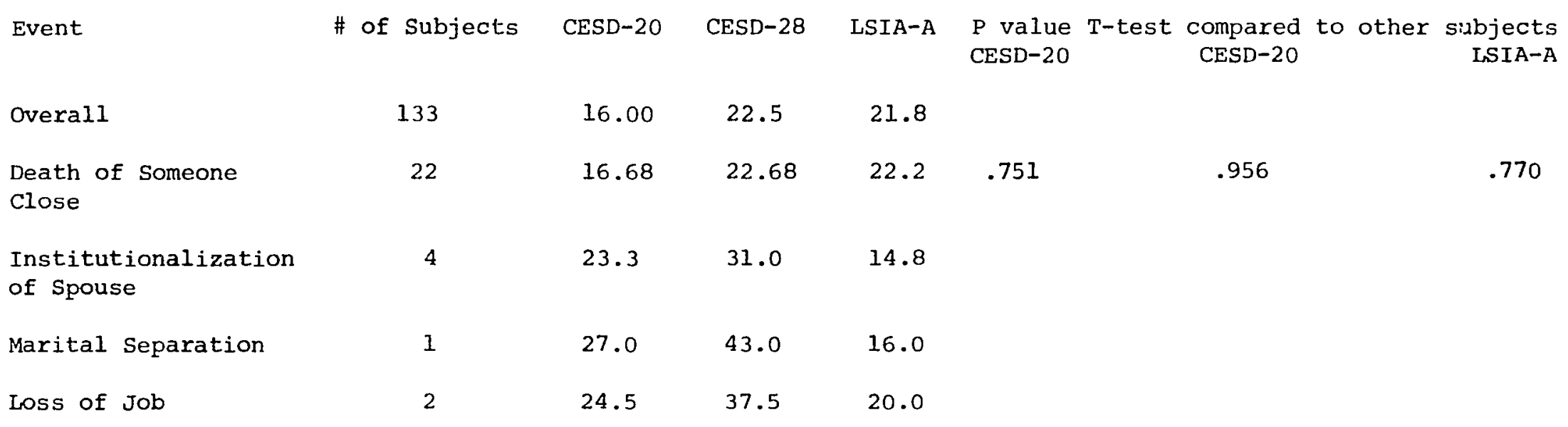


institutionalized their spouse. Therefore t-tests on these data had little validity. However, 22 subjects had experienced the death of someone close. A t-test demonstrated no significant differences between these subjects and the other subjects on depression scores, $\underline{t}=0.32, \quad p<.752$, or life satisfaction scores, $\underline{t}=0.29$, p<.771. Apparently, the stress of negative life events other than physical illness had little additional effect on levels of depression or life satisfaction.

Social Desirability. The social desirability scale has a maximum score of 6 and is scored high for high social desirability. With a range of 0 to 6 , scores on the social desirability scale had a mean of 3.66 , standard deviation 1.54. For the reasons detailed in Chapter II, the results of this scale were not included in the analyses.

Combined Effect of Selected Factors on Depression

Numerous linear regressions were performed in order
to investigate the relative importance of various factors
on the levels of depression. Variables with correlations
to the CES-D greater than .300 were included in the
equation. Physical dependency and life effect strongly
correlated with each other; and physical dependency was
included rather than life effect because physical
dependency was more objective and usually available from


patient records. Life effect also had more questions that were similar to those in the CES-D. Other variables included were subjective health, pain, death anxiety, life expectancy, worry about medical resources, and general health locus of control. In addition, income was included as the best measure of available material resources. The total number of exchanges in the social support system was also included as the best measure of overall social support because of the recent interest in this variable in the literature. Table XVII includes the results for the stepwise regression analysis including all these variables. Because subjective health correlated with many of the other variables and by itself accounted for nearly half of the explained variance, a regression was also done forcing the variables into the equation in reverse order. The results for this regression are included in Table XVIII and allow a more detailed examination of the relative importance of the other variables.

Stepwise Regression Analysis. Together all of the variables resulted in a regression equation with $\underline{R}=.722$, accounting for $52.2 \%$ of the variance in depression level. Because of the interrelationships among the variables and difficulty establishing directions of causality apriori, a stepwise regression procedure was used. The order of variables that emerged in this analysis was subjective 
TABLE XVII

STEPWISE REGRESSION FOR CES-D TIME I

\begin{tabular}{|c|c|c|c|c|c|}
\hline Dependent Variable CES-D & Multiple $\mathrm{R}$ & $\mathrm{R}^{2}$ & $\mathrm{R}^{2}$ Change & Simple $\mathrm{R}$ & Beta \\
\hline Subjective Health & .525 & .275 & .271 & -.525 & -0.255 \\
\hline Pain & .630 & .397 & .122 & .458 & 0.346 \\
\hline Death Anxiety & .661 & .437 & .039 & .341 & 0.210 \\
\hline Income & .699 & .488 & .051 & -.325 & -0.220 \\
\hline Life Expectancy & .713 & .508 & .020 & -.292 & -0.193 \\
\hline Worry Medical Resources & .715 & .512 & .004 & .298 & 0.115 \\
\hline Total Exchanges & .721 & .520 & .008 & -.063 & -0.111 \\
\hline $\begin{array}{l}\text { General Health Iocus } \\
\text { of Control }\end{array}$ & .722 & .522 & .002 & .327 & -0.051 \\
\hline Physical Dependency & .722 & .522 & .000 & .334 & 0.018 \\
\hline
\end{tabular}


TABLE XVIII

HIERARCHICAL REGRESSION FOR CES-D TIME I

\begin{abstract}
Dependent Variable CES-D
Physical Dependency

General Health Locus of Control
\end{abstract}

Total Exchanges

Worry medical Resources

Life Expectancy

Income

Death Anxiety

Pain

Subjective Health

\begin{tabular}{|c|c|c|c|c|}
\hline Multiple $R$ & $\mathrm{R}^{2}$ & $\mathrm{R}^{2}$ Change & Simple $R$ & Beta \\
\hline .334 & .111 & .111 & .344 & 0.018 \\
\hline .430 & .185 & .074 & .327 & -0.051 \\
\hline .433 & .187 & .002 & -.063 & -0.111 \\
\hline .502 & .252 & .065 & .298 & 0.115 \\
\hline .540 & .291 & .039 & -.292 & -0.193 \\
\hline .572 & .328 & .037 & -.325 & -0.220 \\
\hline .616 & .380 & .052 & .752 & 0.210 \\
\hline .702 & .493 & .113 & .458 & 0.346 \\
\hline .722 & .522 & .029 & -.525 & -0.255 \\
\hline
\end{tabular}


health, pain, death anxiety, income, life expectancy, worry about medical resources, total exchanges, general health locus of control, and physical dependency. Subjective health accounted for over half of the variance explained by the equation with a $\underline{R}^{2}$ Change of .275 . Pain accounted for an additional $12.2 \%$ of the variance in depression. Income explained $5.1 \%$ of the variance while death anxiety accounted for $3.9 \%$. Other variables that explained close to $1 \%$ of the variance were life expectancy at $2.0 \%$ and total exchanges at $0.8 \%$. Variables that did not explain at least $1 \%$ of the variance included worry about medical resources, physical dependency, and general health locus of control. Much of the variance in worry about medical resources and physical dependency was probably included in income.

In conclusion, when all the variables were included, subjective health and pain were the most critical factors in level of depression. Income and death anxiety were also of moderate importance. The best predictor of depression level was the subject's assessment of their overall health and how their health compared to others in their age group. Apparently, as long as the physically ill subject could perceive him or herself positively in relation to their age group, their level of depression remained lower. This was somewhat more difficult for the younger subjects which 
might explain the tendency for depression levels to be higher in younger subjects. However, many of these subjects were still able to find someone in their network who was in poorer health. The importance of pain in determining depression levels can be explained by its constant presence and its effect on most aspects of everyday life. Many subjects expressed their concern with their inability to escape their pain or control it. Lack of income and material resources added additional stress for the individual and resulted in inability to accomplish daily tasks. This was especially true for the subjects with moderate incomes who were less accustomed to financial stress and did not qualify for many aid programs. As described above, experiences with serious health problems may alter death anxiety and make these concerns more immediate.

Hierarchical Regression Analysis. Because the subjects appeared to use many of the other factors in order to make their subjective health rating, a hierarchical regression was carried out with the variables in reverse order from the stepwise regression described above. Table XVIII gives the results of this regression with the variables entered in the order of physical dependency first, then general health locus of control, total exchanges, income, death anxiety, pain, and subjective 
health. With this order, physical dependency accounted for $11 \%$ of the variance in depression. General health locus of control had a $\underline{R}^{2}$ Change of .07 , and total exchanges had a $\underline{\mathrm{R}}^{2}$ Change of .00 . Worry about medical resources explained $7 \%$ of the variance while life expectancy added $4 \%$. Income now accounted for $4 \%$ of the variance, and death anxiety accounted for $5 \%$. Pain had a $\underline{R}^{2}$ Change of .11, and subjective health now added $3 \%$ to the explained variance. In this hierarchical regression, physical dependency, general health locus of control, and worry about medical resources became more important. Life expectancy increased slightly while total exhanges decreased slightly in importance. Pain, income, and death anxiety retained about the same level of importance.

Regression Without Life Expectancy and Death Anxiety. Because many cases had missing data for life expectancy and death anxiety, a regression was also done without these variables, and the results are included in Table XIX. This regression had a multiple $\mathrm{R}$ of .64 and explained $41 \%$ of the variance in depression. The other variables retained almost the same order of importance; only physical dependency and general health locus of control reversed their positions. Thus the loss of cases when death anxiety and life expectancy were included did not appear to alter the regression analysis. 
TABLE XIX

STEPWISE REGRESSION FOR CESD-20 TIME 1 LIFE EXPECTANCY AND DEATH ANXIETY NOT INCLUDED

$$
(\mathrm{N}=109)
$$

Dependent Variable CESD-20

\begin{tabular}{ccccc} 
Multiple R & $\mathrm{R}^{2}$ & $\mathrm{R}^{2}$ Change & Simple $\mathrm{R}$ & Eeta \\
\hline .527 & .278 & .278 & -.527 & -0.376 \\
.594 & .353 & .075 & .415 & 0.228 \\
.614 & .378 & .025 & -.240 & -0.079 \\
.624 & .389 & .011 & .284 & 0.148 \\
.634 & .403 & .014 & -.058 & -0.112 \\
.639 & .409 & .006 & .364 & 0.085 \\
.642 & .412 & .003 & .309 & 0.068
\end{tabular}


Regressions Controlling For other Variables. As a final test of the effect of key variables on levels of depression, these variables were forced last in various hierarchical regressions. With this technique their effect on depression scores was measured controlling for all other key variables. The variables of subjective health, pain, death anxiety, income, and physical dependency were used in this hierarchical regression. Controlling for the other four variables, subjective health had an $\underline{R}^{2}$ Change of .089 and accounted for about $9 \%$ of the variance in depression scores. The corresponding values for the other variables were pain, 5.9\%, death anxiety, $4.0 \%$, income, $2.5 \%$, and physical dependency, . $7 \%$. Thus this procedure reduced the $\underline{R}^{2}$ Change of the variables, but did not change their relative importance.

Combined Effect of Selected Factors on Life Satisfaction.

Both stepwise and hierarchical regression analyses were done for life satisfaction. As with depression, the factors that correlated to life satisfaction with an greater than .3 were included, and the result was that the factors included were somewhat different. Death anxiety and worry about medical resources were not included and specific health locus of control and progressiveness of the illness were included. Death anxiety and worry about 
medical resources apparently were more immediate concerns affecting depression but having less effect on the more long term assessment of life satisfaction. Health locus of control for the specific illness and progressiveness of the disease were more strongly correlated to life satisfaction than depression. Table $x x$ gives the statistics for the stepwise regression analysis of life satisfaction, and Table XXI provides these statistics for the hierarchical regression.

Stepwise Regression. The stepwise regression analysis of life satisfaction yielded a multiple $\underline{R}$ of .643 and overall accounted for $41.3 \%$ of the variance in life satisfaction. Subjective health accounted for $29.5 \%$ of the variance in life satisfaction and was the best predictor of life satisfaction just as it was for depression. Pain maintained its importance and explained an additional $4.1 \%$ of the variance. Total exchanges became relatively more important for life satisfaction than it was for depression and accounted for $2.5 \%$ of the variance. Income became relatively less important in the assessment of life satisfaction and life expectancy more important. General health locus of control did account for slightly more than $1 \%$ of the variance in life satisfaction, but specific health locus of control, physical dependency, and progressiveness of the illness had little effect. 
TABLE $X X$

STEPWISE REGRESSION FOR LSIA-A TIME 1

\begin{tabular}{|c|c|c|c|c|c|}
\hline Dependent Variable ISIA-A & Multiple $\mathrm{R}$ & $\mathrm{R}^{2}$ & $\mathrm{R}^{2}$ Change & Simple $R$ & Beta \\
\hline Subjective Health & .543 & .295 & .295 & .543 & 0.294 \\
\hline Pain & .579 & .336 & .041 & -.322 & -0.257 \\
\hline Total Exchanges & .601 & .361 & .025 & .082 & 0.150 \\
\hline Life Expectancy & .617 & .380 & .020 & .376 & 0.213 \\
\hline Income & .629 & .396 & .016 & .216 & 0.175 \\
\hline $\begin{array}{l}\text { General Health } \\
\text { Locus of Control }\end{array}$ & .639 & .408 & .012 & -.429 & -0.140 \\
\hline $\begin{array}{l}\text { Specific Health } \\
\text { Locus of Control }\end{array}$ & .640 & .410 & .002 & -.125 & -0.052 \\
\hline Physical Dependency & .642 & .413 & .002 & -.305 & -0.060 \\
\hline Progressiveness & .643 & .413 & .000 & -.264 & -0.029 \\
\hline
\end{tabular}


TABLE XXI

HIERARCHICAL REGRESSION LSIA-A TIME 1

Dependent Variable ISIA-A

\section{Progressiveness}

Physical Dependency

Specific Health Locus of Control

General Health

Locus of Control

Income

Life Expectancy

Total Exchanges

Pain

Subjective Health

$\begin{array}{ccccc}\text { Multiple R } & \mathrm{R}^{2} & \mathrm{R}^{2} \text { Change } & \text { Simple } \mathrm{Beta} \\ .070 & .141 & .070 & -.264 & 0.029 \\ .376 & .153 & .071 & -.305 & 0.060 \\ .391 & .228 & .012 & -.126 & -052 \\ .478 & .260 & .075 & -.429 & -0.140 \\ .510 & .322 & .031 & .216 & 0.175 \\ .568 & .325 & .063 & .376 & 0.213 \\ .570 & .379 & .003 & .082 & 0.150 \\ .616 & .413 & .034 & .543 & -0.257 \\ .643 & & .054 & 0.294\end{array}$


Hierarchical Regression Analysis. Forcing the variables in reverse order (see Table XXI) resulted in increases in importance for physical dependency, progressiveness of the disease, and general health locus of control. Total exchanges lost some importance while pain increased slightly. As would be expected because of its correlation to the other variables, subjective health decreased greatly in importance.

Regressions Controlling For other Variables. Hierarchical regressions were performed for the variables of subjective health, pain, income, physical dependency, and total exchanges. Controling for the other four variables, subjective health had an $\underline{R}^{2}$ Change of .197 and accounted for $19.7 \%$ of the variance in life satisfaction scores. The corresponding values for the other variables were pain, $1.4 \%$, income, $1.0 \%$, physical dependency, $1.0 \%$, and total exchanges, $0.0 \%$. Thus, only subjective health had much effect on life satisfaction if other variables are entered into the regression first.

In conclusion, in the regression analysis of life satisfaction, subjective health and pain retained their importance as predictors. Total exchanges became relatively more important than they were for depression. Income and life expectancy maintained their moderate importance as predictors of life satisfaction. 
Coping strategies

Before completing this section on the results of the Time 1 interview, a brief qualitative discussion of the coping strategies utilitized by the physically ill middle aged and elderly subjects in this study is appropriate. While coping strategies were not the primary focus of the study, some data was gathered that may help to focus future studies.

Cause of the Illness. When asked who or what they blamed most for their illness, subjects generally externalized the cause of their illness. Thirty-six percent said that nobody was to blame and $20 \%$ believed that their family history was the most important factor accounting for their illness. In the health locus of control scale, the question "people can usually prevent getting subject's dominant iliness" was asked. This question was strongly answered in the external direction with a mean score of 4.99 and a median score of 5.73. As the maximum score of 6 indicated externality, subjects had a very strong external locus for the cause of their illness. Thus one mechanism for coping was to not blame oneself for one's illness. In many cases this was entirely appropriate, but in some cases self-blame might have been closer to the truth. An example is subjects with chronic bronchitis or emphysema (chronic lung disease) who blamed 
their work environment rather than their smoking for their illness.

Strength in Adjusting to the Illness. Subjects were asked who or what was their greatest strength in adjusting to their illness. Spouses ranked highest in the responses to this question as $29 \%$ of the subjects responded that their spouse was their greatest source of strength. Religion was another important source of strength for adjustment as $19 \%$ responded with religion. One's own strength of personality was also very important as $17 \%$ of the subjects believed themselves to be theirgreatest strength. Their family was mentioned as their greatest strength by $15 \%$ of the subjects and the doctor or other health professional provided the greatest strength for $10 \%$ of the subjects. While social support did not appear to be a major factor statistically in levels of depression in this study, the response to this question indicated the importance of that support in adjustment to the stress of illness. Religion and one's own strength were also important factors.

Positive Effect of the Iliness. Subjects were asked to identify what if any positive effect their illness had on their lives. Fifty-seven percent of the subjects were able to identify one or more positive effects of their illness. Answers that were frequently given to this 
question included the recognition of the support of family and friends and the recognition of the truly important aspects of one's life. Subjects who could identify at least one positive aspect to their fllness had significantly lower depression levels, $\underline{t}=-2.39, p<.019$, and higher life satisfaction, $\underline{t}=2.28, p<.025$.

Social Comparison. As emphasized by the importance of subjective health as a predictor of depression and life satisfaction, subjects were frequently able to adjust their social group for comparison in order to place themselves in a favorable position. Subjects were often able to find someone in their network who was in worse condition, and this appeared to reduce their depression levels. This coping strategy was more difficult for the younger subjects, however. Younger subjects tended to respond instead that their illness had forced them to appreciate the more important aspects of life, such as family and friends and the small joys of each day.

TIME 2

As stated in Chapter III, 19 of the subjects did not complete the second interview. T-tests of these subjects compared to those who completed the second interview did not reveal any significant differences for the major 
variables. of the 19 who did not complete the second interview, fourteen had either died or were too sick. Therefore, some of the sickest subjects were not included in the Time 2 data. This may have resulted in a slight decrease in CES-D scores and an increase in LSIA-A scores at Time 2 .

For the subjects who completed the second interview, the course of their health status was quite variable in the intervening time between interviews. Nineteen subjects were diagnosed as having one additional major health problem and 21 had been hospitalized at least once. Nevertheless, $75 \%$ of the subjects believed that their disease was the same or better than it was at the first interview, and $83 \%$ stated that their overall health was the same or better. Thus, generally, the health status of those completing the second interview had stabilized or gotten better. Other major life changes included nine subjects who had moved, six who had experienced the death of someone close, and three who had lost their jobs.

The following sections will review the results of the Time 2 interview for the major variables discussed under Time 1. Tables XXII and XXIII outline the correlations between these variables and CES-D and LSIA-A scores, respectively. Regression analyses for the Time 2 data will also be described. 
TABLE XXII

CORRELATION WITH CES-D TIME 2

$\begin{array}{lr}\text { LIFE EFFECT } & .489 \\ \text { PAIN } & .440 \\ \text { SUBJECTIVE HEALTH } & . .439 \\ \text { DEATH ANXIETY } & .369 \\ \text { PROGRESSIVENESS } & .353 \\ \text { WORRY MEDICAL RESOURCES } & .299 \\ \text { PHYSICAL DEPENDENCY } & .275 \\ \text { GENERAI HEALTH } & .203 \\ \quad \text { LOCUS OF CONTROL } & -.203 \\ \text { INCOME } & .174 \\ \text { SPECIFIC HEALTH } \\ \text { LOCUS OF CONTROL } \\ \text { LIFE EXPECTANCY } \\ \text { RELIGIOSITY } \\ \text { TOTAL EXCHANGES }\end{array}$


TABLE XXIII

CORRELATIONS WITH LSIA-A TINE 2

$\begin{array}{lr}\text { SUBJECTIVE HEALTH } & .541 \\ \text { LIFE EFFECT } & -.469 \\ \text { PHYSICAL DEPENDENCY } & -.433 \\ \text { PROGRESSIVENESS } & -.392 \\ \text { DEATH ANXIETY } & -.360 \\ \text { PAIN } & -.344 \\ \text { INCOME } & -.251 \\ \text { SPECIFIC HEALTH } & .206 \\ \quad \text { LOCUS OF CONTROL } & .221 \\ \text { WORRY MEDICAL RESOURCES } & .125 \\ \text { TOTAL EXCHANGES } & -.177 \\ \text { GENERAL HEAITH } & .167 \\ \text { LOCUS OF CONTROL } & \\ \text { RELIGIOSITY } & \text { LIFE EXPECTANCY }\end{array}$


Descriptive And Correlational Analyses

CES-D. The mean value for the 20 item CES-D was $16.25, S . D .=11.4$. Scores ranged from 0 to 51 . For the 28 item CES-D, the mean score was 22.55 with a standard deviation of 16.0 .

LSIA-A. With a maximum score of 36 , the mean score on the LSIA-A was $22.4, S . D .=8.4$. The correlation of CES-D scores to LSIA-A scores was $\underline{r}=-.606, p<.001$.

Social support. In the second interview, the subjects named an average of 6.90 names in their social support systems $(S D=2.98)$ and an average of 21.5 total exchanges $(S D=11.4)$. Instrumental assistance could have been or was provided by an average of 5.5 persons $(S D=3.3)$, and emotional assistance could have been or was provided by an average of 4.3 persons $(S D=2.8)$. An average of 2.8 persons $(S D=3.3)$ could have or did provide informational assistance. The social support systems of the subjects were $62 \%$ female and $38 \%$ male. Relatives comprised $52 \%$ of the persons named in the support systems; $32 \%$ were friends; $8 \%$ were neigbors; and $4 \%$ were professional health workers. Most subjects had only one key person in their support systems; the average number of persons per subject providing three or more types of help was $0.98 \quad(S D=1.1)$. Thus while many persons were named in the systems, generally only one person provided multiple types of 
support.

As was true at Time 1 , the association between type of support given and relationship to the subject was dependent upon the marital status of the subject. These data are summarized in Table XXIV. For the married subjects with living children, spouses provided $35 \%$ of the personal care while children provided $18 \%$, other relatives $20 \%$, and friends $10 \%$. Household help was provided by spouses $(23 \%)$, children $(25 \%)$, friends $(21 \%)$, other relatives ( $13 \%$ ) and neighbors ( $12 \%$ ). Spouses, children, and friends primarily gave emotional support. For married subjects without children, spouses and friends were the key persons providing personal care, household assistance, and emotional support. For the widowed subjects with living children, children supplied about $32 \%$ of the personal care while other relatives gave $21 \%$, friends $15 \%$, and health professionals $21 \%$. Chiluren, friends, and paid workers primarily gave household assistance. Emotional support came from children, other relatives, and friends. Widowed subjects without children depended upon professional health workers $(37 \%)$, friends $(25 \%)$, and other relatives ( $25 \%)$ for personal care. Other relatives and friends provided nearly all the household assistance. Other relatives were the key providers of emotional support. Separated or divorced subjects with children depended primarily upon friends for 


\section{TABLE XXIV}

TYPE OF SOCIAL SUPPORT AS RELATED TO

MARITAL STATUS AND RELATIONSHIP TO SUBJECT*

INSTRUMENTAL SUPPORT

EMOTIONAL SUPPORT

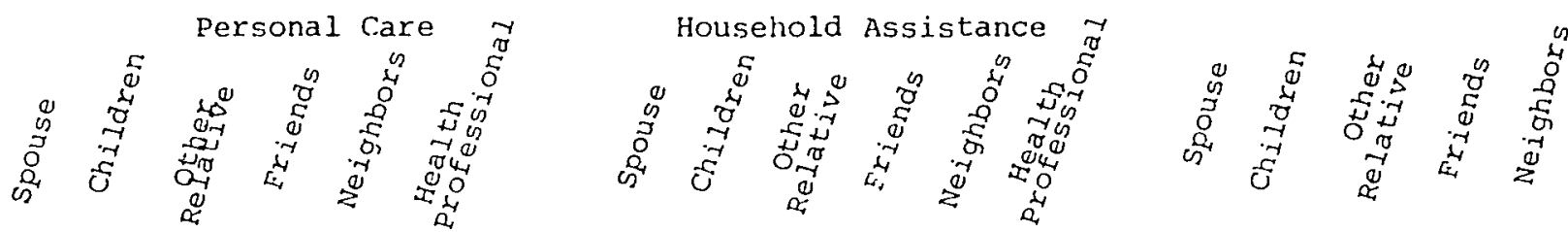

Married with Living

Children

$(\mathrm{N}=60)$

$23 \quad 25 \quad 13$

$21 \quad 12$

$20 \quad 26 \quad 20 \quad 21$

Married without

Children

$(N=4)$

Widowed with Living Children

$(\mathrm{N}=44)$

Widowed without

Children

$(\mathrm{N}=5)$

Divorced of Separated

with Living

Children

$(N=9)$

Single Never Married

$$
(N=7)
$$


personal care, household assistance, and emotional support. Single never-married subjects received personal care from friends and professional health workers. Friends provided household assistance and emotional support. Thus the provision of instrumental assistance appeared to fall first to the spouse, then to children and other relatives, and then to filends. When spouses were not available to provide personal care, professional workers became key providers.

Generally, the subjects were satisfied with their relationships with the persons in their support systems. They rated themselves as very satisfied with $83 \%$ of the persons named. They were somewhat satisfied with $11 \%$ of the persons; $3 \%$ were rated as neutral and $1 \%$ as dissatisfied.

Total exchanges, judged to be the best overall measure of the social support system, correlated with CES-D scores with an $\underline{r}=-.053, p<.30$. Total exchanges had a stronger relationship to life satisfaction, with a correlation to LSIÁ-A scores of $\underline{r}=.206, p<.015$.

Death Anxiety. Scores on the Templer DAS had a mean of 4.94, S.D. $=2.9$. The range on the 15 point maximum scale was from 0 to 11. Death anxiety correlated strongly to CES-D scores with an $\underline{r}=.369, \mathrm{p}<.001$. The association with life satisfaction was also strong, but in a negative direction, $\underline{r}=-.360, p<.001$. 
Worry About Medical Resources. Fifty-five percent of the subjects worried some or a great deal about their medical resources. The association of this worry to CES-D scores was fairly strong with $\underline{r}=.299, \mathrm{p}<.002$. The correlation to LSIA-A scores was $\underline{r}=-.221, \mathrm{p}<.010$.

Religiosity. Scores on the 12 point religiosity index ranged from 1 to 12 . The average score was 6.36 , S.D.=3.1. Religiosity had a weak negative association with CES-D scores, $x=-.063, p<.254$; the association with life satisfaction was somewhat stronger, $\underline{I}=.167, p<.039$.

Pain. Scores on the pain index ranged from 0 to 19 (19 possible), with a mean of 8.52 , S.D. $=5.61$. Correlation to CES-D scores was strong at $\underline{r}=.440, p<.001$. Correlation to LSIA-A was slightly less at $\underline{r}=-.344, p<.001$.

Physical Dependency. The average score on the physical dependency index was 13.5, S.D. $=11.9$, out of a maximum possible of 44. Scores ranged from 0 to 42 . The association of physical dependency to CES-D scores was moderate with an $\underline{r}=.275, \mathrm{p}<.003$. LSIA-A scores showed a much stronger association with physical dependency with a $\underline{r}=-.433, p<.001$.

Life Effect. With a maximum possible of 45 , the scores on the 1 ife effect index ranged from 9 to 40 . The mean was 23.1, S.D. $=9.8$. This index correlated strongly with the CES-D scores with an $\underline{r}=.489, \mathrm{p}<.001$. The 
correlation to LSIA-A scores was strong and negative, $\underline{I}=-.469, \mathrm{p}<.001$.

Progressiveness of the Disease. The progression of the subjects' illness during the previous three months and the expected progression in the future were assessed during the second interview. This added an additional question to the progressiveness index so that the index now had a maximum of 16. This index scored high for the subject's illness getting worse. Scores on this index ranged from 4 to 14 with an average of 8.34, S.D.=2.88. High progressiveness of the disease scores were associated with high CES-D scores, $\underline{I}=.353, \mathrm{p}<.001$. The relationship to life satisfaction was strong also, $\underline{r}=-.392, p<.001$. Controllability and Predictability. Scores on the first question on the Health Locus of Control Scale were slightly in the external direction with a mean of 3.03 , S.D.=1.86. Twenty percent of the subjects strongly disagreed with this statement "If I take care of myself, I can avoid illness". Answers to the question "I can generally control the symptoms of my disease" were more strongly external with a mean of 3.82, S.D. $=1.97$. Thirty-six percent of the subjects strongly disagreed with this statement. An additional question, "The symptoms of my illness are not very predictable", was added on the second interview. The answers to this question scored 
strongly externally with a mean of 4.07 , S.D.=1.93. This score was reversed to score high for externality. Thirty-five percent of the subjects strongly agreed with the statement. Total scores on the standard section of the Health Locus of Control Scale were an average of 39.4 , S.D. $=8.17$. Scores ranged from 11 to 61 .

Scores on the general health locus of control (question 1) were moderately correlated with CES-D scores, $\underline{r}=.203, p<.019$. This was also true of the correlation with LSIA-A scores, $\underline{r}=-.177, \mathrm{p}<.034$. The controllability of the symptoms of the specific illness (question 13) had only a slight relationship to CES-D scores, $\underline{r}=.174, p<.038$. The association with LSIA-A scores was slightly stronger, $\underline{r}=-.251, \mathrm{p}<.006 . \quad$ Predictability of disease symptoms (question 15) had little relationship to CES-D scores, $\underline{r}=.132$, $p<.089$, but a strong association with LSIA-A scores, $\underline{r}=-.341, p<.001$.

Life Expectancy. Subjects rated their expected length of life at an average of 77.3 years, S.D.=10.7. This correlated to CES-D scores weakly with an $\underline{r}=-.150, p<.096$. The magnitude of correlation to LSIA-A scores was similar at $\underline{r}=.125, \mathrm{p}<=138$. It should be noted that $32 \%$ of the subjects refused to answer this question or stated that they didn't know how many more years they expected to live. Some subjects replied that the length of their life was in 
God's hands; others stated that the course of their illness was just too unpredictable. Some subjects simply refused to think about it.

Subjective Health. Thirty-eight percent of the subjects rated their health as good to excelient. on the other hand, their health was rated as poor to fair by $62 \%$ of the subjects. subjects compared themselves more favorably to others their age; only $30 \%$ rated their health as worse than others their age.

Subjective health had a strong negative association with CES-D scores with a $r=-.439, p<.001$. The relationship to LSIA-A scores was even higher with $\underline{r}=.531, \mathrm{p}<.001$.

\section{Relationships Between Variables}

The correlations between variables is outlined in Table XXV. Subjective health again correlated fairly strongly with most of the other factors. Subjects appeared to consider pain, physical dependency, progressiveness of their illness, and their life expectancy when making this assessment. Physical dependency was strongly. correlated to life effect, and somewhat negatively associated with total exchanges. Despite the extra needs of the physically dependent, their support systems were smaller. Pain, physical dependency, and life effect were associated together. In general, pain would be expected to be 
TABIE $\triangle X V$

CORRELATIONS IBETWEEN SELECTED VARIABLES TIME 2

Life Effect

Physical Dependency

Pain

Progressiveness

Death Anxiety

Worry Medical Expenses

General Health Locus of Control

Specific Health Locus of Control

\section{Income}

Social Support

Total Exchanges

Religiosity

Life Expectancy 
associated with more severe disease and reduced functional capacity.

\section{Combined Effect of Selected Factors on Depression}

Based upon their high correlations with depression, the same factors of subjective health, pain, death anxiety, worry about medical resources, and physical dependency were included in the regression analysis for Time 2 . Life expectancy had much less association with depression in Time 2 so it was dropped from the analysis. Progressiveness of the disease increased in importance, and it was included. Income was also included as a measure of socioeconomic status.

Stepwise Regression. A stepwise regression outlined in Table XXVI resulted in the following order of variables as to their relative effect on depression: pain, worry about medical resources, subjective health, physical dependency, death anxiety, income, and progressiveness. The multiple $\underline{R}$ was .666 , explaining $44 \%$ of the variance in depression. Pain had an $\underline{R}^{2}$ Change of .197 and accounted for nearly $20 \%$ of the variance in depression. Worry about medical resources explained $11 \%$ of the variance in depression while subjective health explained $8 \%$. Three percent of the variance was explained by physical dependency, and $2 \%$ was explained by death anxiety. Both 


\section{TABIE XXVI}

STEPWISE REGRESSION FOR CES-D TIME 2

\section{Dependent Variable CES-D}

Pain

Worry Medical Resources

Subjective Health

Physical Dependency

Death Anxiety

Income

Progressiveness

\begin{tabular}{ccccc} 
Multiple R & $\mathrm{R}^{2}$ & $\mathrm{R}^{2}$ Change & Simple $\mathrm{R}$ & Beta \\
\hline .444 & .198 & .198 & .444 & 0.294 \\
.554 & .307 & .110 & .354 & 0.243 \\
.619 & .383 & .076 & -.418 & -0.189 \\
.646 & .417 & .035 & .296 & 0.180 \\
.660 & .435 & .018 & .332 & 0.165 \\
.664 & .441 & .005 & -.213 & -0.095 \\
.666 & .444 & .004 & .292 & 0.070
\end{tabular}


income and progressiveness accounted for less than $1 \%$ of the variance in depression.

Hierarchical Regression. Because of the intercorrelations between variables, a hierarchical regression was done with the variables in the reverse order from the stepwise regression described above. The results are included in Table XXVII. This regression resulted in progressiveness of the disease explaining $9 \%$ of the variance in depression while income explained $7 \%$. Death anxiety accounted for $9 \%$ and physical dependency $4 \%$. Both subjective health rating and worry about medical resources explained $4 \%$ of the variance in depression while pain explained $7 \%$.

Hierarchical Regressions Controlling For other Variables. As was done for Time 1 , the key variables of pain, worry about medical resources, physical dependency, subjective health, and death anxiety were entered last in regression analyses in order to determine their effect on depression after all of the other variables had been included. After the effect of worry about medical resources, physical dependency, subjective health, and death anxiety were taken out, pain still accounted for $8.5 \%$ of the variance in depression. The corresponding figures for the other variables were worry about medical resources, $6.1 \%$, physical dependency, $3.7 \%$, subjective health, $3.4 \%$, 


\section{TABLE XXVII}

HIERARCHICAL REGRESSION FOR CES-D TIME 2

Dependent Variable CES-D

\section{Progressiveness}

Income

Death Anxiety

Physical Dependency

Subjective Health

Worry Medical

Resources

pain

\begin{tabular}{ccccc} 
Multiple $\mathrm{R}$ & $\mathrm{R}^{2}$ & $\mathrm{R}^{2}$ Change & Simple $\mathrm{R}$ & Beta \\
\hline .292 & .085 & .085 & .292 & 0.070 \\
.394 & .155 & .070 & -.213 & -0.095 \\
.491 & .241 & .086 & .332 & 0.165 \\
.535 & .286 & .045 & .296 & 0.180 \\
.572 & .327 & .041 & -.418 & -0.189 \\
.609 & .370 & .043 & .354 & 0.243 \\
.666 & .444 & .074 & .444 & 0.294
\end{tabular}


and death anxiety, $1.8 \%$.

In conclusion, compared to Time 1 , pain retained its predictive ability for levels of depression. Subjective health and death anxiety became less important while physical dependency became slightly more important.

Combined Effect of Selected Variables on Life

Satisfaction

For the Time 2 data, subjective health, physical dependency, income, progressiveness of the disease, total exchanges, and pain were again entered into the regression analysis. Death anxiety became more important and was added to the analysis while health locus of control was not included.

Stepwise Regression. Data from the stepwise regression is included in Table XXVIII. This regression resulted in a multiple $\underline{R}$ of .664 , explaining $44.1 \%$ of the variance in life satisfaction. The variables in order of their relative importance were subjective health, physical dependency, death anxiety, income, progressiveness of the disease, total exchanges, and pain. Subjective health was again the best predictor of life satisfaction accounting for $25.1 \%$ of the variance. Physical dependency explained $7.0 \%$ while death anxiety explained $5.2 \%$. Three percent of the variance was explained by income while progressiveness 
TABLE XXVIII

STEPWISE REGRESSION FOR LSIA-A TIME 2

\begin{tabular}{|c|c|c|c|c|c|}
\hline Dependent Variable LSIA-A & Multiple $\mathrm{R}$ & $\mathrm{R}^{2}$ & $\mathrm{R}^{2}$ Change & Simple $R$ & Beta \\
\hline \multicolumn{6}{|l|}{ Subjective Health } \\
\hline & .502 & .252 & .252 & .502 & 0.300 \\
\hline Physical Dependency & .567 & .322 & .070 & -.388 & -0.194 \\
\hline Death Anxiety & .611 & .374 & .052 & -.310 & -0.246 \\
\hline Income & .637 & .405 & .032 & .246 & 0.180 \\
\hline Progressiveness & .654 & .427 & .022 & -.335 & -0.151 \\
\hline Total Exchanges & .660 & .436 & .009 & .218 & 0.101 \\
\hline Pain & .664 & .441 & .004 & -.299 & -0.072 \\
\hline
\end{tabular}


of the disease explained $2 \%$. Total exchanges explained $1 \%$ while pain explained less than $1 \%$ of the variance in life satisfaction.

Hierarchical Regression. As was done previously, the variables were forced in a regression in reverse order. The statistics are given in Table XXIX. In this order, pain accounted for $8.9 \%$ of the variance in life satisfaction while total exchanges accounted for $2.6 \%$. Progressiveness of the disease now explained $8.1 \%$ of the variance and income explained $4.7 \%$. Eight percent of the variance is explained by death anxiety and $5.2 \%$ by physical dependency. Finally, even when last, subjective health accounted for $6.5 \%$ of the variance in life satisfaction.

Hierarchical Regressions Controlling For other Variables. The variables of subjective health, death anxiety, physical dependency, income, and physical dependency were entered last in regression analyses in order to determine their effect after control for the other variables. When entered last, subjective health accounted for $6.8 \%$ of the variance in life satisfaction. The corresponding values for the other variables were death anxiety, $4.9 \%$, physical dependency, $4.6 \%$, income, $4.1 \%$, and progressiveness of the disease, $2.2 \%$.

In conclusion, at Time 2, subjective health maintained its lmportance as a predictor of life 
TABLE XXIX

HIERARCHICAL REGRESSION FOR LSIA-A TIME 2

\begin{tabular}{|c|c|c|c|c|c|}
\hline Dependent Variable LSIA-A & Multiple $\mathrm{R}$ & $\mathrm{R}^{2}$ & $\mathrm{R}^{2}$ Change & Simple $R$ & Beta \\
\hline Pain & .299 & .089 & .089 & -.299 & -0.072 \\
\hline Total Exchanges & .339 & .115 & .026 & .218 & 0.101 \\
\hline Progressiveness & .443 & .196 & .081 & -.335 & -0.151 \\
\hline Income & .493 & .243 & .047 & .246 & 0.180 \\
\hline Death Anxiety & .568 & .323 & .080 & -.310 & -0.246 \\
\hline Physical Dependency & .612 & .375 & .052 & -.388 & -0.194 \\
\hline Subjective Health & .664 & .441 & .065 & .502 & 0.300 \\
\hline
\end{tabular}


satisfaction. Death anxiety, income, physical dependency, and progressiveness of the disease increased in importance while total exchanges and pain decreased in importance.

\section{Primary Concerns of the Subjects}

At the end of the second interview, subjects were asked what was the greatest effect their illness had had on their lives. The most common answer was limitation of activities, as $57 \%$ of the subjects expressed this effect. The other frequent response was the emotional impact of the illness which was mentioned by $14 \%$ of the subjects.

The subjects were also asked what was their greatest concern regarding their illness. Twenty percent of the subjects had no particular concerns at the time of the second interview. Nineteen percent of the subjects were concerned about their level of disability while $7 \%$ were primarily worried about the financial impact of their illness. Only $3 \%$ specifically mentioned their level of pain. The most frequent concern, mentioned by $34 \%$ of the subjects, was the future progression or recurrence of their iliness. Subjects feared the impact that a worsening of their illness would have on themselves and their families. The next chapter will describe changes in depression and life satisfaction over time and the factors associated with that change. 
CHAFTER VI

CHANGES IN DEPRESSION AND LIFE SATISFACTION OVER TIME

The panel design of this study allowed for the analysis of change in depression and life satisfaction over time and the factors associated with that change for physically ill middle aged and elderly persons. The following sections will describe the descriptive and correlational analysis of change over time, the regression analysis of change over time, and the dynamic (change focused) correlational analysis for depression and life satisfaction.

DESCRIPTIVE AND CORREATIONAL ANALYSIS

Depression-CES-D

Scores on the CES-D were moderately stable from Time

1 to Time 2. The average change on the 60 point CES-D scale was $0.40, S . D .=8.59$. For $62 \%$ of the subjects, their CES-D score at Time 2 was within 6 points of their score at Time 1. However, some subjects did show large changes in depression scores. The range of change in scores was from -22 to +26 points. The correlation between Time 1 and Time 2 CES-D scores was $\underline{r}=.705, \mathrm{p}<.001$. As the CES-D is 
designed to measure depression levels in the recent past, a three month period of time would be expected to result in some change in depression scores. The factors associated wth this change will be discussed in later sections.

Life Satisfaction - LSIA-A

The average change on the 36 point LSIA-A scale was 0.85 , S.D.=5.88. While the change in scores ranged from -10 to +19 points, $61 \%$ of the Time 2 LSIA-A scores were within 4 points of the Time 1 score. The correlation between Time 1 LSIA-A scores and Time 2 scores was $\underline{r}=.738$, p<.001. Previous longitudinal studies of the elderly indicated strong stability in life satisfaction (Palmore \& Kivett, 1977); however, life satisfaction scores in this study were only slightly more stable than depression scores. This was probably due to the heavy emphasis in the LSIA-A on present circumstances. Eleven of the 18 items on the LSIA-A deal with the present, and for some of the subjects in this study, their health status was quite variable. This may have made LSIA-A scores less stable over time.

$\underline{\text { Pain }}$

As would be expected, pain levels varied from Time 1 to Time 2. The average change on the 19 point pain index was -0.11 , S.D. $=4.66$; the range of change was from -12 to 
+13. Forty-eight percent of the subjects had Time 2 pain index scores within 2 points of the Time 2 level. The correlation between Time 1 and Time 2 pain scores was $\underline{r}=.640, \mathrm{p}<.001$

Death Anxiety

Scores on the DAS were stable with an average change of $-0.14, S . D .=2.16$. While $59 \%$ of the subjects had scores within 1 point of each other on this 15 point scale, the range of change was from -5 to +6 points. The correlation of Time 1 to Time 2 DAS scores was $\underline{x}=.738, p<.001$. Templer (1970) demonstrated a test-retest reliablity for the DAS of . 83; however, the correlation over a 3 month period was less in this study. While the DAS is accepted as a trait measure, its value seemed somewhat influenced by present circumstances for this sample.

\section{Subjective Health}

The subjective health of the subjects was fairly stable over time with an average change on the nine point scale of 0.07 points, S.D.=1.41. Change in scores ranged from +5 to -3 points on the 9 point scale with $68 \%$ having no more than a 1 point difference between $T$ ime 1 and $T$ ime 2. The correlation between the two subjective health ratings was $\underline{I}=.735, p<.001$. 
Worry About Medical Resources

Sixty-one percent of the subjects showed no change in worry about medical resources from Time 1 to Time 2. The average change was -0.07 points on the 3 point scale, $S . D .=0.73$, with a range of -2 to +2 points. The correlation between Time 1 and Time 2 scores was $\underline{r}=.566$, $\mathrm{p}<.002$.

Physical Dependency

For the subjects in this study, their physical dependency level was fairly stable with a correlation between Time 1 and Time 2 levels of $\underline{r}=.879, p<.001$. The average change on the 44 point scale was -1.80 , S.D. $=5.90$ with $69 \%$ of the subjects having no more than a 4 point difference between the 2 scores. A few subjects did change greatly on this variable, however, as the change in scores ranged from -24 to +11 points.

\section{Life Expectancy}

The life expectancy of the subjects had an average change from Time 1 to Time 2 of 0.94 years, S.D. 6.20 , with a range of -10 to +29 years. The correlation between the two scores was $\underline{r}=.739, p<.001$, and $58 \%$ of the subjects did not vary more than 2 years on their estimation of their life expectancy. 
Social support

The measures of social support used in this study demonstrated a fair amount of change between Time 1 and Time 2. Answers to the questions regarding the social support system appeared to be strongly influenced by recent contacts, so that much variation was found. The number of total exchanges at Time 1 and Time 2 were only moderately correlated, $\underline{r}=.388, p<.001$. As this could have been influenced by dependency levels, the change in total names was also analyzed. The correlation in total names was somewhat higher, $\underline{r}=.602, \mathrm{p}<.001$. The persons named in the social support systems were only moderately stable with sixty-four percent of those named in the first support system also appearing in the second system. This change was probably partly due to the influence of recent experience. If the person had not had direct contact with the subject in the last few weeks, they generally were not named in the system. However, some of the change was attributable to the illness. Several subjects stated that no one came to visit them anymore.

\section{Controllability}

The measure of general health locus of control showed a mean change of $-0.41, S . D .=2.05$. Change scores on this 6 point scale ranged from -5 to +5 with $61 \%$ of the subjects 
having a change of 1 point or less. Correlation between Time 1 and Time 2 was $\underline{I}=.438$, p<.002, indicating a fair amount of change over time. Controllability of specific illness showed less average change with a mean change of $-0.07, S \cdot D .=2.24$. However, the correlation for specific health locus of control was less at $\underline{r}=.336, p<.002$. It appears that the assessment of controllability of general health and the specific illness is variable and probably influenced by recent experiences.

In conclusion, except for the measures of controllability and the social support system, most of the variables demonstrated considerable stability over time. Nevertheless, some subjects exhibited large changes in a three month period of time. The following sections will investigate this change.

\section{KEGRESSION ANALYSES}

\section{Depression - CES-D}

A hierarchial regression was done to investigate the effect of key variables over time on the level of depression at Time 2. Factors that had the greatest effect on depression at both Time 1 and Time 2 were chosen for the analyses. The results of this regression are included in Table XXX. This regression equation had a multiple $\underline{R}$ of .725 and accounted for $53 \%$ of the variation in depression 
TABLE $X X X$

HIERARCHICAL REGRESSION FOR CES-D TIME 1 AND TIME 2

Dependent Variable CES-D Score at Time 2

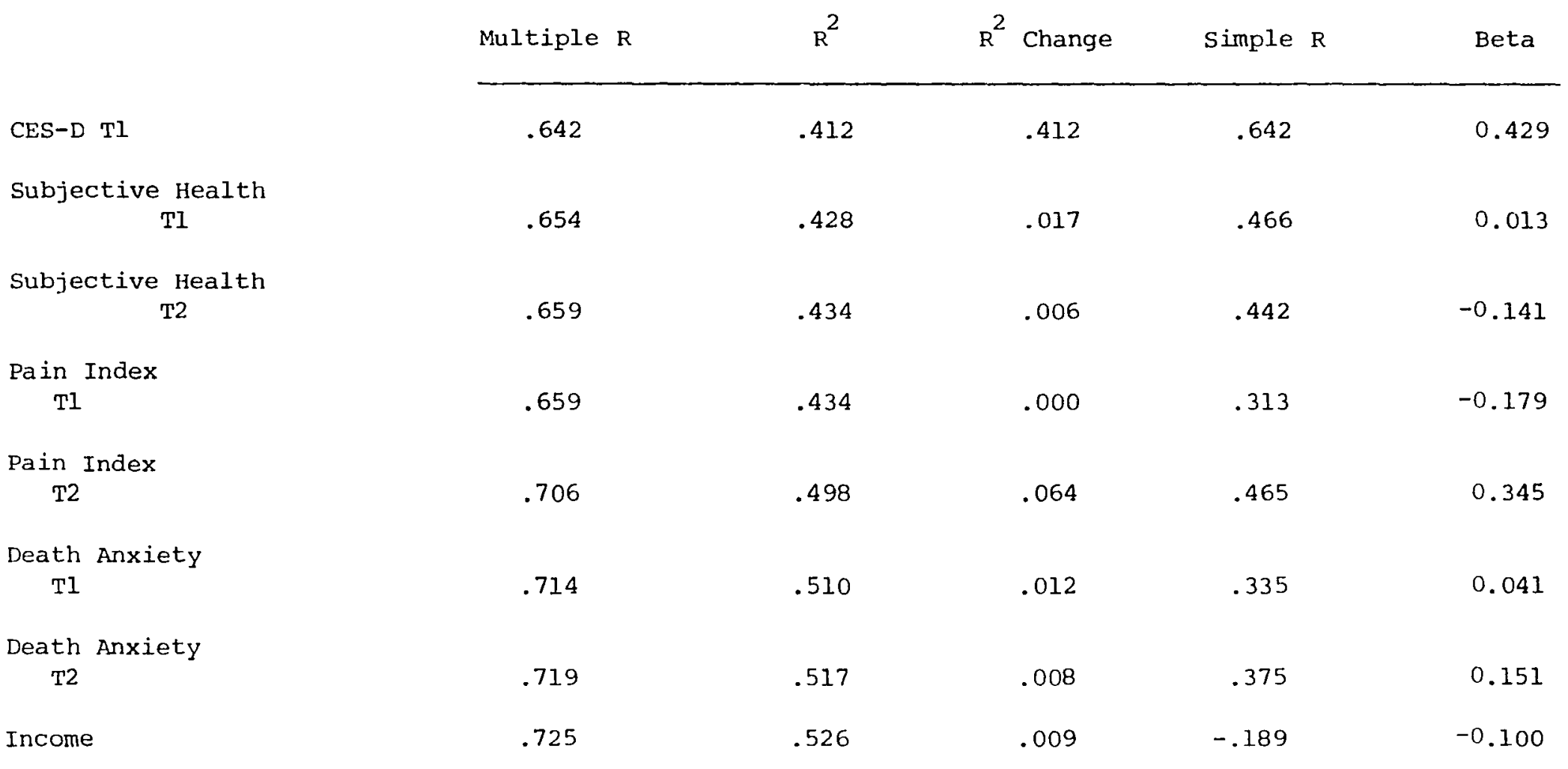


level at Time 2. With the CES-D score at Time 2 being the dependent variable, the depression level at $T i m e ~ i$ was entered first into the regression. Because depression scores were fairly stable, the depression score at Time 1 accounted for $41 \%$ of the variance in depression at Time 2 . Thus, the best predictor of Time 2 depression score was the score at Time 1. Subjective health at Time 1 and Time 2 were added next to the regression with Time 1 entered first. Neither contributed much to the prediction of depression scores at Time 2. Time 1 subjective health added $1.7 \%$ and Time 2 subjective health added .6\%. Pain levels at Time 1 and Time 2 were included next in the regression. Pain level at Time 1 did not add any to the prediction of depression level. However, pain level at Time 2 was the second best predictor of depression at Time 2 as it accounted for an additional $6.4 \%$ of the variation in Time 2 depression levels. Death anxiety at Time 1 and Time 2 was entered next in the regression. Time 1 death anxiety added $1.2 \%$ to the prediction of depression levels, and Time 2 death anxiety added . $7 \%$. As the last variable entered, income accounted for an additional.9\% of the explained variance in depression level at Time 2 .

In conclusion, $79 \%$ of the explained variance in Time 2 depression scores was accounted for by Time 1 depression levels. The effects of Time 1 subjective health, Time 1 
pain, Time 1 death anxiety, and income were probably already taken up by the Time 1 CES-D score; and these variables had little additional effect on depression levels at Time 2. Subjective health and death anxiety were fairly stable over time so that their Time 2 values added little to depression levels at Time 2. The one additional variable that affected change in depression was pain at Time 2. Apparently, change in pain over time had a major effect on depression levels. Although the present study only investigated change over a three month period of time, this relationship of Time 2 pain to Time 2 depression points to pain as a critical causative factor in depression for physically ill middle aged and elderly persons.

\section{Life Satisfaction-LSIA-A}

As with depression, key factors from both Time 1 and Time 2 were forced in a hierarchical regression using LSIA-A scores as the dependent variable. The results are included in Table XXXI. Overall, the variables of Time 1 LSIA-A score, Time 1 and Time 2 subjective health, Time 1 and Time 2 total exchanges, income, and Time 1 and Time 2 pain accounted for $66 \%$ of the variability in Time 2 LSIA-A scores, Multiple $\underline{R}=.816$. The Time 1 LSIA-A score was entered first and used up $87 \%$ of the explained variance in the Time 2 LSIA-A score, $\underline{\mathrm{R}}^{2}$ Change $=.581$, showing that life 


\section{TABLE XXXI}

HIERARCHICAL REGRESSION FOR LSIA-A TIME 1 AND TIME 2

Dependent Variable LSIA-A Time 2

\begin{tabular}{lccccc} 
& Multiple $\mathrm{R}$ & $\mathrm{R}^{2}$ & $\mathrm{R}^{2}$ Change & Simple R & Beta \\
\cline { 2 - 5 } ISIA-A T1 & .762 & .581 & .581 & .762 & 0.584 \\
$\begin{array}{l}\text { Subjective Health } \\
\text { T1 }\end{array}$ & .773 & .598 & .017 & .536 & 0.023 \\
$\begin{array}{l}\text { Subjective Health } \\
\text { T2 }\end{array}$ & .787 & .620 & .022 & .517 & 0.200 \\
Total Exchanges T1 & .789 & .622 & .002 & .027 & -0.036 \\
Total Exchanges T2 & .802 & .643 & .020 & .234 & 0.087 \\
Income & .808 & .653 & .011 & .292 & 0.081 \\
Pain T1 & .815 & .665 & .002 & -.316 & 0.093 \\
Pain T2 & .816 & .666 & .013 & -.365 & -0.151
\end{tabular}


satisfaction scores were fairly stable over time. Both Time 1 and Time 2 subjective health ratings added two percent each to the explained variance in Time 2 LSIA-A scores. Total exchanges at Time 1 added less than $1 \%$ to the explained variance; however, total exchanges at Time 2 accounted for an additional two percent. Income raised the explained variance by one percent. Finally, as both pain and physical dependency had moderate effects on LSIA-A scores, separate regressions were done adding either Time 1 and Time 2 physical dependency or Time 1 and Time 2 pain. The resultant multiple $\underline{R}^{\prime}$ s were nearly identical. Time 1 physical dependency added $1 \%$ to the explained variance while Time 2 physical dependency added less than $1 \%$. The reverse was true for pain with Time 1 pain adding less than $1 \%$ while Time 2 pain added $1 \%$.

In summary, LSIA-A scores werefairly stable over time. Time 1 LSIA-A scores explained most of the variance in Time 2 scores. Change in subjective health and total exchanges were the next best predictors of change in LSIA-A scores, adding two percent each to the explained variance. Change in pain accounted for an additional one percent of the change in life satisfaction scores.

DYNAMIC (CHANGE FOCUSED) CORRELATIONAL ANALYSIS

Using a statistical techinique developed by stewart 
(1980), regression analyses were used to divide the subjects into subgroups based on the type of change experienced. These subgroups of change were then investigated for differences in key variables. Finally, key variables were used to predict group membership through discriminant function analysis.

Depression - CES-D

The regression of Time 1 to Time 2 CES-D scores resulted in a $\mathrm{r}$ of $.705, \mathrm{p}<.001, \mathrm{r}^{2}$ of .50, slope of .74 , intercept to 4.44 , and standard error of the estimate (SEE) of 8.1. Using this regression of CES-D scores, the subjects were categorized as stable if their scores were within \pm .5 SEE of the predicted score. For some analyses, these stable subjects were further subdivided into stable low $(L \rightarrow L)$, stable middle $(M \rightarrow M)$, and stable high $(H \rightarrow H)$ groups based upon their depression scores. Subjects with depression scores greater than \pm .5 SEE from the predicted score were divided into those that increased their scores and those that decreased their scores. These increasers and decreasers were further subdivided into low to middle change $(L \rightarrow M)$, middle to high change $(M \rightarrow H)$, high to middle change $(H, M)$, and middle to low change $(M \rightarrow L)$. When subjects were divided into the three groups (stable, Increasers, and decreasers) based upon CES-D scores, 50 
persons were stable, 31 were increasers, and 33 subjects were decreasers. If the subjects were further subdivided Into the seven subgroups, 9 were in the L $\rightarrow$ L group, 23 were in the $M \rightarrow M$ group, 18 were in the $H \rightarrow H$ group, 5 were in the $L \rightarrow M$ group, 26 were in the $M \rightarrow H$ group, 13 were in the $M \rightarrow L$ group, and 20 were in the $H \rightarrow M$ group. Division of the subjects into seven subgroups resulted in some groups with small N's, and this may have contributed to some of the nonsignificant findings in the analyses reported below.

Using the selection criteria described above, the data were first analyzed with the subjects divided into three groups: stable, increasers, and decreasers. Numerous analyses of variance were done to identify differences between the groups on key variables. Many variables showed differences in the expected direction but few were significant at the $p<.1$ level. Again, pain was a critical factor and one of the few variables that demonstrated a significant difference across groups. The increasing CES-D group had significantly more pain at time 2, $\underline{F}(2,111)=2.886, p<.07$; and the decreasing CES-D group had significanty more reduction in pain between time 1 and Time 2, $F(2,109)=3.04, p<.053$. Dividing the groups into seven subgroups resulted in a less clear pattern in regard to pain. Both the $H \rightarrow H$ groups and the $M \rightarrow H$ groups had high levels of pain at Time 2. Also, while the $M \rightarrow L$ and $H \rightarrow M$ 
groups clearly decreased in pain between Time 1 and Time 2 , the $L \rightarrow M$ group also decreased. Thus, pain was a good discriminator between stable, increasing, and decreasing groups, but its effect became slightly less clear when the groups were further subdivided.

Health locus of control was also a predictor at a significant level of group membership when three groups were used. At both Time 1 and Time 2, the decreasing CES-D group had significantly more internal general health locus of control, $\underline{F}(2,111)=2.37, \quad \mathrm{p}<.100$ for time 1 , $E(2,104)=3.75, p<.028$ for Time 2 . Change in general health locus of control showed no significant differences between groups. Specific health locus of control demonstrated a less consistent pattern. The decreasers were significantly more internal at Time $1, \underline{F}(2,111)=3.38, p<.039$, but showed more change to externality over time, $\underline{F}(2,104)=2.60$, p<.080. Subdividing the groups into seven groups demonstrated the same pattern.

The decreasing CES-D group also showed significantly less progression of their disease at Time $2, \underline{F}(2,98)=2.49$, $p<.089$. The same difference was found when the analysis was based on seven subgroups.

With the subjects divided into three groups, subjective health showed a tendency to be lower for the increasing CES-D group and higher for the decreasing group, 
but the differences were not statistically significant at the $p<.1$ level. Death anxiety tended to be higher for the increasers, but again the data were not statistically significant. The decreasers had a lower physical dependency at Time 1 and $T$ ime 2 and also decreased more between Time 1 and Time 2 , but the differences were not statistically significant. The same pattern was true of worry about medical resources. With regard to social support, the increasers had a greater decrease in total exchanges over time and the decreasers were the only group that showed an increase in total names over time. However, these differences were not statistically significant. The increasing CES-D group did show decreases in LSIA-A scores, but not at a statistically significant level. No clear pattern was evident between groups for income, age, or life expectancy.

A discriminant function analysis was done with the variables of subjective health, pain, death anxiety, income, physical dependency, worry about medical resources, progressiveness of the disease, and health locus of control in order to try to predict membership into the three groups of stable, increasers, and decreasers. These variables did not predict change in depression over time very well as on 1 y $60 \%$ of the cases were correctly classified into groups. The membership in the decreasing group was best 
predicted with $72 \%$ of the subjects correctly classified. Only $54 \%$ of the stable group and $57 \%$ of the increasers were correctly classified. The cannonical correlations of the two functions in the discriminant analysis were only .500 and .363 . Thus the variables in this study were able to predict individuals decreasing in depression over time fairly well, but were not able to predict stable or increasing CES-D scores very well.

Cross-lagged Panel Analysis

Because of the importance of pain in both the regression and dyramic (change focused) correlational analyses, a cross-lagged panel analysis of the relationship between pain and depression was carried out. The results are given in Figure 6. This analysis indicated a strong relationship between pain at Time 1 and depression at Time 1 and between pain at Time 2 and depression at Time 2. The relationship of pain at Time 1 to depression at Time 2 was less, indicating a stronger contemporaneous effect of pain on depression. The correlation of depression at Time 1 to pain at Time 2 was strong, however. This would suggest that depression may affect the perception of pain over a three month period of time.

\section{Life Satisfaction - LSIA-A}

Using the same technique described above, the 


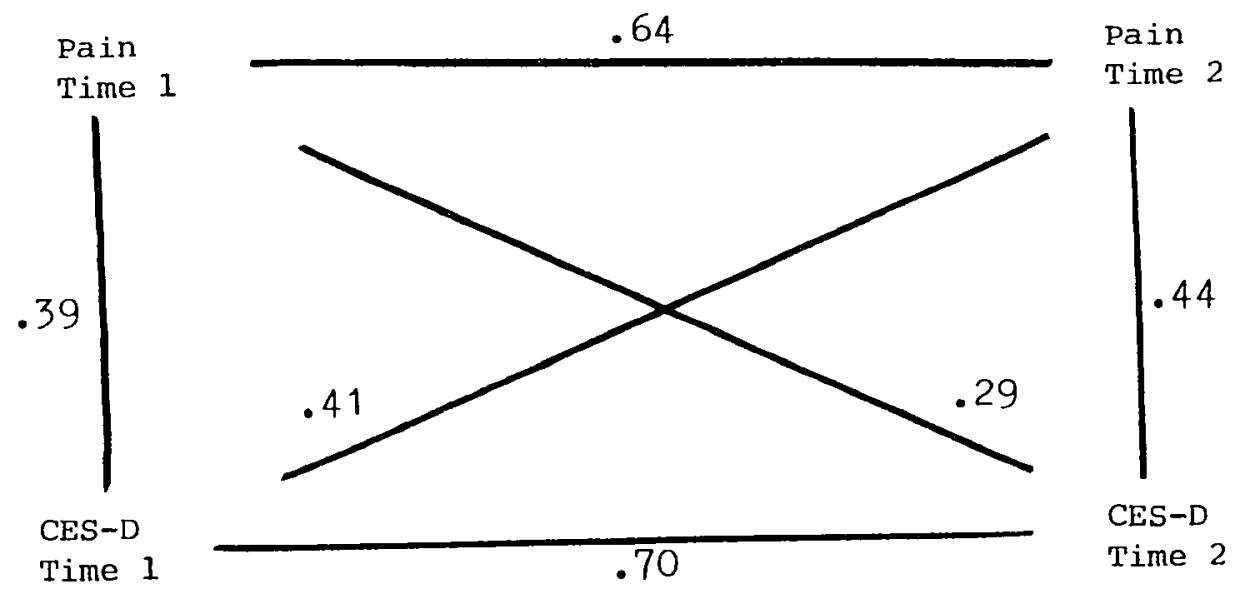

Figure 6. Cross-Lagged Panel Analysis Pain and CES-D 
subjects were divided by LSIA-A scores. The regression of Time 1 to Time 2 LSIA-A scores resulted in a $\underline{r}$ of .738, $p<.001, I^{2}$ of .55, slope of .76 , intercept of 6.03 , and SEE of 5.7. Analysis revealed 54 subjects in the stable group, 29 in the increasing LSIA-A group, and 30 in the decreasing LSIA-A group. Subdividing the groups resulted in 4 subjects in the $L \rightarrow L$ group, 15 in the $M \rightarrow M$ group, 35 in the $H \rightarrow H$ group, 6 in the $L \rightarrow M$ group, 23 in the $M+H$ group, 14 in the $M \rightarrow L$ group and 16 in the $H \rightarrow M$ group.

Analyses of variance revealed several significant group differences. The decreasing LSIA-A group had sigrificantly lower subjective health at Time 1 , $\underline{F}(2,98)=4.34, p<.017$, and at Time $2, \underline{F}(2,106)=7.28, p<.002$. The increasing LSIA-A group described lower pain levels at Time $2, \underline{F}(2,110)=2.55, p<.084$. This group also showed more decrease in pain over time but the difference was not statistically significant at the $p<.1$ level. The decreasing LSIA-A group was significantly more physically dependent at both Time 1 and Time $2, \underline{F}(2,110)=12.59, \mathrm{p}<.001$ at Time 1, and $\underline{F}(2,110)=12.60, p<.001$ at Time 2. This strong relationship remained after the groups were subdivided into seven groups, $\underline{F}(6,106)=6.69, p<.001$ at Time 1 , and $\underline{F}(6,106)=5.80, p<.001$ at Time 2 . Those increasing in LSIA-A scores had the highest income, $F(2,101)=2.91$, $p<.060$. The lowest life expectancy was expressed by the 
decreasing LSIA-A group, $E(2,79)=3.01, \quad p<.056$. This pattern was true at Time 2 and the decreasers also had the greatest decrease in life expectancy; however, these differences were not statistically significant at the $p<.1$ level. The decreasing LSIA-A group were the most external in their general locus of control at Time $1, \underline{F}(2,110)=3.11$, p<.050. The same pattern occurred at Time 2. These decreasers were also significantly more external in their specific health locus of control at Time $1, \quad F(2,110)=5.67$, $\mathrm{p}<.006$, and at Time $2, \quad \underline{F}(2,103)=4.04, \mathrm{p}<.022$. The decreasers showed several losses in their social support systems, but only the decrease in total names between $T$ ime 1 and Time 2 reached statistical significance, $\underline{F}(2,110)=2.89, \quad p<.061$. Finally, the decreasing LSIA-A group had significantly more progression in their illness, $\underline{F}(2,97)=4.81, \mathrm{p}<.011$.

The decreasing LSIA-A group had more increase in their CES-D scores but the difference was not statistically significant. Death anxiety, worry about medical resources, and age demonstrated no clear pattern or statistical significance.

Generally, subdividing the groups did not assist in the analysis of the data. The $L \rightarrow L$ group often had similar values to the decreasing LSIA-A group so that patterns became less distinct with seven groups. 
The discriminant function analysis of the LSIA-A change groups predicted group membership somewhat better than it did for depression. Using the same variables as for depression, the discriminant analysis correctly classified $67 \%$ of the cases for change in LSIA-A. The increasing group was best predicted with $76 \%$ of the cases correctly classified. Fifty-nine percent of the decreasing group were placed in the correct group, and $65 \%$ of the stable group were correctly categorized. The two resultant discriminant functions had canonical correlations of .665 and .413. For both depression and life satisfaction, the discriminant function analyses demonstrated that subjective health, pain, death anxiety, and progressiveness of the disease were the variables that best discriminated between change groups. These variables best predicted those who increased in life satisfaction or those who decreased in depression.

Cross-lagged Panel Analysis - Depression and Life Satisfaction

A cross-lagged panel analysis was carried out in order to investigate the relationship between depression and life satisfaction over time. The results are shown in Figure 7. The relationship of life satisfaction to depression at one point in time was quite similar for both 


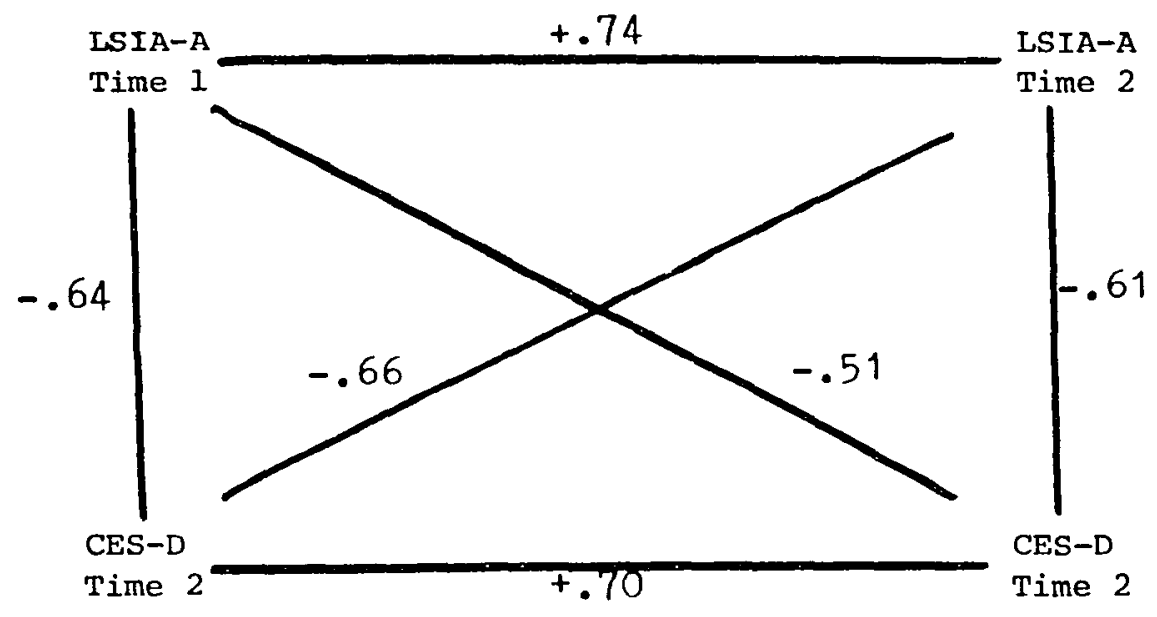

Figure 7. Cross-Lagged Panel Analysis CES-D and LSIA-A 
Time 1 and Time 2. The correlation of life satisfaction at Time 1 to depression at Time 2 was less than the correlation of depression at Time 1 to life satisfaction at Time 2, however. This would suggest that over time depression may have a greater effect on life satisfaction than life satisfaction has on depression.

Summary

In conclusion, analyses of the data in this study revealed that the measurement of most of the variables was fairly stable over a three month period of time. Two exceptions were the factors of social support and health locus of control. For both depression and life satisfaction, the best predictor of level at Time 2 was the level on the same variable at Time 1 . In addition, change in pain level significantly added to the prediction of $T$ ime 2 depression level. Pain, progressiveness of the disease, and health locus of control were able to distinguish between CES-D change groups at a significant level. Subjective health at Time 1 and Time 2 and change in total exchanges were able to add some to the prediction of life satisfaction at Time 2. Subjective health, pain, death anxiety, physical dependency, and progressiveness of the disease were able to significantly distinguish between change groups for life satisfaction. 
The last chapter will discuss the general findings of the study and their implications for policy and future research. 


\section{CHAPTER VII}

\section{DISCUSSION AND IMPLICATIONS OF THE STUDY}

\section{DISCUSSION}

Based on the initial framework as outlined in Chapter II, characteristics of the individual, characteristics of the disease, and perceptions of the disease were investigated to determine their effect on CES-D depression scores in physically ill middle aged and elderly persons.

Previous research indicated a probable inverse relationship between level $\therefore$ depression and income and social support. That is, higher depression levels would be expected to be associated with lower levels of income and social support. other research indicated a direct relationship between pain, physical dependency, and external locus of control for health and levels of depression. Thus high levels of these three variables would be expected to be associated with higher levels of depression.

Prior studies regarding the relationship of age, gender, and length of illness to depression resulted in such varied results that prediction regarding these variables was difficult. Epidemiological studies on the 
rates of depression and physical illness suggested, however, that elderly persons coped at least as well as younger persons to the stress of physical illness. Other variables suggested in the literature that have seldom been systematically studied in this context included subjective health, religiosity, death anxiety, life expectancy, perceived progressiveness of the disease, and role centrality.

In this study, information was gathered on all of these variables from 133 physically ill middle aged and elderly persons. In addition to measures from the CES-D, scores on the LSIA-A were also gathered as another measure of subjective well-being. In order to study these variables at two points in time and to investigate change in them over time, additional data on the variables was gathered from 114 of the same subjects approximately 3 months later.

The data were first investigated for relationships occurring at one point in time. Intercorrelations between variables as well as their correlations with CES-D scores at Time 1 and Time 2 were calculated. These data were used to identify the most important factors for later analysis.

As described in detail in Chapter V, all of the variables identified in the model had correlations with the CES-D scores in the expected direction. That is, subjective 
health, life expectancy, income, role centrality, religiosity, and social support were all inversely related to level of depression. Conversely, pain, death anxiety, worry over medical resources, physical dependency, external locus of control for health, and perceived progressiveness of the disease were directly related to level of depression. Based on the magnitude of these correlations, subjective health, pain, death anxiety, and worry about medical resources were chosen at both Time 1 and Time 2 for further analyses using multiple regression. In addition, general health locus of control, physical dependency, and life expectancy were included in the $T$ ime 1 analysis. At Time 2 perceived progressiveness of the disease became an important variable for inclusion in the regression analysis. Physical dependency and life expectancy may have decreased in importance at Time 2 because many of the subjects who did not complete the second interview were quite $i 11$ or had died between interviews.

As the effect of age on depression and life satisfaction levels for this group of physically ill individuals was a central question of this study, a number of analyses were carried out to investigate the importance of age. Correlational analyses, analyses of variance, and regression analyses revealed a slight but consistent decrease in depression levels with age. The ability to 
favorably compare oneself within one's age group may be a powerful means of maintaining self esteem and coping with the stress of illness. Analyses of change in depression over time did not reveal age as a significant factor.

While the direction of the relationships between predictor variables and depression as measured at one point in time confirmed the expectations of the investigator, their magnitude was not always as expected. Subjective health was strongly associated with depression levels at both Time 1 and Time 2. The importance of subjective health in predicting level of depression can be partially explained by its high correlations with many of the other health related variables. Subjects appeared to consider such factors as physical dependency, pain, areas of life affected, perceived progressiveness of the disease, and life expectancy as they rated their health and compared it to others their age.

Because of the financial stresses associated with serious physical illness, income might have been expected to be more strongly associated with depression. While many subjects expressed concern about their medical resources for the future, others believed that their medical needs would be provided for despite their limited resources. Thus income was only moderately related to depression.

High death anxiety was unexpectedly and strongly 
related to depression levels at both Time 1 and Time 2 . Death anxiety was also moderately associated with perceived progressiveness of the disease, life expectancy, and subjective health. As a whole, this pattern of relationships suggests that current health experiences in the context of a serious physical illness have a strong impact on death anxiety.

The association of social support to depression was less strong than anticipated. This might be due to the existence of a critical level of social support above which additional support had no effect on depression. Most of the subjects had fairly extensive support systems, and changes in size of these systems may have had little additional effect on depression.

Perceptions of external control for general health had a moderately strong association with depression; however this relationship was stronger at Time 1 than at Time 2. Subjects were more external in their perceptions of control for their specific disease, and this had less association with depression than their perceptions regarding general health. This suggests that the subjects were able to differentiate between control over general health and control over specific diseases. Subjects who were internal regarding general health experienced lower levels of depression, regardless of their perceptions of 
control for their specific disease.

Decreased life expectancy was strongly related to depression at Time 1 but not at Time 2. The exacerbation of the illness before Time 1 may have made these concerns important at Time 1; but as the health status of many of the subjects improved before Time 2 , life expectancy became less important.

As predicted by the literature, pain and physical dependency were strongly associated with depression levels at both Time 1 and Time 2 .

The next step in the analyses of the data was to investigate the relative importance of these key variables in predicting levels of depression at both Time 1 and Time 2 through multiple regression analysis. Thus, for Time 1 , subjective health, pain, death anxiety, physical dependency, and life expectancy were included in a stepwise regression with CES-D scores as the dependent variable. Income was also included as a measure of socioeconomic status, and social support was included because of its importance in the literature. Using stepwise regression, subjective health, pain, death anxiety, and income significantly added to the prediction of depression levels. When included with these variables, social support, controllability of general health, and physical dependency added little to the prediction of depression. Both social 
support and physical dependency were moderately associated with income, and physical dependency was also related to pain and social support. Therefore, these variables could contribute little added variance to the prediction of depression. Regression analyses for the same variables at Time 2 revealed a similar pattern of results; however, income and death anxiety became less important and physical dependency became more important as predictors of depression at Time 2 .

In order to study changes in depression over time, regression analyses of Time 2 results controlling for Time 1 values were carried out. Change in pain added $6 \%$ to the explained variance in Time 2 depression after controlling for Time 1 depression and Time 1 pain. Subjective health, death anxiety, and income added less than $1 \%$ each to the explained variance in Time 2 depression.

In summary, the four strongest predictors of depression for middle aged and elderly persons suffering an exacerbation of a physical illness were subjective health, pain, death anxiety, and income. Levels of depression three months later were best predicted by previous levels of these same variables, however, change in pain significantly added to the prediction of Time 2 depression. While the effects of these various characteristics of the individual and the disease on the level of depression 
were the primary focus of this study, the effects of these variables on LSIA-A scores were also investigated. Unlike the Harris (1975) study, life satisfaction did not decrease with age for the subjects in this study. For physically ill persons, other factors may have a much greater effect on life satisfaction so that age becomes unimportant. As anticipated, life satisfaction was more stable over time than depression.

Generally, the same variables were important in predicting life satisfaction as were important in predicting depression. However, their relative importance varied somewhat. Physical dependency and social support became more important in predicting LSIA-A scores while death anxiety and worry about medical resources became less important. Physical dependency tended to be inversely related to social support so these two variables would be expected to have opposite effects. Some of the subjects had been physically dependent for a long time, and this negative effect on their social support could have affected their overall life satisfaction.

The variables used in this study were able to predict change in life satisfaction a little better than change in depression; however, no variable was able to add more than $2 \%$ to the explained variance in Time 2 LSIA-A scores after Time 1 values for LSIA-A and the predictor variables were 
included. Pain and subjective health maintained the same importance as predictors of life satisfaction as they had for depression.

Dynamic (change focused) correlational analysis yielded a pattern of results similar to regression analysis. Compared to the group with increasing CES-D scores, the group with decreasing CES-D scores had higher subjective health scores, greater life expectancy, and more persons in their support systems at Time 2. They also showed a greater increase in iffe expectancy and in the number of persons in their support systems. In addition, the decreasing CES-D group reported less pain, death anxiety, physical dependency, worry about medical resources, progression of their iliness, and external locus of control for health at Time 2. In the interval from Time 1 to Time 2, they experienced a greater decrease in pain and physical dependency.

The group with decreasing LSIA-A scores demonstrated the same pattern as those with increasing CES-D scores. That is, when compared to the increasing LSIA-A group, the decreasing LSIA-A group had higher levels of pain, death anxiety, physical dependency, worry about medical resources, external locus of control for health, and progressiveness of the disease at Time 2. They also had lower levels of subjective health, life expectancy, fewer 
persons in their support systems, and fewer exchanges at Time 2. When compared to the group with increasing LSIA-A scores, the group with decreasing LSIA-A scores reported less decrease in paln and physical dependency and more decrease in subjective health, worry about medical resources, and number of persons and exchanges in their support systems.

Finally, it should be noted that some of these differences for the CES-D and LSIA-A change groups did not reach statistical significance because, as a whole, scores were relatively stable over time.

With the data available from this study, the general model as described in chapter I was refined and further developed. In this expanded model as outlined in Figure 8 , pain, as a characteristic of the disease, subjective health, as a perception of the disease, and death anxiety and income, as characteristics of the individual maintained their direct impact on level of depression. Based upon correlational analysis and stepwise and hierarchical regression analysis, the effect of other variables was also examined. Although their direct effect on depression was limited, they had an indirect effect through their relationship to the four primary predictor variables. Physical dependency, life effect, external locus of control for health, life expectancy, and progressiveness of the 


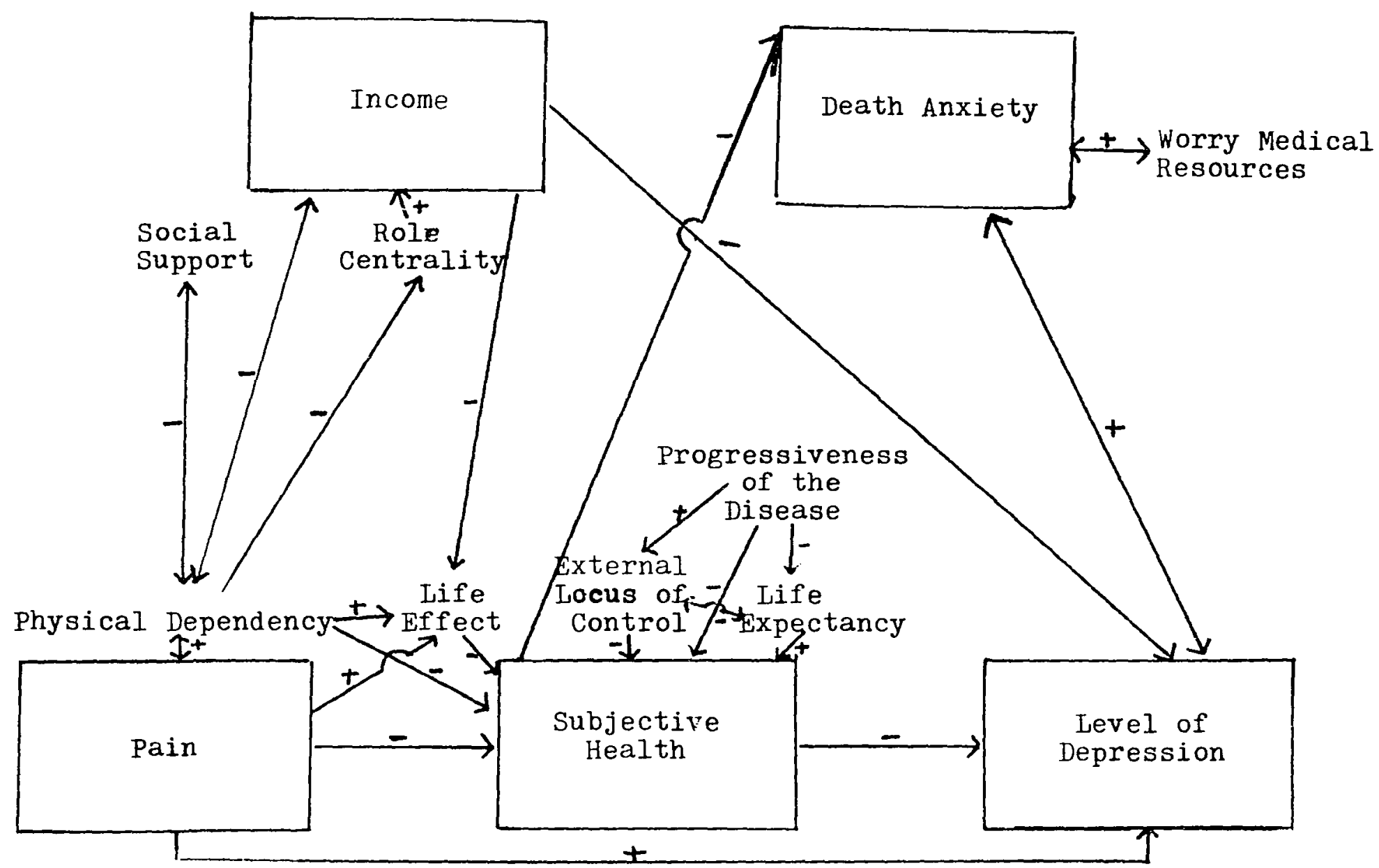

* major predictor and outcome variables in boxes

Figure '?. Model for the study. 
disease correlated strongly to subjective health, and their impact on depression was represented through subjetive health as a mediator variable. In addition to its association with subjective health, physical dependency was strongly positively related to pain and life effect and negatively related to income, social support, and role centrality. Increased progressiveness of the disease was associated with increased external locus of control for health and decreased life expectancy. Social support was strongly related to physical dependency and somewhat related to income; therefore, its effect on depression was taken up by these variables in the regression, and it had little added effect on depression. In addition to their independent effect on depression, pain and death anxiety were also strongly associated to subjective health. In sum, the refined model demonstrates a complex web of Interrelationships between factors that affect the level of depression.

Most of the variables demonstrated relative stability over time; however, change in key variables, particularly pain, did predict change in depression levels. Analyses of the change groups for depression demonstrated that the same variables predicted by the model for depression at one point in time also differentiated between stable, increasing, and decreasing groups. 
IMPLICATIONS FOR POLICY AND FUTURE RESEARCH

The descriptive data gathered on the subjects regarding their social support system, service utilization and needs, and financial concerns have many policy implications. The social support sytems of the subjects reafirmed the importance of relatives and friends in the maintenance of residence in the community. Spouses provided the majority of personal care; and if they were not present, service agencies became more important parts of the support system. While relatives and friends provided much assistance, neighbors who were not also friends provided little support. Any agency involved in the interaction of informal and formal networks should consider this pattern of support.

The importance of formal support systems was reaffirmed for many subjects, especially those with small support systems. One subject who was wheelchair-bound and could not get in and out of bed by herself survived alone in her apartment with the assistance of housekeeping, personal care, and meals on wheels from formal support systems. This subject had only fellow church members and a nephew in her informal support system.

The subjects in this study seldom utilized the transportation systems and organizations designed for the 
general elderly population. Their special needs made the automobile their preferred mode of transportation, though it was often driven by someone else. One key area of support for these persons was the provision of individualized automobile transportation. The subjects in this study seldom belonged to formal organizations so that this form of recreation and outside contact was not avallable to them. The provision of alternative modes of activity and contact for these people was a major problem. Worry about medical resources was frequent in the subjects in this study and strongly associated with depression levels. These subjects had experienced the high cost of medical care directly; and although they often had Medicare and private insurance available, medical costs still were a major expense. For some of the middle aged subjects, even though the subject had health insurance the high cost of future medical procedures could soon restrict their access to care. Though these subjects gave little indication of political involvement, they represented a group that might demand more assistance with health care costs in the future.

The relationship between income and worry about medical resources was only moderate as both income and worry about medical resources tended to decline with age. Even though the older subjects had fewer monetary 
resources, medical expenses were not as great a problem as they were for the younger subjects.

The physical illness - depression model developed in this study also has many implications for service needs and future research. The model, of course, needs further confirmation and elaboration with additional studies. Experimental and intervention research designed to modify the key variables identified in this study would be critical to the development of a causal model for depression in persons with physical iliness. These causal relationships could then serve as a basis for appropiate intervention strategies.

The model presented in this study explained only $52 \%$ of the variance in depression levels. This model needs further elaboration to find additional key factors. One area of particular interest might be the existence of previously existing factors. The stability of depression over time suggests that longitudinal studies over a longer period that included predisposing factors would be of interest.

Finally, the slgnificance of pain suggested by this study has important implications for the physical and mental health caresystems. Pain has potential control mechanisms from both the physiological and psychological perspectives yet few physically 111 persons are giver the 
opportunity to exercise control over their pain level. While not all pain can be relieved, many persons, and especially many older persons, are not given training in the means of reducing or controlling pain. Interventions to control pain level have the advantage of enhancing perceptions of control as well as reducing pain.

SUMMARY AND CONCLUSIONS

\begin{abstract}
One hundred thirty-three middle aged and elderly persons who had recently suffered an exacerbation of a physical illness were given in-depth interviews. The primary purpose of the study was to identify the intercelationships of characteristics of the individual, characteristics of the disease, and perceptions of the disease as they affected levels of depression. In order to investigate the effect of these variables over time, follow-up interviews were completed with 114 of the subjects approximately three months later. Specific variables that were measured were age, gender, income, social support, religiosity, death anxiety, role centrality, pain, physical dependency, length of iliness, health locus of control, preceived progressiveness of the disease, life expectancy, worry about medical resources, areas of life affected, and subjective health. The two outcome measures were level of depression as determined by
\end{abstract}


CES-D scores and life satisfaction as determined by LSIA-A scores.

Correlations with CES-D scores indicated that, as anticipated, lower depression levels were associated with higher levels of age, income, social support, religiosity, role centrality, internal locus of control for health, subjective health, and Iffe expectancy. Conversely, higher depression levels were related to higher levels of pain, physical dependency, death anxiety, perceived progressiveness of the disease, worry about medical expenses, external locus of control for health, and length of illness. Generally, age, gender, and length of illness demonstrated little relationship to level of depression.

Regression analyses identified the four best predictors of depression levels at Time 1 to be subjective health, pain, death anxiety, and income. other variables were indirectly related to depression through their impact on these four variables. Depression levels at Time 2 were best predicted by depression levels at Time 1 . Changes in pain added over $6 \%$ to the prediction of depression levels at Time 2 while change in subjective health and death anxiety added only $1 \%$ each after controlling for level of depression at Time 1.

Analyses of change groups using dynamic (change focused) correlational analysis demonstrated that the 
variables important in the model for depression at one point in time also differentiated between groups decreasing or increasing in depression over time. Analysis of variance of these change groups showed that pain, progressiveness of the disease, and health locus of control were able to significantly discriminate between change groups.

In conclusion, this study indicated that physically ill older persons are at risk for developing depression. Approximately half of the sample were judged to be at risk for clinical depression, and over 20 percent of the respondents qualified as being clinically depressed. This risk of depression declined slightly with age. When measured at one point in time, subjective health, pain, death anxiety, and income best predicted level of depression. Factors associated with change in depression over time included pain, progressiveness of the disease, and health locus of control. Additional research is needed to confirm and elaborate the model presented in this study. As the important factors relating physicaliliness and depression are further specified, appropriate intervention strategies designed to prevent depression in physically ill older persons may be developed. 


\section{REFERENCES}

Adams, D. (1969). Analysis of a life satisfaction index. Journal of Gerontology, $24,470-474$.

Aday, R. (1984-85). Belief in afterlife and death anxiety: correlates and comparisons. Omega, 15, 67-75.

American Psychiatric Association. (1980). Diagnostic and statistical manual of mental disorders (3rded.). Washington, DC: Author.

Anderson, D. F., \& Davidson, R. (1975). Concomitant physical states. In J. Howells (Ed.), Modern perspectives in psychiatry of old age. New York: Brunner/Mazel.

Aneshensel, C., \& Frericks, R. (1982). Stress, support, \& depression: a longitudinal causal model. Journal of Community Psychology, 10, 363-376.

Aneshensel, C., Frericks, R., \& Huba, G. (1984). Depression and physical illness: a multiwave, nonrecursive causal model. Journal of Health and Social Behavior, $25,350-371$.

Blazer, D. (1982). Social support and mortality in an elderly community population. American Journal of Epidemiology, $115,684-694$.

Blazer, D. (1983). Impact of late life depression on the social network American Journal of Psychiatry, 140 , $162-166$.

Blazer, D., \& Williams, C. (1980). Epidemiology of dysphoria and depression in an elderly population. American Journal of Psychiatry, $137,439-444$.

Blumenthal, M. $\quad$ D. (1975). Measuring depressive symptomatology in a general population. Archives of General Psychiatry, $32,971-978$.

Bollerup, T. (1975). Prevalence of mental illness among 70-year-olds domiciled in nine Copenhagen suburbs. Acta Psychologica Scandinavica, 51, 327-339. 
Boyd, J. \& Welssman, M. (1981). Epidemiology of affective disorders: a reexamination \& future directions. Archives of General Psychiatry, 38, 1039-1046.

Brody, E., \& Kleban, M. (1983). Day to day mental and physical health symptoms of older people: a report of health logs. The Gerontologist, 23, 75-85.

Cape, R., \& Henschke, P. (1980). Perspective of health in old age. Journal of the American Geriatrics Society, $28,295-299$.

Cassileth, B., Lusk, E., Strouse, T., Miller, D., Brown, L., Cross, P., \& Tenaglia, A. (1984). Psychosocial status in chronic illness, a comparative analysis of six diagnostic groups. New England Journal of Medicine, 311, 506-511.

Cavenaugh, S. (1983). The Prevalence of emotional and cognitive dysfunction in a general medical population. General Hospital. Psychiatry, 5, 15-24.

Cay, E., Vetter, N., Philip, A., \& Dugard, P. (1972). Psychological status during recovery from an acute heart attack. Journal of Psychosomatic Research, 16, $425-435$.

Chapman, N., Pancoast, D., \& Parker, P. (1983). Supporting caregivers of the elderly (Final report for the Regional Institute for Human Services). Portland, OR: Portland State University.

Cheah, K., \& Beard, 0. (1980). Psychiatric findings in the population of a geriatric evaluation unit. Journal of the American Geriatrics Society, 28, 153-156.

Cohen, F., \& Lazarus, R. (1979). Coping with the stresses of illness. In Stone, Cohen, \& Adler (Eds.), Health psychology, a handbook. San Francisco: Josse $\overline{y-B a s s}$ Publishers.

Cohen, C., Teresi, J., \& Holmes, D. (1985). Social networks, stress, and physical health: a longitudinal study of an inner city elderly population. Journal of Gerontology, 40, 478-486.

Comstock, G., \& Helsing K. (1976). Symptoms of depression in two communities. Psychological Medicine, 6, 51-563. 
Conlin, M., \& Fennell, E. (1983). Depression, anxiety and health locus of control orientation in an out-patient elderly population. Paper presented at the 36 th Annual Meeting of the Gerontological society of America, San Francisco.

Conlin, M., \& Fennell, E. (1985). Anxiety, depression and health locus of control orientation in an out-patient elderly population. Journal of the Florida Medical Association, $72,281-2 \overline{88}$.

C.raig, T., \& Abeloff, M. (1974). Psychiatric symptomatology among hospitalized cancer patients. American Journal of Psychiatry, 13, 1323-1327.

Craig, T. \& Van Natta, P. (1976). Presence and persistence of depressive symptoms in patient and community populations. American Journal of Psychiatry, 133, $1426-1429$.

Crowne, D., Marlowe, D. (1960). A new scale of social desirability independent of psychopathology. Journal of Consulting Psychology, 24, 349-354.

Davis, S. (1984). Measuring depression in the elderly: psychometric and psycho-social issues, part III, psychometric considerations. Paper presented at the meeting of the Gerontological Society of America, San Antonio, Texas.

Dean, A., \& Ensel, W. (1982). Modelling social support, life events, competence, and depression in the context of age and sex. Journal of Community Psychology, $10,392-408$.

Decker, S. (1982). Social support and well-being in middle aged and elderly spinal cord injured persons: a social psychological analysis. Unpublished doctoral dissertation, Portland State University.

Department of Health, Education, \& Welfare. (1979). Data from the national health survey - basic data on depressive symptomatology, United States 1974-75. Vital and Health Statistics. (DHEW Publ \#80-1666, Series 11, \#16). Washington, DC: US Government Printing office. 
Department of Health \& Human Services. (1982). Current estimates from the national health interview survey. Vital \& Health Statistics. (DHHS Publ \#82-1569, Series 10, \#141). Washington, DC: US Government Printing office.

Department of Health \& Human Services. (1983). Prevalence of selected impairments, United States, 1977 . Vital \& Health Statistics. (DHHS Pub1 \#81-1562, Series 10, \#134). Washington, DC: US Government Printing Office.

DiMatteo, M., \& Hays R. (1981). Social support and serious iliness. In B. H. Gottlieb (Ed.) Social Networks and Social Support. Beverly Hills: Sage Publications.

Doehrman, S. (1977). Psycho-social aspects of recovery from coronary heart disease: a review. Social Science \& Medicine, $11,199-218$.

Dohrenwend, B. (1975). Sociocultural and social psychological factors in the genesis of mental disorders. Journal of Health \& Social Behavior, 16 , $365-92$.

Dovenmuehle, R., \& Verwoerdt, A. (1963). Physical illness and depressive symptomatology, factors of length of illness and frequency of hospitalization. Journal of Gerontology, $18,260-266$.

Dunn, S., \& Turtle, J. (1981). The myth of the diabetic personality. Diabetes Care, 4, 640-646.

Eaton, W., \& Kessler, L. (1981). Rates of depression in a national sample. American Journal of Epidemiology, $114,526-538$.

Erikson, E. (1968). Generativity and ego-integrity. Chicago: University of Chicago Press.

Essen-Moller, E., \& Hagnel1, 0. (1961). The frequency of mental disorders in old age. Acta Psychologica Scandinavica, Supp1. $162,28-32$.

Fauman, M. (1983). Psychiatric components of medical and surgical practice, II: referral and treatment of psychiatric disorders. American Journal of Psychiatry, $140,760-763$. 
Flaherty, J., Gaviria, F., Black, E., Altman, E., \& Mitcheli, T. (1983). The role of social support in the functioning of patients with unipolar depression. American Journal of Psychiatry, 140,473-476.

Gallagher, D., Thompson, L., \& Levy, S. (1980). Clinical psychological assessment of older adults. In L. W. Poon (Ed.) Aging in the Eighties. Washington DC: American Psychological Association.

Garber, J., \& Seligman, M. (1980). Human helplessness, theory and applications. New York: Academic Press

Gardiner, B. (1980). Psychological aspects of rheumatoid arthritis. Psycholological Medicine, 10, 159-163.

George, L. (1981). Subjective well-being: conceptual and methodological issues. In C. Eisdorfer (Ed.), Annual review of gerontology and geriatrics (Vol 2$)$ (pp 345-382). Springer, New York, N.Y.

George, L., Landerman, R., \& Melville, M. (1984) Age differences in the relationships beteen physical illness and psychiatric disorder. Unpublished manuscript, Dept of Psychiatry, Duke University, Durham, NC.

Goldberg, E., Van Natta, P., \& Comstock, G. (1985). Depressive symptoms, social networks and social support of elderly women. American Journal of Epidemiology, $121,448-456$.

Goldstein, M. (1979). The sociology of mental health and iliness. Annual Review of Sociology, 5, 381-409.

Gore, S. (1973). The influence of social support and related variables in ameliorating the consequences of job loss. Unpublished doctoral dissertation, University of Pennsylvania.

Gore, S. (1978). The effect of social support in moderating the health consequenses of unemployment. Journal of Health \& Social Behavior, $19,157-165$. 
Gurland, B., Copeland, J., Kuriansky, J., Kelleger, M., Sharpe, L., \& Dean, L. (1983). The mind and mood of aging. New York: Haworth Press.

Gurland, B., \& Toner, J. (1982). Depression in the elderly: a review of recently published studies. In C. Eisdorfer (Ed.), Annual Review of Gerontology and Geriatrics (Vo1 3). New York: Springer.

Harkins, S., \& Warner, M. (1980). Age \& pain. In C. Eisdorfer (Ed.), Annual review of gerontology and geriatrics (Vol. 1). Springer, New York.

Harris, L., \& Associates. (1975) The myth and reality of aging in America. Washington DC: National Council on the Aging, Inc.

Hauser, S., \& Pollets, D. (1979). Psychological aspects of diabetes mellitus: a critical review. Diabetes Care, $2,227-232$.

Haynes, S., Feinleib, M., \& Kannel, W. (1980). The relationship of psychosocial factors to coronary heart disease in the Framingham study, III, eight year incidence of coronary heart disease. American Journal of Epidemiology, 111, 37-58.

Helgason, L. (1977). Psychiatric services \& mental illness in Iceland. Acta Psychologica Scandinavica, Suppl. $268,11-127$.

Hirschfeld, R., \& Cross, C. (1982). Epidemiology of affective disorders, psychosocial factors. Archives of General Psychiatry, 39, 35-46.

House, J., \& Wells, J. (1979). Occupational stress, social support, and health. In Mclean, Black, Colligan (Eds.), Reducing occupational stress, DHEW Publ. \# $78-140$.

Hoyt, D., \& Creech, J. (1983). The life satisfaction index: a methodological and theoretical critique. Journal of Gerontology, 38, 111-116.

Johnson, C. (1983). Dyadic family relationships and social support. The Gerontologist, $23,377-383$. 
Kavanaugh, T., Shephard, R., \& Tuck, J. (1975). Depression after myocardial infarction. Canadian Medical Association Journal, $113(1), 23-27$.

Kessler, R., \& Mcleod, J. (1985). Social support in community samples. In Cohen \& Syme (Eds.), Social Support and Health (pp. 219-240). Orlando, FL: Academic Press.

Kramlinger, K., Swanson, D., \& Maruta, T. (1983). Are patients with chronic pain depressed? American Journal of Psychiatry, 140, 747-749.

Krantz, D., Baum, A., \& Wideman, M. (1980). Assessment for preference for self-treatment and information in health care. Journal of Personality and Social Psychology, 39, 977-990.

Langer, E., Janis, I., \& Wolfer, J. (1975). Reduction of psychological stress in surgical patients. Journal of Experimental Social Psychology, 11, 155-165.

LaRocco, J., House, J., \& French, J. (1980). Social support, occupational stress, and health. Journal of Health \& Social Behavior, 21, 202-218.

Larson, R. (1978). Thirty years of research on the subjective well-being of older americans. Journal of Gerontology, 33, 109-125.

Leavy, R. (1983). Social support and psychological disorder: a review. Journal of Community Psychology, $11,3-21$.

Liang, J. (1984). Dimensions of the life satisfaction index A: a structural formulation. Journal of Gerontology, $39,613-622$.

Lin, N., Ensel, W., Simone, R., \& Kuo, W. (1979). Social support, stressful life events, and illness: a model and empirical test. Journal of Health and Social Behavior, 20, 108-119.

Linn, M., Hunter, K, \& Harris, R. (1980). Symptoms of depression and recent 1 ife events in the community elderly. Journal of Clinical Psychology, 36, 675-682. 
Littlefield, C., Fleming, S. (1984-85). Measuring fear of death: a multidimensional approach. Omega, 15, $131-138$.

Mccrae, R. (1982). Age differences in the use of coping mechanisms. Journal of Gerontology, 37, 454-460.

McIvor, G., Riklan, M., \& Reznikoff, M. (1984). Depression in multiple sclerosis as a function of length and severity of illness, age, remissions, and perceived social support. Journal of Clinical Psychology, 40, $1028-1033$.

Moos, R., \& Solomon G. (1964). Personality factors associated with rheumatoid arthritis. Journal of Chronic Diseases, $17,41-55$.

Molinari, V., Niedereke, G. (1984-85). Locus of control, depression, and anxiety, in young and old adults: a comparison study. International Journal of Aging \& Human Development, $20,41-52$.

Murawski, B., Chazan, B., Balodimos, M., \& Ryan, J. (1970). Personality patterns in patients with diabetes melitus of long standing duration. Diabetes, 19 , $259-263$.

Myers, J., \& Weissman, M. (1980). Use of a self-report symptom scale to detect depression in a community sample. American Journal of Psychiatry, 137, $1081-1084$.

National Decisions Systems. (1982). 1980-US Census Population \& Housing Characteristics, Vol 1. Washington, DC: National Decision Systems.

Nerenz, D., \& Leventhal, H. (1983). Self-regulation theory in chronic illness. In T. Burish \& L. Bradley (Eds.), Coping with Chronic Disease, Research \& Applications. New York: Academic Press.

Neugarten, B. (1979). Time, age, and the life cycle. American Journal of Psychiatry, 136, 887-894.

Neugarten, B., Havighurst, R., \& Tobin, S. (1961). The measurement of life satisfaction. Journal of Gerontology, 16,134-143. 
Nie, N., Hull, C., Jenkens, J., Steinbrenner, K., \& Bent, D. (1975). Statistical Package for the Social Sciences. New York: McGraw-Hill.

Niven, R. (1976). Psychologic adjustment to coronary artery disease. Post Graduate Medicine, 60, 152-157.

Noh, S., Wood, D., \& Turner, R. (1984). Depression among the physically disabled: somatic and psychological contributions. Paper presented at the American Public Health Association Meeting, Anaheim, CA.

Noll, G., \& Dubinsky, M. (1985). Prevalence, and predictors of depression in a suburban county. Journal of Community Psychology, 13, 13-19.

Okun, M., Stock, W., Haring, M., \& Witter, R. (1984). Health and subjective well-being: a meta-analysis. International Journal of Aging and Human Development, $19,111-132$.

Palmore, E. (1981). Social patterns in normal aging: findings from the Duke longitudinal study, Durham: Duke University Press.

Palmore, E., \& Kivett, V. (1977) Change in life satisfaction: a longitudinal study of persons aged 46-70. Journal of Gerontology, 32, 311-316.

Pearlin L., \& Schooler, C. (1978). The structure of coping. Journal of Health \& Social Behavior, 19, 2-21.

Pfelffer, E. (1977). Psychopathology and social pathology. In Birren \& Schaie (Eds.), Handbook of the Psychology of Aging. New York: Van Nostrand Reinhold.

Pfeiffer, E., \& Busse, E. (1973). Mental disorders in later life- affective disorders: paranoid, neurotic and situational reactions. In Busse \& Pfeiffer (Eds.), Mental Illness in Later Life, Washington DC: American Psychiatric Association.

Plumb, M., \& Holland, J. (1977). Comparative studies of psychological function in patients with advanced cancer I: self-reported depressive symptoms. Psychosomatic Medicine, 39, 264-276. 
Plumb, M., \& Holland, J. (1981). Comparative studies of psychological function in patients with advanced cancer II: interview rated current and past psychological symptoms. Psychosomatic Medicine, 43, $243-254$.

Radloff, L. (1977). The CES-D scale: a self-report depression for research in the general population. Applied Psychological Measurement, 1, 385-401.

Radloff, L. \& Rae, D. (1981). Components of the sex difference in depression. Research in Community \& Mental Health, 2, 111-137.

Rhudick, P. \& Dibner, A. (1961). Age, personality, and health correlates of death concerns in normal aged individuals. Journal of Gerontology, 16, 44-49.

Roberts, R., \& Vernon, S. (1983). The center for epidemiologic studies depression scale: its use in a community sample. American Journal of Psychiatry, $140,41-46$.

Rodda, B., Miller, M., \& Bruhn, J. (1971). Prediction of anxiety and depression patterns among coronary patients using a Markov process analysis. Behavioral Science, $16,482-489$.

Romano, J. \& Turner, J. (1985). Chronic pain and depression: does the evidence support a relationship. Psychological Bulletin, $97,18-34$.

Rosen, J., \& Bibring, G. (1966). Psychological reactions of hospitalized male patients to a heart attack. Psychosomatic Medicine, 28, 808-821.

Roth, M., \& Kay, D. (1956). Affective disorder arising in the senium. Journal of Mental Science (British Journal of Pschiatry), 102, 141-150.

Roy, R. (1984). Chronic pain and depression: a review. Comprehensive Psychiatry, 25, 96-105. 
Rutter, B. (1977). Some psychological concomitants of chronic bronchitis. Psychological Medicine, 7, $459-464$.

Salzman, C., \& Shader, R. (1978). Depression in the elderly: relationship between depression, psychologic defense mechanisms and physical illness. Journal of the American Geriatrics Society, 26, 253-260.

Sanders, C., Mills, J., Martin, R., \& Horne, D. (1975). Emotional attitudes in insulin-dependent diabetics. Journal of Psychosomatic Research, 19, 241-246.

Sauer, W. (1977). Morale of the urban aged: a regression analysis by race. Journal of Gerontology, 32 , $600-608$.

Schaefer, C., Coyne, J., \& Lazarus,R. (1981). The health related functions of soctal support. Journal of Behavioral Medicine, 4, 381-407.

Schlossberg, N. (1981). A model for analyzing human adaptation to transition. The Counseling Psychologist, $9,5-18$.

Schulz, R. (1976). Effects of control and predictability on the physical and psychological well-being of the institutionalized aged. Journal of Personality and Social Psychology, $33,363-373$.

Schulz, R., \& Brenner G. (1977). Relocation of the aged: a review and theoretical analysis. Journal of Gerontology, $32,323-333$.

Schulz, R. \& Rau, M. (1985). Social support through the life course. In Cohen \& Syme (Eds.) Social Support \& Health (pp. 129-149). Orlando, FL: Academic Press.

Sparacino, J. (1982). The type A (coronary prone), behavior pattern, aging and mortality. Journal of the American Geriatrics Society, $27,251-257$.

Sterbach, A. (1978). Illness and health behavior in septuagenarians. Journal of Gerontology, 33, 57-61.

Stenbach, A. (1980). Depression and suicidal behavior in old age. In Birren \& Sloane (Eds.), Handbook of Mental Health and Aging. Englewood Cliffs, NJ: Prentice Hall. 
Steuer, J., Bank, L., Olsen, E., \& Jarvik, L. (1980). Depression, physical health, \& somatic complaints in the elderly, a study of the Zung self-rating depression scale. Journal of Gerontology, 35 , $683-688$.

Stewart, B. (1980). Dynamic (change focused) correlational analysis. Personal communication.

Templer, D. (1970). The construction and validation of the death anxiety scale. Journal of General Psychology, $92,165-177$.

Templer, D. (1971). Death anxiety as related to depression and health of retired persons. Journal of Gerontology, 26,521-523.

Templer, D., \& Ruff, C. (1971). Death anxiety scale means, standard deviations, and embeding. Psychological Reports, $29,173-174$.

Thoits, P. (1982). Conceptual, methodological, \& theoretical problems in studying social support as a huffer against life stress. Journal of Health \& Social Behavior, 23, 145-159.

Thomae, H. (1980). Personality and adjustment to aging. In Birren \& Sloane (Eds.), Handbook of Mental Healthand Aging, Englewood Cliffs, NJ: Prentice Hall.

U.S. Bureau of the Census. (1983a). 1980 census of population: characteristics of the population, United States summary. (Dept of Commerce Publ No. PC80-1-C1). Washington, DC: US Government Printing office.

U.S. Bureau of the Census. (1983b). 1980 Census of the Population: general population characteristic, Oregon. (Dept of Commerce Publ No. PC80-1-B39). Washington, DC: US Government Printing Office.

Verwoerdt, A. (1973). Emotional responses to physical illness. In C. Eisdorfer \& W. Fann (Eds.), Psychopharmacology and aging. New York: Plennum Press. 
Wailston, B., Wallston, K., Kaplan, G., \& Maides, S. (1976). Development and validation of the health locus of control (HLC) scale. Journal of Consulting and Clinical Psychology, 44, 580-585.

Warheit, G., Holzer, C., \& Schwab,J. (1973). An analysis of social class \& racial differences in depressive symptomatology: a community study. Journal of Health \& Human Behavior, 14, 291-299.

Wass, H., \& Myers, J. (1982). Psychosocial aspects of death among the elderly: a review of the literature. Personnel and Guidance Journal, 61, 131-137.

Watson, D. (1982). Neurotic tendencies among chronic pain patients: an MMPI analysis. Pain, 14, 365-385.

Weissman, M., \& Myers, J. (1978). Affective disorders in a U.S. urban community. Archives of General Psychiatry, $35,1304-1311$.

Weisman, M., Sholomskas, D., Pottenger, M., Prusoff, B., \& Locke, B. (1977). Assessing depressive symptoms in five psychiatric populations: a validation study. American Journal of Epidemiology, 106, 203-214.

West, S., \& Wicklund, R. (1980). A primer of social psychological theories. Monterey, CA: Brooks/Cole Publishing Co.

Westbrook, M., \& Viney,L. (1982). Psychological reactions to the onset of chronic illness. Social science \& Medicine, $16,899-905$.

Wilkinson, D. (1981). Psychiatric aspects of diabetes mellitus. British Journal of Psychiatry, $138,1-9$.

Williams, A., Ware, J., \& Donald, C. (1981). A model of mental health, life events, and social supports applicable to general populations. Journal of Health \& Social Behavior, $22,324-336$.

Wills, T. (1985). Supportive functions of interpersonal relationships. In Cohen \& Syme (Eds.), Social Support and Health (pp. 61-82). Orlando, FL: Academic Press.

Winnubst, J., Marcilissen, F., \& Kleber, R. (1982). Effects of social support in the stressor strain relationship. Social Science \& Medicine, 16, 475-482. 
Woodforde, J., \& Merskey, H. (1972). Personaiity traits of patients with chronic pain. Journal of Psychosomatic Research, $16,167-172$.

Wortman, C., \& Conway, T. (1985). The role of social support in adaption and recovery from physical illness. In Cohen \& Syme (Eds.), Social Support and Health (pp.281-302). Orlando, FL: Academic Press.

Wright, B. (1960). Physical disability - a psychological approach. New York: Harper Row.

Zautra, A., \& Hempel, A. (1984). Subjective well-being and physical health: a narrative literature review with suggestions for future research. International Journal of Aging and Human Development, 19, 95-110. 
APPENDIX A

Informed Consent

I hereby agree to participate in the study, nThe Effect of Chronic Medical Illness on the Lives of Elderly Persons," conducted by Ana Williams and Richard Schulz, Director or the Institute on Aging at portland state university. I understand that the purpose of the study is to learn more about the impact of various chronic medical diseases on the lives of elderly pergons residing in the community.

I realize that parts of the interview way be sensitive, and I reserve the right to talk only about those things with which I feel confortable. My participation in the study will involve two persona: interviews of approximately $11 / 2$ hours long, about three gonths apart. While I may rot recelve any direct benefit rom participating in the study, I realize that my participation will help increase knowiedge which may benefit others in the future.

I understand that my responses will be completely confidentia: and that neither my name nor identirying personal information will be used when the findings of the study are described. I also undersiand that my participation is voluntary and that I can withdran at any time. I understand that refusal to participate or a decision to withdraw from the study will not involve any penalty or ioss of benefits to which I am otherwise entitled.

I understand that my physician has been contacted and agrees to wy participation in the study. I also understand ay hospital record will be reviewed to accurately establish mi dedical or surgical diagnosis. 
The Interviewer has offered to answer any

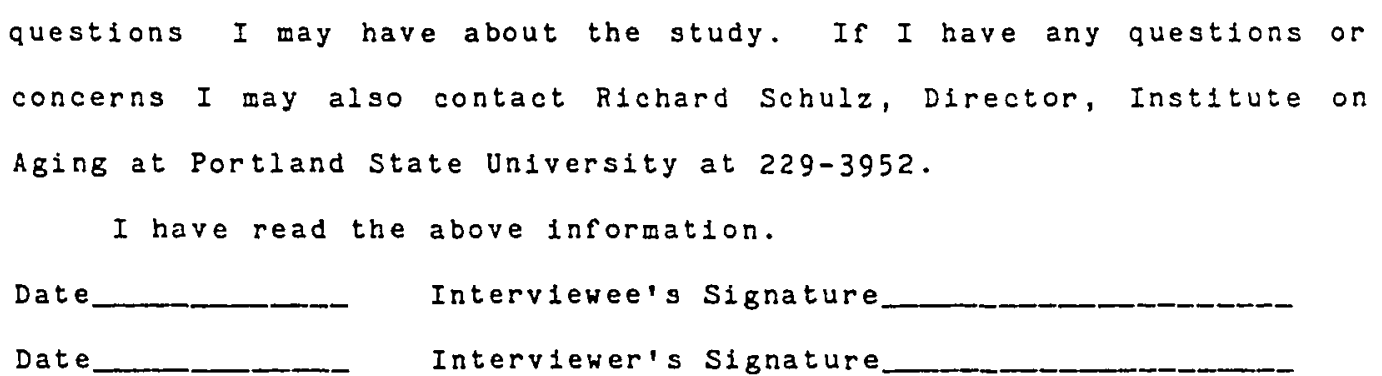


APPENDIX B

Effects of Chronic Illness

Initial Interview

Subject ID
Interviewer
Date
Time Interview Begun

Time Interview Completed

Diagnoses for referral

CHD, CLD, CA, ARTH, DIAB, FRX

Other

Referred by

\begin{abstract}
I would like to thank you for taking time to talk with me. The purpose of this study is to gain information about how chronic illness has affected many various aspects of your life. I have a number of questions to ask you so please let me know if you need to rest, take a break, or need further information. Let me reassure you that all information will be confidential and will never be identifled with you by name.
\end{abstract}

OBTAIN SIGNATURE ON RELEASE AND CONSENT FORM.

The first set of questions will deal with general background information.

1. What is your date of birth?

Age

2. $\operatorname{sex}$ (Interviewer code)

$1=$ female

$2=\operatorname{male}$

3. What is your ethnic background?
1 = Caucasian
$2=\mathrm{Black}$
$3=$ Hispanic
4 = American Indian
$5=$ Asian
$6=$ other
$8=$ refused
$9=$ missing

4. What is your marital status? (HAND CARD)
$1=$ single, never married
5 = divorced
2 = married
$3=$ widowed
$4=$ separated
$6=$ living as married
$8=$ refused
$9=$ missing

5. How long have you been ?

years months 
6. This question is about the people who live with you. What are the first names of all other persons who live with you on a regular basis? $00=$ nobody

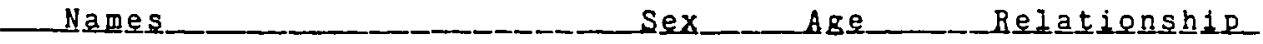

1 .

2.

3

4

5.

\section{Relationship Codde}

Gender

$01=$ spouse
$02=$ child
$03=$ grandchild
$04=$ sibling
$05=$ friend
$06=$ spouse's sibling
$07=$ spousal friend
$08=$ parent

$09=$ grandparent

$10=$ child's spouse

$1=$ remale

11 = other in-law

12 = niece/nephew

13 = aunt/uncle

$14=$ other

$88=$ refused

08 = parent

$99=$ missing

7. Do you have any children, stepchildren, or adopted children?
$0=$ no
1 = yes-how many?

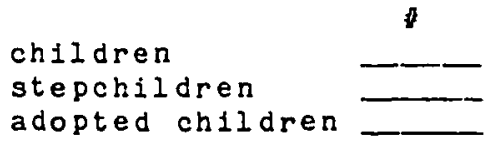

8. What is the highest level of education that you have completed?

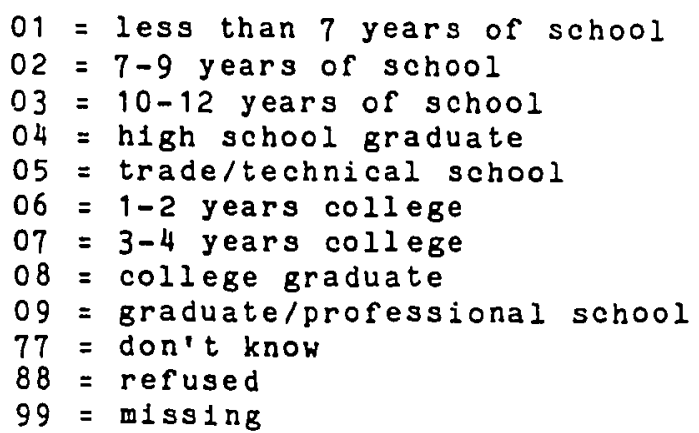


14. Do you own or rent your residence?

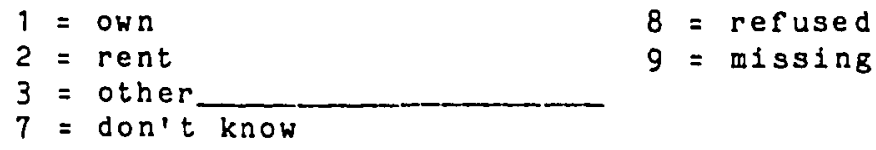

$8=$ refused

$g=$ missing

15. How long have you lived here?

16. What forms of transportation do you regularly use? (HAND CARD) (CIRCLE ALL THAT APPLY)

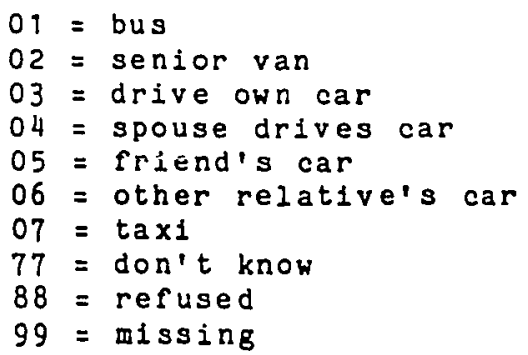

Now, I would like to ask you some questions about your activities.

17. What is your religious preference?

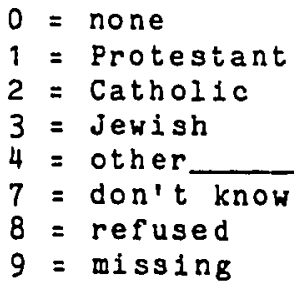

18. How important is religion in your life?

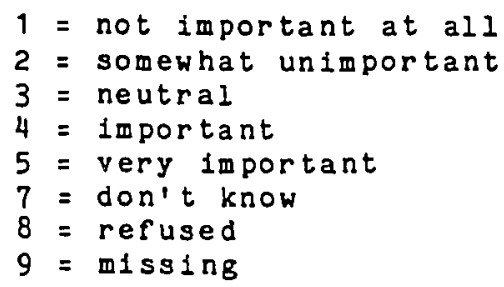


Subject ID

22. How of ten do you drink alcoholic beverages? (HAND CARD)

\section{Erequency}

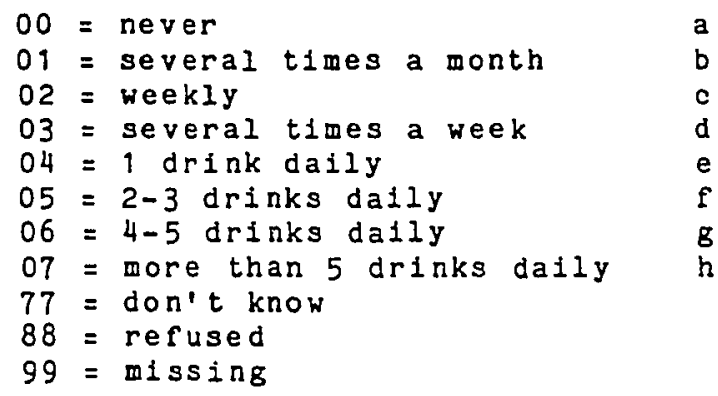


23. Now I would like to ask you about your ability to perform the following activities of daily living.

Do you need help or use an assistive device for:

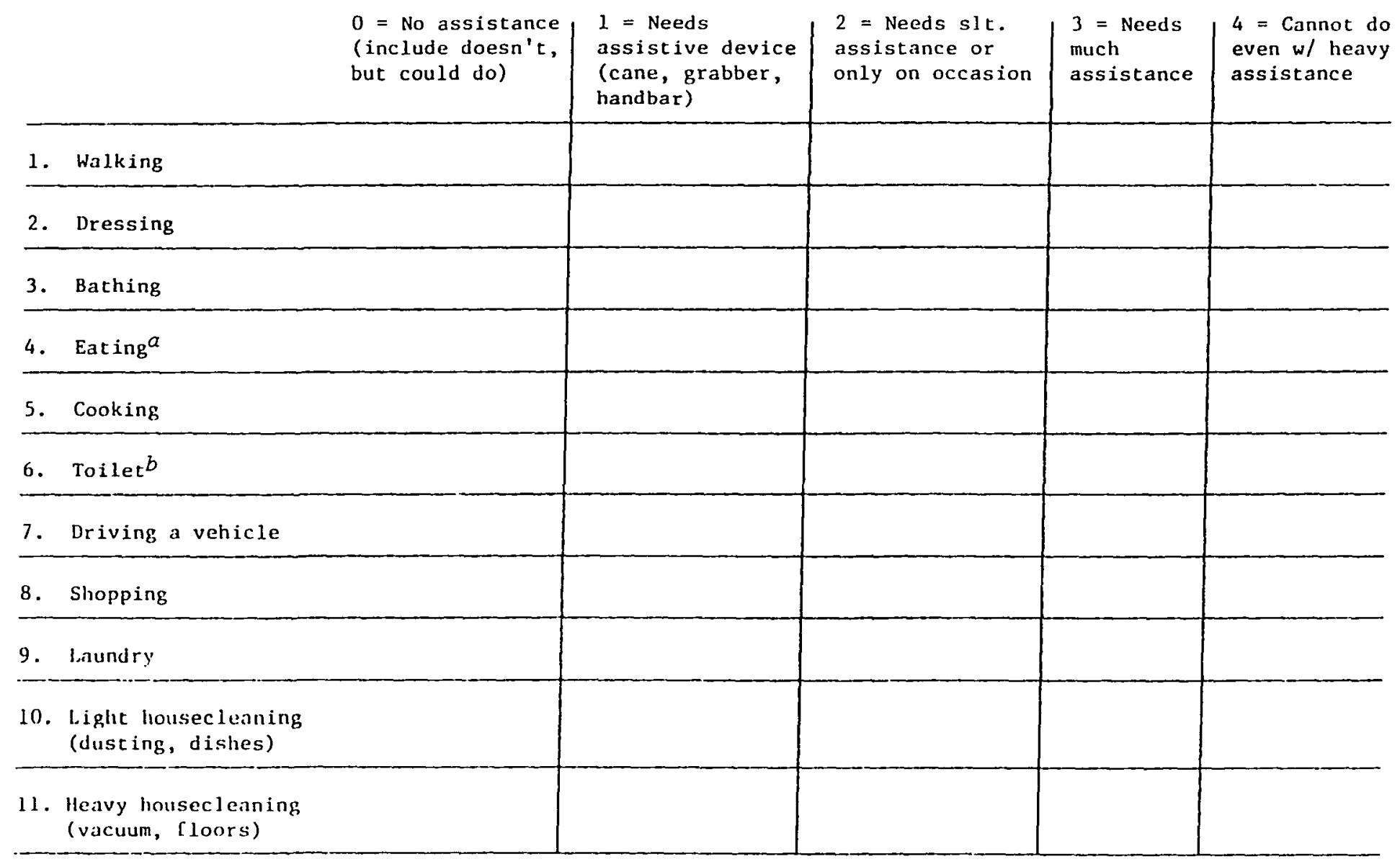

$a=$ code 2 for needs food cut or pureed

$b=$ code 4 for bedpan use

Total 
Now, as a change, I would like to ask you to complete these two questionnaires. ADMINISTER SOCIAL DESIRABILITY, HLC.

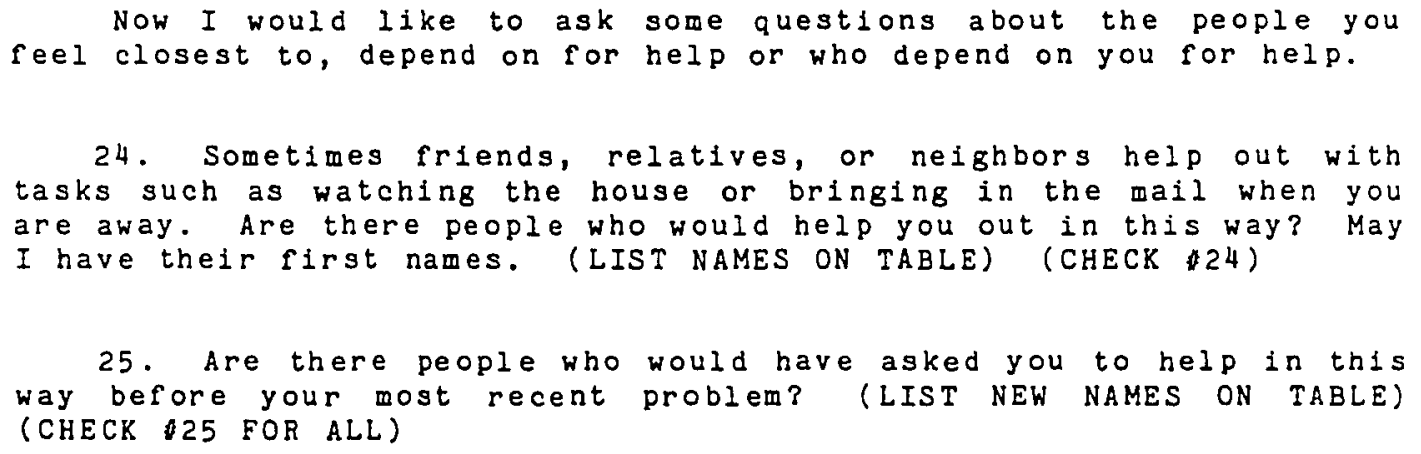

26. When you are concerned about a personal matter, is there anyone you would talk to about it? (LIST NEW NAMES) (CHECK 26 FOR ALL)

27. Is there anyone you would ask for advice in making important decisions? (LIST NEW NAMES) (CHECK 27 FOR ALL)

28. Is there anyone who would come to you for advice or to discuss personal matters? (LIST NEW NAMES) (CHECK 28 FOR ALL)

29. Before your recent health problem, were there people you would help if they were sick for a short time? (LIST NEW NAMES) (CHECK 29 FOR ALL)

30. Before your recent health problem, were theme people you would help if they were sick for a long time, say weeks or months? (LIST NEW NAMES) (CHECK 34 FOR ALL)

31. Is there anyone not on this list who is especially important to you? (ADD TO LIST) 
32. Did anyone on this list help you during your most recent problems. In which of these ways? (HAND CARD)

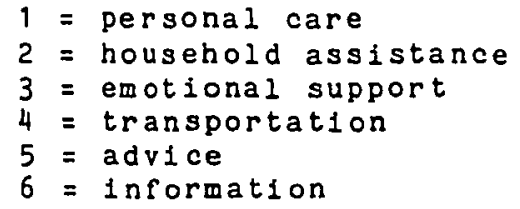

33. Who do you think would have helped you in these ways if you had needed more help?

34. COMPLETE CHART. IF MORE THAN 10 NAMES ON LIST--ASK FOR 10 MOST IMPORTANT PERSONS ON LIST. PUT STAR BY NAME AND COMPLETE ONLY FOR THESE 10. 


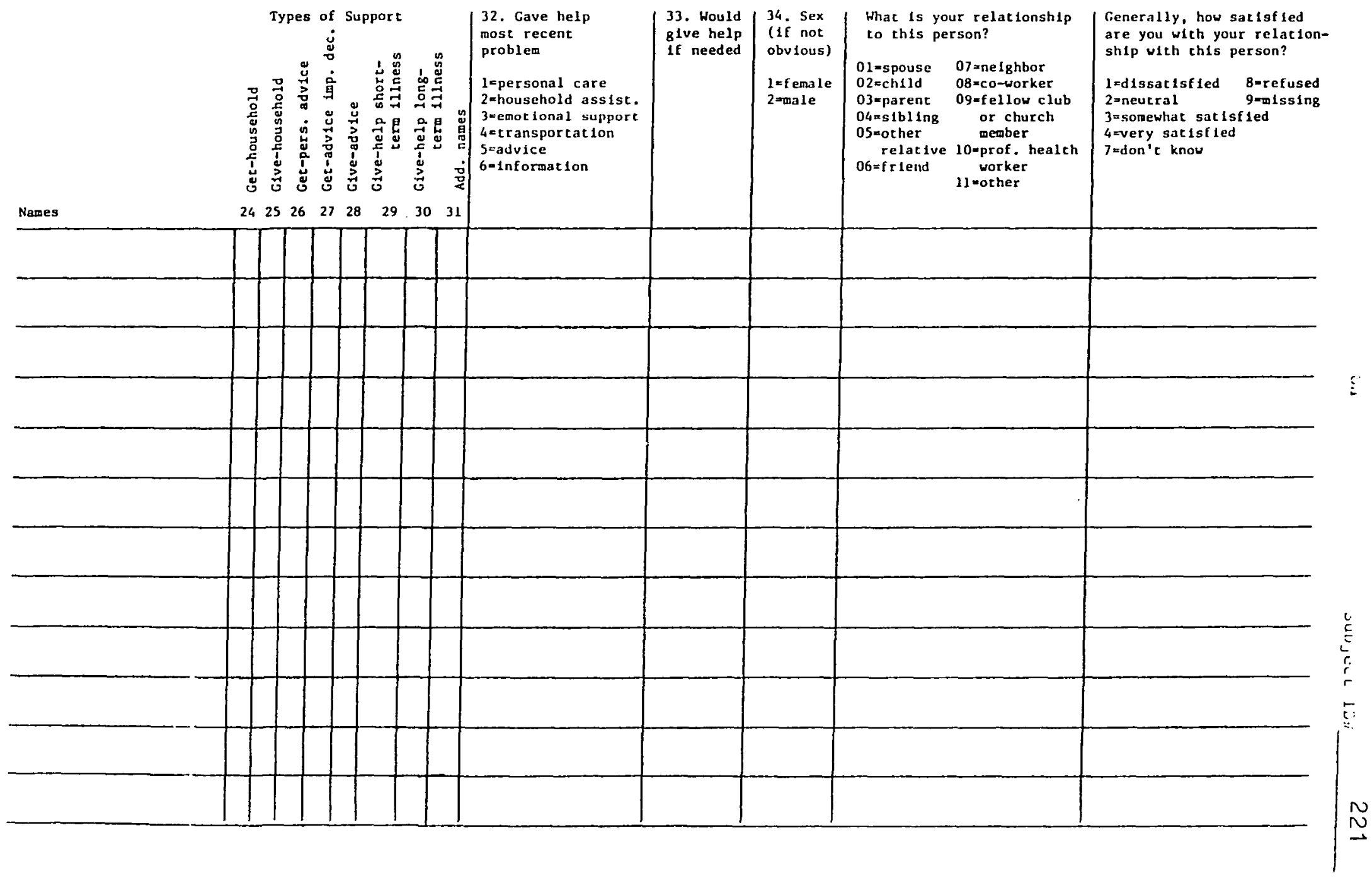


Next, I would like to ask some questions about your health.

35. In six months, do you expect your to be:

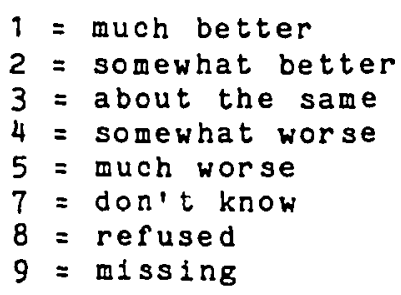

36. Overall, how would you rate your health?

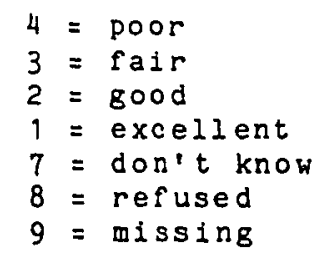

37. Compared to other people your age, would you rate your health as :

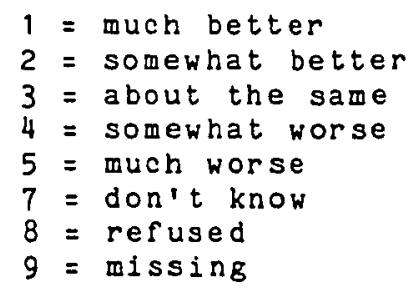

38. Do you believe that in the next 6 months, your overall health is likely to:

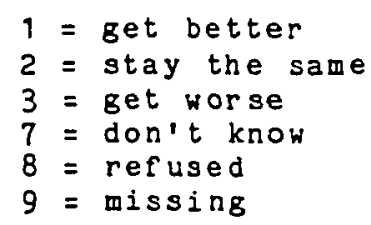

39. Compared to most people with ___, would you rate yourself as:

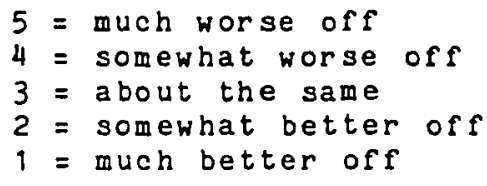


The next questions will deal with your illness, its history, and your feelings about it.

40. How long ago did you first find out you had ?

$\begin{array}{ll}\longrightarrow & \text { years } \\ \longrightarrow & \text { months } \\ \longrightarrow & \text { days }\end{array}$

41. How did you find out you had ? (HAND CARD)

1 = learned from health professional

2 = suspected it myself, confirmed by health professional

3 = discussion with friend or relative, confirmed by health professional

4 = other

$7=$ don't know

$8=$ refused

$9=\operatorname{missing}$

42. What other chronic ilinesses, if any, do you have? (IF NONE, PROBE: HYPERTENSION, HEART PROBLEMS?)

$00=$ none

II loess H으느음 have you had it?

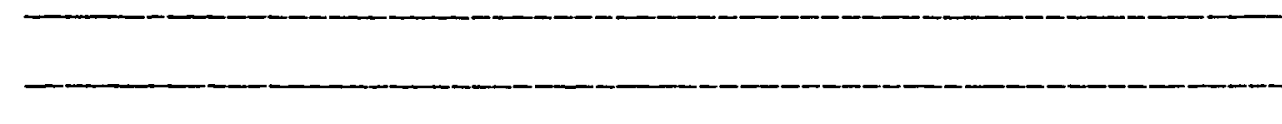

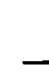

43. years?

How many times have you been hospltalized in the last 2

$0=$ none

When

Generas Beason

1.

2 .

3.

44. How many times have you seen a doctor or nurse practitioner in the last 6 months? $0=$ none 
45. What was the reason for your most recent visit to the doctor (or hospitalization)?

\section{Interyiewer code}

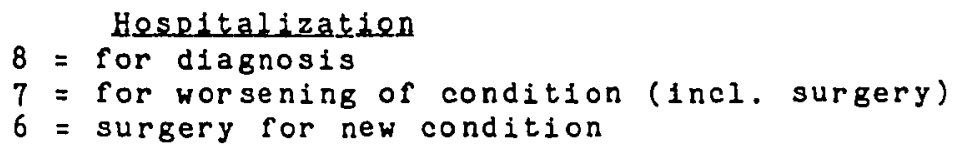

46. What medicines do you regularly take? (If cannot name, get color, pill or capsule, reason for use) $00=$ none 
47. Do you take any medicines to help you sleep? $0=$ none Name er Description Erequency

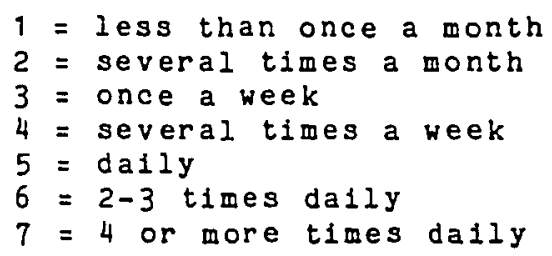

48. Do you take any medicines for your nerves? $0=$ none

Name or Description

49. Are you now receiving professional help for emotional problems? (for example, seetng a psychologist or psychosocial worker)

$$
\begin{aligned}
& 0=\text { no } \\
& 1=\text { yes }
\end{aligned}
$$

For what reason?

50. Have you ever before recelved professional help for an emotional problem?

$$
\begin{aligned}
& 0=\text { no } \\
& 1=\text { yes }
\end{aligned}
$$

When was that?

For what reason? 
51. Other than your iliness, were there any 1mportant events, good or bad, that happened to you in the last year? For example, birth of a grandchild, serious accident, moving, death of someone close, etc.

$$
0=\text { none }
$$

52. How much has having following areas? (HAND CARD)

$\begin{array}{ll}0=\text { have never done this } & 5=\text { no longer able to do } \\ 1=\text { not at all } & 7=\text { don't know } \\ 2=\text { a little } & 8=\text { refused } \\ 3=\text { a fair amount } & 9=\text { missing } \\ 4=\text { a great deal } & \end{array}$

A. Self care

B. Care of others (specify whom)

C. Eating habits

D. Sleeping habits

E. Doing household chores

F. Getting out to go shopping

G. Visiting friends

H. Enjoying hobbies

I. Working (if applicable)

J. Maintaining friendships

ADMINISTER CES-D. (IF VERBALLY, HAND CARD) 
Now I would like to ask you about the medical care you are receiving.

53. Which of these resources are you now using to pay for your medical expenses? (HAND CARD)

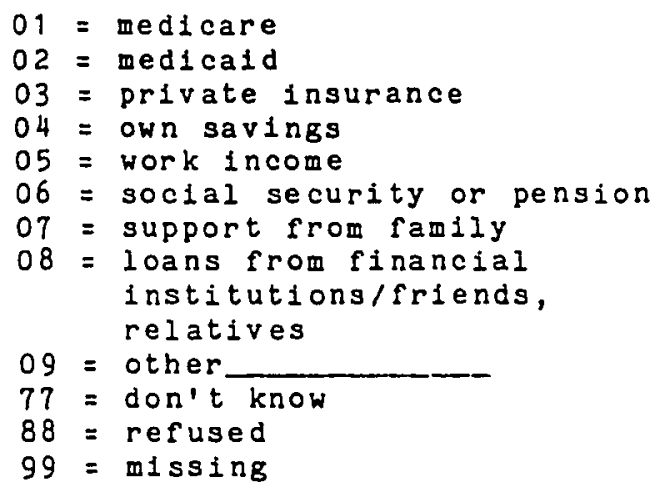

54. As best as you can tell, do you think your insurance and financial resources for future health care needs are:

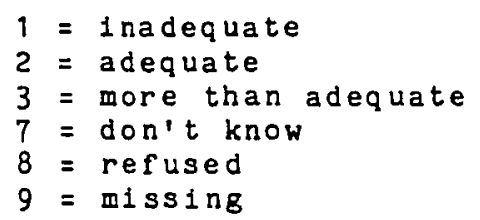

55. How much do you worry about being able to cover your health care expenses in the future?

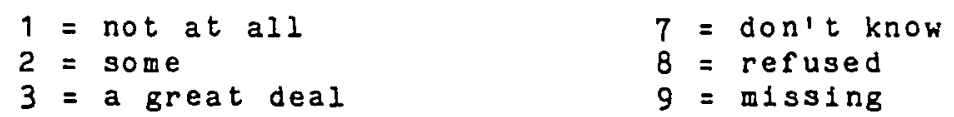

56. Is transportation to and from the doctor (clinic) a problem for you?

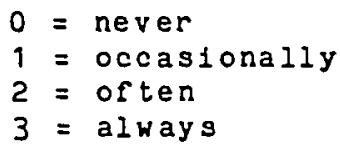

57. Would you say that the amount of care you are getting is

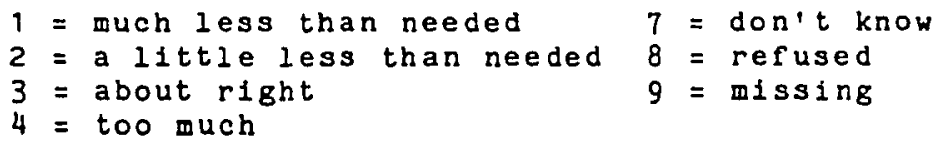


58. If you could afford 1t, what other services or care (if any) would you get? (HAND CARD)
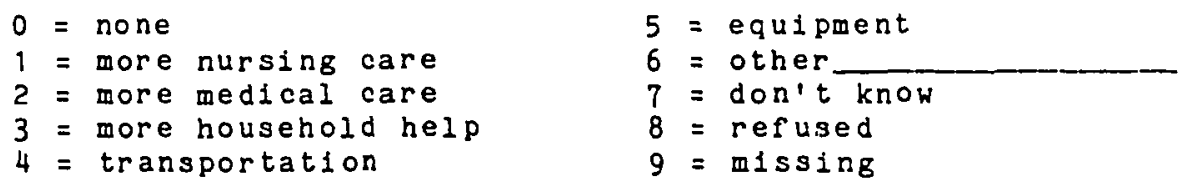

59. In general, how satisfied are you with the medical care you have received for your latest health problem?

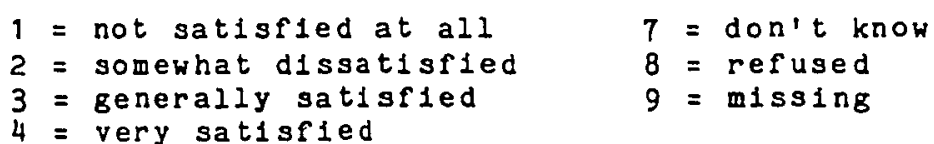

60. Do you use any community agencies or services now? For example, meals on wheels, home health. $0=$ no 1 = yes (specify)

Agency

C을

Erequency

\section{Asency code}

$1=$ meals on wheels

2 = housekeeping (social services)

$3=$ transportation

4 = senior center

5 = home health

$6=$ other

$7=$ don't know

$8=$ refused

$9=$ missing

Erequency

01 = once a year or less

02 = several times a year

$03=$ monthly

04 = several times a month

$05=$ weekly

06 = several times a week

07 = every day but weekends or sunday

$08=d a i l y$

$77=$ don't know

$88=$ refused

$99=$ missing 

ill ness.

Now I would like to ask you about the pain associated with your

61. In general, how much pain has been associated with your illness(es)? Would you say

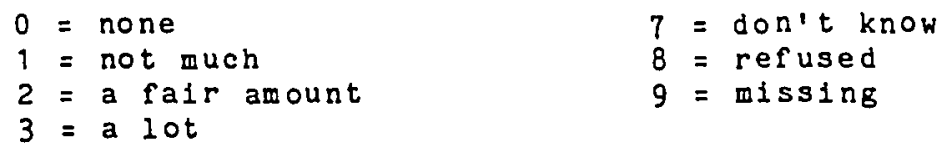

62. If 0 represents no pain, and 100 the worst pain you can imagine, what number would you give the most paln you have had as a result of your illness(es)?

$$
\begin{aligned}
& 7=\text { don't know } \\
& 8=\text { refused } \\
& 9=\text { missing }
\end{aligned}
$$

63. How wuch pain has been associated with your illness(es) in the last week? (IF 0 , GO TO 67 )

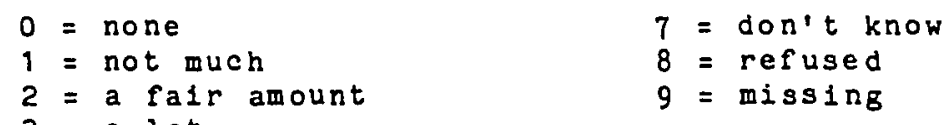

64. If 0 represents no pain, and 100 the worst pain you can imagine, what number would you give your pain in the last week?

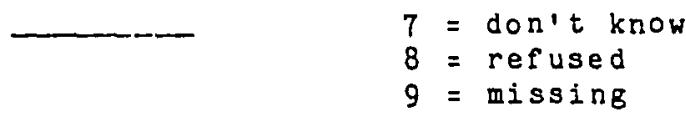

65. How long did the pain last?

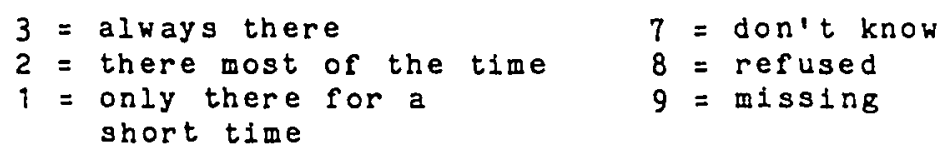

66. Compared to others with ___, would you say the amount of pain you have experienced is:
$5=$ much more
$4=a$ little more
$3=$ about the same
$2=a$ little less
1 = much less 


\section{What medications do you take for pain? $0=$ none}

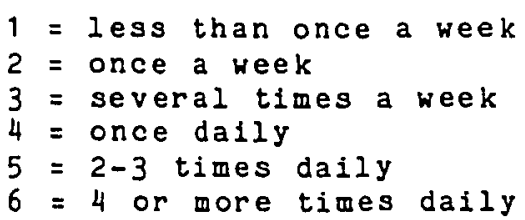

68. Sometimes an illness can cause little pain, but still be annoying or uncomfortable. In general, how much annoyance has been associated with your lliness(es)? Would you say

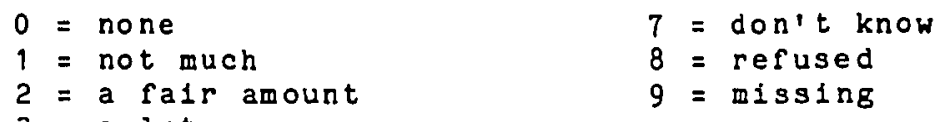

Now, I would like to ask a few questions about general thoughts and your thoughts about the future.

69. Do you believe you will ever recover from ___

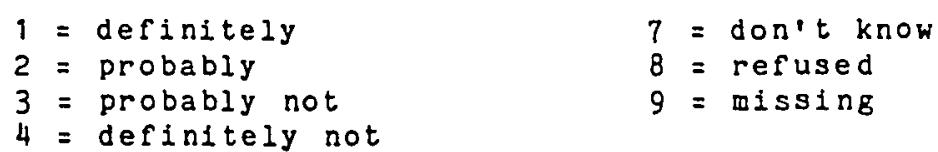

70. How many more years do you expect to live?

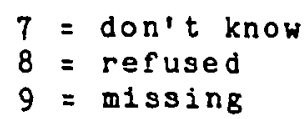

71. In general, do you believe people with can expect a Iffe that is

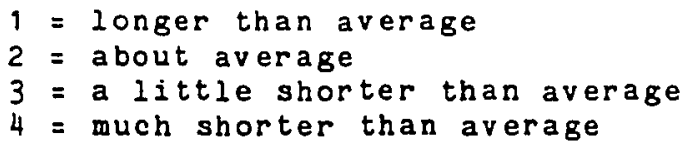

$$
\begin{aligned}
& 7=\text { don't know } \\
& 8=\text { refused } \\
& 9=\text { missing }
\end{aligned}
$$


72. Do you believe that your l1fe will be

1 longer than average

2 = about average

$3=$ a littie shorter than average

$4=$ much shorter than average

73. For people your age, how old do you think they usually live to be?

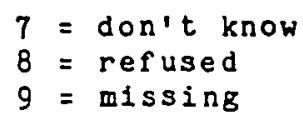

74. Have you ever felt you were living on borrowed time?

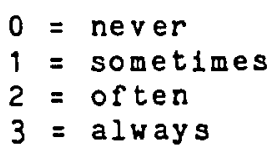
(ARD)

75. Who or what do you blame most for your 11lness(es). (HAND

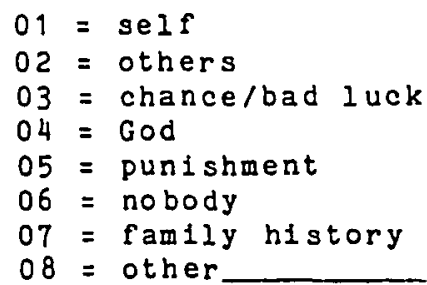

76. Who or what has been your greatest strength in adjusting to your illness(es)? (HAND CARD)

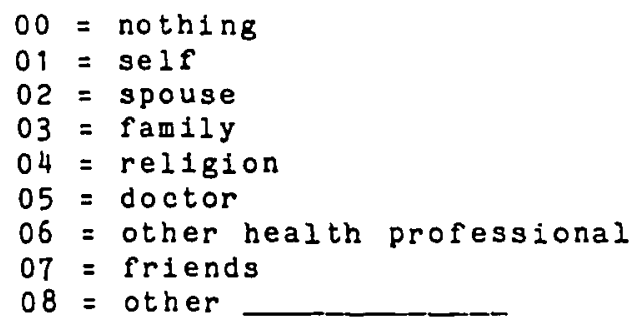

77. What is the worst thing about having $?$ 
78. What, if any, positive effect has having had on your life?

79. There are two more questionnaires for you to complete.

ADMINISTER LIFE SATISFACTION AND DEATH ANXIETY SCALE.

80. I have asked you a lot of questions about how has affected your life. But everyone is different, and $I$ may have forgotten to ask you about something 1mportant to you. Do you have anything further to say about how has affected your life? 
INTERVIEW EVALUATION

ID Code

Interview 12

1. Did the respondent mention wanting a report of the study?

$0=$ no

1 = yes

2. Subject's degree of cooperation

4 = excellent

$3=\operatorname{good}$

$2=$ fair

$1=$ poor

3. How well did the subject appear to understand the items on the interview?

$4=$ understood all items with no trouble

$3=$ had trouble with a few items

2 = had trouble with most items

1 = had trouble understanding all items

4. Was anyone else present during the interview?

$0=$ no

1 = yes

5. How inuch did those present participate in the interview?

$0=$ not at all

1 = gave help with factual information only

2 = gave input on subjective items

6. Note below any other unusual problems with this interview: 
I.D. No.

SD

PLEASE CIRCLE THE ANSWER THAT BEST APPLIES TO YOU.

1. I have never intensely disliked anyone. $a$

1 = true

2 = false

2. I sometimes feel resentful when I don't get my way.

$1=$ true

2 = false

3. I'm always willing to admit it when I make a mistake. $a$

1 = true

2 = false

4. I sometimes try to get even rather than forgive and forget.

1 = true

2 = false

5. At tines I have really insisted on having things my own way.

1 = true

2 = false

6. I have never been irked when people expressed ideas very different from my own. ${ }^{2}$

1 = true

$2=$ false 
I.D. No.

Control of Health (HLC)

These questions ask about your general feelings about control of your health. Circle the appropriate number to indicate your disagreetent or agreement with the statement.

$\begin{array}{cccccc}\begin{array}{l}\text { Strongly } \\ \text { Disagree }\end{array} & \begin{array}{l}\text { Somewhat } \\ \text { Disagree }\end{array} & \begin{array}{l}\text { Somewhat } \\ \text { Agree }\end{array} & \begin{array}{l}\text { Strongly } \\ \text { Agree }\end{array} \\ 1 & 2 & 3 & 4 & 5 & 6\end{array}$
1. If I take care of myself, I can
avoid illness.

2. Good health is largely a matter

$1 \quad 2 \quad 3 \quad 4 \quad 5 \quad 6$ of good fortune.

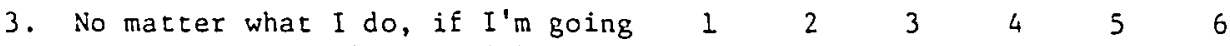
to get sick I will get sick.

4. Most people do not realize the extent to which their illnesses

$\begin{array}{llllll}1 & 2 & 3 & 4 & 5 & 6\end{array}$
are controlled by accidental happenings.

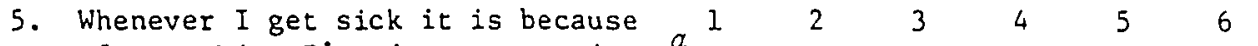
of something I've done or not done.

6. I can only do what my doctor tells me to do.

$\begin{array}{llllll}1 & 2 & 3 & 4 & 5 & 6\end{array}$

7. There are so many strange diseases around that you can never know how or when you might pick one up.

8. When I feel ill, I know it is because I have not been getting the proper exercise or eating right. $a$

9. People who never get sick are just plain lucky.

$\begin{array}{lllllll}1 & 2 & 3 & 4 & 5 & 6 & - \\ 1 & 2 & 3 & 4 & 5 & 6 & - \\ 1 & 2 & 3 & 4 & 5 & 6 & -\end{array}$


$-2-$

$\begin{array}{ll}\text { Strongly } & \text { Somewhat } \\ \text { Disagree } & \text { Disagree }\end{array}$

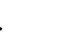

I.D. No.

$\begin{array}{ll}\text { Somewhat } & \text { Strongly } \\ \text { Agree } & \text { Agree }\end{array}$

10. People's ill health results from their own carelessness.

1

2

4

6

11. I an directly responsible for my health. ${ }^{a}$

12. People usually can prevent getting

1

1

23

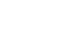

4

56

13. I can generally control the symptoms of my disease. ${ }^{a}$

23

3

45

6

14. How I do with this illness really depends on me. $a$

2

3

45

HLC Score

$12-14$

Total Score 
L.U. No.

CES-DI

Here is a list of items of ways you might have felt or behaved. Please indicate how often you felt this way during the past week by circling the appropriate response next to each item.

IN THE PAST WEEK, HOW MANY DAYS DID THIS HAPPEN TO YOU?

I was bothered by things that usually don't bother me.

I did not feel like eating, my appetite was poor.

I felt that I could not shake off the blues even with help from my friends and family.

I felt that I was just as good as

other people.

I had trouble keeping my mind on what I was doing.

I felt depressed.

I felt that everything I did was an effort.

I felt hopeful about the future.

I thought my life had been a failure.

I felt fearful.

\begin{tabular}{l} 
Rarely \\
or none \\
of the \\
time \\
(Less \\
than 1 \\
day) \\
\hline
\end{tabular}

0

0

0

3

0

0

0

3

0

0

\begin{tabular}{l} 
Some or \\
a little \\
of the \\
time \\
$(1-2$ \\
days $)$ \\
\hline
\end{tabular}

Occasion-

ally or a

moderate

amount

of time

(3-4

days)

1

2

1

2

3

1

2

3

Most or

all of

the time

(5-7

days

\section{3}

2

1

0

I

2

3

1

2

3

1

2

3

1

0

1

2

3

1

2

3 
CES-D2

My sleep was restless.

I was happy.

I talked less than usual.

I felt lonely.

People were unfriendly.

I enjoyed life.

I had crying spells.

I felt sad.

I felt that people

disliked me.

I could not get

"going."

I had trouble falling asleep.

I felt irritable.

I have been worrying a lot.
Rarely or none of the time (Less than 1 day)

0

3

0

0

0

3

0

0

0

0

0

0

0

\begin{tabular}{l} 
Some or \\
a little \\
of the \\
time \\
$(1-2$ \\
days) \\
\hline
\end{tabular}

1

2

1

1

1

2

1

1

1

1

1

1

1
Occasion-

ally or a

moderate

amount

of time

(3-4

days)

2

1

2

2

2

1

2

2

2

2

2

2

2

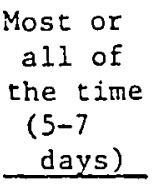

3

0

3

3

3

0

3

3

3

3

3

3

3 


\section{CES-D3}

I wake up in the middle of the night (not to go to the bathroom).

I was interested in my usual activities.

I slept much more than usual.

I felt guilty.

Did you blame yourself for anything you have done or not done?

\begin{tabular}{|c|c|c|c|}
\hline $\begin{array}{l}\text { Rarely } \\
\text { or none } \\
\text { of the } \\
\text { time } \\
\text { (Less } \\
\text { than } 1 \\
\text { day) } \\
\end{array}$ & $\begin{array}{l}\text { Some or } \\
\text { a little } \\
\text { of the } \\
\text { time } \\
\text { (1-2 } \\
\text { days) } \\
\end{array}$ & $\begin{array}{l}\text { Occasion- } \\
\text { ally or a } \\
\text { moderate } \\
\text { amount } \\
\text { of time } \\
(3-4 \\
\text { days }) \\
\end{array}$ & $\begin{array}{l}\text { Most or } \\
\text { all of } \\
\text { the time } \\
(5-7 \\
\text { davs) } \\
\end{array}$ \\
\hline 0 & 1 & 2 & 3 \\
\hline 3 & 2 & 1 & 0 \\
\hline 0 & 1 & 2 & 3 \\
\hline 0 & 1 & 2 & 3 \\
\hline 0 & 1 & 2 & 3 \\
\hline
\end{tabular}

CES-D Total Score:

New CES-D Score: 
Instructions: Indicate whether you agree or disagree with the following statements:

\begin{tabular}{|c|c|c|c|}
\hline & \\
\hline & Agree & Disagree & Uncerta in \\
\hline 1. I am just as happy as when I was younger. & & & \\
\hline 2. These are the best years of my life. & & & \\
\hline 3. My life could be happier than it is now. $a$ & & & \\
\hline 4. This is the dreariest time of my life. & & & \\
\hline 5. Most of the things I do are boring or monotonous. $a$ & & & \\
\hline $\begin{array}{l}\text { 6. Compared to other people, I get down in the a } \\
\text { dumps too often. }\end{array}$ & & & \\
\hline $\begin{array}{l}\text { 7. The things I do are as interesting to me as } \\
\text { they ever were. }\end{array}$ & & & \\
\hline $\begin{array}{l}\text { 8. I have made plans for things l'll be doing } \\
\text { a month or year from now. }\end{array}$ & & & \\
\hline $\begin{array}{l}\text { 9. Compared to other people my age, I make a } \\
\text { good appearance. }\end{array}$ & & & \\
\hline $\begin{array}{l}\text { 10. As I grow older, things seem better than } 1 \\
\text { thought they would be. }\end{array}$ & & & \\
\hline $\begin{array}{l}\text { 11. I expect some interesting and pleasant things } \\
\text { to happen to me in the future. }\end{array}$ & & & \\
\hline 12. I feel old and somewhat tired. a & & & \\
\hline 13. As I look back on my life, I am fairly well satisfi & & & \\
\hline 14. I would not change my past even if I could. & & & \\
\hline 15. I've gotten pretty much what I expected out of life. & & & \\
\hline $\begin{array}{l}\text { 16. When I think back on my life, I didn't get most of } \\
\text { the important things I wanted. } a\end{array}$ & & & \\
\hline $\begin{array}{l}\text { 17. In spite of what people say, the lot of the average } \\
\text { man is getting worse. not better. } a\end{array}$ & & & \\
\hline $\begin{array}{l}\text { 18. I have gotten more of the breaks in life than most } \\
\text { of the people I know. }\end{array}$ & & & \\
\hline
\end{tabular}


ID No.

DA Scale

PLEASE CIRCLE THE ANSWER THAT BEST APPLIES TO YOU.

T $F$ 1. I am very much afraid to die.a

T F 2. The thought of death seldor enters my mind.

I F 3. It doesn't make me nervous when people talk about death.

T $\mathrm{F}$ 4. I dread to think about having to have an operation.

T F 5. I am not at all afraid to die.

I $F$ 6. I am not particularly afraid of getting cancer.

T $\mathrm{F}$ 7. The thought of death never bothers me.

T F 8. I am often distressed by the way time flies so very rapidly.

I $\quad$ 9. I fear dying a painful death.

$\mathrm{T}$ F 10. The subject of life after death troubles me greatly.

T F 11. I am really scared of having a heart attack. a

T F 12. I often think about how short life really is.

T F 13. I shudder when I hear people talking about World War III.

I F 14. The sight of a dead body is horrifying to me. ${ }^{a}$

T $F$ 15. I feel that the future holds nothing for me to fear. 


\author{
APPENDIX C \\ Effects of Chronic Illness \\ 2nd Interview
}

Subject ID:

Interviewer

Date

\author{
Time Interview Begun \\ Time Interview Completed \\ Additional Diagnoses NCNE \\ CHD, CLD, CA, ARTH, DIAB, FRX \\ Other
}

I would like to thank you for taking the time to talk with me again. The purpose of this second interview is to see how your iliness continues to affect your life and any changes that have occurred in the last three months. I again have a number of questions to ask so please let me know if you need to rest, take a break, or need further information. Let me reassure you that all information will be confidential and will never be identified with you by name.

1. Has your marital status changed in the last three months?

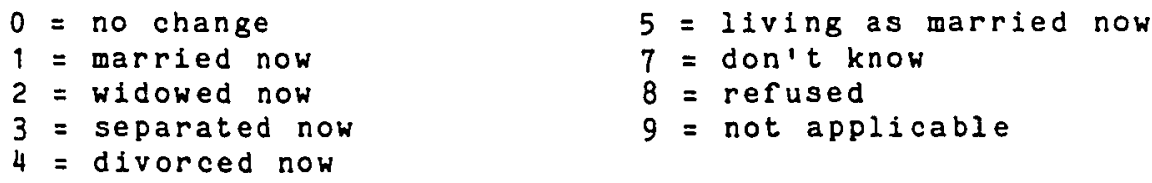

2. This question is about the people who live with you now. What are the first names of all other persons who live with you on a regular basis? $00=$ nobody

Names오

Sexx A B로

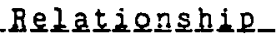

1.

2.

3.

4.

5.

$01=$ spouse

$02=$ child

$03=$ grandchild

$04=$ sibling

$05=$ friend

06 = spouse's sibling

07 = spousal friend

08 = parent
$09=$ grandparent

$10=$ child's spouse

$11=$ other in-law

12 = niece/nephew

$13=$ aunt/uncle

14 = other

$88=$ refused

$99=$ not applicable 
12. How often do you drink alcoholic beverages? (HAND CARD)

Ereguensy

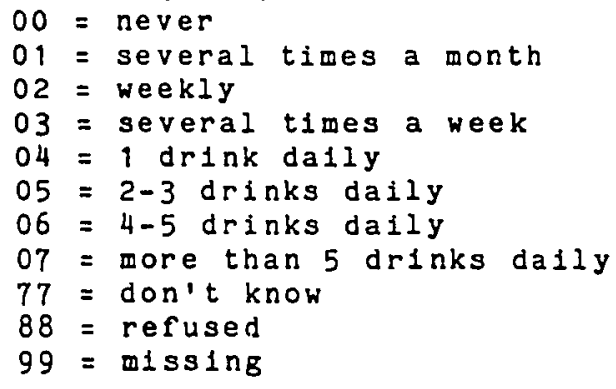


13. Now I would like to ask you about your ability to perform the following activities of daily living. Do you need help or use an assistive device for:

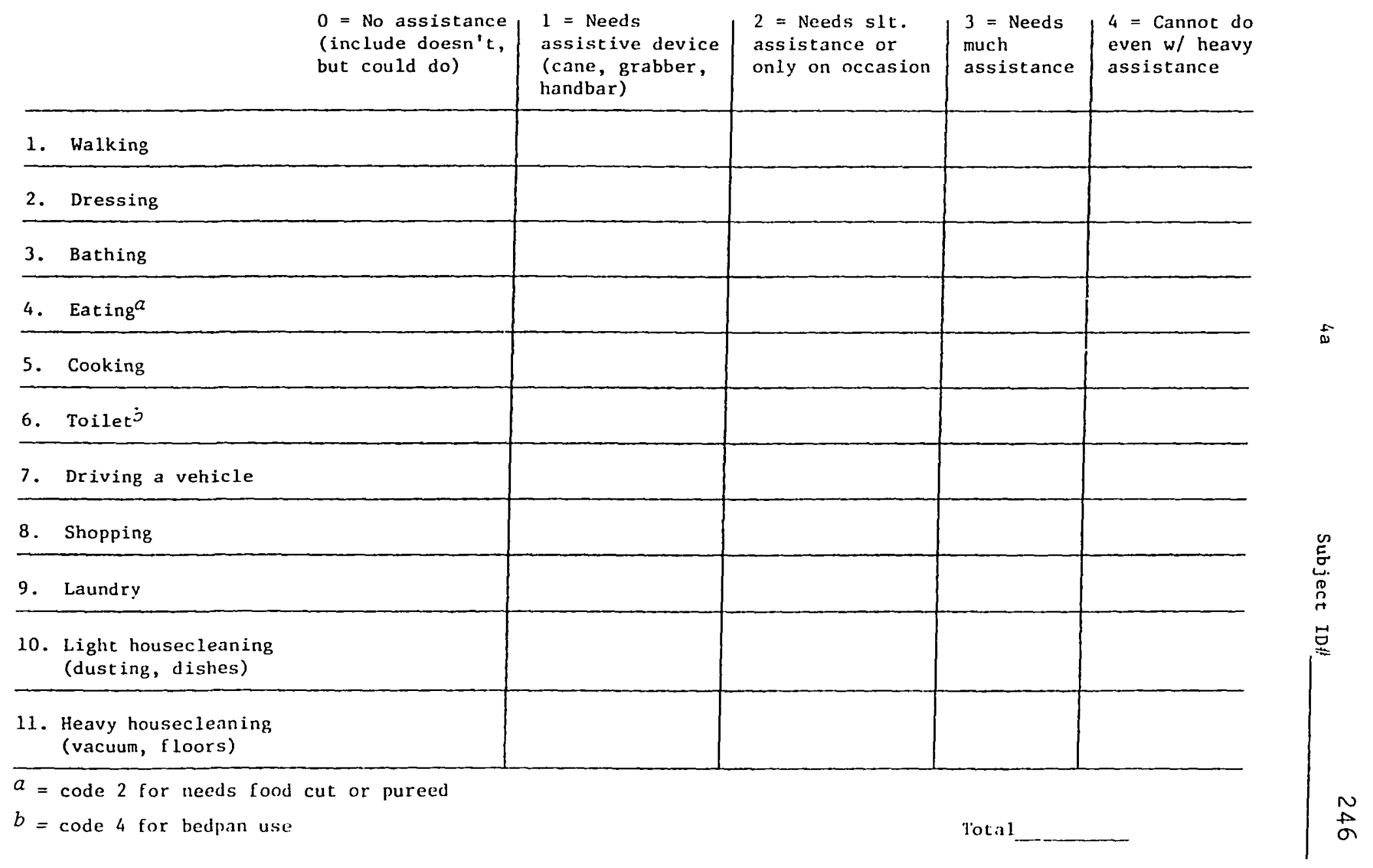


5 Subject ID

Now I would like to ask some questions about the people you feel closest to, depend on for help, or depend on you for help.

14. Sometimes friends, relatives, or neighbors help out with tasks such as watching the house or bringing in the mail while you are away. Are there people who would help you out in this way? May I have their first names? (LIST NAMES ON TABLE) (CHECK 14 )

15. Are there people who would ask you to help in this way? (LIST NEW NAMES ON TABLE) (CHECK 15 FOR ALL)

16. When you are concerned about a personal matter, is there anyone you would talk to about it? (LIST NEW NAMES) (CHECK 16 FOR $A L L$ )

17. Is there anyone you would ask for advice in making important decisions? (LIST NEW NAMES) (CHECK 17 FOR ALL)

18. Is there anyone who would come to you for advice or to discuss personal matters? (LIST NEW NAMES) (CHECK 18 FOR ALL)

19. Are there people you would help if they were sick for a short time? (LIST NEW NAMES) (CHECK 19 FOR ALL)

20. Are there people you would help if they were sick for a long time, say weeks or months? (LIST NEW NAMES) (CHECK 20 FOR ALL)

21. Is there anyone not on this list who is especially important to you? (ADD TO LIST) (CHECK 21)

22. Did anyone on this list, or anyone else, help you during the last 3 months? In which of these ways? (HAND CARD)

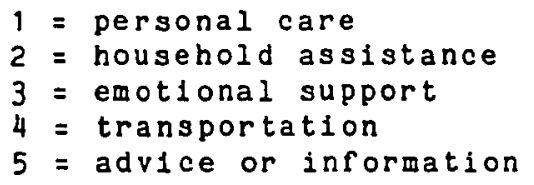

23. Who do you think would have helped you in these ways if you had needed more help?

24. Complete chart. If more than 10 names on list--ask for 10 most important persons (INTERVIEWER MAY BE ABLE TO JUDGE THIS FROM COMMENTS). Put star by these names and complete for these 10 . 


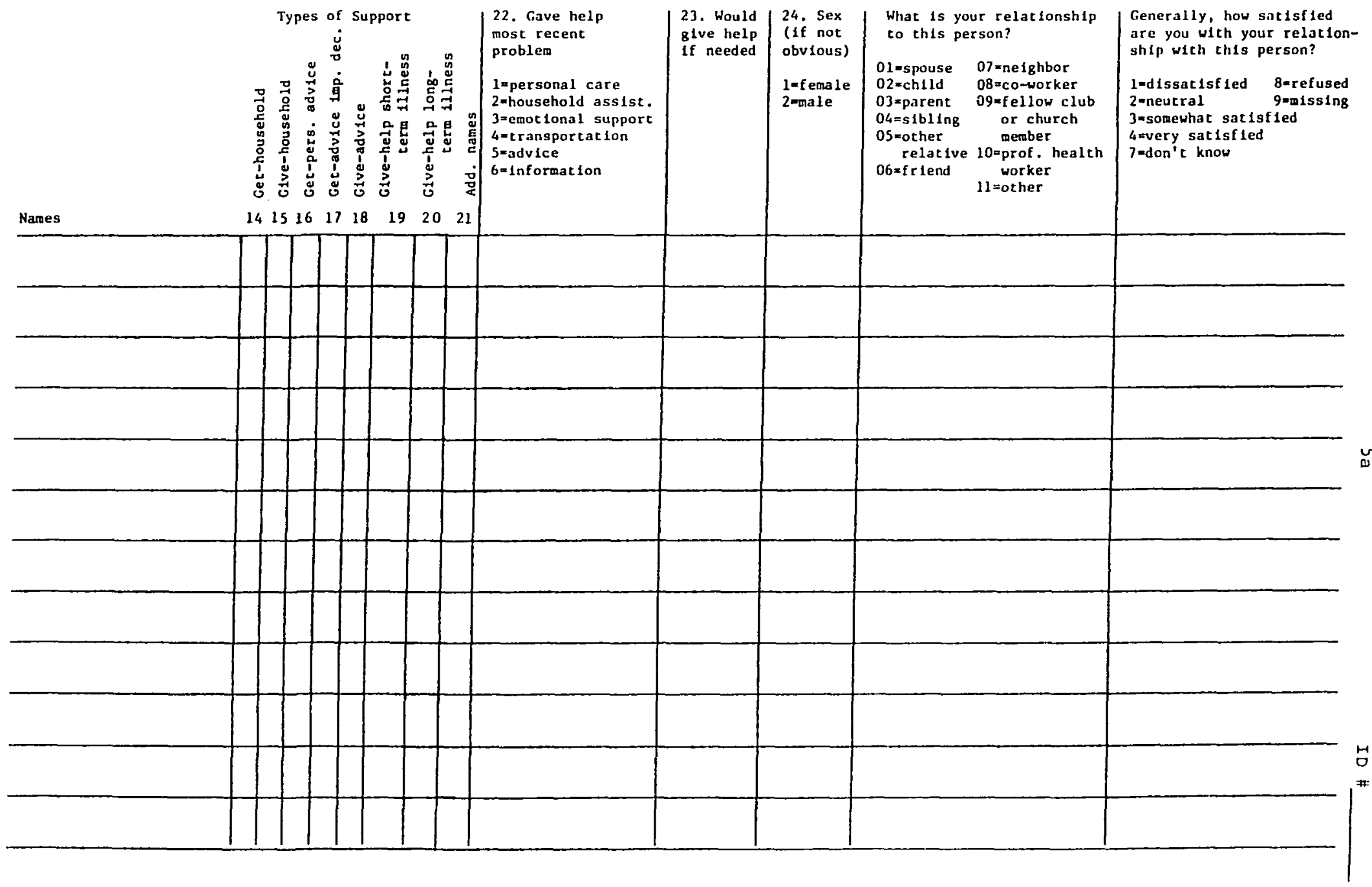


Next, I would like to ask some questions about your health.

25. In the past three months, would you say your has

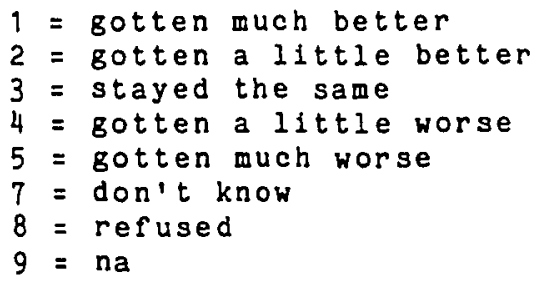

27. In the last three months, has your overall health

$1=$ gotten better

2 = stayed the same

$3=$ gotten worse

$7=$ don't know

$8=$ refused

$9=n a$

28. Overall, how would you rate your health?
$4=$ poor
$3=$ rair
$2=\operatorname{good}$
$7=$ don't know
$1=$ excellent
$8=$ refused
$9=$ na

29. Compared to other people your age, would you rate your health as
$1=$ much better
2 = somewhat better
3 = about the same
4 = somewhat worse
$5=$ much worse
7 = don't know
- refused
$9=$ na 
7 subject ID

30. Do you believe that in the next six months your overall health is likely to
$1=$ get better
2 = stay the same
3 = get worse
$7=$ don't know
8 = refused
$9=$ na

31. Compared to most people with ___, would you rate yourself as:

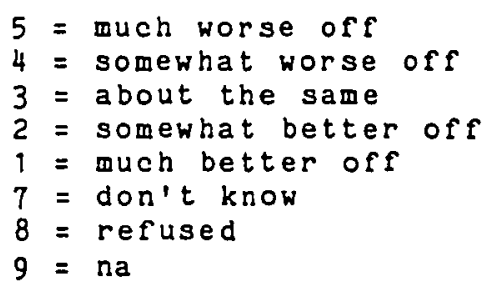

32. In the last three months, have you been diagnosed as having any additional chronic illnesses? 00 = none

IIneㅗㅗ

1.

2.

3.

4.

33. How many times have you been hospitalized in the last three months? $00=$ none

When R로로오으

1 .

2 .

34. How many times have you seen a doctor or nurse practitioner in the last three months? $0=$ none 
35. What medicines do you regularly take now? (If cannot name, get color, pill or capsure, reason for use)

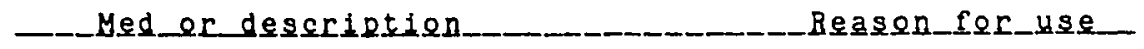

36. Do you take any medicines to help you sleep? $0=$ none Nåme er_descriptien___________Egequençy

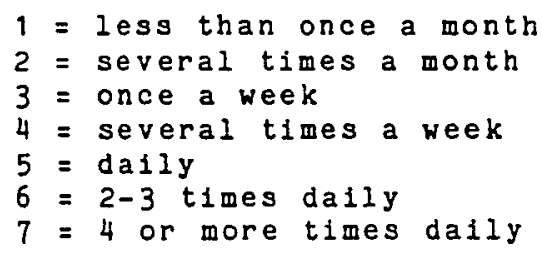

37. Do you take any medicines for your nerves? 0 = none (same as above)

Name or deseription Ex료보료도

38. Are you now receiving help for emotional problems? (For example, seeing a psychologist or psychosocial worker)

$$
\begin{aligned}
& 0=\text { no } \\
& 1=\text { yes } \\
& \text { For what reason? }
\end{aligned}
$$


39. Have you recelved professional help for an emotional problem in the last three months?

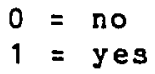

41. This question is about how now affects your life in various ways. Here are the choices of answers (HAND CARD)

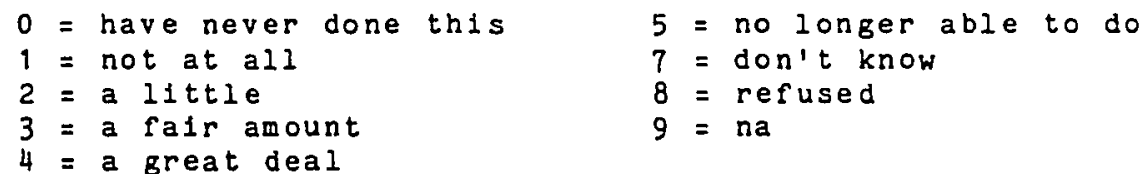

How much does having ___ affect your:

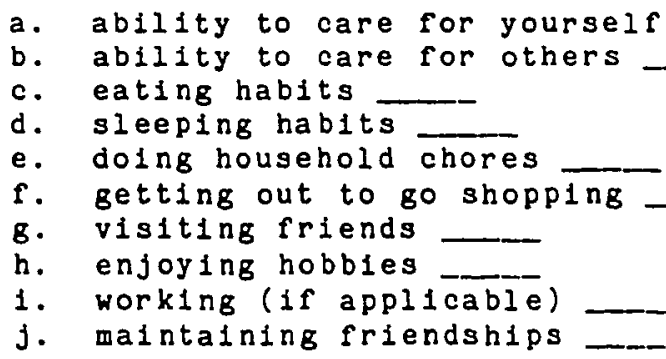

42. Now, as a change of pace, I would like to ask you to fill out two questionnaires. These are standardized questionnaires so some questions may not exactly fit your situation. Remember there are no right or wrong answers. Please answer each question as best as you can as it applies to you.

Administer HLC and CES-D. 
Now I would like to ask a few questions about the medical care you are receiving.

43. Which of these resources are you now using to pay for your medical expenses? (HAND CARD)

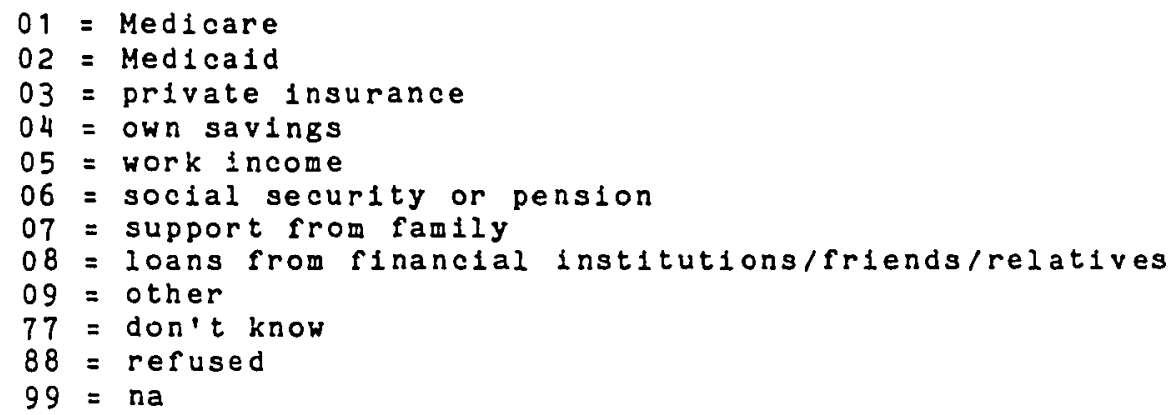

44. As best as you can tell, do you think your insurance and financial resources for health care needs have been:

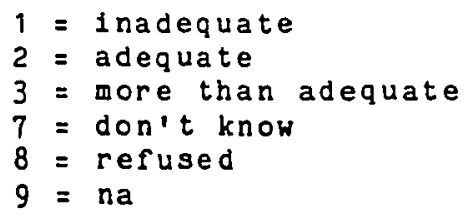

45. Do you think your insurance and financial resources for fusture health care needs are:

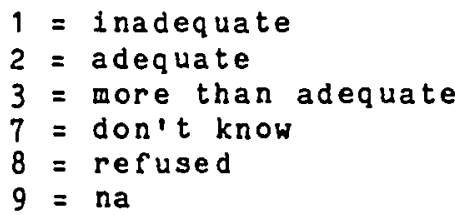

46. How much do you worry about being able to cover your health care expenses in the future?

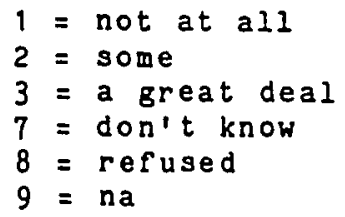

47. Would you say that the amount of care you are getting is

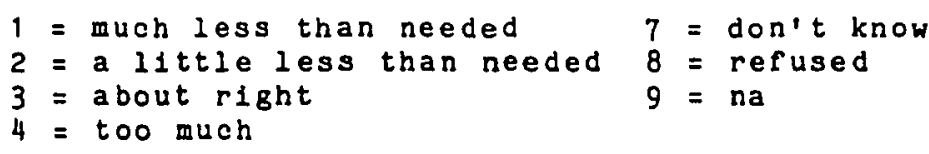


Now, I would like to ask you about the pain associated with your iliness.

51. In general, how much pain has been associated with your illness(es) in the last three months? Would you say

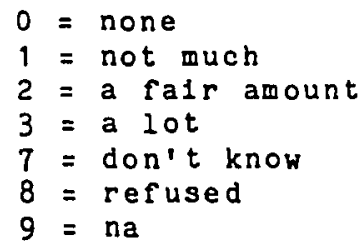

52. If 0 represents no pain, and 100 the worst pain you can Imagine, what number would you give the most pain you have had as a result of your 111 ness(es) in the last three months?

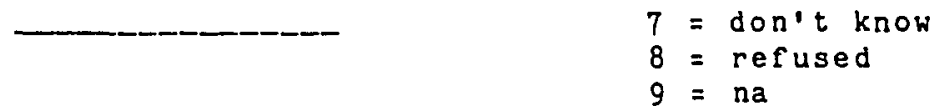

53. How much pain has been associated with your illness(es) in the last week?

$$
\begin{aligned}
& 0=\text { none } \\
& 1=\text { not much } \\
& 2=a \text { fair amount } \\
& 3=a \text { lot } \\
& 7=\text { don't know } \\
& 8=\text { refused } \\
& 9=\text { na }
\end{aligned}
$$

54. If 0 represents no pain, and 100 the worst pain you can imagine, what number would you give your pain in the last week?

$7=$ don' know
$8=$ refused
$9=$ na

55. How long did the pain last?

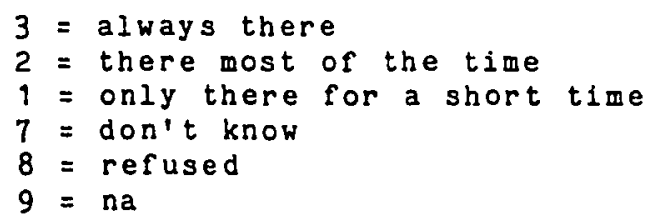


56. Compared to others with of pain you have experienced is
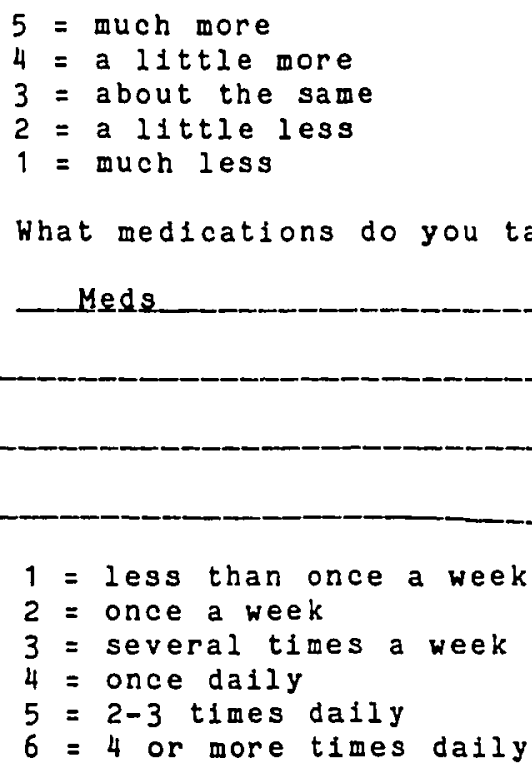

58. Sometimes an illness can cause little pain, but still be annoying or uncomfortable. In general, how much annoyance has been assoclated with your lliness(es) in the last three months? Would you say

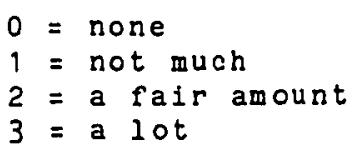

Now I would like to ask a few questions about your general thoughts and thoughts about the future.

59. Do you belleve you will ever recover from ?
$1=$ definitely
2 = probably
3 = probably not
7 don't know
$8=$ refused
$9=$ na

$4=$ definitely not

60. How many more years do you expect to live?

$7=$ don't know
$8=$ refused
$9=$ na 
61. In general, do you believe people with a Iife that is

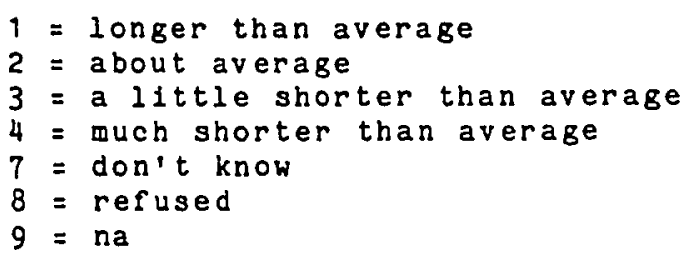

62. Generally, do you consider yourself (HAND CARD)

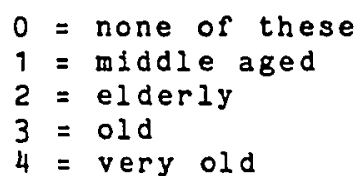

$7=$ don't know

$8=$ refused

$9=n a$

63. Do you believe that your life will be

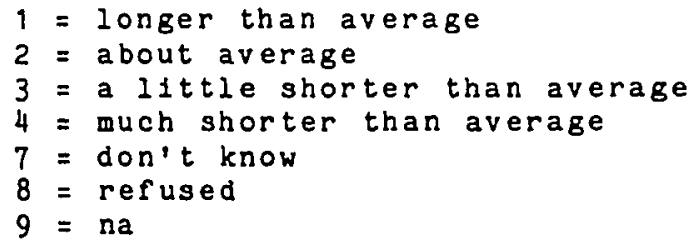

64. What is the greatest effect this illness has had on your life in the last three months?

65. In regards to your illness(es), what, if any, is your greatest concern at this time?

66. There are two more questionnaires we would like you to complete.

Administer Life Satisfaction and Death Anxiety Scale. 
67. I have asked you a lot of questions about how your 11 lness(es) has affected your 11 fe. But everyone is different, and I may have forgotten to ask you about something important to you. Do you have anything further to say about how has affected your life.

68. Now that you have completed both interviews, is there anything you would like to say about the interviews?

69. Interviewer code:

Impression of the social support system

4 = extensive

3 = adequate, but there are only a few key persons

2 = generally adequate, but some key areas are lacking

1 = inadequate to meet needs

$0=$ can't assess

70. Interviewer code:

Is the subject's predominant mood depression?

$0=$ no

1 = yes

71. Interviewer code:

Is the subject's predominant mood anger?

$0=$ no

$1=$ yes

72. Interviewer code:

Is the subject's predominant mood anxiety?

$0=$ no

1 = yes 
73. Interviewer code:

Impression of the subject's available material resources (i.e., financial, medical)

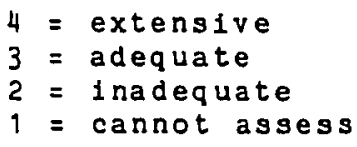


I.D. No.

Control of Health (HLC)

These questions ask about your general feelings about control of your health. Circle the appropriate number to indicate your disagreement or agreement with the statement. The first 11 questions deal with your feelings about health in general. The last four questions deal with your specific illness(es).

$\begin{array}{llll}\text { Strongly } & \text { Somewhat } & \text { Somewhat } & \text { Strongly } \\ \text { Disagree } & \text { Disagree } & \text { Agree } & \text { Agree }\end{array}$

1. If I take care of myself, I can

1

2

34

$5 \quad 6$
avoid illness. $a$

2. Cood health is largely a matter of good fortune.

$\begin{array}{llllll}1 & 2 & 3 & 4 & 5 & 6\end{array}$

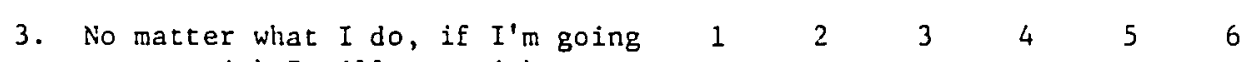
to get sick I will get sick.

4. Most people do not realize the extent to which their illnesses are controlled by accidental happenings.

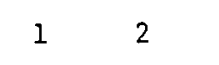

5. Whenever I get sick it is because of something I've done or not done.

6. I can only do what my doctor tells me to do.

7. There are so many strange diseases around that you can never know how or when you might pick one up.

8. When I feel ill, I know it is because I have not been getting the proper exercise or eating right. $a$

9. People who never get sick are just plain lucky.

$\begin{array}{lllllll}1 & 2 & 3 & 4 & 5 & 6 & = \\ 1 & 2 & 3 & 4 & 5 & 6 & -\end{array}$


$-2-\quad$ I.D. No.

$\begin{array}{llll}\text { Strnngly } & \text { Somewhat } & \text { Somewhat } & \text { Strongly } \\ \text { Disagiee } & \text { Disagree } & \text { Agree } & \text { Agree }\end{array}$

10. People's ill health results from 1 their own carelessness. $a$

11. I am directly responsible for my health. ${ }^{a}$

12. People usually can prevent getting a

13. I can generally control the symptoms of my disease. ${ }^{a}$

14. How I do with this illness really depends on me. ${ }^{a}$

15. The symptoms of my illness are not very predictable.

$\begin{array}{lllllll}1 & 2 & 3 & 4 & 5 & 6 & - \\ 1 & 2 & 3 & 4 & 5 & 6 & - \\ 1 & 2 & 3 & 4 & 5 & 6 & - \\ 1 & 2 & 3 & 4 & 5 & 6 & - \\ 1 & 2 & 3 & 4 & 5 & 6\end{array}$

HLC Score

$12-14$

15

Total 
APPENDIX D

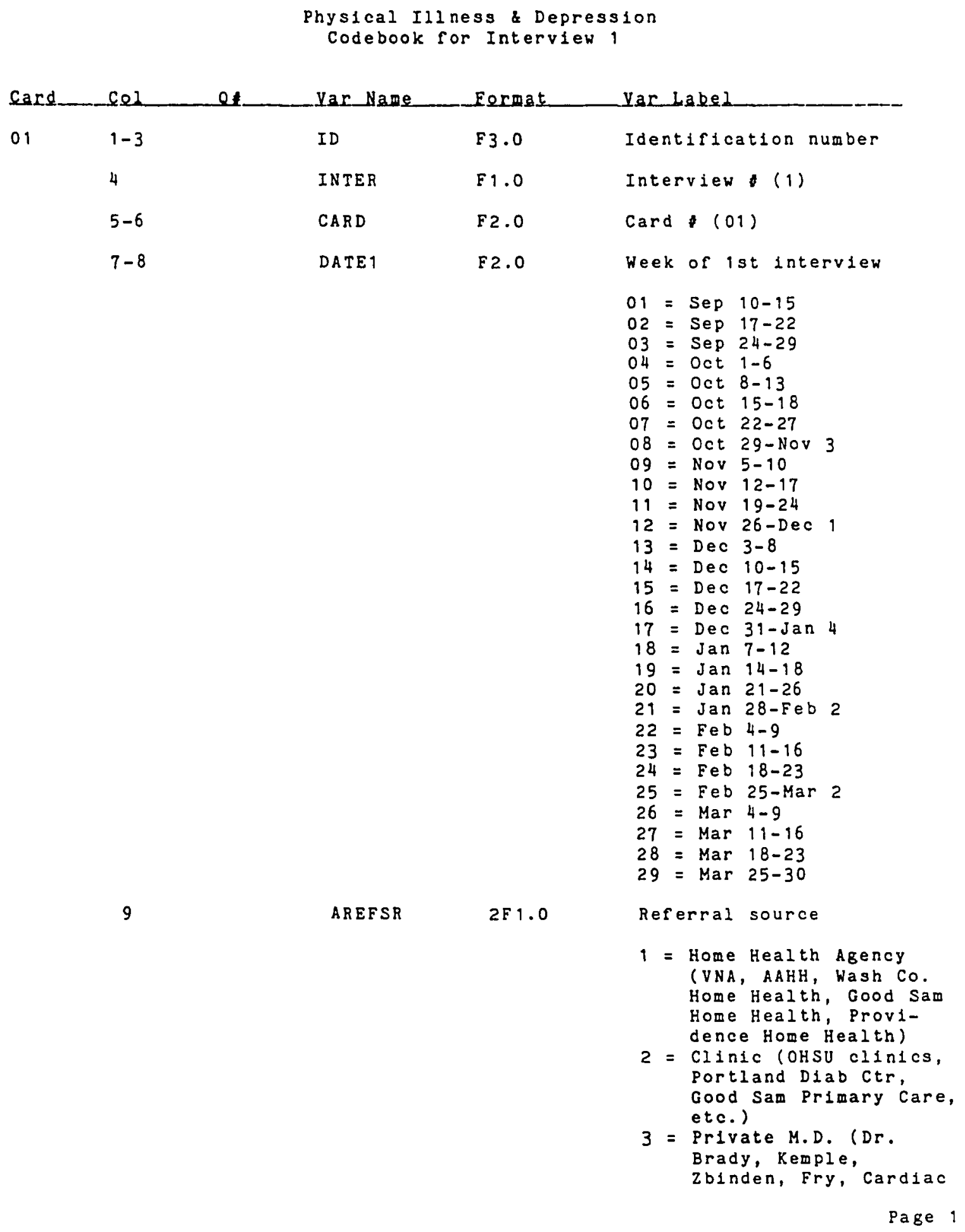


Conventions

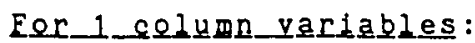

$7=$ don't know

$8=$ refused

$9=$ not applicable

Eor 2 column yariables :

$77=$ don't know

$88=$ refused

$99=$ not applicable 
car호

도이

요

Yar Name

01

10

AINTERER

BLAN K

ARDIAG

13

94

15

16

17

18

19

$1-12$

3

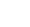

ATDIAG

ACHD
Eermat

Yar Label

4 = Social services (Emanuel, Providence)

$5=$ other

Interviewer

$$
\begin{aligned}
& 1=\text { Allce Scannell } \\
& 2=\text { Ann Williams } \\
& 3=\text { Rosella Moseley } \\
& 4=\text { other }
\end{aligned}
$$

$2 \mathrm{X}$

$9 \mathrm{~F} 1.0$

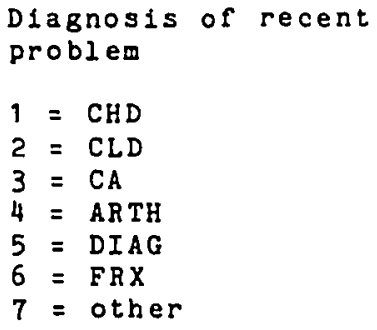


Card___cel____

01

20

21

25

3

AETHNIC

$26-27 \quad 4$

$28-29$

5

30

6

31

32

ATOTHHG R

AAGE

ASEX

A TOTHH 18
E으모호

Var Label

Presence of fracture?

$0=$ no

1 = yes

Presence of other diagnosis?

$0=$ no

1 = yes

F2. 0

Age

$2 F 1.0$

Gender

1 = female

$2=$ male

Ethnic status

1 = Caucasian

2 = Black

$3=$ Hispanic

4 = American Indian

$5=$ Asian

$6=$ other

AMARSTAT 2F2.0

Marital status

1 = single, never married

2 = married

3 = widowed

4 = separated

5 = divorced

$6=1$ iving as warried

10 = married, but spouse in nursing home

Length of marital status in years

Total other people in household

$0=$ no one

Total other persons in household under age 18

$0=$ no one

Total other persons in household older than 65

$0=$ no one 
card 도이 Q Yar_Name

Eormat Yar Label

01 $33-34$ AHHMKP

F 2.0

Makeup of household

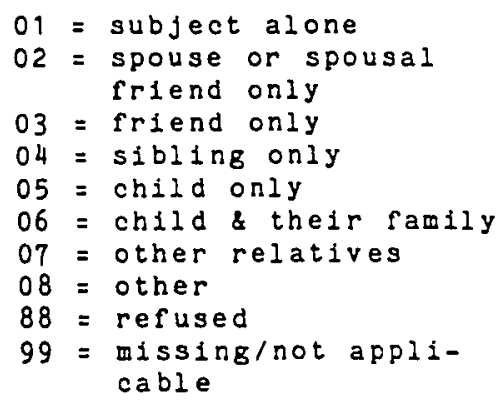

ATOTCHD

F 1.0

- of living children

$36-37$

8

AEDUC

$2 F 2.0$

AEMPSTAT
9

$38-39$

40

10

AOCCUP
$0=$ none

\section{Education}

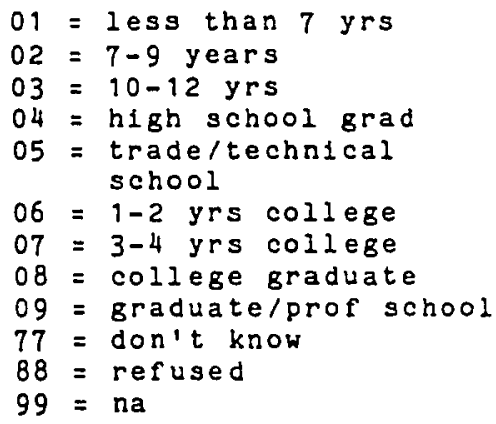

F 1.0

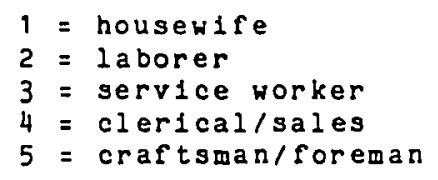


card

c요 1

$-21$

Yar Name

01

\begin{tabular}{|c|c|c|c|c|}
\hline $41-42$ & 11 & AIN COME & F2.0 & $\begin{array}{l}\text { Last year's income } \\
01=\text { less than } 5,000 \\
02=5,000-9,999 \\
03=10,000-14,999 \\
04=15,000-19,959 \\
05=20,000-24,999 \\
0 t=25,000-29,999 \\
07=30,000-34,999 \\
08=35,000-39,999 \\
09=40,000-49,999 \\
10=50,000 \text { or greater } \\
77=\text { don't know } \\
88=\text { refused } \\
99=\text { missing }\end{array}$ \\
\hline 43 & 12 & ARESSET & F 1.0 & $\begin{array}{l}\text { Residential setting } \\
1=\text { urban } \\
2=\text { rural } \\
3 \text { = suburban/town }\end{array}$ \\
\hline $44-45$ & 13 & ARESTYPE & F 2.0 & $\begin{array}{l}\text { Type of residence } \\
01=\text { single ramily } \\
02=\text { duplex } \\
03=\text { condo } \\
04=\text { apartment } \\
05=\text { mobile home } \\
06=\text { residential care } \\
07=\text { other }\end{array}$ \\
\hline 46 & 14 & ARESOWN & F1.0 & $\begin{array}{l}\text { Residential ownership } \\
\begin{array}{l}1=\text { own } \\
2=\text { rent } \\
3=\text { other }\end{array}\end{array}$ \\
\hline $47-48$ & 15 & ALGRESID & F2.0 & $\begin{array}{l}\text { Length in current } \\
\text { residence in years } \\
\text { If } 6-11 \text { mos, code as } \\
1 \text { year; } 0-5 \text { mos }=0 \text { yr. }\end{array}$ \\
\hline 49 & 16 & ABUS & $9 \mathrm{~F} 1.0$ & $\begin{array}{l}\text { Use of bus } \\
\begin{array}{l}0=\text { no } \\
1=\text { yes }\end{array}\end{array}$ \\
\hline
\end{tabular}

$6=$ farmer

$7=$ official/proprietor

$B=$ professional/technical

$9=\operatorname{missing}$

Page 5 


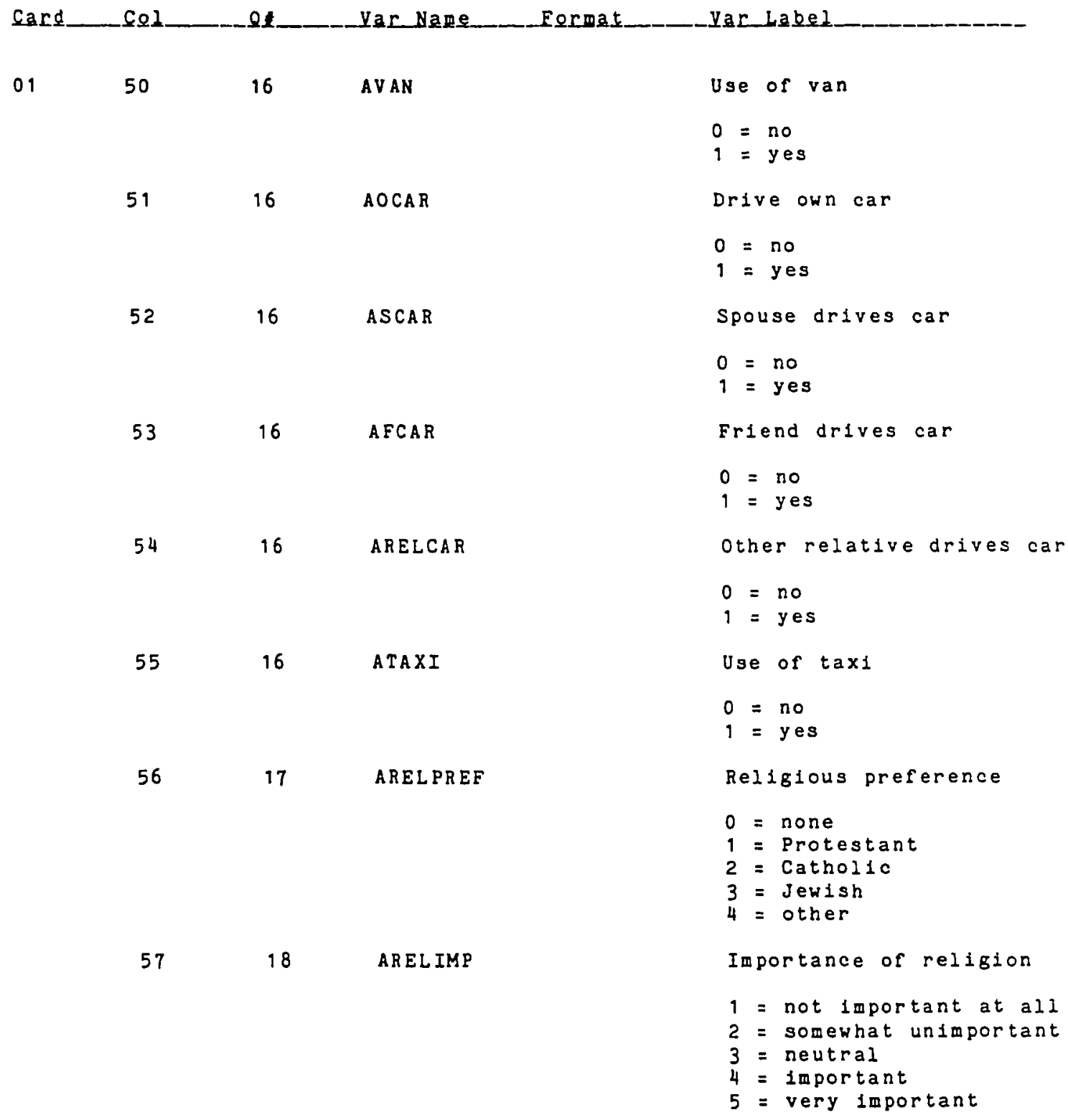




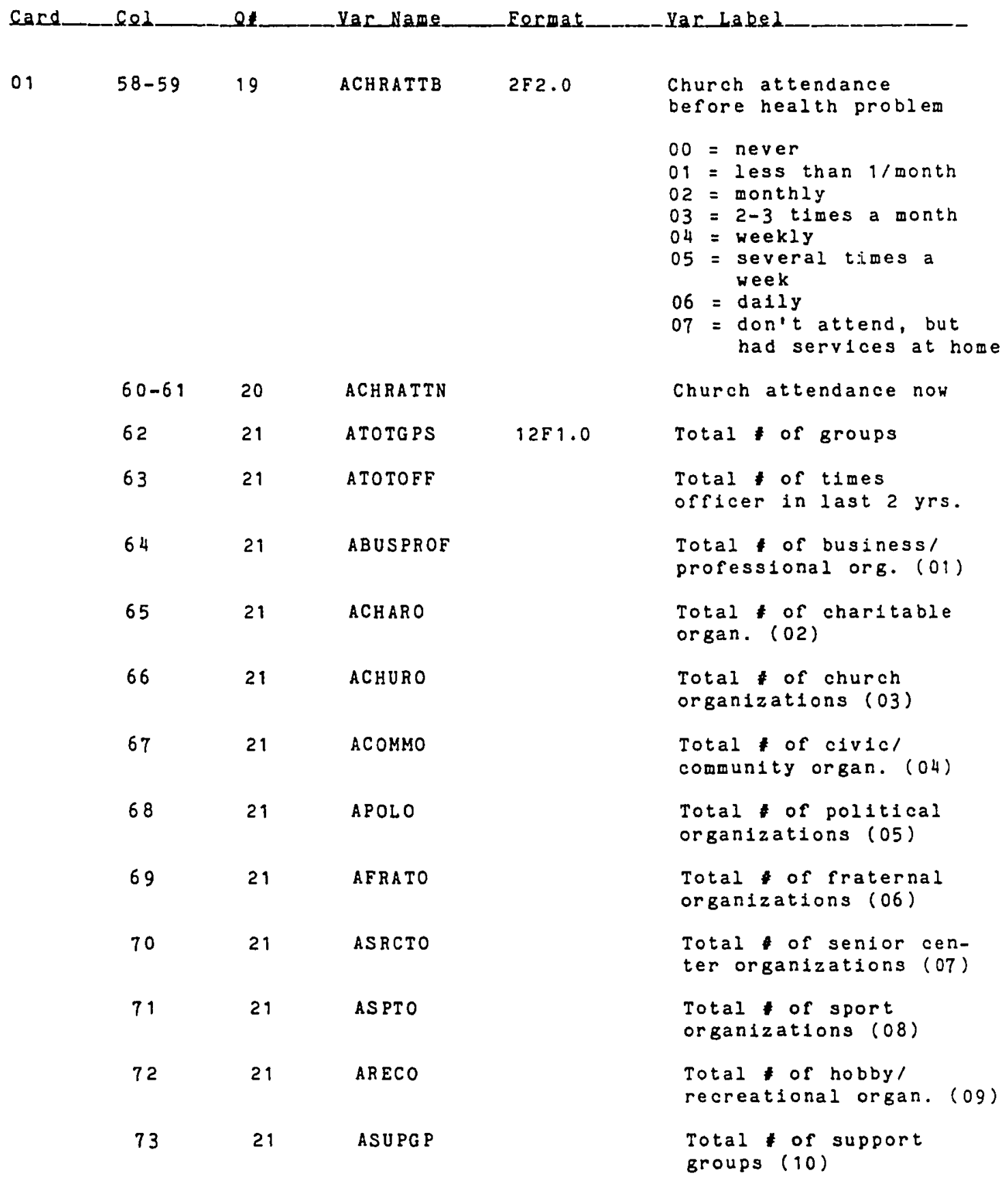


card c요

01 $74-75$

21

AACTDIE

21

AAVATDIF

76

$77-78$

22

AALCOHOL

BLANK

$79-80$

02

$$
\begin{aligned}
& 1-3 \\
& 4 \\
& 5-6 \\
& 7-8
\end{aligned}
$$

9

$$
23(1)
$$

ID

INTER

CARD

BLANK

AWALR

(n)

$\begin{array}{lll}10 & 23(2) & \text { ADRESS } \\ 11 & 23(3) & \text { ABATH } \\ 12 & 23(4) & \text { AEAT }\end{array}$

F1.0

F2.0

F2.0

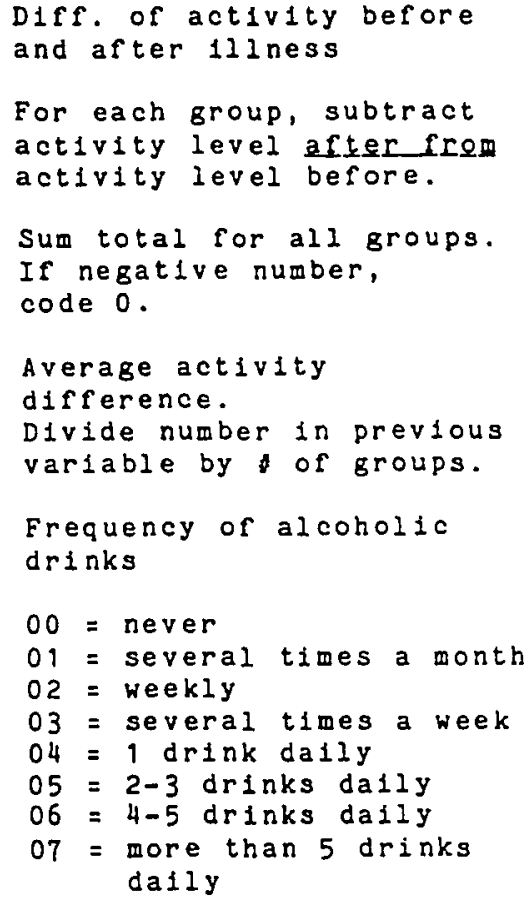

$2 x$

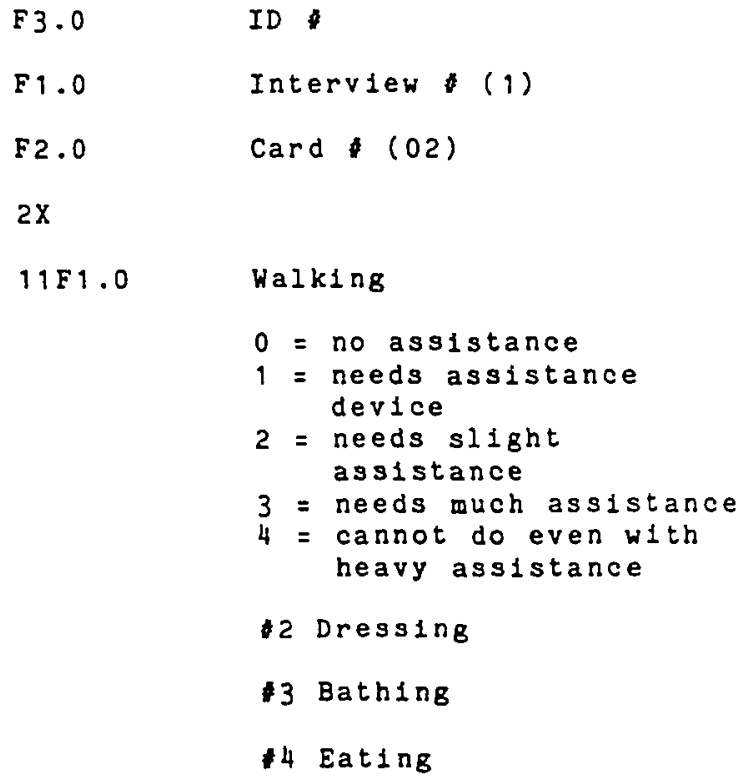


cars Col.

02

\begin{tabular}{|c|c|c|c|}
\hline 13 & $23(5)$ & ACOOK & \\
\hline 14 & $23(6)$ & ATOILET & \\
\hline 15 & $23(7)$ & ADRIVE & \\
\hline 16 & $23(8)$ & ASHOP & \\
\hline 17 & $23(9)$ & ALAUND & \\
\hline 98 & $23(10)$ & ALTHWK & \\
\hline 19 & $23(11)$ & A HV HWK & \\
\hline $20-21$ & 23 & ATOTPYSD & $2 F 2.0$ \\
\hline $22-23$ & $24-34$ & ATOTNAME & \\
\hline 24 & 24 & ATGETHH & $15 \mathrm{~F} 1.0$ \\
\hline 25 & 25 & ATG IV EHH & \\
\hline 26 & 26 & ATGETAD & \\
\hline 27 & 27 & ATGETID & \\
\hline 28 & 28 & ATGIVEAD & \\
\hline 29 & 29 & ATGVHST & \\
\hline 30 & 30 & ATGVHLT & \\
\hline 31 & 31 & ATAD & \\
\hline 3 & 32 & ATHLPERS & \\
\hline
\end{tabular}
$\$ 5$ Cooking
$\$ 6$ To1let
\$ Driving
* Shopping
* Laundry

10 Light housework

i Heavy housework

Physical dependency Total on ADL scale

Total of names on social support list

Total of names from which subject gets household help $(24)$

Total of names to which subject gives household help $(25)$

Total of names from which subject gets personal advice (\$26)

Total * of names from which subject gets advice for important decisions ( 27$)$

Total of names to which subject gives advice $(28)$

Total of names to which subject would give help in short term 11 iness (29)

Total of names to which subject would give help in long term 11 iness (30)

Total number of additional names

Total number of persons that helped as listed In 32 . 


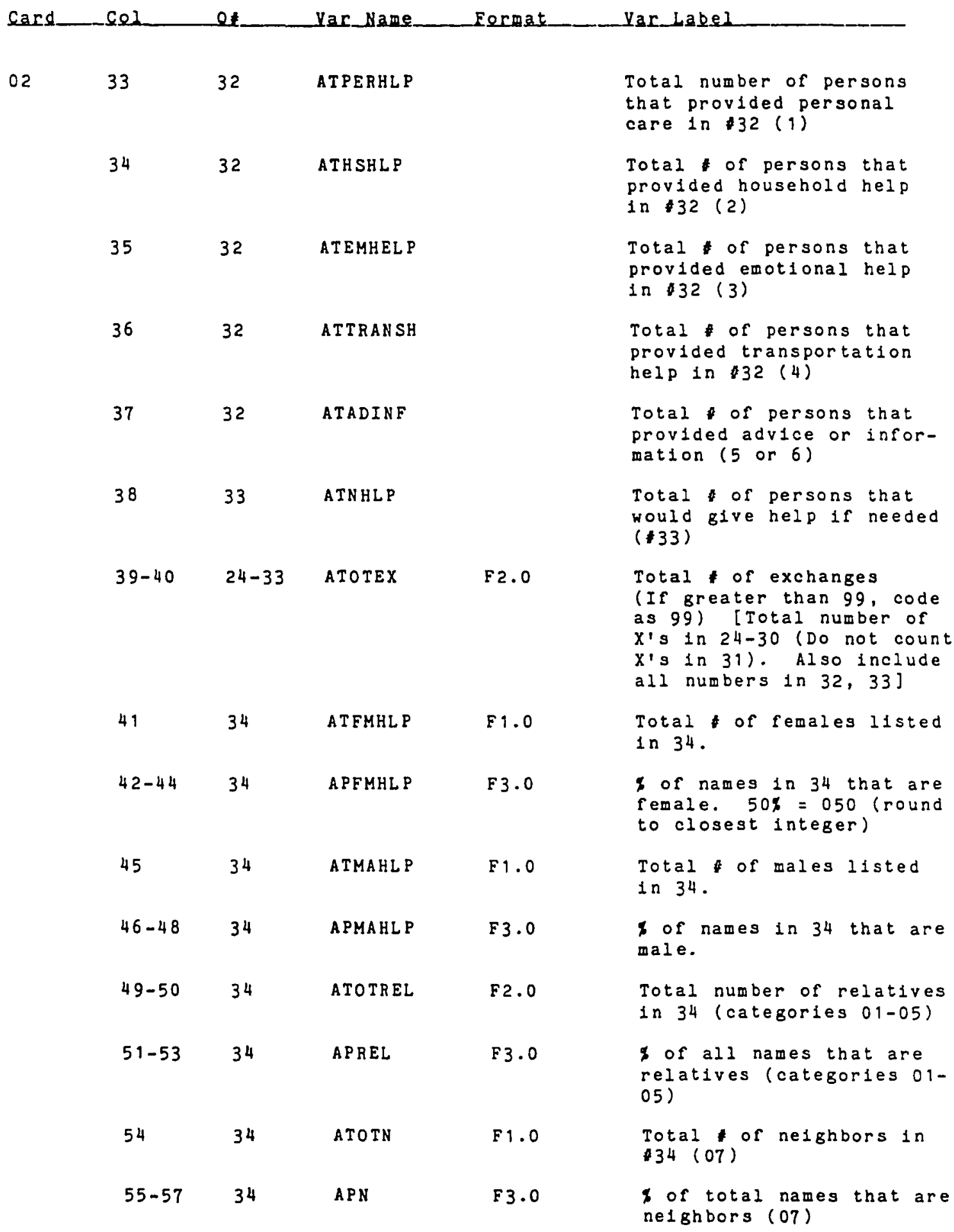




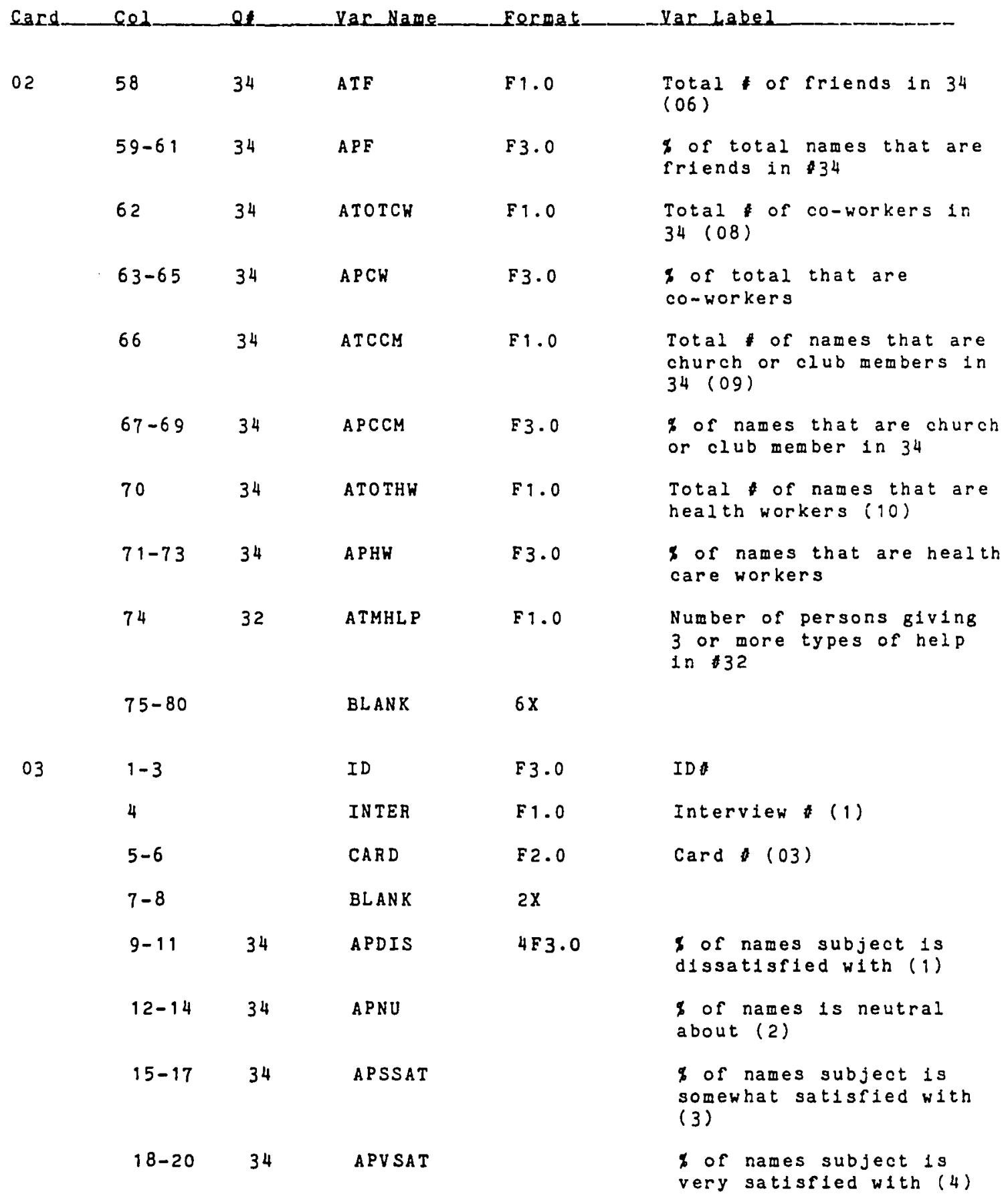




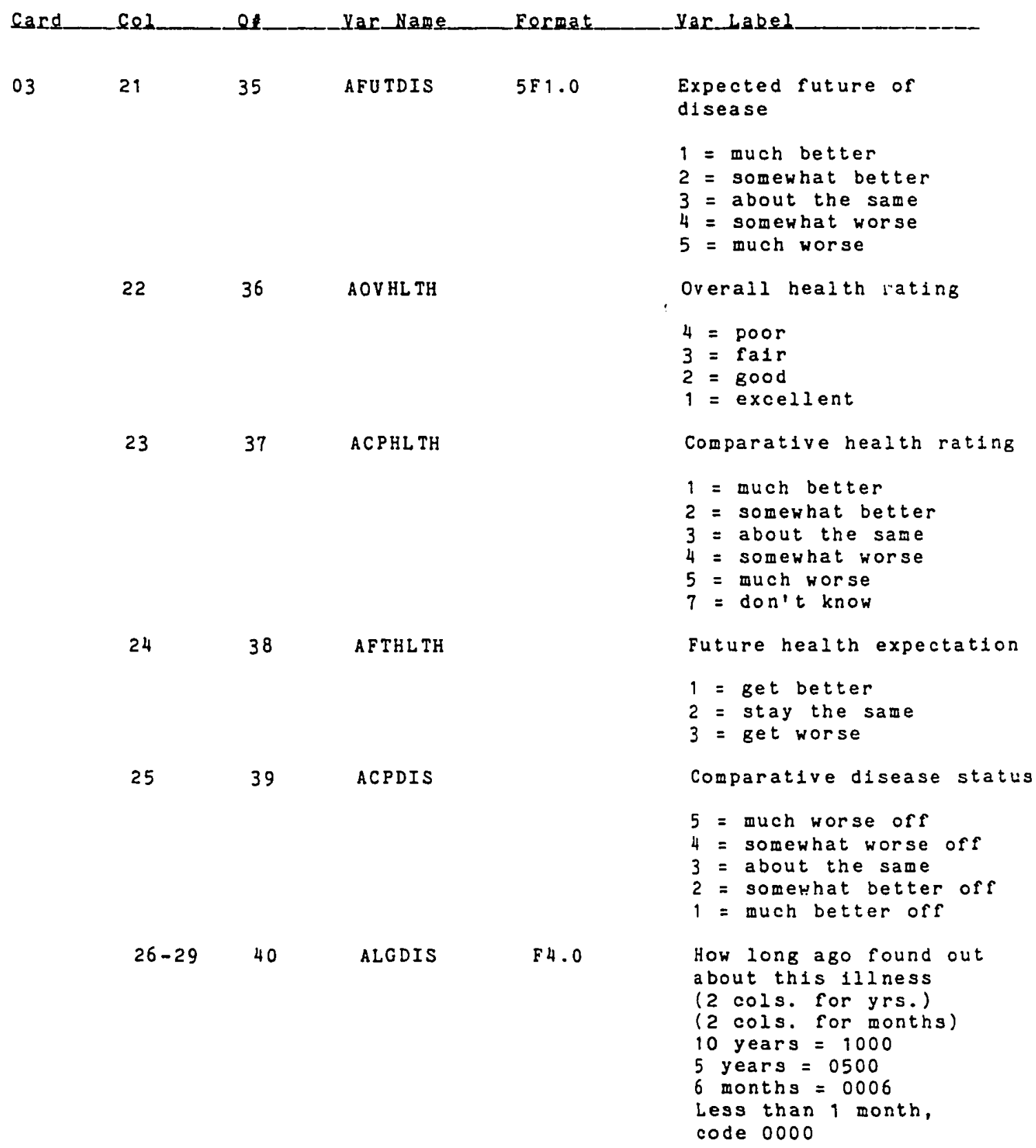


card

03

30

41

ADIAGSR

ATCRDIS

ATRECD

ATHOS

ATDR

$36-37$

44

45

AMAGCRPR

38

AMACCRPR

$39-40$

46

ATMEDS

$41-42$

46

AMEDSCDP

Eonrmat

Yar Labed

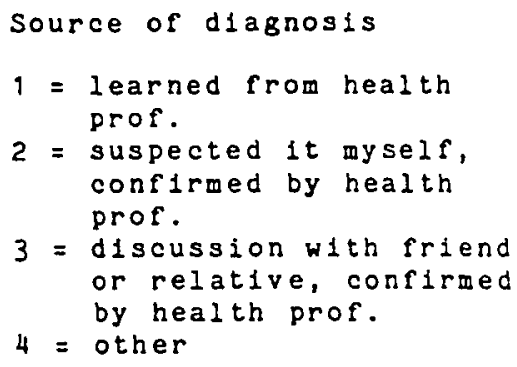


Card___ed___

03

43

46

47

ASLMEDS

45

47

AFQSLMED

46

48

AN RMEDS

47

48

AFQNRMD 1

48

49

50

49

AFQNRMD 2

APEMHPN

51

50

APEMH P P
Eormat

yar Label

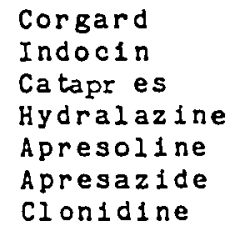

Corgard

Indocin

Catapr es

Hydralazine

Apresoline

Apresazide

Clonidine

Meds taken for depression

Total of the rollowing

meds listed

ElaviI

Tofranil

Desyrel

Asendin

Sinequan

Total of sleep

medications

Frequency of taking

most common sleep med

$1=$ less than once a month

2 = several times a month

3 = once a week

4 = several times a week

$5=d a i l y$

$6=2-3$ times daily

$7=4$ or more times daily

Total of medications

for nerves

Frequency of nerve

medications 1

Frequency of nerve

medication 2

Receiving prof emotional help now

$0=n_{0}$

$1=$ yes

Reason for emotional help

Code 1 = depression

$0=$ any other

$9=$ not applicable

* or times recelved professlonal emotional help in the past?

$0=$ never 
card

cel

Q

Var Name

AREEMHPP

03

52

57

51

ARET

58

51

AJ OBL

59

60

51

AINSTSP

61

$52 \mathrm{~A}$

AEFSC

$\begin{array}{lll}62 & 52 B & \text { AEFCO } \\ 63 & 52 C & \text { AEEEH } \\ 64 & 52 D & \text { AEFS: } \\ 65 & 52 E & \text { AEFHHC }\end{array}$

Eormat.

Var Label

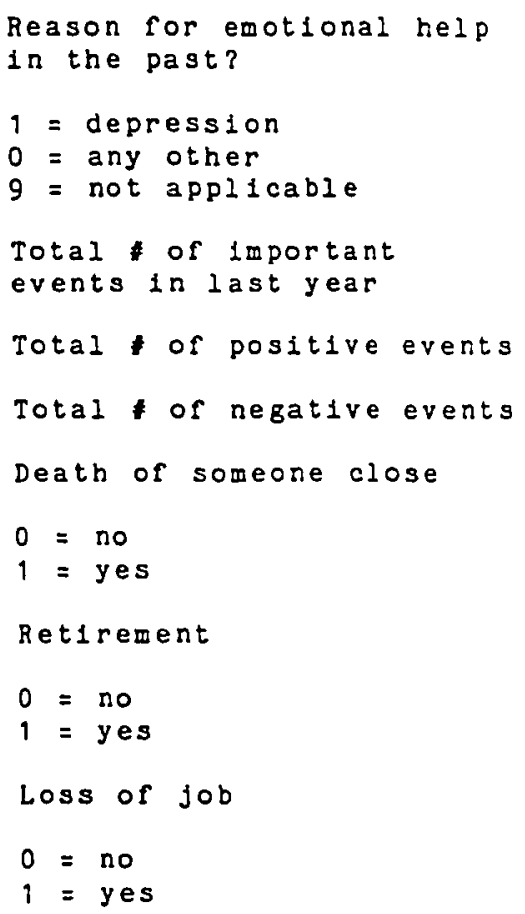




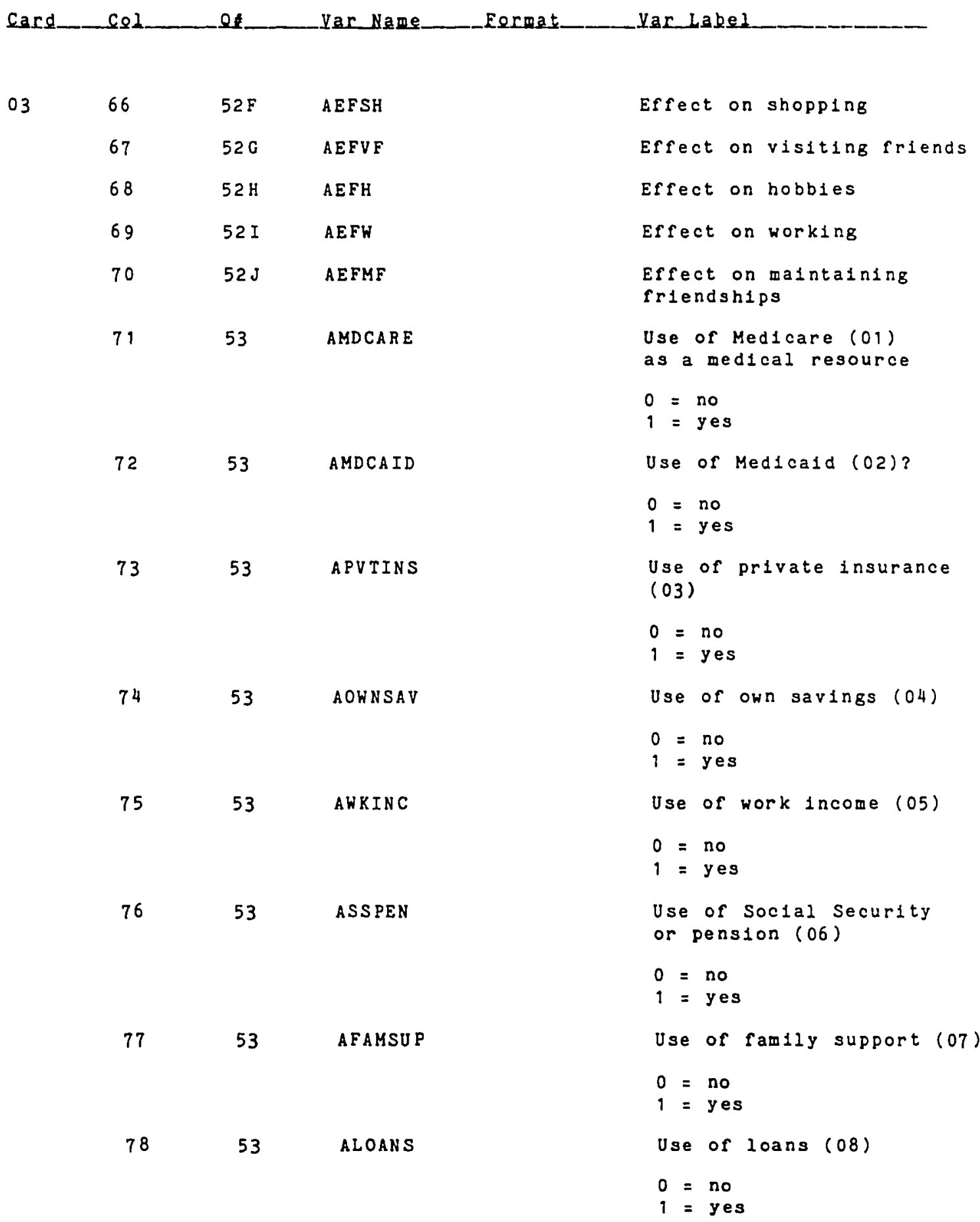




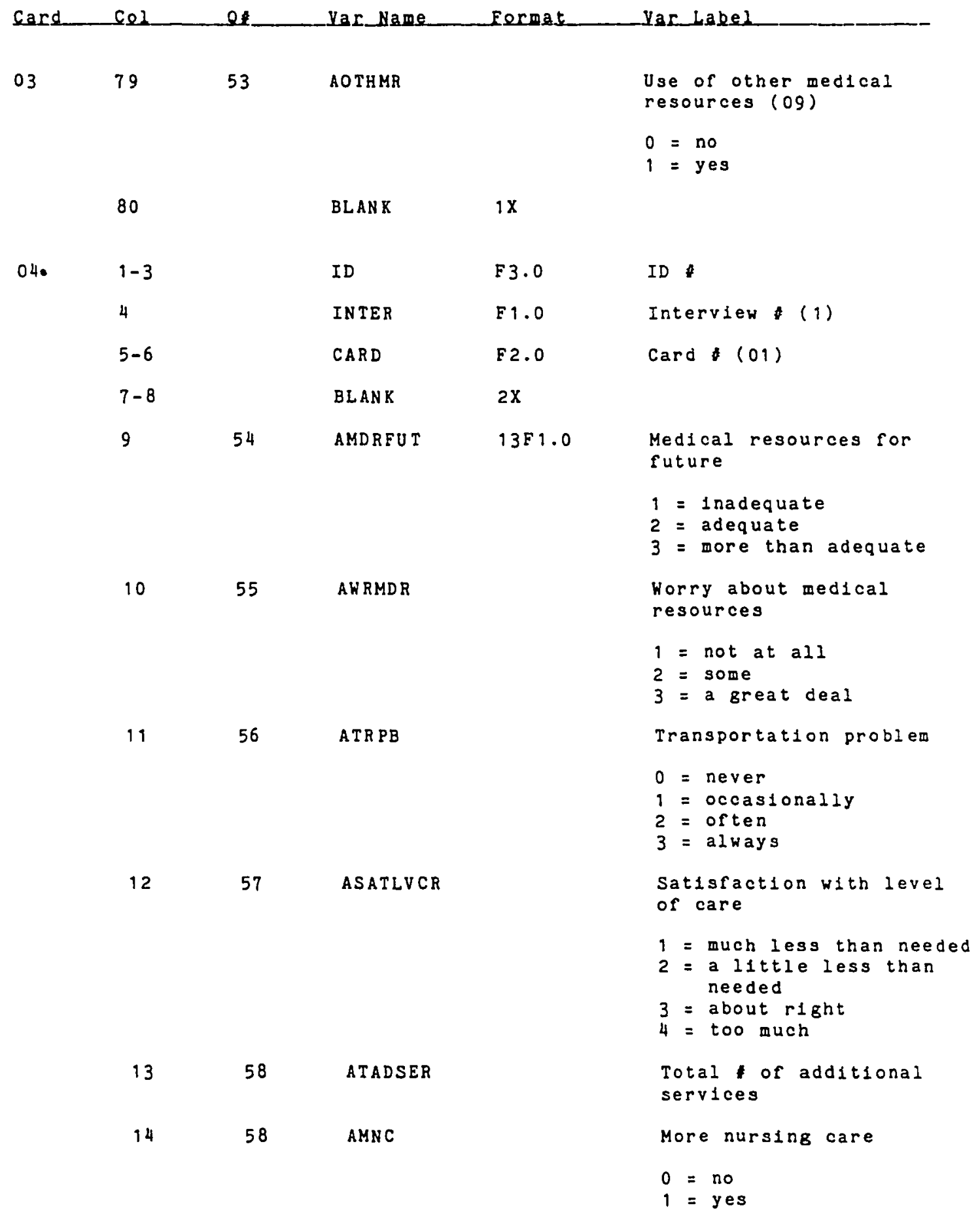




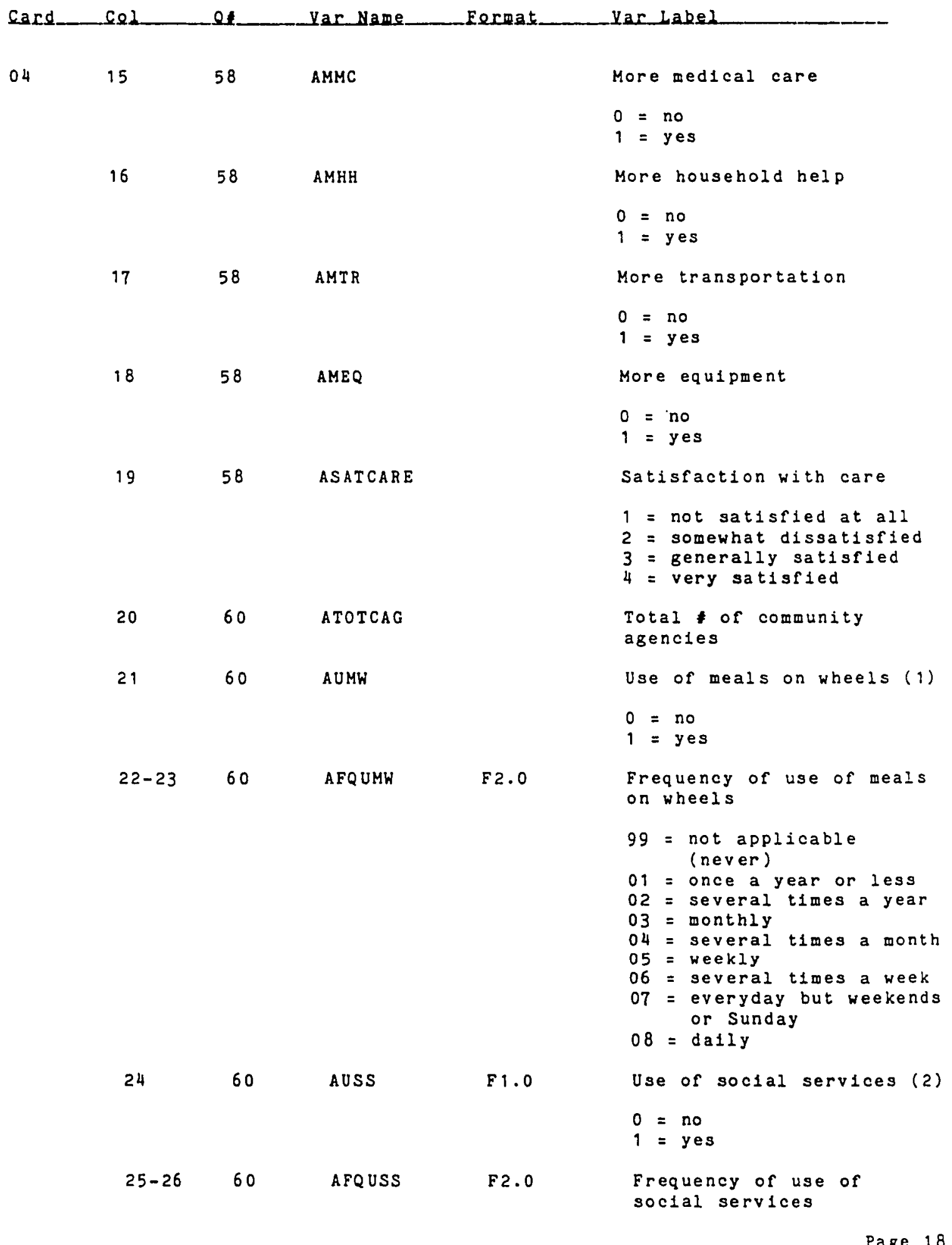


Qf

Yar Name

Fermat

F1.0

AUTR

04

27

60

AU T

60

AFQUTR

60

AUSRCT

F1.0

F2.0

30

60

$31-32$

AFQSRCT

A UHH

33

$34-35$

AFQUHH

61

AGNPN

36

AGNPN

$37-39$

62

AGN PNSC

E3. 0

E2.0

F1.0

F 2.0

F 1.0

F1.0

APNWK

40

63

A

41-4

64

A PN SCHK

F 3.0

44

65

ALG PN
Yar label

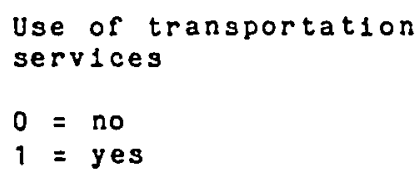

Frequency of use of transportation services

Use of senior center

$0=$ no

1 = yes

Frequency of use of senior center

Use of home health agency

$0=$ no

1 = yes

Frequency of use of home health

Amount of pain in general

$0=$ none

$1=$ not much

$2=a$ fair amount

$3=a$ lot

General pain score

(max.100)

$70=070$

Amount of pain in last week

$0=$ none

$1=$ not much

$2=a$ falr amount

$3=a$ Iot

Pain score for last week $(100$ max.)

$70=070$

Length of pain

3 = always there

2 = there most of tioe

$1=$ only there for a short tIme 
cars

cos

Qt

Yar Name

Eermat

Var Label

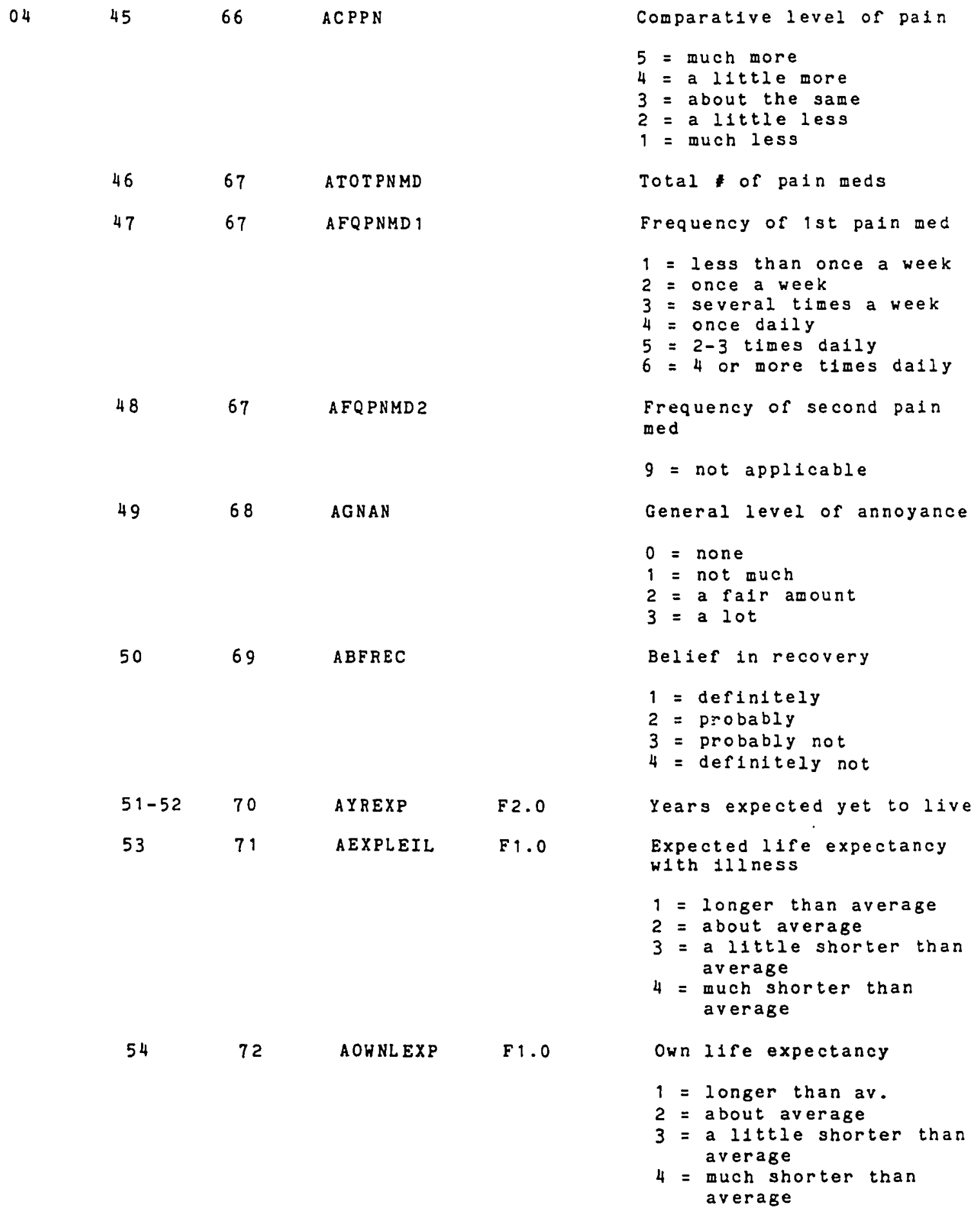

Page 20 


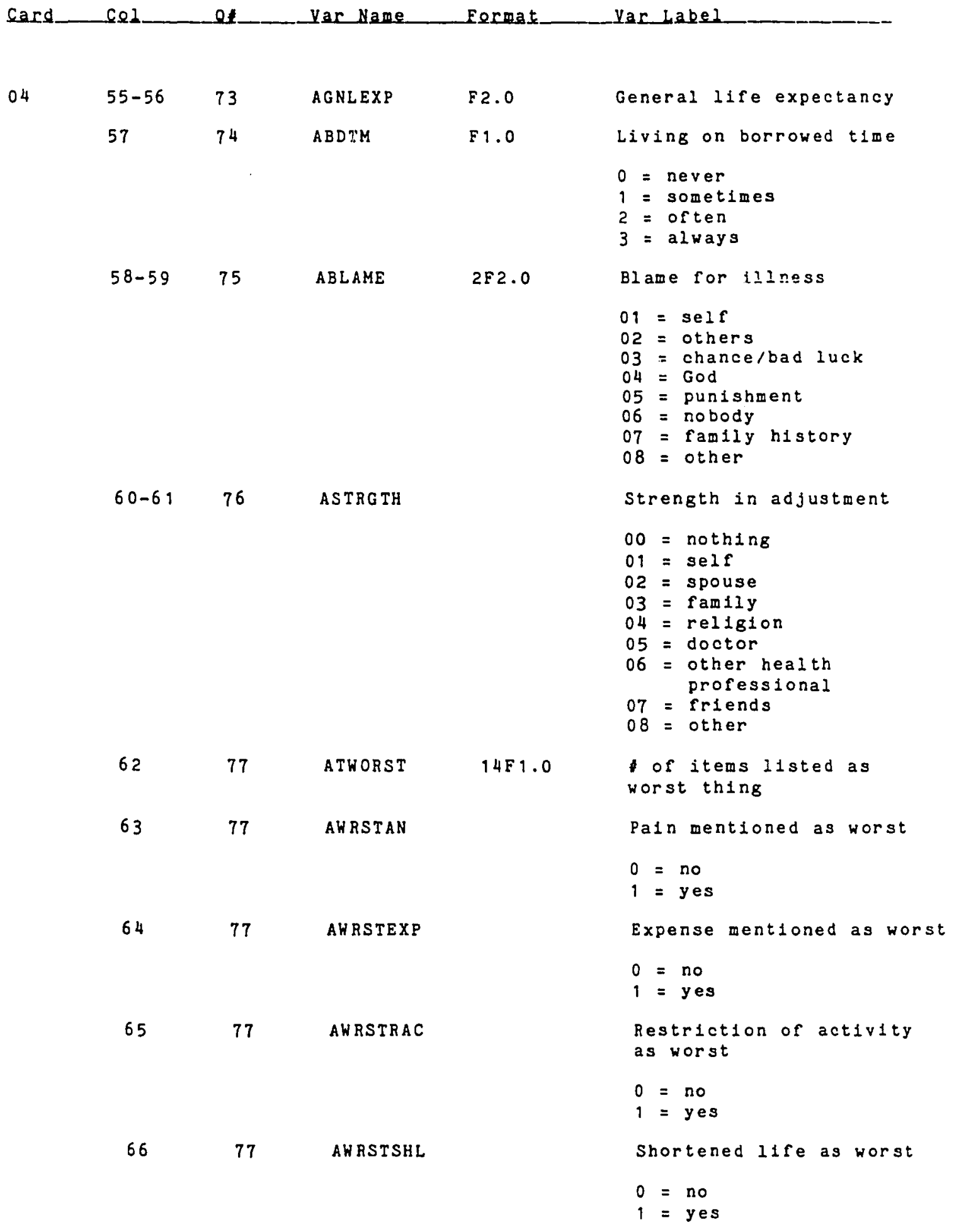


Card_en_el Qf Yac Name

AN POS

04

$\begin{array}{ccc}67 & 78 & \text { ANPOS } \\ 68 & 80 & \text { ANADD } \\ 69 & \text { Evaluation } & \\ 6 & 1 & \text { ANTREP } \\ 70 & 2 & \text { ASUBCOOP }\end{array}$

71

3

ASUBUND

72

4

AOTH PRE

73

5

AOTHPAR

74

6

AOTH PROB

75

6

AVERB

$76-80$

ASUBCOOP
Eormat

Yar label

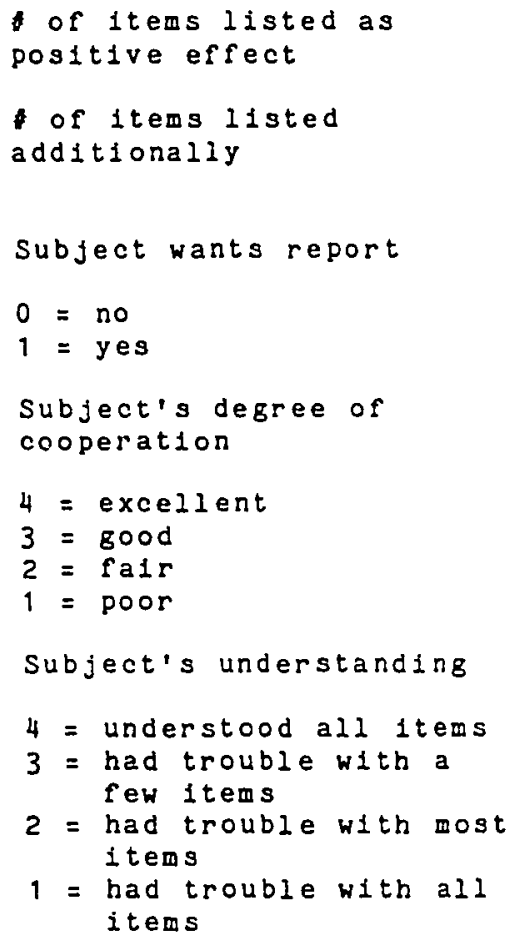

$5 X$ 


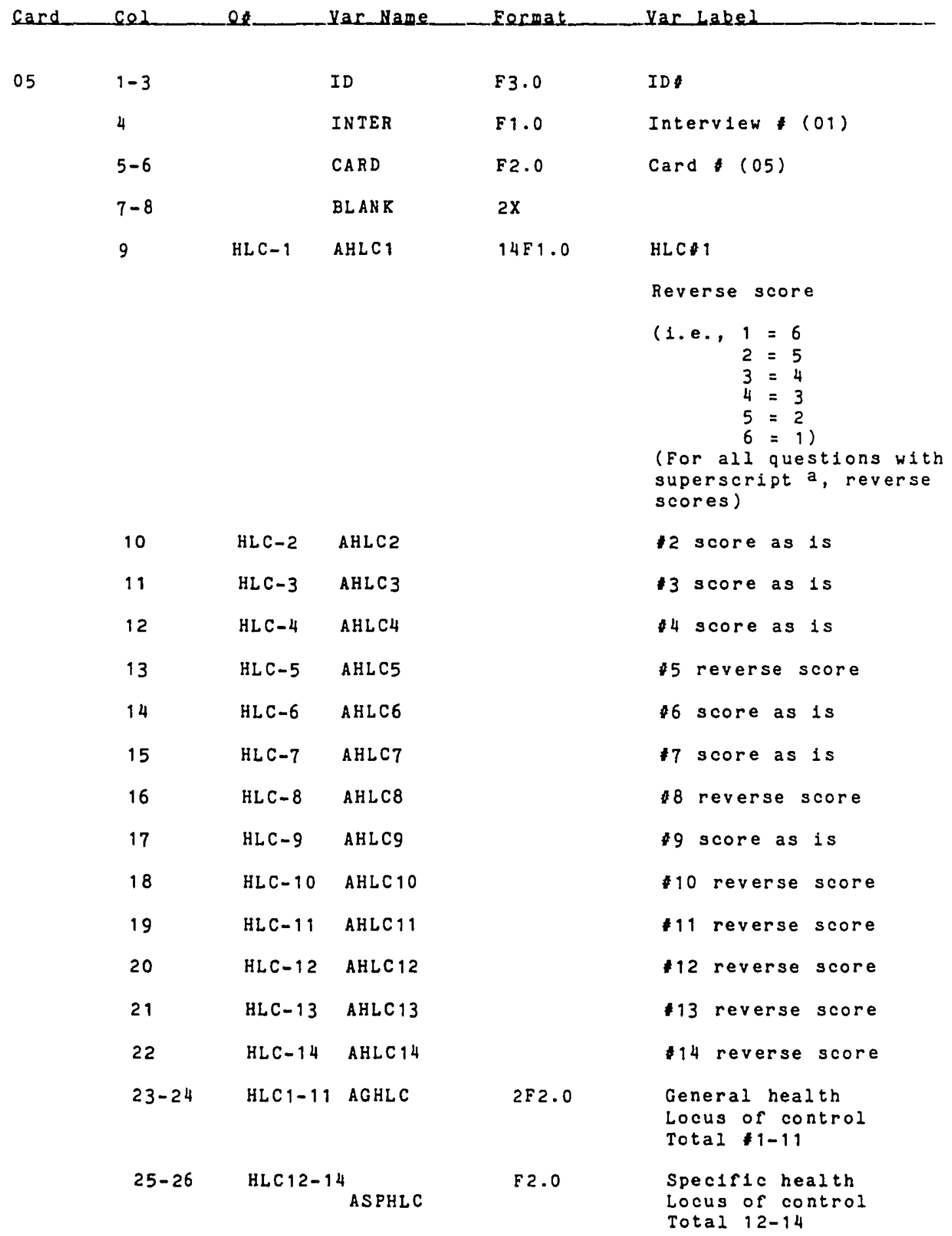




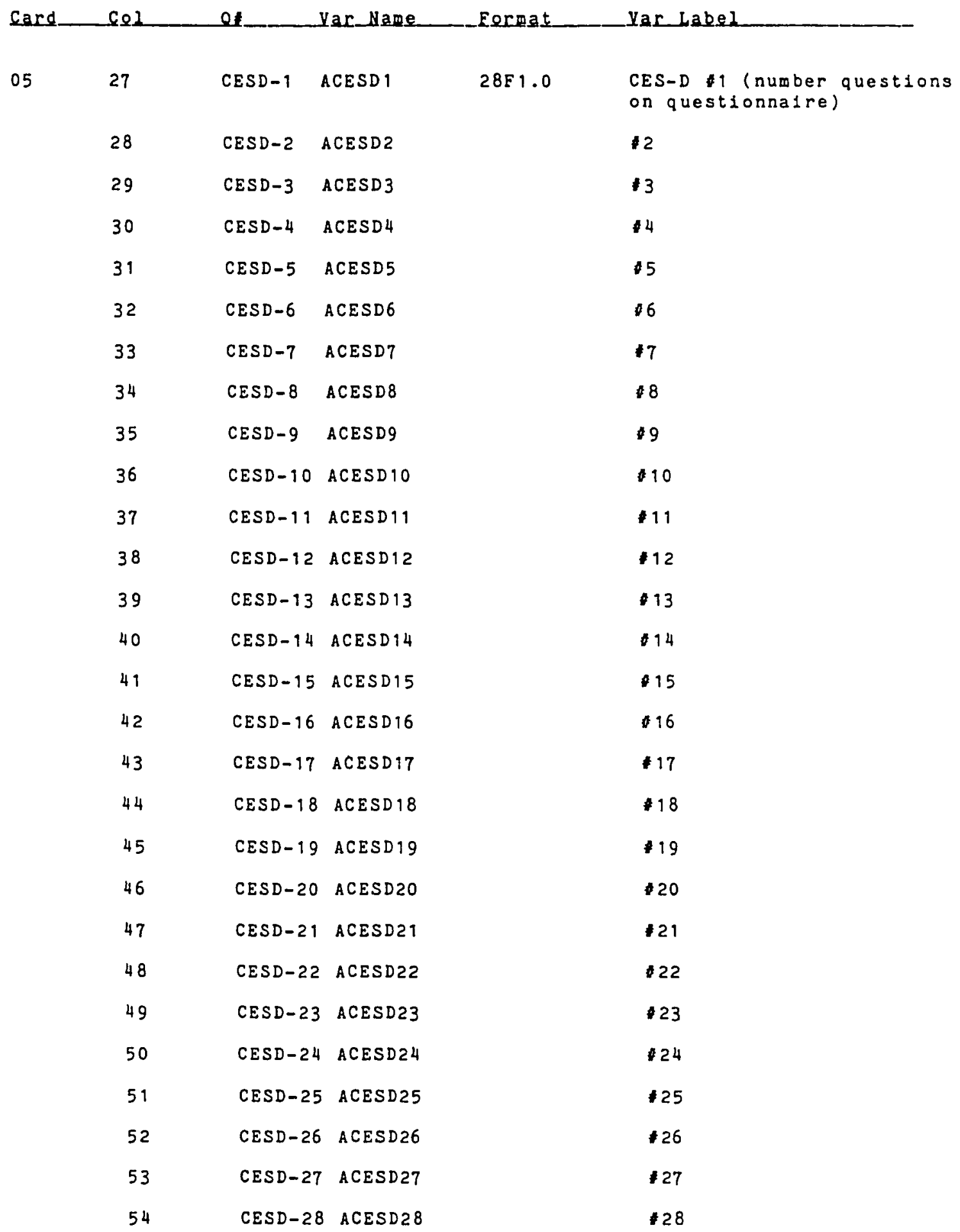




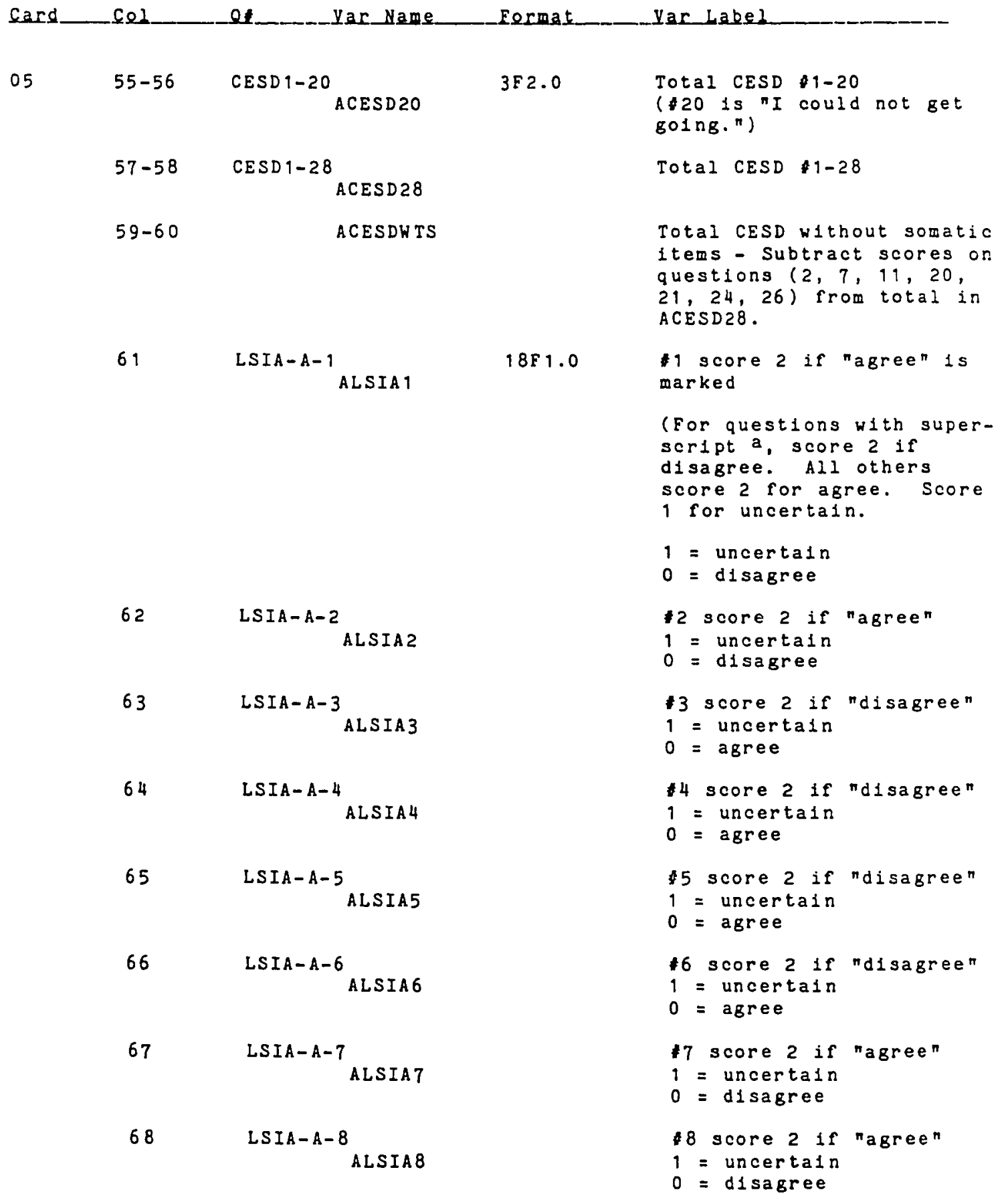




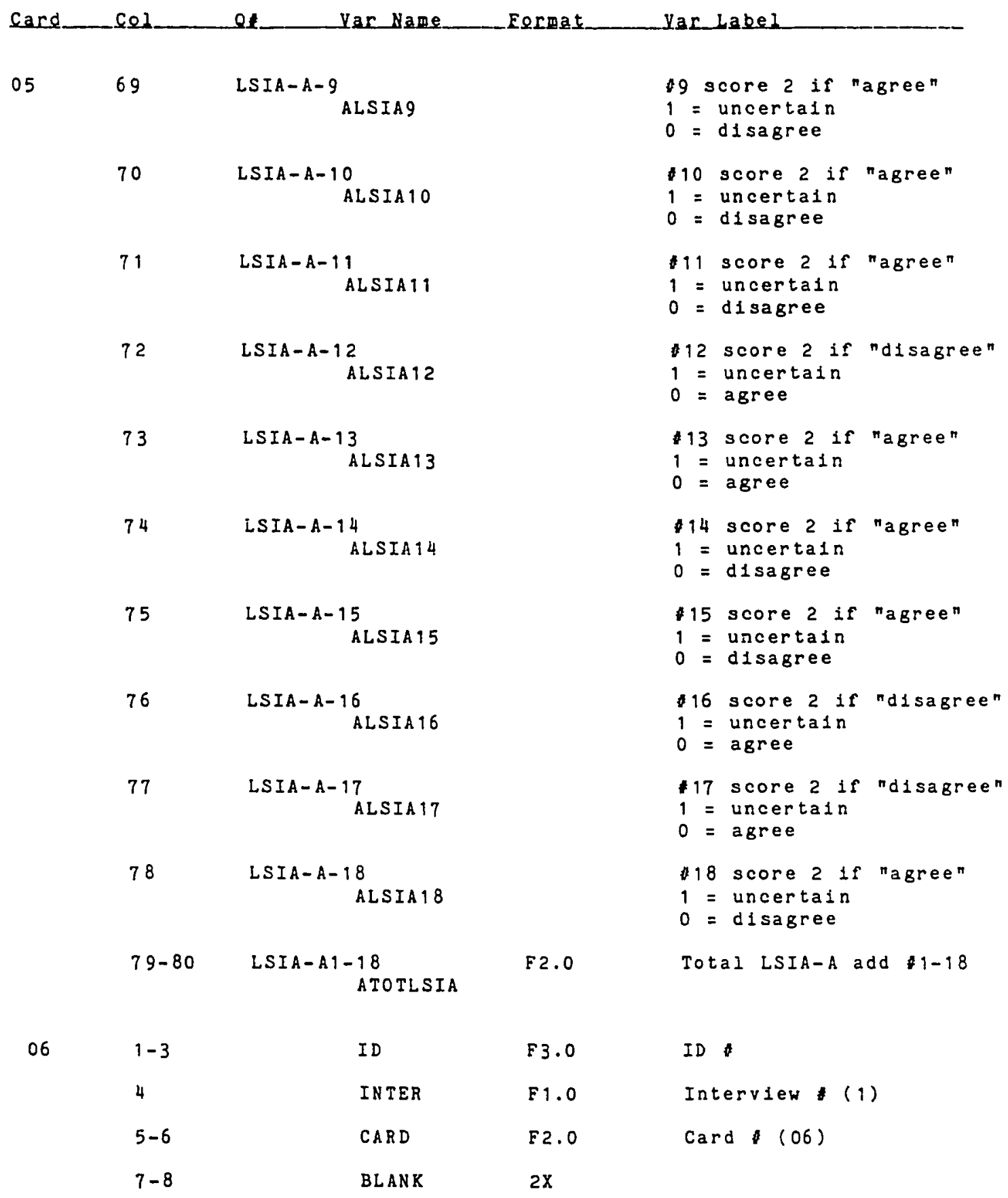




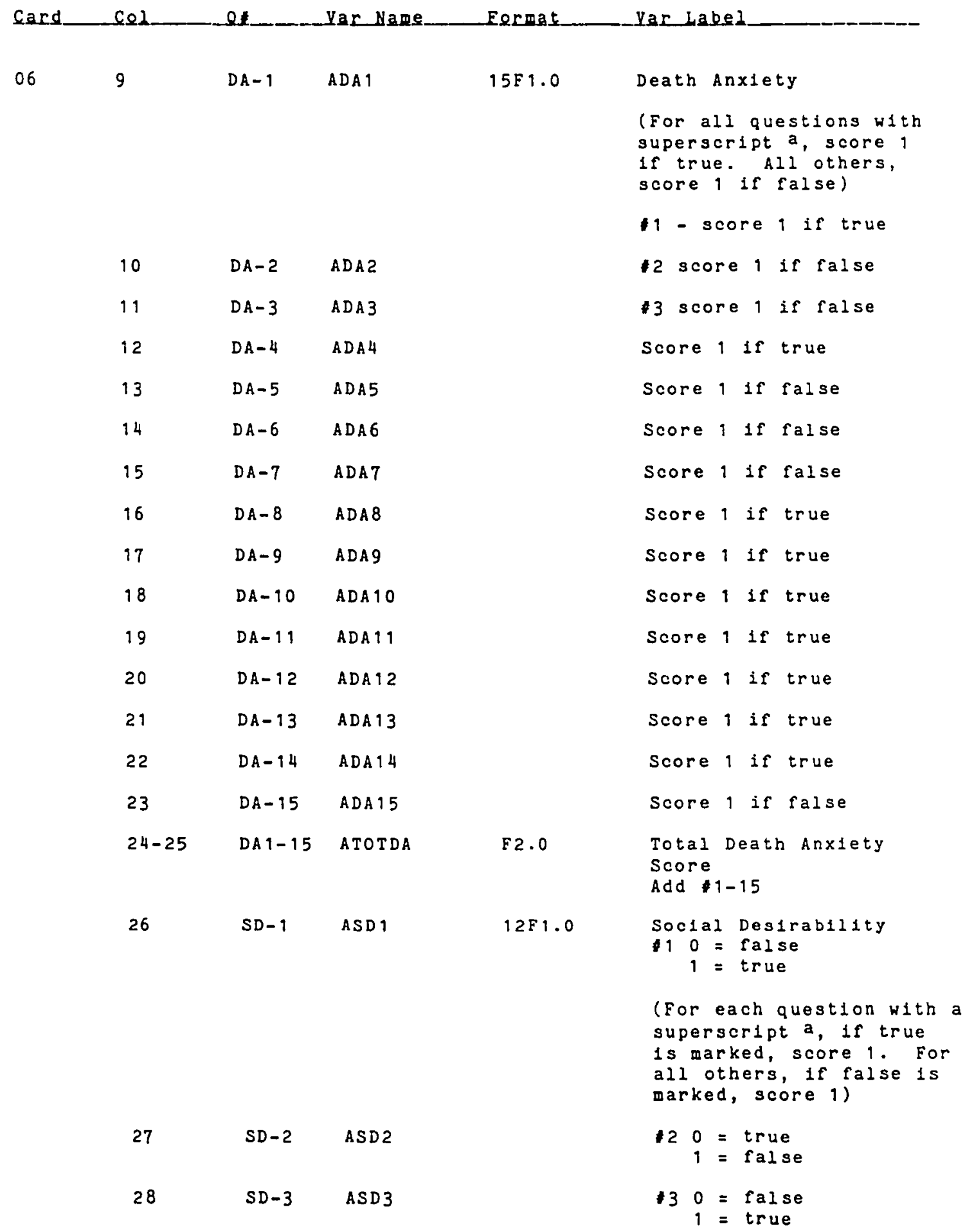




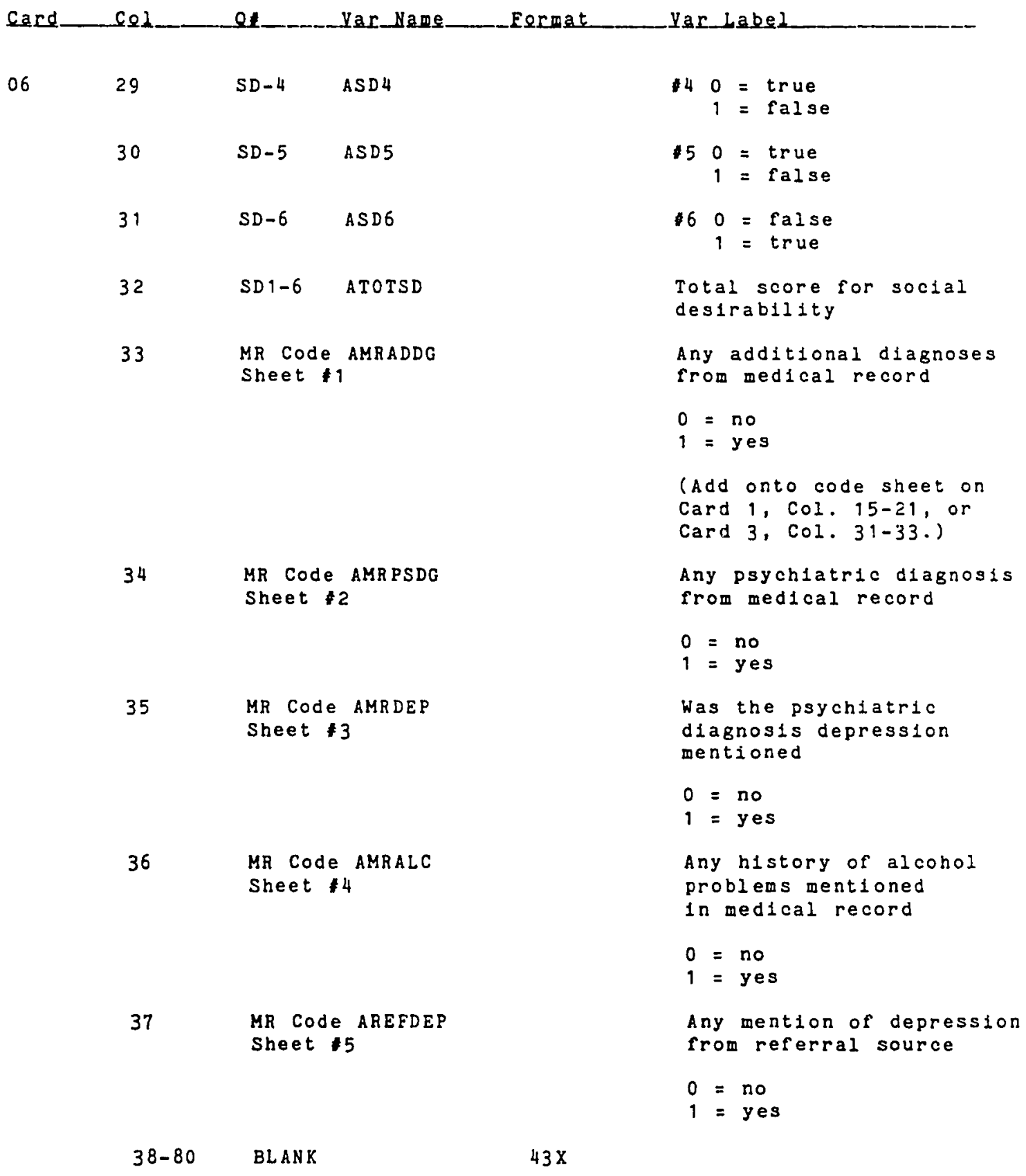




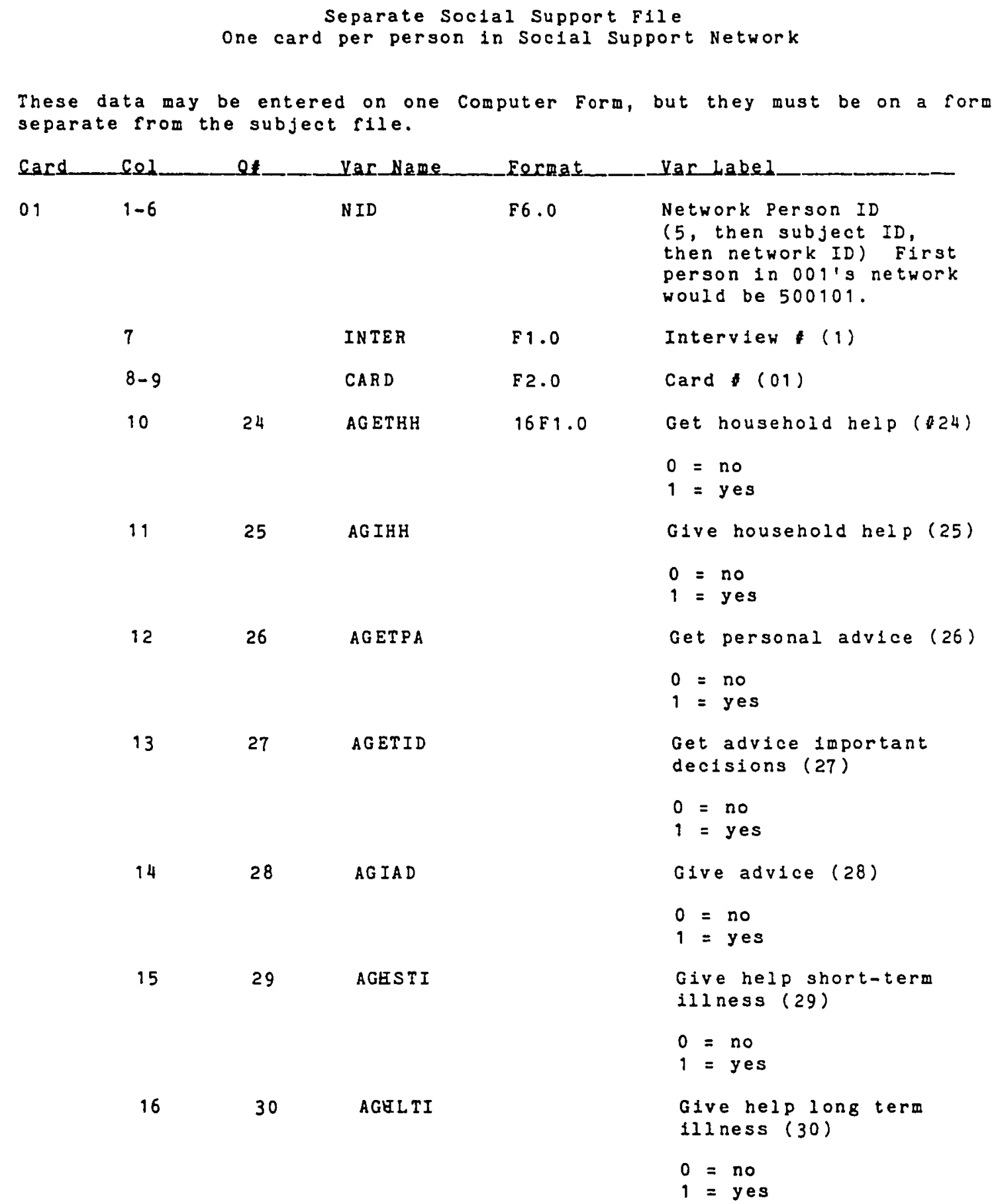




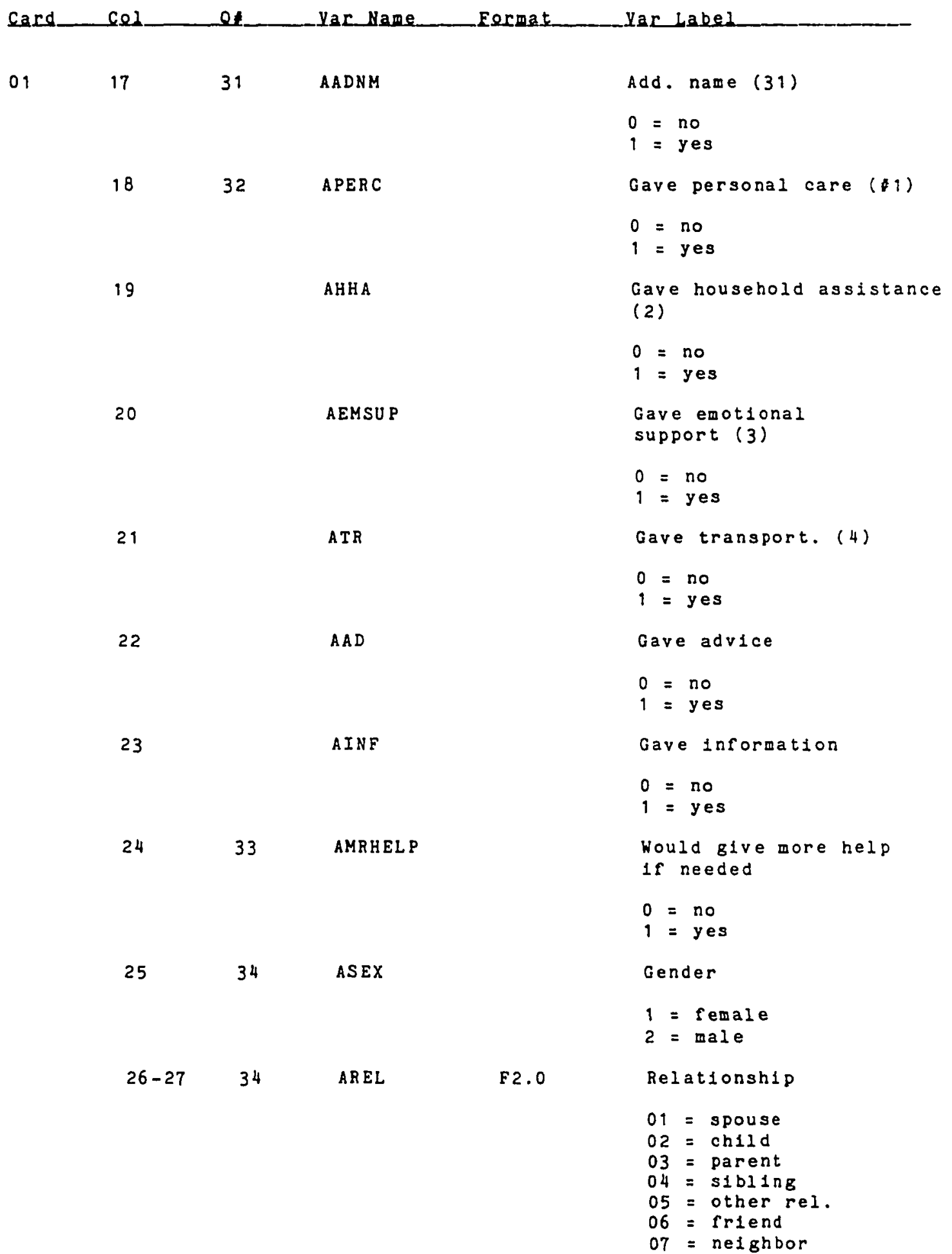




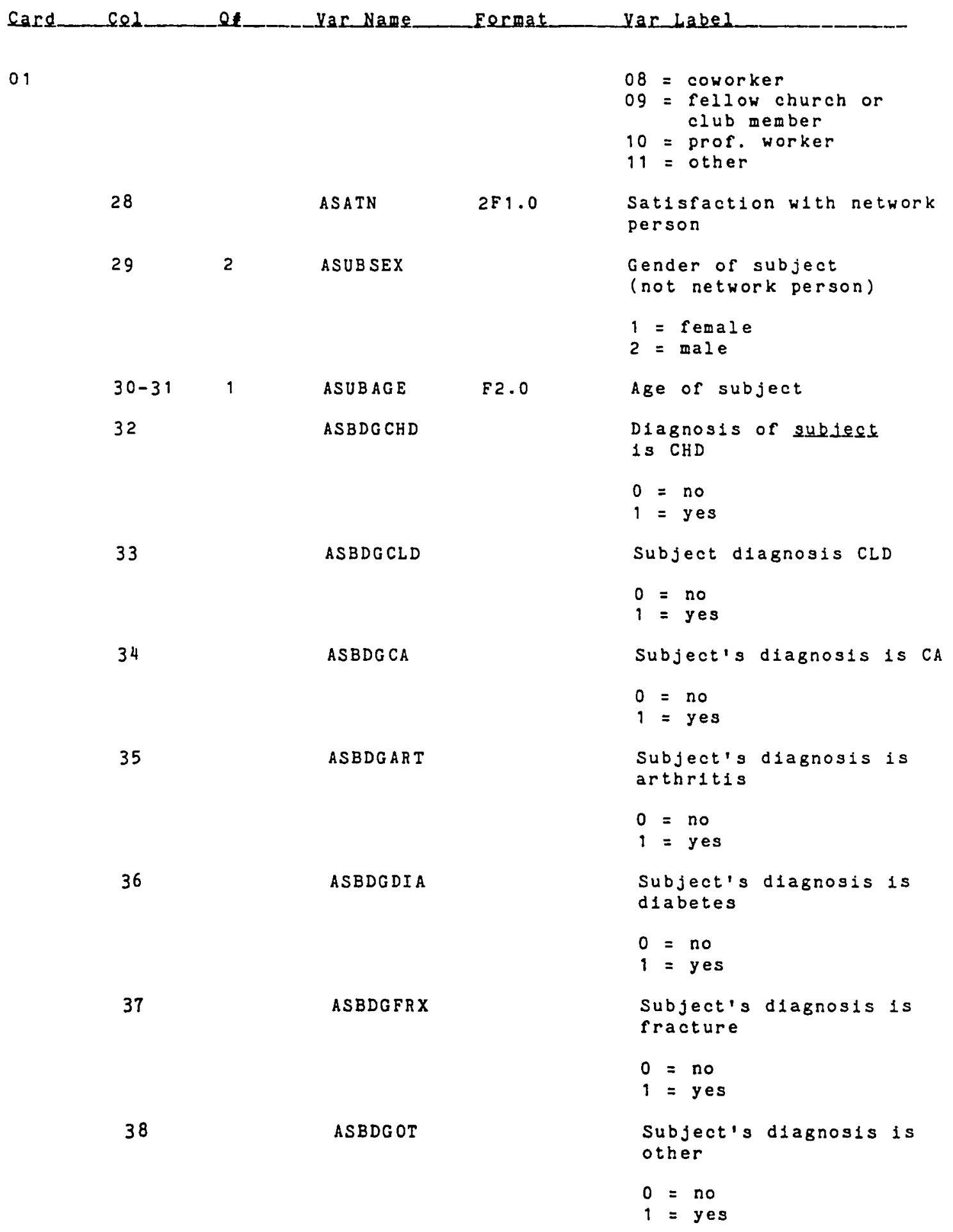


APPENDIX E

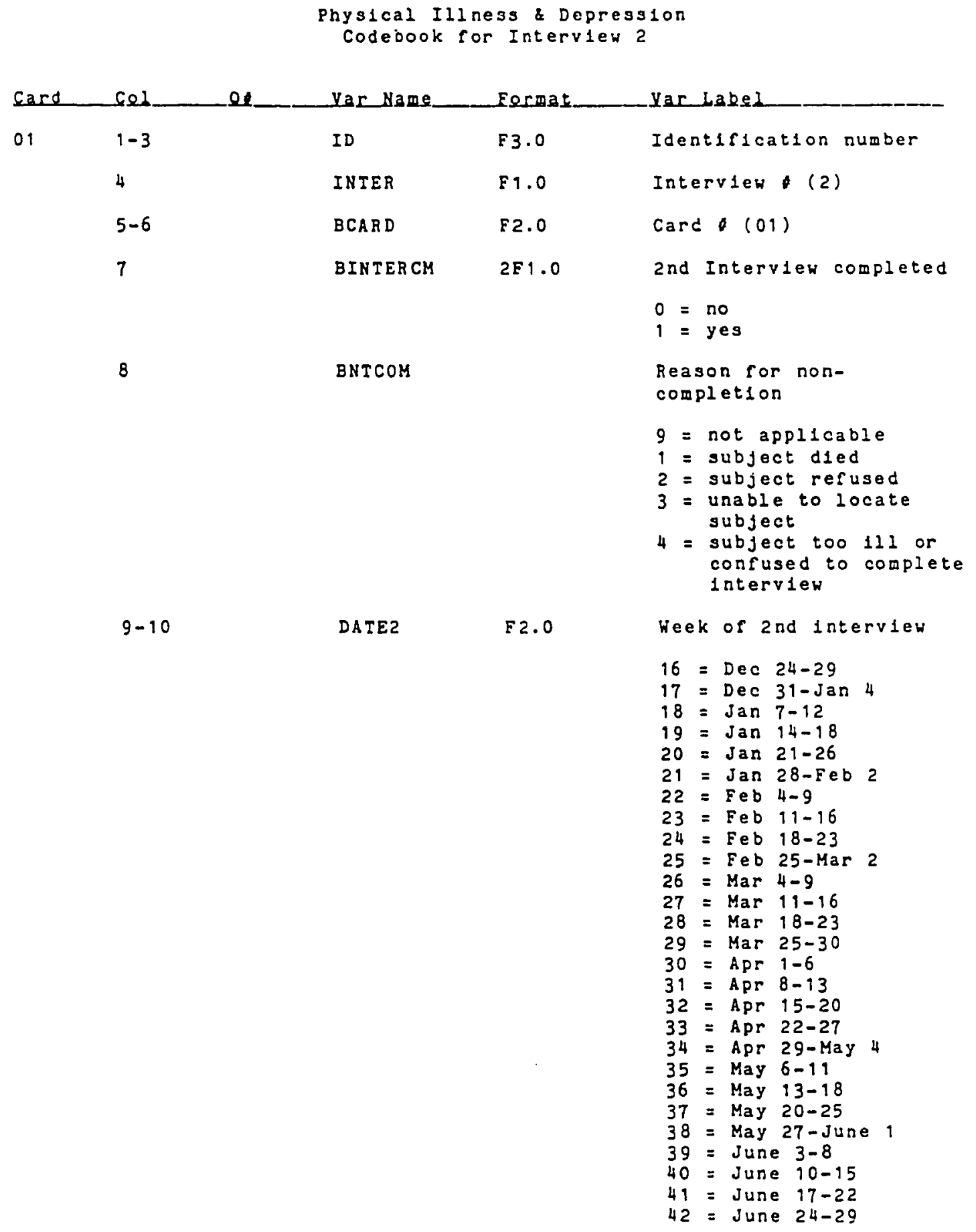




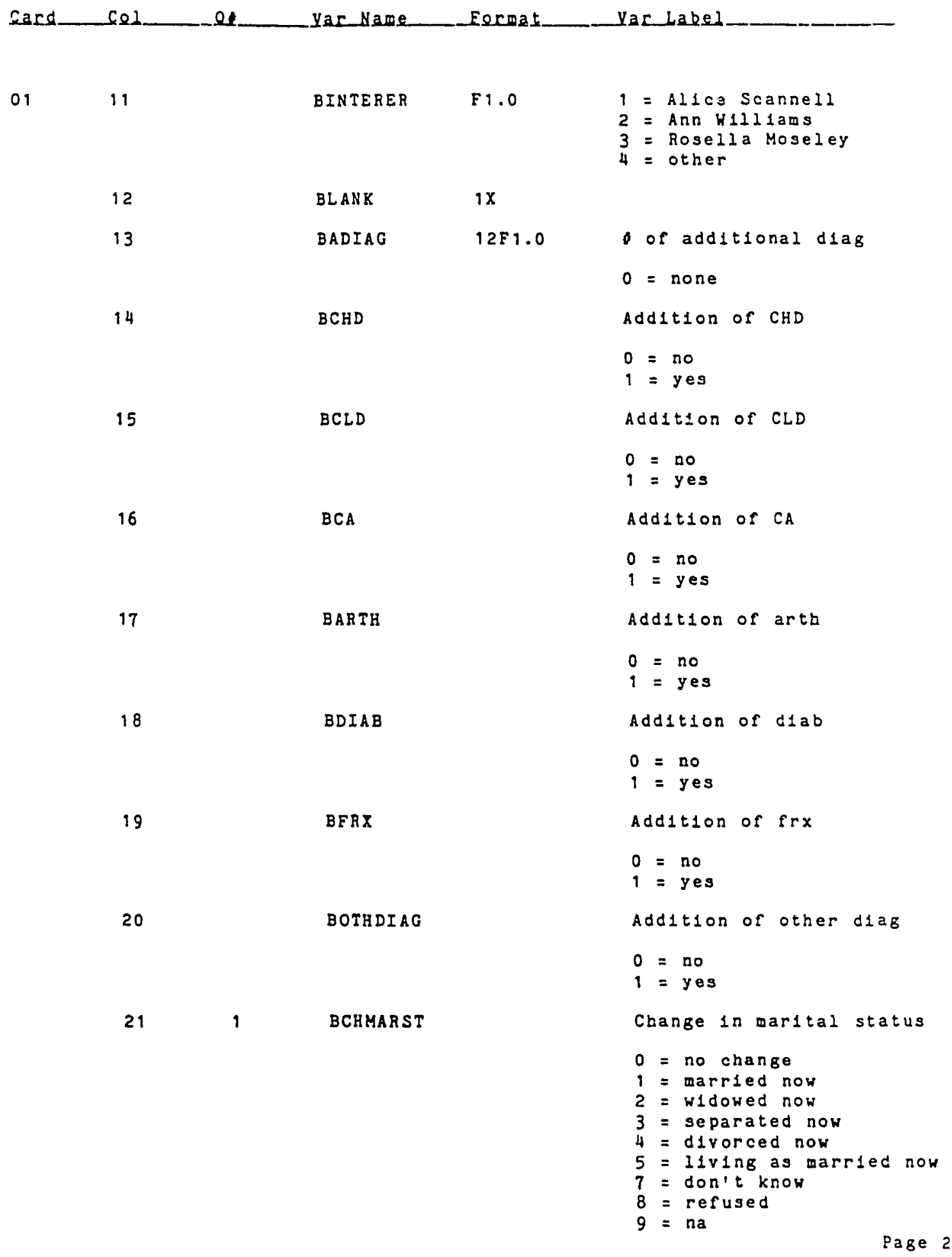




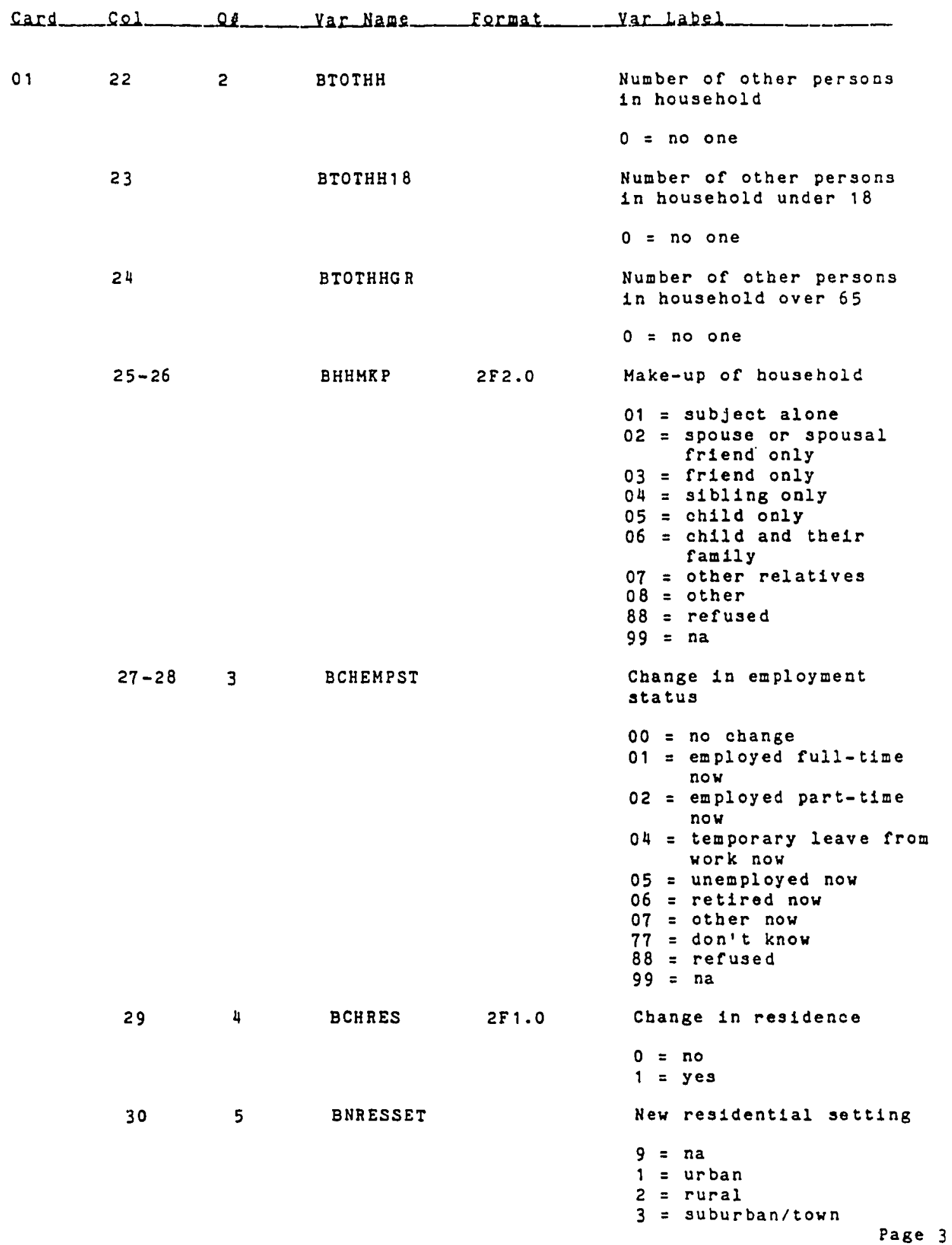




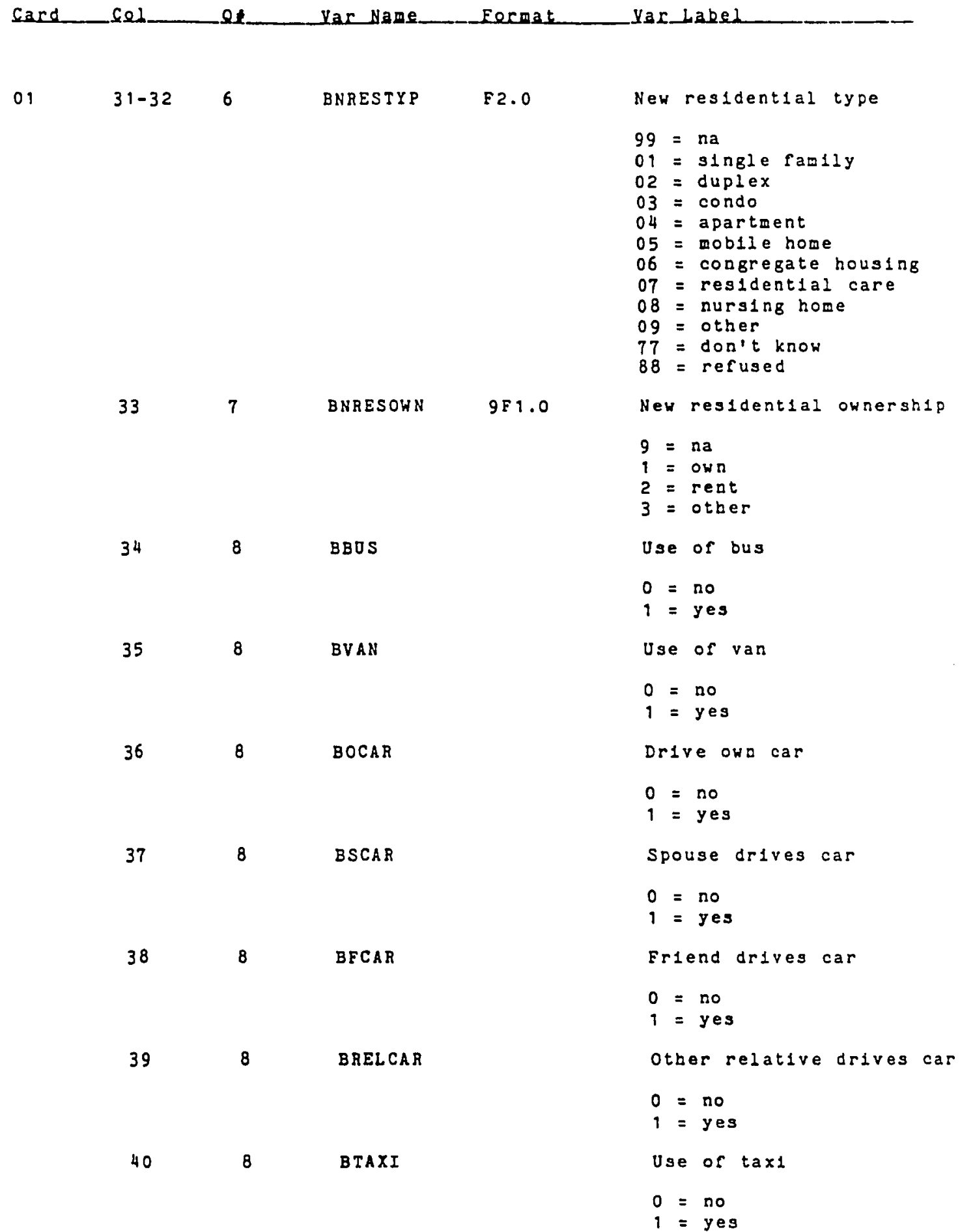




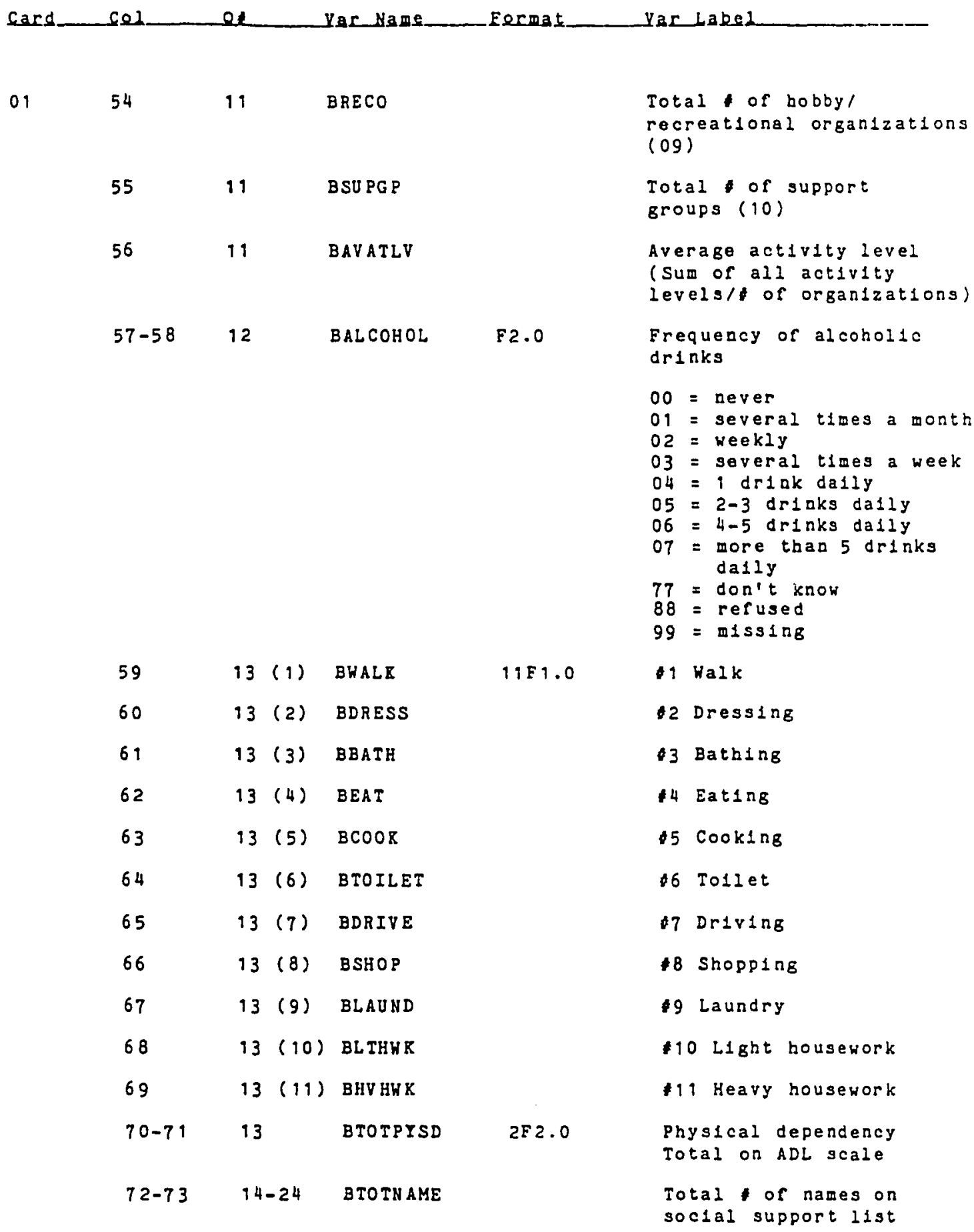




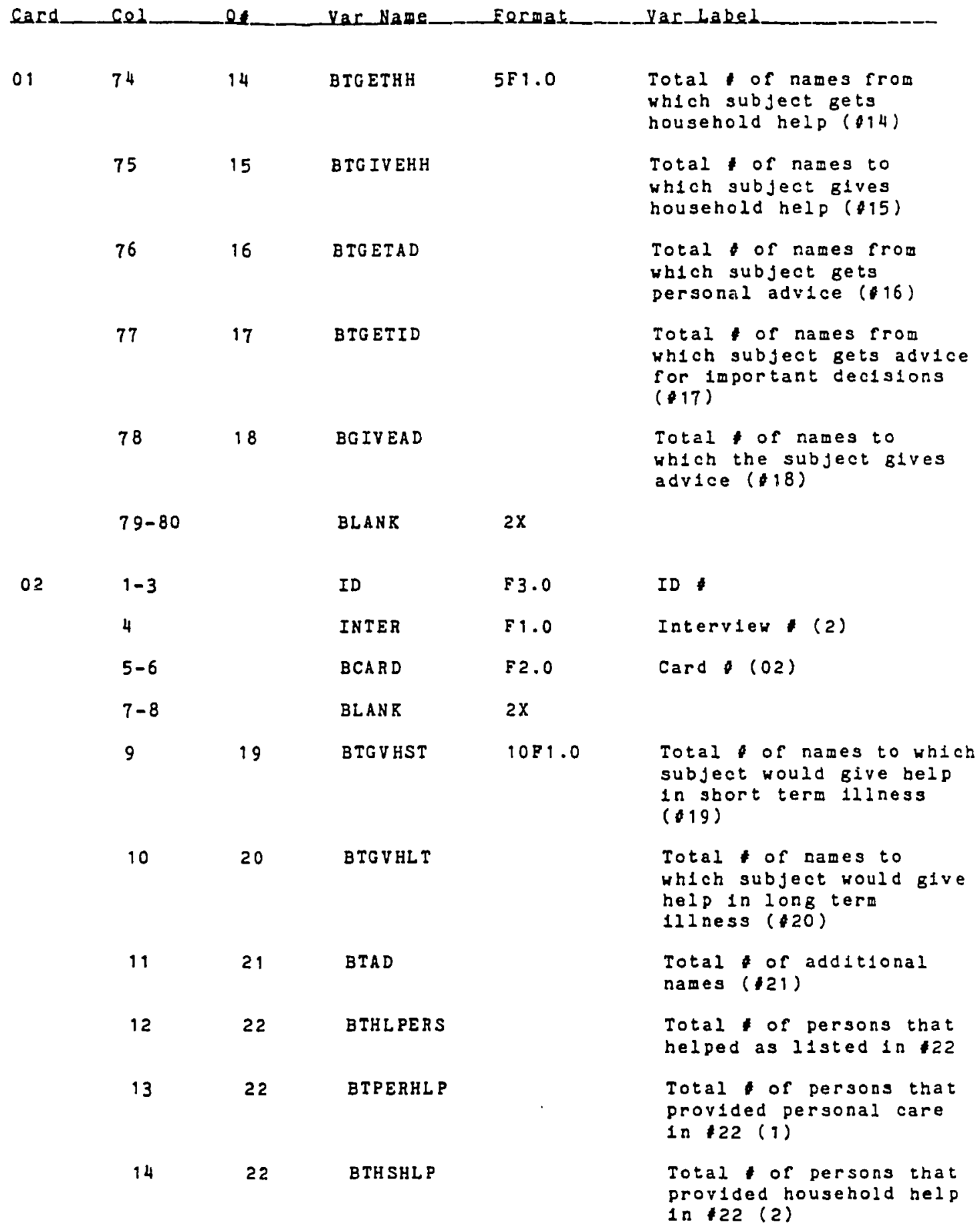




\begin{tabular}{|c|c|c|c|c|c|}
\hline \multirow[t]{15}{*}{02} & 15 & 22 & BTEMHLP & & $\begin{array}{l}\text { Iotal of persons that } \\
\text { provided emotional help } \\
\text { in } 22 \text { (3) }\end{array}$ \\
\hline & 16 & 22 & BTTRANSH & & $\begin{array}{l}\text { Total of pergons that } \\
\text { provided transportation } \\
\text { help in } 22 \text { (4) }\end{array}$ \\
\hline & 17 & 22 & BTADINF & & $\begin{array}{l}\text { Total of persons that } \\
\text { provided advice or } \\
\text { information } 1 \text { n } 22 \\
(5 \text { or } 6)\end{array}$ \\
\hline & 18 & 23 & BTNHLP & & $\begin{array}{l}\text { Total of persons that } \\
\text { would give more help if } \\
\text { needed }(23)\end{array}$ \\
\hline & $19-20$ & $14-24$ & BTOTEX & $\mathrm{F} 2.0$ & $\begin{array}{l}\text { Total of exchanges } \\
\text { (If greater than } 99 \text {, code } \\
\text { as } 99 \text { ) [Total of X's } \\
\text { ln i4-20. Do not count } \\
\text { X's 1n } 21 \text {. Also 1nciude } \\
\text { ali numbers } 1 \text { n } 22,23]\end{array}$ \\
\hline & 21 & 24 & BIFMHLP & $F 1.0$ & $\begin{array}{l}\text { Total of females } \\
\text { listed in } 24\end{array}$ \\
\hline & $22-24$ & 24 & BPFMHLP & F 3.0 & $\begin{array}{l}\text { S of names in } 24 \text { that } \\
\text { are female. } 50 \%=050 \text {. } \\
\text { Round to closest integer. }\end{array}$ \\
\hline & 25 & 24 & BTMAHLP & E1.0 & $\begin{array}{l}\text { Total of males listed } \\
\text { in } 24 \text {. }\end{array}$ \\
\hline & $26-28$ & 24 & BPMAHL P & E3.0 & $\begin{array}{l}\text { x of names in } 24 \text { that } \\
\text { are male }\end{array}$ \\
\hline & $29-30$ & 24 & BTOTREL & F 2.0 & $\begin{array}{l}\text { Total number of relatives } \\
\text { in } 24 \text { (categories } 01-05 \text { ) }\end{array}$ \\
\hline & $31-33$ & 24 & BPREL & F3.0 & $\begin{array}{l}\text { of all names that } \\
\text { are relatives (categories } \\
01-05 \text { ) }\end{array}$ \\
\hline & 34 & 24 & BTOTN & F 1.0 & $\begin{array}{l}\text { Total of neighbors in } \\
124 \text { (07) }\end{array}$ \\
\hline & $35-37$ & 24 & BPN & F 3.0 & $\begin{array}{l}\text { of names that are } \\
\text { neighbors ( } 07 \text { ) }\end{array}$ \\
\hline & 38 & 24 & BTE & F1.0 & $\begin{array}{l}\text { Total or friends in } \\
024(06)\end{array}$ \\
\hline & $39-41$ & 24 & $B P F$ & 53.0 & $\begin{array}{l}\text { F of names in } 24 \text { that } \\
\text { are friends }(06)\end{array}$ \\
\hline
\end{tabular}




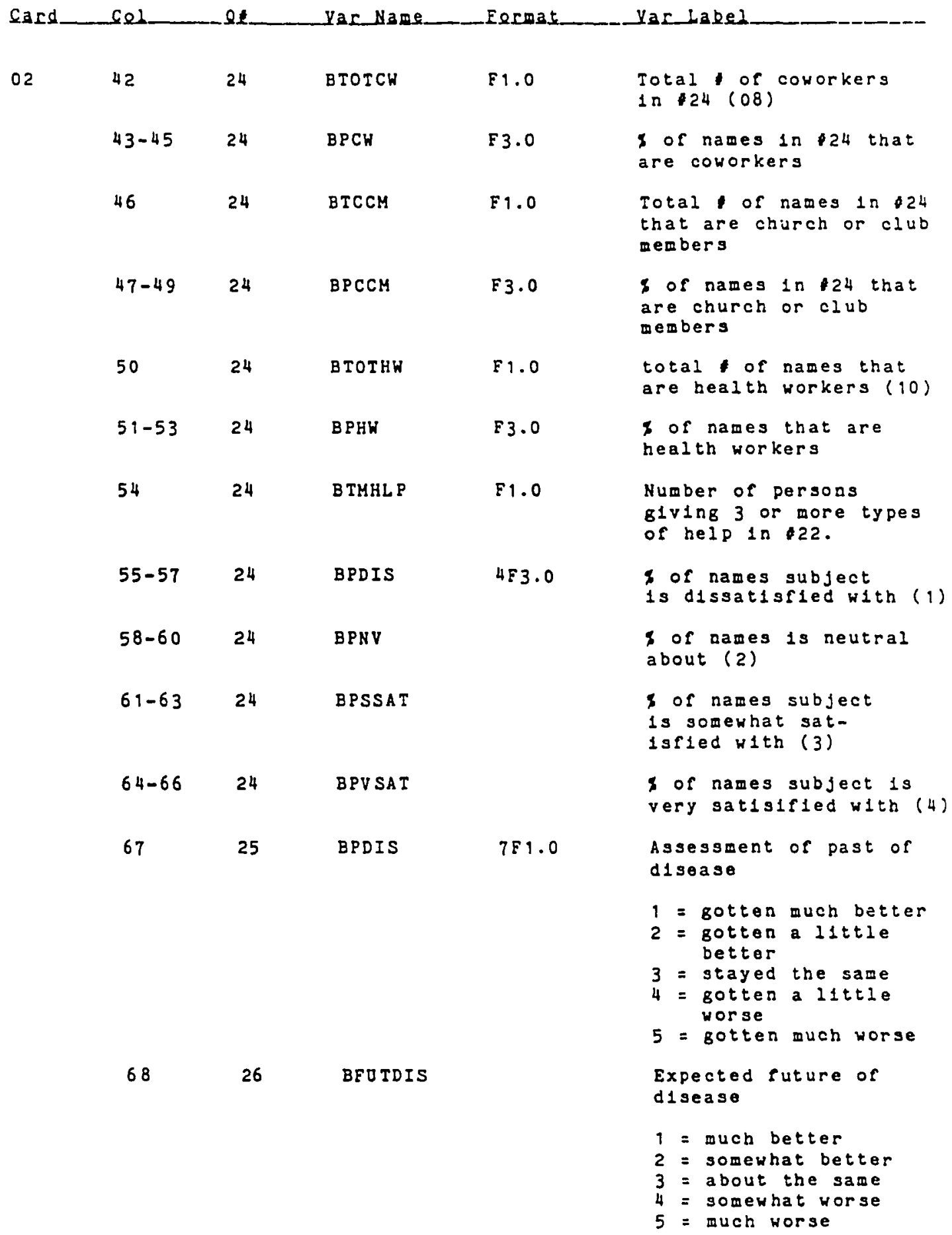




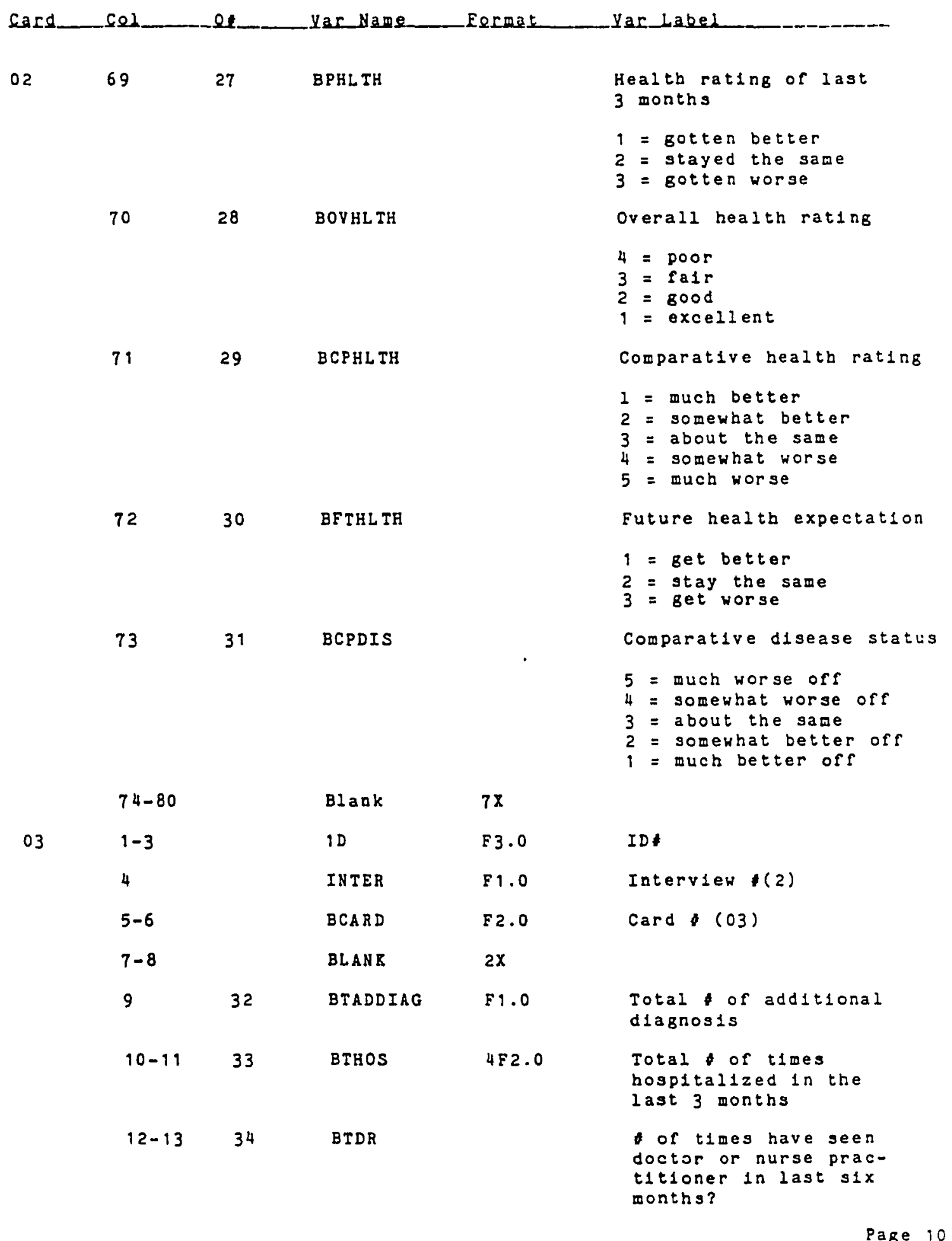




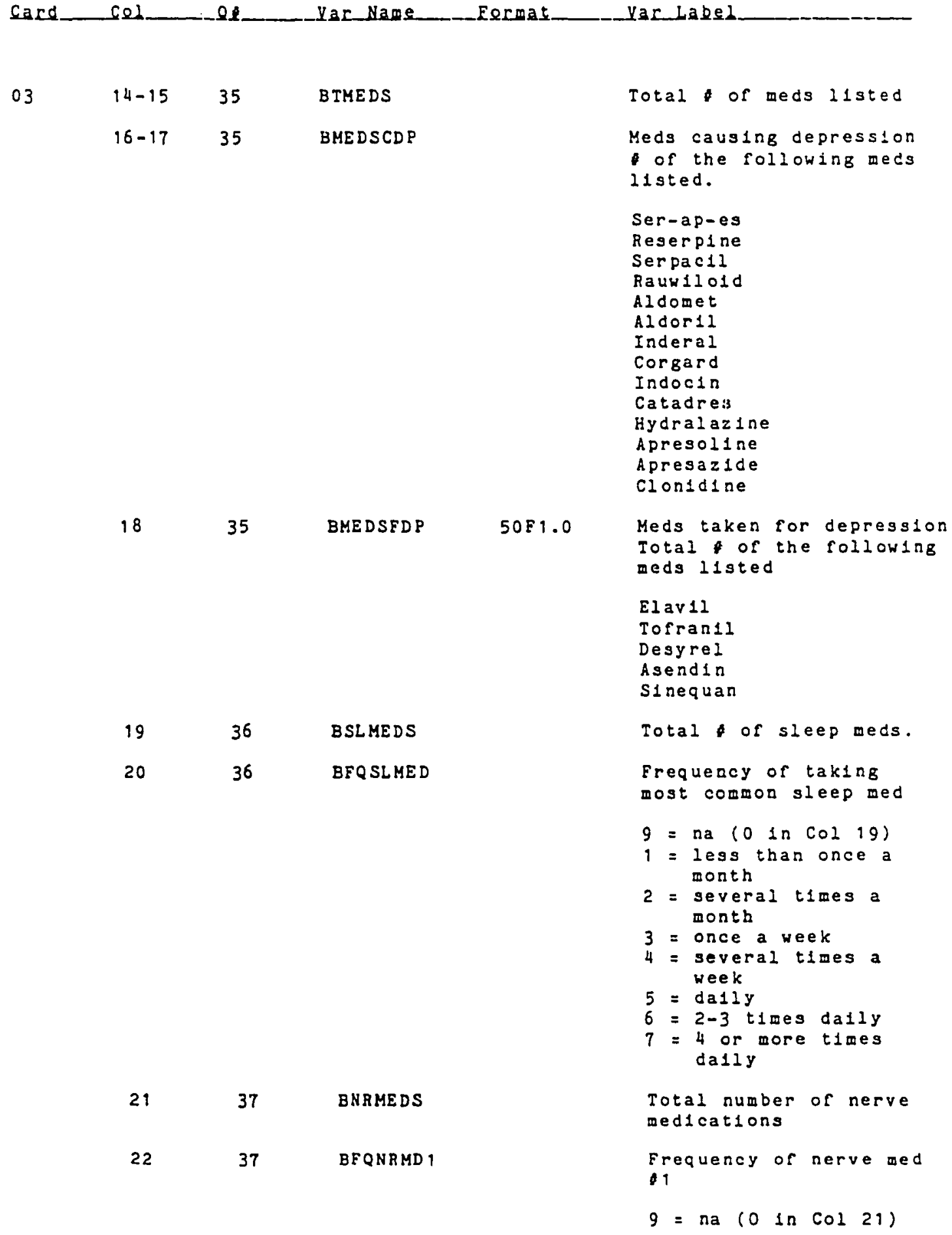




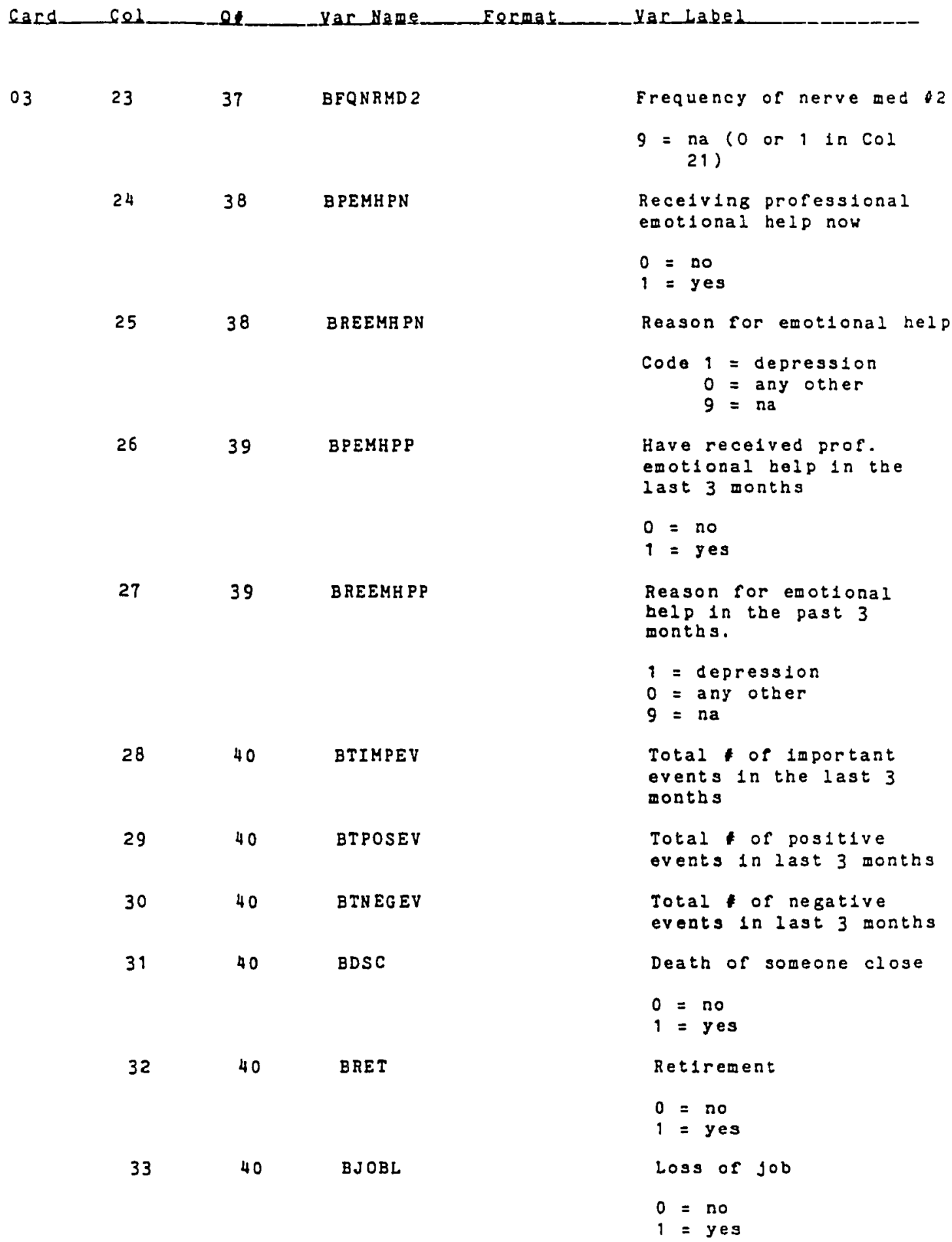


card.

C요 est

Yar Name

BMSEP

03

34

40

BMSEP

35

40

BINSTSP

36

41A BEFSC

37

38

39

40

41

42

43

44

45

46

41

$41 B$ BEFCO

$41 \mathrm{C}$

BEFER

4ID BEESH

$41 E$ BEFHHC

41F BEFSH

$41 \mathrm{G}$ BEFVF

41 日 BEFH

$41 I$ BEFW

$41 \mathrm{~J} \mathrm{BEFMF}$

43

BMDCARE

47

48
43

43
BPVTINS
Yar babed.

Marital separation

$$
0=\text { no }
$$$$
1=\text { yes }
$$

Institutionalization of spouse

$0=$ no

$1=$ yes

Effect on self-care

0 = have never cone this

$1=$ not at all

$2=a 11 t t 1 e$

$3=a$ falr amount

4 = a great deal

$5=$ no longer able to do

Effect on care of others

Effect on eating babits

Effect on sleeping habits

Effect on household

chores

Effect on shopping

Efrect on visiting

friends

Erfect on hobbies

Erfect on working

Errect on main-

talning friendshipg

Use of Medicare (01)

as medical resource

$0=n_{0}$

1 = yes

use of medicald (02)

$0=$ no

$1=$ yes

Use private insurance (03)

$0=$ no

$1=$ yes

Page 13 


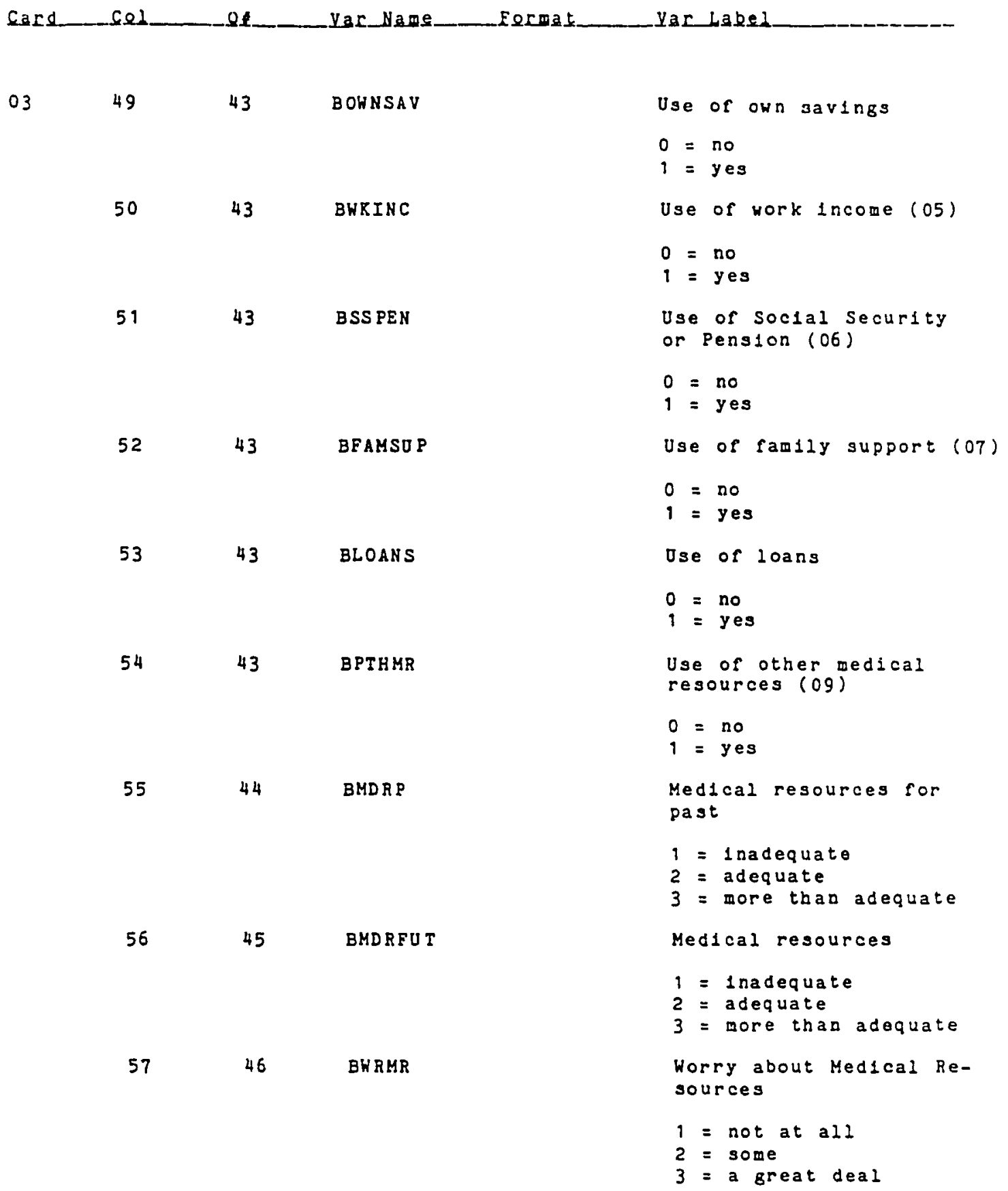




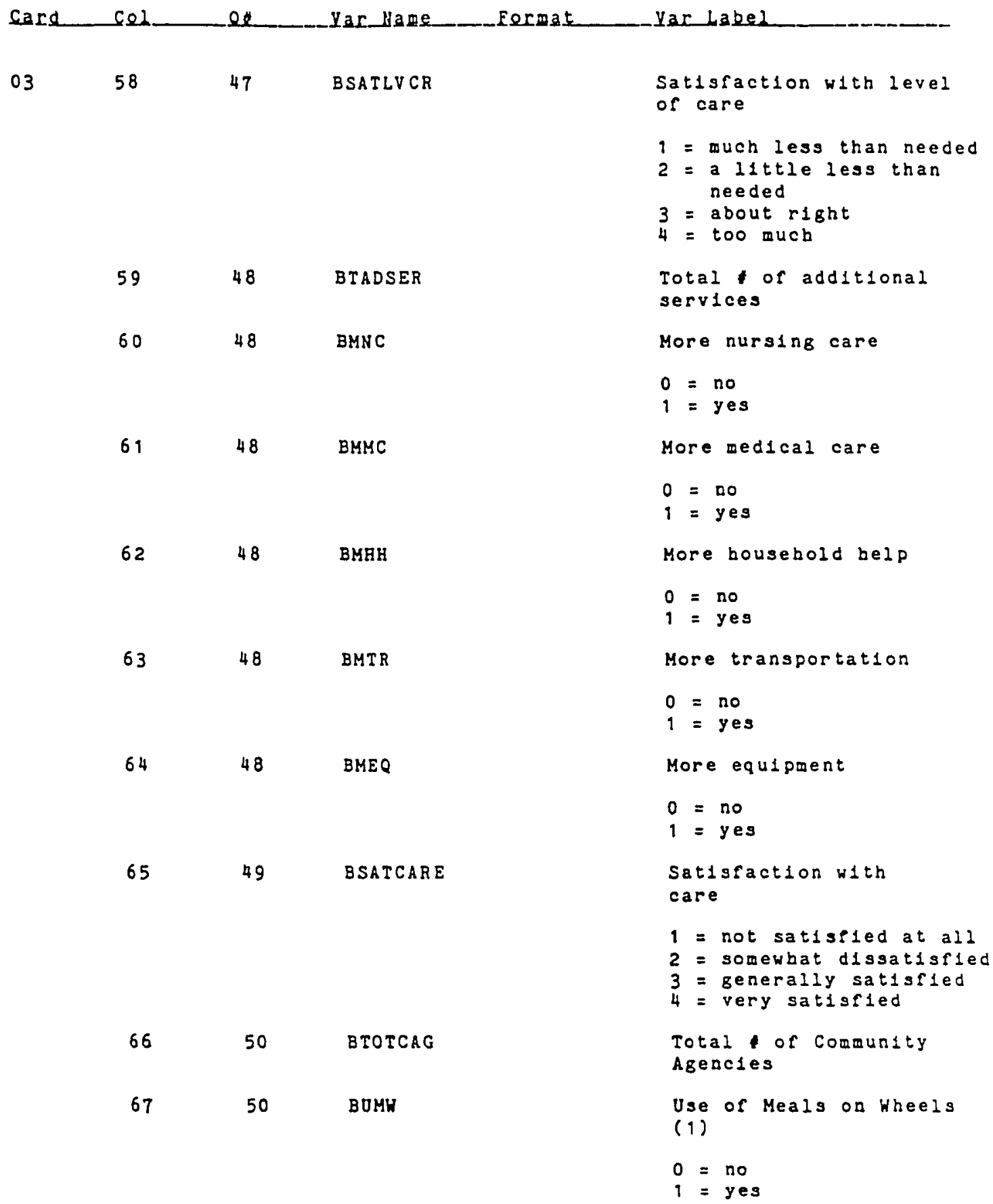


card. col.

요

Yas Name

Eermat

yar Label

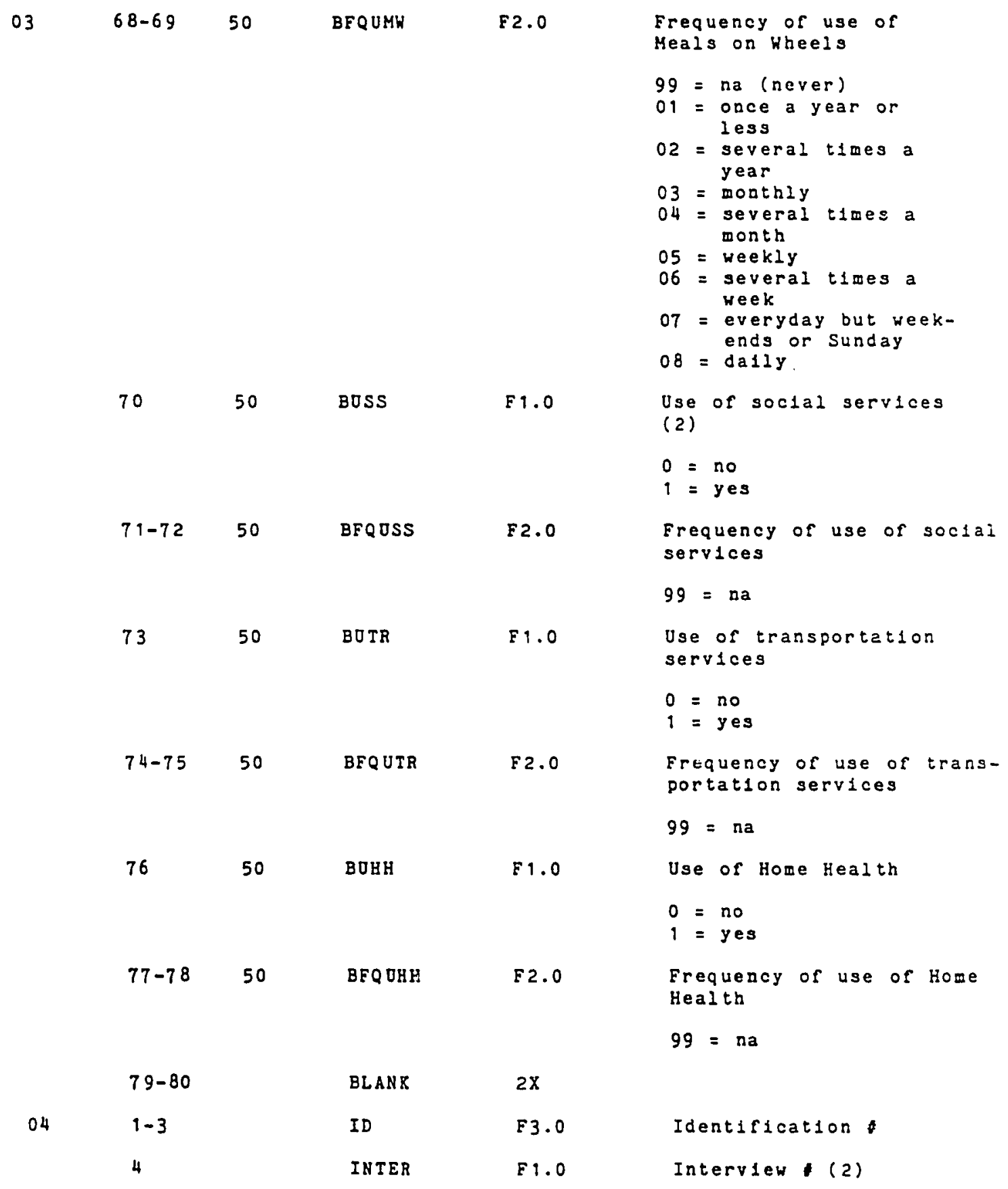


card ces 0 Var Na묘 Fermat

Yac Label

04

$$
5-6
$$$$
7-8
$$

9

50

BUSRCT

$10-11$

50

BFQSRCT

12

51

BGN PN

$$
13-15
$$

52

BGNPNSC

53

16

BPNWR

F1. 0

F 3.0

F2.0

Card $(04)$

$2 \mathrm{X}$

F 1.0

Use or sentor Center

$0=$ no

$1=$ yes

$2 F 2.0$

Frequency of use of

Senior center

$99=n a$

Asount of pain in

general

$0=$ none

$1=$ not much

$2=a$ rair amount

$3=a$ lot

General pain score

(maximum 100)

$70=070$

Amount of pain in

last week

$0=$ none

$1=$ not much

$2=a$ rair awount

$3=a 10 t$

$17-19$

54

BPNSCWR

F3.0

Pain score for last week ( 100 maximum)

$70=070$

20

55

BLG PN

$7 F 1.0$

Length of pain

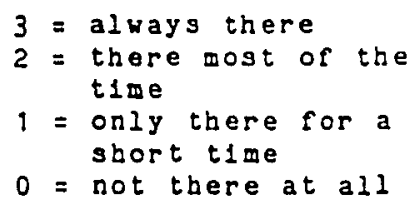

21

56

BCPPN
Comparative level of pain

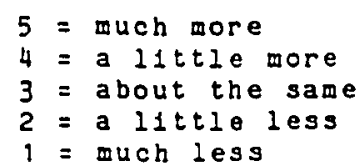

$5=$ wuch more

$4=a 11 t t l e$ more

$2=a$ littio less

$1=$ much less 
Cars col.

et

Yar Name

Yac label

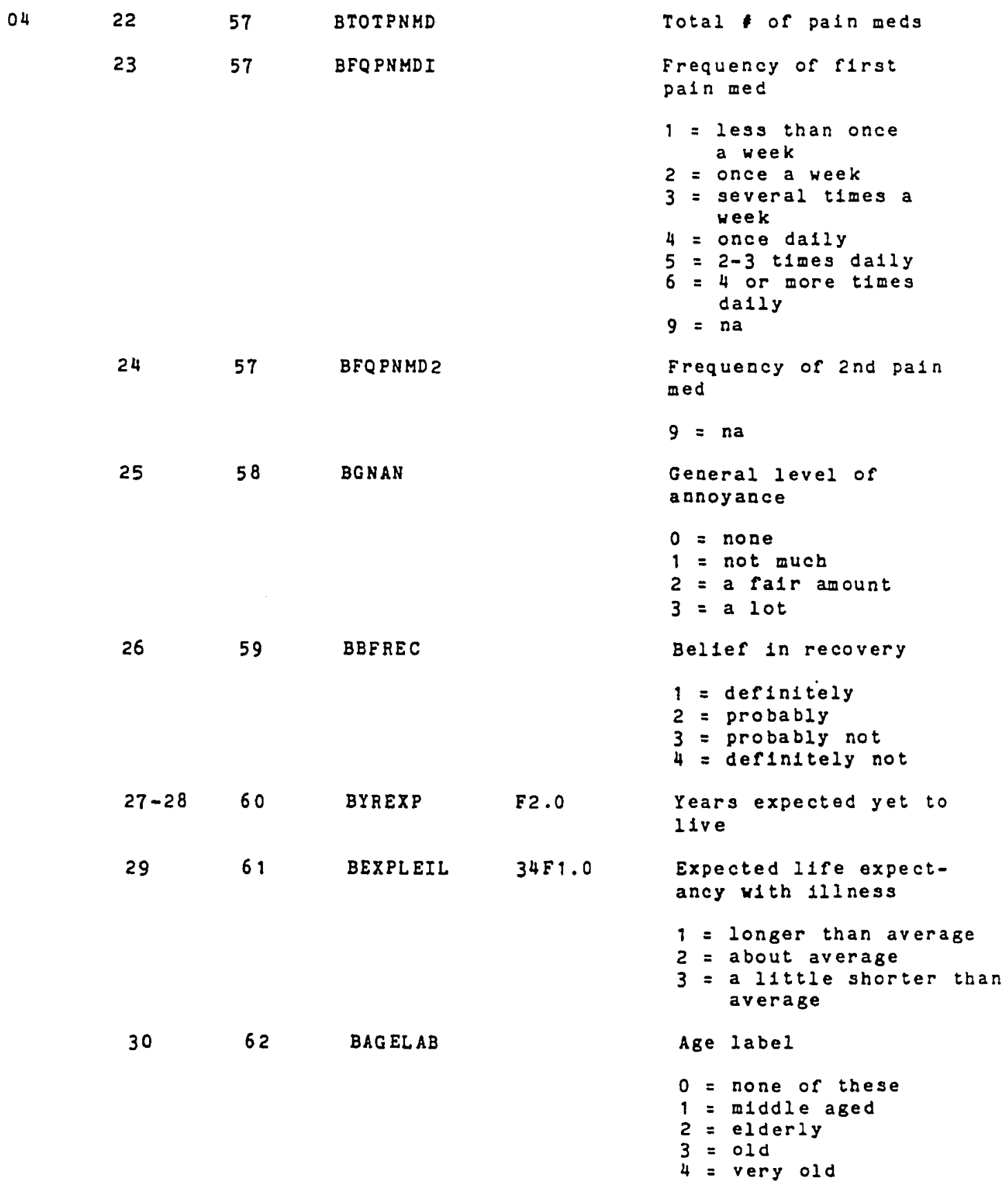




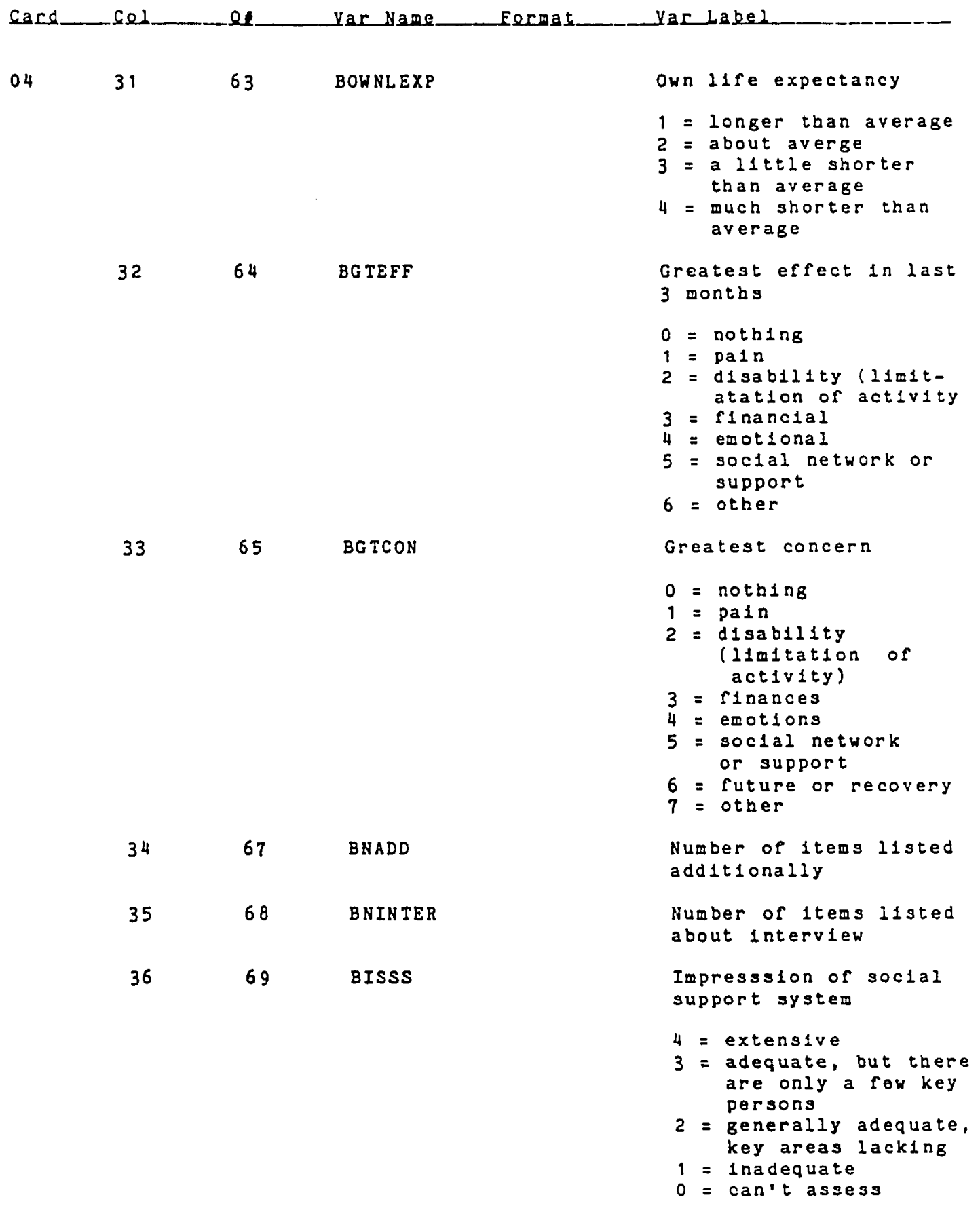




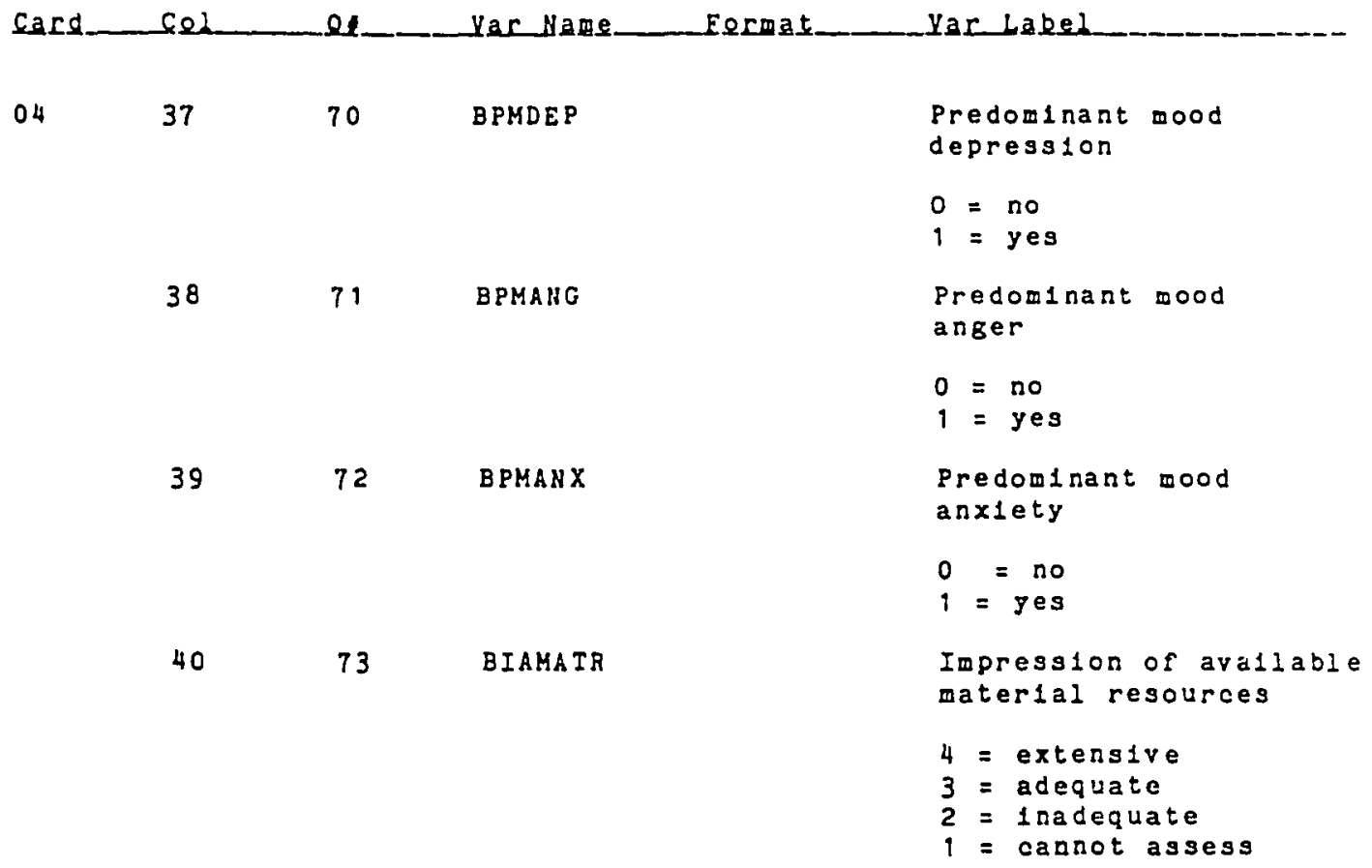

Evaluation

\begin{tabular}{|c|c|c|c|}
\hline 41 & 1 & BHTREP & $\begin{array}{l}\text { Subject wants report } \\
0=\text { no } \\
i=\text { ses }\end{array}$ \\
\hline 42 & 2 & BSOBCOOP & $\begin{array}{l}\text { Subject's degree of } \\
\text { cooperation } \\
\begin{array}{l}4=\text { excellent } \\
3=\text { good } \\
2=\text { falr } \\
1=\text { poor }\end{array}\end{array}$ \\
\hline 43 & 3 & BSUB OND & $\begin{array}{l}\text { Subject's understanding } \\
4=\text { understood all items } \\
3=\text { bad trouble with a } \\
\text { few Items } \\
2=\text { bad trouble with most } \\
\text { Items } \\
1=\text { had trouble with ald } \\
\text { ltems }\end{array}$ \\
\hline 44 & 4 & BOTHPRE & $\begin{array}{l}\text { Others present } \\
\begin{array}{l}0=\text { no } \\
1=\text { yes }\end{array}\end{array}$ \\
\hline
\end{tabular}




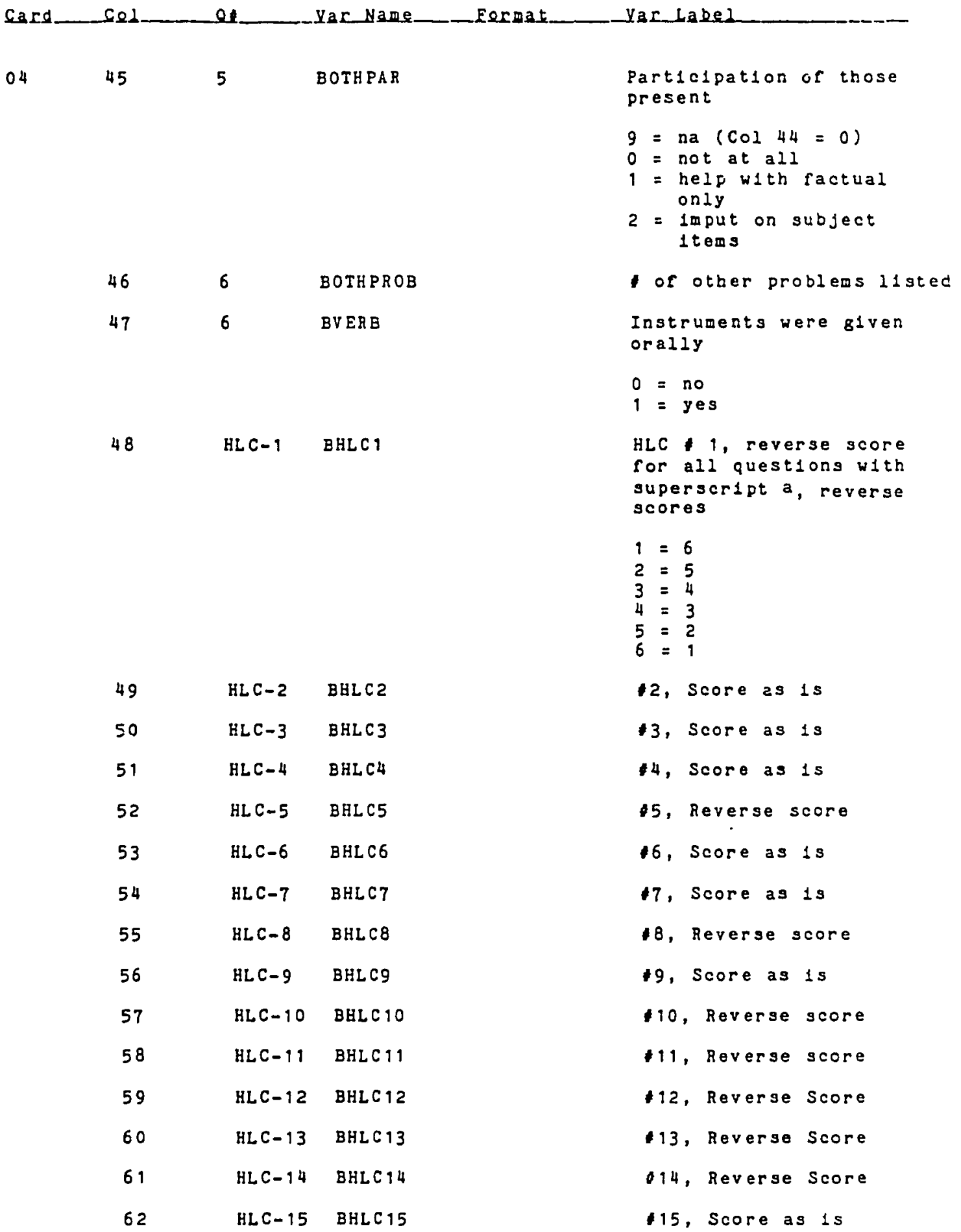




\begin{tabular}{|c|c|c|c|c|c|}
\hline \multirow[t]{7}{*}{04} & $63-64$ & HLC1-11 & BGHLC & $2 F 2.0$ & $\begin{array}{l}\text { General health locus } \\
\text { of control } \\
\text { Total } 1-11\end{array}$ \\
\hline & $65-66$ & $\begin{array}{l}\text { HLC12- } \\
14\end{array}$ & BSPHLC & & $\begin{array}{l}\text { Specific health locus } \\
\text { of control } \\
\text { Total } 12-14\end{array}$ \\
\hline & 67 & HLC15 & BPHLC & E1.0 & $\begin{array}{l}\text { Predictabllity of health } \\
\text { locus of control }\end{array}$ \\
\hline & 68 & $14-24$ & BDNNET & 251.0 & $\begin{array}{l}\text { of different nimes in } \\
\text { second network as com- } \\
\text { pared to first (see ist } \\
\text { interview) }\end{array}$ \\
\hline & 69 & & BNNETG & & $\begin{array}{l}\text { of names in first net- } \\
\text { work that did not appear } \\
\text { in second network }\end{array}$ \\
\hline & $70-72$ & & BPNETSAM & E3.0 & $\begin{array}{l}\text { of network that is sane } \\
\text { (names from } 2 \text { nd network } \\
\text { adso in-1at) } \\
\text { (t names in ist network) }\end{array}$ \\
\hline & $73-80$ & & BLAN K & $8 x$ & \\
\hline \multirow[t]{15}{*}{05} & $1-3$ & & ID & F3.0 & Id \\
\hline & 4 & & INTER & F 1.0 & Interview 2 \\
\hline & $5-6$ & & BCARD & 52.0 & Card (05) \\
\hline & $7-8$ & & BLAN $\mathrm{E}$ & $2 x$ & \\
\hline & 9 & CESD-1 & BCESD1 & $28 \mathrm{~F} 1.0$ & CESD 1 \\
\hline & 10 & CESD-2 & BCESD2 & & 42 \\
\hline & 11 & CESD-3 & BCESD 3 & & 13 \\
\hline & 12 & CESD -4 & BCESD 4 & & 14 \\
\hline & 13 & CESD-5 & BCESD 5 & & 15 \\
\hline & 14 & CESD -6 & BCESD6 & & 16 \\
\hline & 15 & CESD -7 & BCESD7 & & 17 \\
\hline & 16 & CESD -8 & BCESD8 & & 18 \\
\hline & 17 & CESD -9 & BCESD9 & & 19 \\
\hline & 18 & CESD- 10 & BCESD 10 & & 10 \\
\hline & 19 & CESD-11 & BCESD11 & & +11 \\
\hline
\end{tabular}




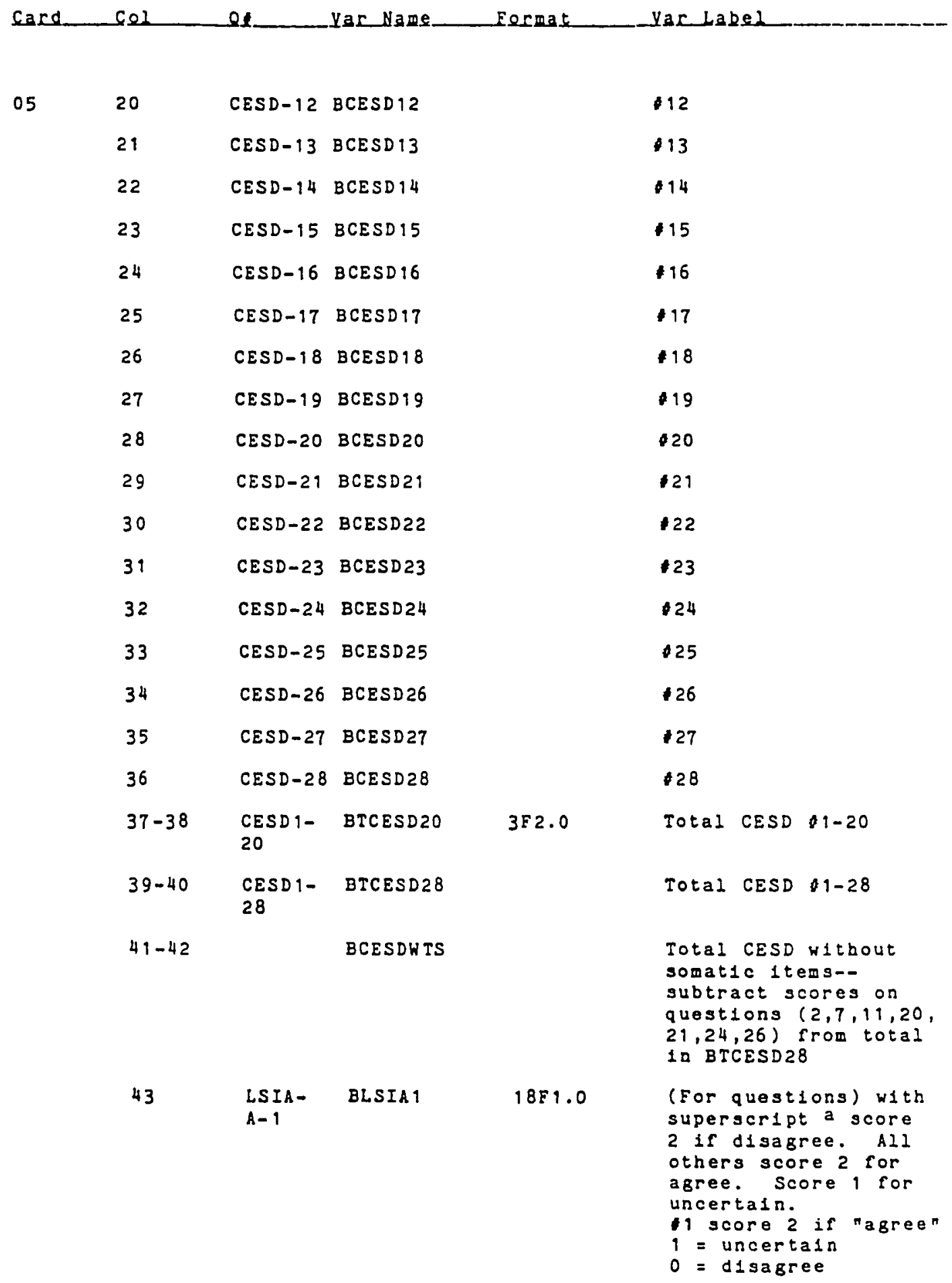




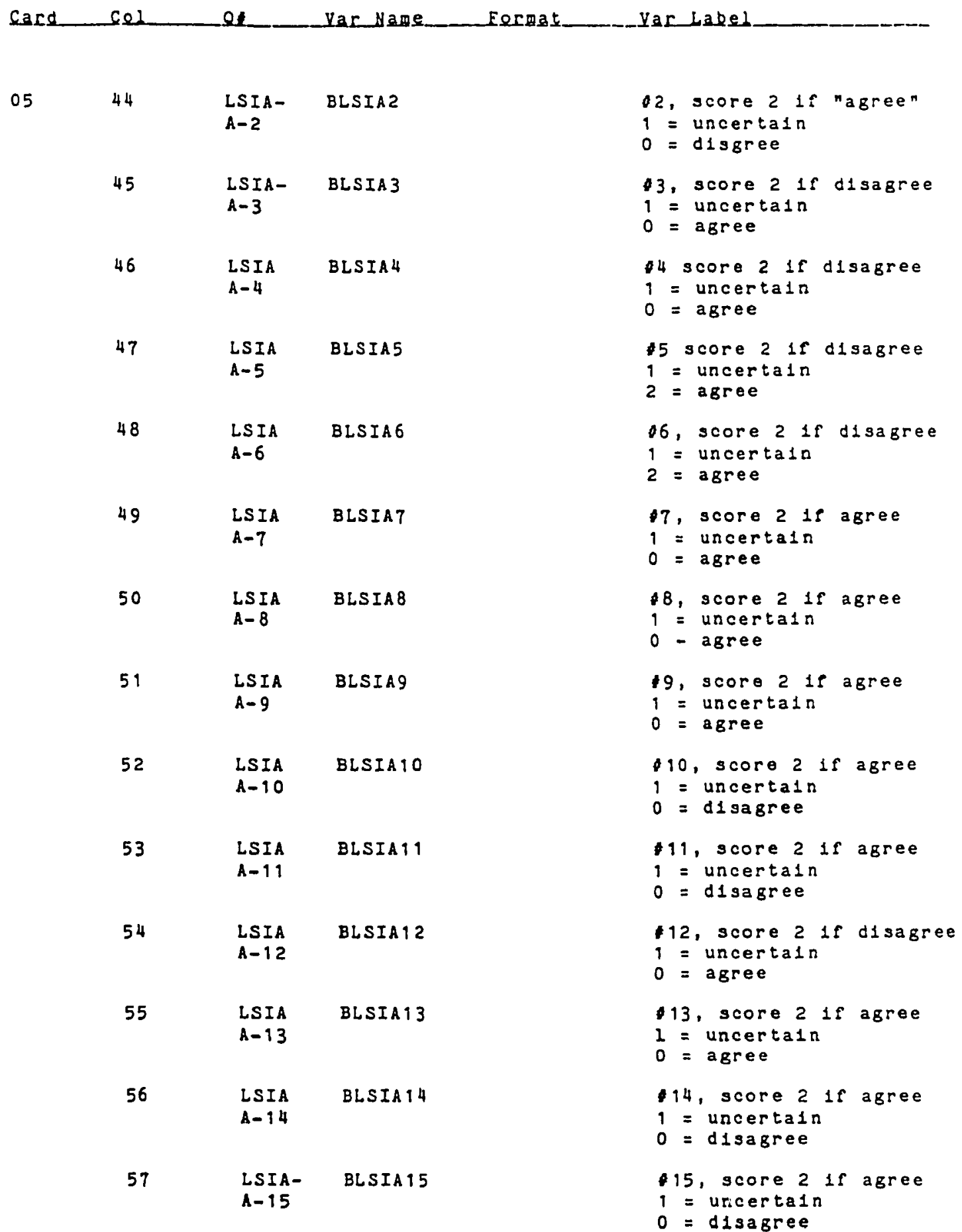




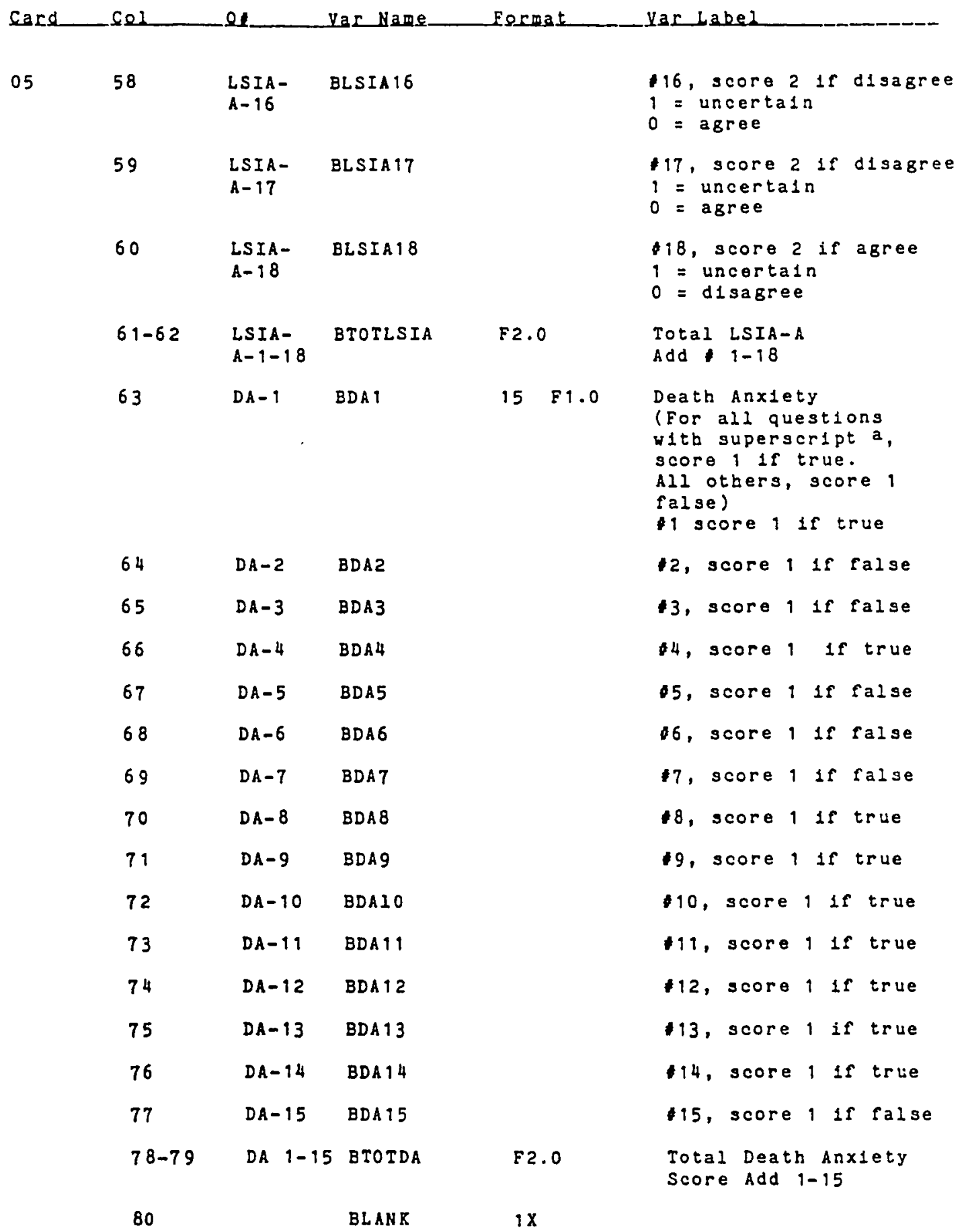

